Summer 2019

\title{
Validation of Predicted Tsunami Inundation for the Inland Coast of the Salish Sea Associated with Cascadia Subduction Zone Earthquakes
}

Paige Morkner

Western Washington University, paigemorkner@gmail.com

Follow this and additional works at: https://cedar.wwu.edu/wwuet

Part of the Geology Commons

\section{Recommended Citation}

Morkner, Paige, "Validation of Predicted Tsunami Inundation for the Inland Coast of the Salish Sea Associated with Cascadia Subduction Zone Earthquakes" (2019). WWU Graduate School Collection. 895.

https://cedar.wwu.edu/wwuet/895 
Validation of Predicted Inundation for the Inland Coast of the Salish Sea Associated with Cascadia Subduction Zone Earthquakes

\author{
By \\ Paige Morkner \\ Accepted in Partial Completion \\ of the Requirements for the Degree \\ Master of Science
}

ADVISORY COMMITTEE

Chair, Dr. Bernard Housen

Dr. Jackie Caplan-Auerbach

Dr. Eric Grossman

GRADUATE SCHOOL

David L. Patrick, Interim Dean 


\section{Master's Thesis}

In presenting this thesis in partial fulfillment of the requirements for a master's degree at Western Washington University, I grant to Western Washington University the non-exclusive royalty-free right to archive, reproduce, distribute, and display the thesis in any and all forms, including electronic format, via any digital library mechanisms maintained by WWU.

I represent and warrant this is my original work, and does not infringe or violate any rights of others. I warrant that I have obtained written permissions from the owner of any third party copyrighted material included in these files.

I acknowledge that I retain ownership rights to the copyright of this work, including but not limited to the right to use all or part of this work in future works, such as articles or books.

Library users are granted permission for individual, research and non-commercial reproduction of this work for educational purposes only. Any further digital posting of this document requires specific permission from the author.

Any copying or publication of this thesis for commercial purposes, or for financial gain, is not allowed without my written permission

Paige Morkner

$8 / 8 / 2019$ 
Validation of Predicted Inundation for the Inland Coast of the Salish Sea Associated with Cascadia Subduction Zone Earthquakes

\author{
A Thesis \\ Presented to \\ The Faculty of \\ Western Washington University
}

In Partial Fulfillment

Of the Requirements for the Degree

Master of Science

by

Paige Morkner

August 2019 


\begin{abstract}
The Cascadia subduction zone is understood to produce large, Mw 9.0, earthquakes every 300-1000 years. As a result of large ruptures along the fault, Washington, Oregon and Northern California, are susceptible large tsunamis along the coast. Recent earthquakes in Indonesia, Japan, and Chile, and resultant tsunamis, have helped constrain potential slip along large subduction zone margins, such as Cascadia. Accurate slip parameters, such as sea floor deformation and upper plate subsidence, are essential for accurate tsunami modeling. Hazard modeling and mapping along the Cascadia subduction zone has concluded that large tsunamis are able to travel through the Strait of Juan de Fuca and inundate coastal regions of the Salish Sea and Puget Sound. However, to improve modeling efforts, field validation of models is required. Tsunamis can move material from the near shore and beach and deposit in low-laying coastal marshes and ponds, acting as a proxy for past tsunami inundation. This research focuses on two locations in the northern Puget Sound, Ship Harbor marsh Anacortes, and Eliza Island. Using gouge auger cores and vibracores, subsurface features of each marsh were reconstructed to look for laterally continuous sand sheets indicative of tsunami inundation. Magnetic methods were used to correlate between cores, and look at sedimentary depositional fabrics within stratigraphic beds. Potential Cascadia tsunami origin for a deposit at Ship Harbor was confirmed with the use of ${ }^{14} \mathrm{C}$ dates and magnetic paleosecular variation dates. This research has implications for validation of the L1 seismic-scenario-based tsunami models, currently being produced by the Washington Geological Survey for hazard planning, and may indicate that L1 based tsunami models are valid regarding the inundation threat along the inland coast for future Cascadia earthquakes.
\end{abstract}




\section{Acknowledgments}

Thanks to my committee, especially Bernie, for the support and guidance of my research. I acknowledge and thank the USGS for providing the means for vibracoring, and Eric Grossman for guiding me through use of the vibracoring system. I acknowledge and thank Andy Christensen and Kelby Carambot for providing help in the field, and without whom I would not have been able to complete field work. Thank you Ben Paulson, for providing the resources and facilities necessary to complete lab work and research at WWU, and for providing materials for field work. Thanks to Doug Clark for letting us use his field equipment. Thank you Carrie Garrison-Laney, for guidance in the field and with radiocarbon dating, and Breanyn MacInnes for research support and guidance, and for teaching me how to model. Thanks to Dean Christensen for boating us to and from Eliza Island.

I am grateful to the City of Anacortes and the Eliza Island Beach Club for allowing access to the land.

This research was made possible due to grants from the PADI Foundation, the Geological Society of America, the Research and Sponsored programs at WWU, and the WWU Geology department. 


\section{Table of Contents}

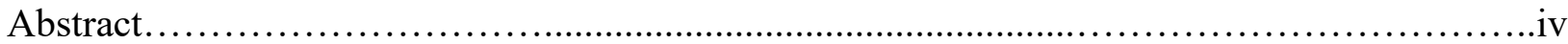

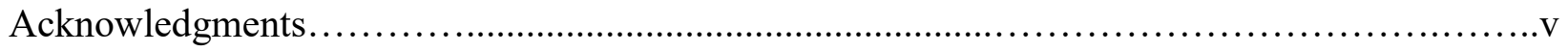

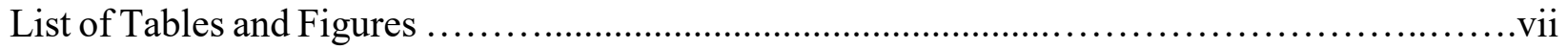

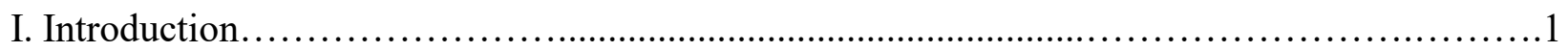

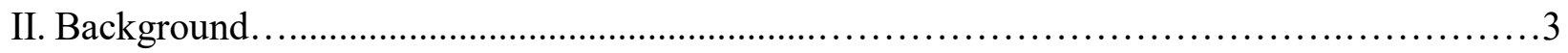

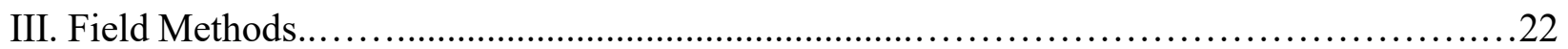

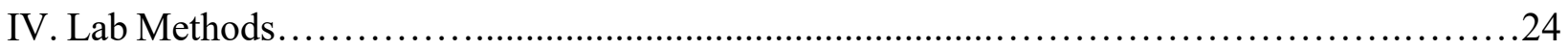

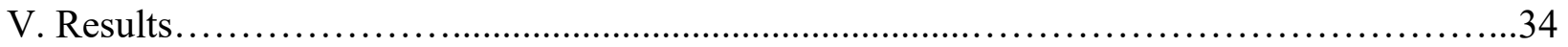

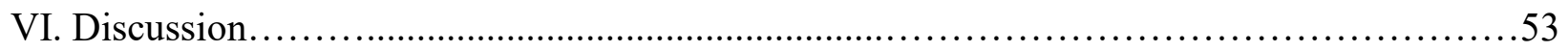

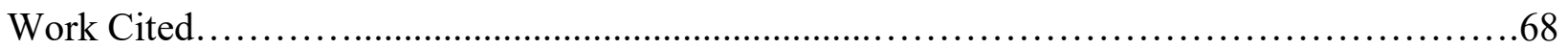

Appendix 1. Gouge Auger Core Logs................................................... 145

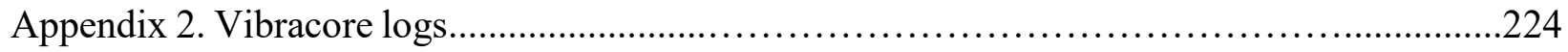

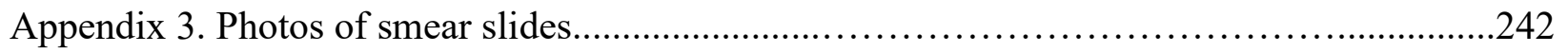

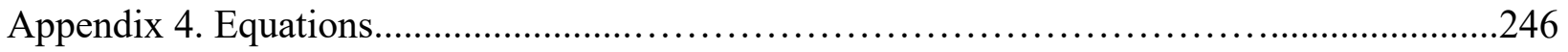




\section{List of Figures and Tables}

Figure 1. Context image of Puget Sound field locations and L1 modeling.......................74

Figure 2. Context image of Puget Sound and other tsunami deposit locations.......................75

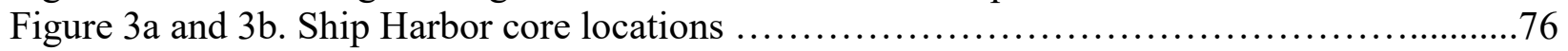

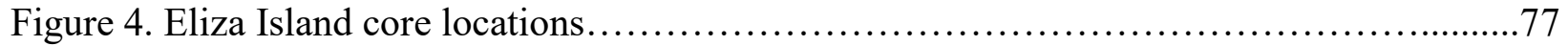

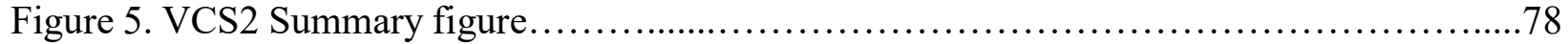

Figure 6. Vibracore stratigraphy of Ship Harbor............................................ 79

Figure 7. Image of mollusk shell found in VCS2 ........................................ 80

Figure 8a-d. AMS results for Ship Harbor and Eliza Island...................................81

Figure 8e. Sampling locations for AMS for VCS2 from Ship Harbor...........................85

Figure 8f. Sampling locations for AMS from VCEI2 form Eliza Island........................86

Figure $8 \mathrm{~g}$. Flinn diagram for SHb1 samples from Ship Harbor ............................. 87

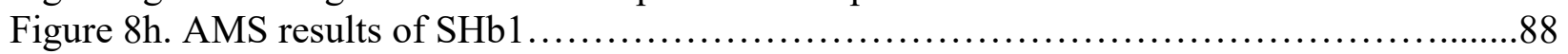

Figure 9. Bulk susceptibility results ............................................... 89

Figure 10. Hysteresis loop examples............................................... 91

Figure 11. IRM examples........................................................... 92

Figure 12. High temperature vs susceptibility results...................................93

Figure 13. Low temperature vs susceptibility results..................................94

Figure 14. Typical Zijderveld diagrams from demagnetization PSV results.....................95

Figure 15. PSV curves and results for Ship Harbor..................................... 96

Figure 16. PSV curves and results for Eliza Island..........................................97

Figure 17. L1 model results............................................................98

Figure 18. M1 model results........................................................ 101

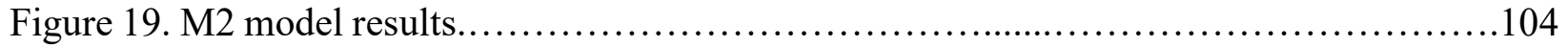

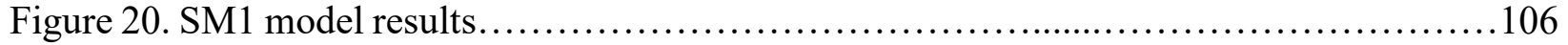

Figure 21. Seattle fault model results.................................................. 108

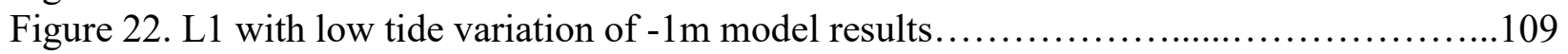

Figure 23. L1 with low tide variation of $-2 \mathrm{~m}$ model results.................................111

Figure 24. M1 with high tide variation of $+1 \mathrm{~m}$ model results..............................113

Figure 25. Stratigraphic correlation of subsurface for Ship Harbor...........................115

Figure 26. Stratigraphic correlation of subsurface for Eliza Island .......................... 116

Table 1. Compaction calculations for Vibracores...................................... 117

Table 2. Radiocarbon samples sent to NOSAMS ........................................ 118

Table 3. Particle size analysis results for Ship Harbor..................................... 119

Table 4. Particle size analysis results for Eliza Island ..................................... 120

Table 5. Lateral extent of SHb1 ..................................................... 121

Table 6. Lateral extent of sand and gravel sheets, Eliza Island .............................. 122

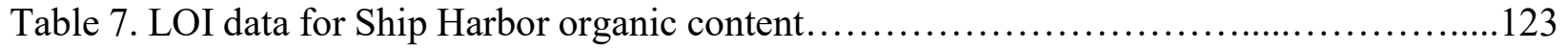

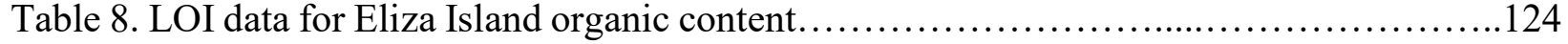

Table 9. Table of calibrated OxCal results for radiocarbon samples............................ 125

Table 10. OxCal sequence model for Ship Harbor.........................................126

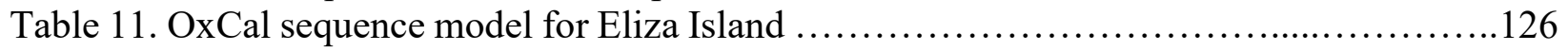

Table 12. Error for AMS results, Ship Harbor......................................... 128

Table 13. Error for AMS results, Eliza Island ........................................... 130

Table 14. AMS mean tensors for Ship Harbor........................................... 131 
Table 15. AMS mean tensors for Eliza Island ............................................ 131

Table 16. AMS calculated parameters..................................................... 132

Table 17. Hysteresis and IRM data for Ship Harbor.......................................... 135

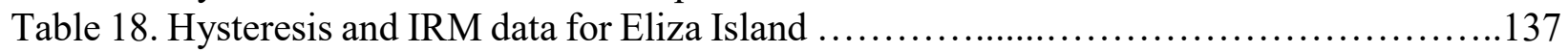

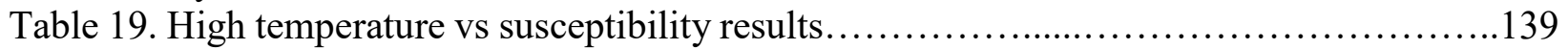

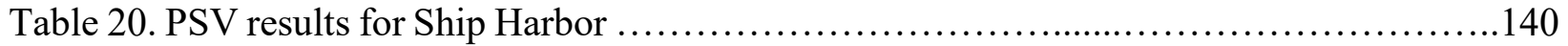

Table 21. PSV results for Eliza Island.................................................. 141

Table 22. GeoCLAW model parameters, defined by Witter et al. (2013).........................142

Table 23. Sequence models incorporating PSV dating.................................. 143 


\section{Introduction}

Natural hazard impact prediction is increasingly important in the built environment as population grows, as we gain better understanding of the extent and recurrence of hazards, and as certain types of hazards are impacted by climate change. The limited ability to predict and mitigate the effects of natural hazards, such as large earthquakes and tsunamis, has historically led to catastrophic consequences and loss of life. Tsunami hazard prediction and mitigation have been unsuccessful in places where risk was not well understood; the Chile 1960 tsunami, Papua New Guinea 1998 tsunami, the 2004 Indonesia tsunami, and the Japanese Tohoku earthquake and tsunami in 2011, resulted in severe damage, and loss of life. The lack of understanding of displacement in recent subduction zone earthquakes and resultant larger-than-expected tsunamis has forced growth within all tsunami related science. As an example, the Tohoku earthquake had mitigation planning in place for the subduction zone earthquake - however, rupture width extended well beyond expected, causing an extension of rupture to the toe of the accretionary wedge. The extension of the rupture through the wedge caused a much larger than expected vertical displacement and the resultant tsunami was much larger than models predicted (Ozawa

et al., 2012; Koshimura et al., 2014). Understanding model accuracy is essential for future hazard mitigation efforts.

Past Cascadia subduction zone (CSZ) earthquakes are understood to have a recurrence interval of 300-1000 years over the last 10,000 years (Atwater and Hemphill-Haley, 1997; Atwater et al., 2003; Goldfinger, 2012; Gica and Arcas, 2016; Eungard et al., 2018). CSZ earthquakes are recorded in local Native American history, but have all occurred prior to the advent of instrumental seismology, and so the spatial extent and event sizes are modeled based on geological constraints, and are thought to be similar to events recorded in other subduction 
zone settings. CSZ earthquakes are large $(\mathrm{Mw} 7+)$ and present a hazard to the West Coast as both seismic shaking, and as a resultant tsunami inundation (flooding). Specifically, CSZ megathrust events present significant known tsunami hazard to the outer coast of Washington (Figure 1), where inundation may be greater than $4 \mathrm{~m}$ and warning times less than 30 minutes (Cherniawsky et al., 2007).

While the risks for large-scale tsunami inundation of the outer Pacific coast of Washington and Oregon are better understood, possible tsunami inundation hazards for the inland coast of the Salish Sea and Puget Sound (Figure 1) are less understood. Fault dislocation models have been produced to try to estimate how slip along the CSZ has occurred in the past and predict how it will occur in the future (Satake et al., 1996; Flück et al., 1997; Wang et al., 2003). Fault dislocation models produce slip parameters which can be applied to sea floor deformation. With an estimate of sea floor deformation, inundation predictions are made and tsunami modeling can be executed. Priest et al. (1997) and Witter at al. (2013) produced several potential deformation models to use as initial boundary conditions for tsunami modeling, which have been applied to models for the outer coast of Washington and Oregon, and for the inner coast of the Puget Sound. One such scenario, the L1 (Mw 9) simulates wave propagation into the inland waters of the Puget Sound, with inundation depths of low-elevation coastal areas of the north Puget Sound varying from 0.5 to 5.6m (Gica and Arcas, 2016; Eungard et al., 2018). Because the predicted inundation risk to the inner coast of the Puget Sound is spatially varied, poorly understood, and model dependent, field verification to identify past inundation locations is important to validate and refine model predictions of tsunami processes and coastal responses, and to better constrain timing and spatial extent of events in the geological record and future.

Deposits potentially created by CSZ tsunami events have been identified in several 
protected local marshes in the Puget Sound (Figure 2) (Atwater and Hemphill-Haley, 1997; Williams and Hutchinson, 2000; Atwater et al., 2003; Williams et al., 2005; Hutchinson et al., 2013). Evidence of tsunami run-up from a site with significant modeled inundation also allows for analysis of the tsunami inundation distance while considering tide, sea level, and roughness of the coastal surface, all commonly used as initial parameters in tsunami modeling. Using models produced from the recent seismic modeling of the CSZ to choose field locations for paleotsunami studies will aid in validation of the newer L1 model, which is currently being considered for use in future hazard modeling in Washington (Eungard et al., 2018).

Identification of predicted deposits with coring, radiometric dating, anisotropy of magnetic susceptibility, and magnetic paleosecular variation dating, will help constrain the spatial distribution of tsunami run-up associated with past tsunami events, and test methods not yet used on Puget Sound tsunami deposits in the published literature. The purpose of this research is to test for evidence of past tsunami inundation in a new location, correlate any deposits found to other deposits in the Puget Sound predicted to be from CSZ sources, and test the L1 scenario-based model as an explanatory mechanism.

\section{Background}

\subsection{Tectonic Setting}

The CSZ is a convergent boundary between the subducting Juan de Fuca plate and the North American plate, extending approximately north-south from British Columbia, Canada to Northern California. The CSZ presents a clear earthquake hazard, with megathrust earthquake events predicted to be Mw 8-9 recurring $\sim 550$ years (Atwater et al., 2003). Geodetic measurements suggest that the CSZ is currently locked and that inter-seismic strain accumulation 
is creating shortening and uplift along a majority of the outer coast, and decoupling of the plates will result in large rupture events in the future (Atwater et al., 2003; Kelsey et al., 2012).

Uplift and subsidence of the outer coast is determined by interseismic and coseismic periods of CSZ megathrust events. During an interseismic period the outer coast of Washington, because it is located over the locked, or coupled, section of the plate interface, experiences elastic uplift from building stress. During an earthquake, this uplift is accomodated as coseismic subsidence which occurs in a matter of seconds to minutes during the earthquake (Atwater, 1987). Because the inland coast of Washington is located east of this coupled zone, there is less interseismic uplift and thus a lesser amount of coseismic subsidence. For the western Puget Sound lowlands $0-50 \mathrm{~cm}$ of subsidence is predicted to be possible (Leonard et al., 2004).

Accommodating movement along the CSZ on the overriding plate are a series of faults that extend through Whatcom and Skagit counties, and these present their own earthquake and tsunami hazard to the Puget Sound coastal areas (Johnson et al., 1996, 2004; Kelsey et al., 2012; Personius et al., 2014). Movement of these faults in the offshore environment could act as additional tsunami sources that should be considered. Seismic activity underwater along these smaller faults could potentially produce a tsunami large enough that its deposit is preserved in the sediment record nearby (Williams and Hutchinson, 2000; Kelsey et al., 2012). Submarine landslides and delta collapse are also potential causes of tsunamis. However, the history of all these events, their size, and locations, are even less well constrained than the large CSZ events.

\subsection{Seismic modeling}

Potential rupture scenarios for future CSZ events establish boundary conditions for tsunami modeling. However, the modeling of these boundary conditions has evolved as new research has been published. Variability of potential seismic scenarios presents a challenge when 
modeling for hazard prediction and mitigation planning. Priest et al. (1997) describe a rupture scenario, referred to as $1 \mathrm{~A}$, modeled after the 1700 event, based on a fault dislocation model and paleoseismic data. The 1A scenario predicts a Mw 9.1 earthquake and explores a N-S full rupture length of $\sim 1050 \mathrm{~km}$ and a narrow E-W rupture width of $\sim 70 \mathrm{~km}$, with a total estimated average slip along the fault of $17.5 \mathrm{~m}$ propagating through the fault zone and to the surface. Based on the Hyndman and Wang, (1995) finite element model of the thermal regime, Priest et al. (1997) calculated a dislocation model of megathrust rupture for tsunami modeling with proposed bathymetric vertical uplift up to $6 \mathrm{~m}$ along the length of the subduction zone. Coseismic coastal subsidence is variable in this scenario from North to South along the subduction zone. This seismic scenario has been used in older tsunami models of the Salish Sea (Priest et al., 1997; Cherniawsky et al., 2007), however it is based on outdated rupture parameters which have been expanded upon in the last 10 years.

Witter et al. (2013) published a set of 15 different modeled ruptures, ranging in size and fault dynamic parameters. The seismic scenarios produced were used to model tsunami inundation in Bandon OR, located on the outer coast. Turbidite records from Goldfinger et al. (2012) were used as a basis to calculate recurrence intervals and seismic strain accumulation between events. The modeled results produce three variations of each size SM, M, L, XL, and XXL scenario: the \#1 iterations are modeled using splay faulting, which diverts some of the slip to a hypothetical splay fault in the accretionary wedge, increasing seafloor deformation (Witter et al., 2013). The \#2 and \#3 iterations of each size slip model are based on two buried rupture models which used different up-dip limits of coseismic slip, suggesting that the up-dip section of the fault will act to prevent slip from reaching the seafloor; these scenarios produce a smaller amount of sea floor deformation. The likelihood of splay faulting seems high, as other major 
subduction zones have exhibited splay faulting in recent ruptures - such as Japan, Sumatra, and Chile (Witter et al., 2013).

When evaluating the statistical likelihood of the models, Witter suggests that the M1 and L1 scenarios, which factor splay faulting, to be good scenarios for building planning. The L1 scenario predicts $0-2.1 \mathrm{~m}$ of coseismic subsidence along the outer coast of Washington and Oregon (Witter et al., 2013). Due to the short interseismic period since the 1700 event, the L1 is determined statistically possible but not likely to occur soon, as the slip deficit (the amount of stress created along the locked boundary) is not yet large enough (Witter et al., 2013). The L1 scenario has been and likely will continue to be used as the seismic source for hazard-prediction related tsunami modeling in Washington because it predicts a full rupture CSZ event and likely represents a maximum near-future event and risk (Cherniawsky et al., 2007; Witter et al., 2013; Gica and Arcas, 2016; Eungard et al., 2018). There is very little subsidence predicted for the inland coast when using the L1 to model tsunamis in the Puget Sound, but is variable in coastal subsidence along the outer coast (Witter et al., 2013, 2013).

\subsection{Cascadia Turbidite Records}

Goldfinger et al. (2012) describe a set of turbidite deposits found off the coast of Oregon and Washington which are used to estimate a long-term sequence of Holocene CSZ ruptures. Age estimate for each turbidite is based on the datum of Mazama ash as well as ${ }^{14} \mathrm{C}$ dates from organic material found in these cores (Goldfinger, 2012). Witter et al. (2013) use the turbidite record and ${ }^{14} \mathrm{C}$ dates from related marsh record tsunami deposits as the basis for reoccurrence intervals to calculate the slip parameters necessary to create the Bandon, OR seismic sources.

There are 19 turbidite events recorded, T 1-18, which range between 170-10,000 years B.P. This record is considered the most extensive way to determine the previous earthquake 
record of the CSZ, since marsh records only span the late Holocene (Atwater and HemphillHaley, 1997). The turbidite record ages have been commonly used to determine if marsh stratigraphic records are from CSZ rupture, or from other tsunamigenic sources.

Atwater et al., (2014) bring into question the turbidite record interpretation by Goldfinger et al. (2012). They suggest that the turbidite record, due to simplified assumptions about flow paths, stratigraphic correlation, and record completeness are not a perfect record of the history of rupture along the CSZ. Combining the late Holocene record from marshes with the turbidite record provides a higher resolution set of potential dates for the most recent CSZ tsunamis.

\subsection{Tsunami Hazards and Modeling}

Current hazard evacuation in Skagit and Whatcom counties are based on older tsunami models produced from the Priest et al. (1997) seismic scenarios. Walsh et al (2004) used the Method of Splitting Tsunamis (MOST) to model run-up through different parts of the Puget Sound. MOST is a modeling method which uses the chosen parameters of tide gauge levels and wave propagation as the basis for output cells containing flow depths (inundation). Walsh et al (2004) base the MOST parameters on the 1A Priest et al. (1997) scenario for the rupture geometry of a Cascadia subduction zone earthquake and using the thermal constraints of Hyndman and Wang (1995) and model the outer coast to subside 1-2m. This causes a predicted inundation from $0.5-5.0 \mathrm{~m}$ along sections of the inland coast, while some areas are predicted to have no inundation. Because this older tsunami model is based on an older seismic rupture scenario and low-resolution topographic data, this model may not predict maximum tsunami inundation for hazard planning purposes.

The L1 scenario from Witter et al. (2013) has been recently used to produce several published tsunami models for Washington and Oregon. Gica and Arcas (2016) produced a high- 
resolution model using MOST based on the L1 scenario (Witter et al. 2013), and predicts inundation to 5.6m in Anacortes and other coastal areas in the Puget Sound. This model uses updated bathymetric data and digital terrain models to calculate tsunami run up. Similar modeling was completed by (Eungard et al., 2018), in a joint effort to bring Washington Department of Natural Resources together with NOAA to produce standard models for hazard planning purposes in the Puget Sound. Though the L1 does not represent the largest modeled inundation from Witter et al. (2013), it does predict a significant amount of inundation compared to models produced by Walsh et al. (2004), and this is clear in the amount of spatial variation between the older 1A based models and the newer L1 based models.

All the tsunami inundation models described here were simulated with either mean highwater level (MHW) or mean high higher water level (MHHW), tidal datums representing higher tides and conditions appropriate to assess the greatest hazard and risk for planning purposes. Modeling based on MHW or MHHW likely underestimates the total potential tsunami inundation that would be accentuated by higher tides (e.g., king tides), storm surges that can range 2-3 ft, and future sea level rise, and potentially overestimates inundation during low tides (Gica and Arcas, 2016; Walsh, et al. 2004). Sea level local to Bellingham Bay is modeled to rise $0.5-1 \mathrm{~m}$ by 2100 , indicating that MHW could increase by $25 \mathrm{~cm}$ in less than 50 years (Board on Earth Sciences, 2012; Pollard and DeConto, 2016). By evaluating the effects of high tides, storm surge, and sea level rise on inundation, the full range of risk scenarios can be assessed.

\subsection{Depositional Processes of Tsunamis and Storms}

Tsunamis are typically erosional near the shoreline, redistributing sediment further inland and producing a deposit. Tsunami deposits have certain characteristics that help distinguish them from storm or other coastal marsh deposits: they are spatially extensive, conform to landscape, 
are generally $<25 \mathrm{~cm}$ thick, and consist of one or a few homogeneous graded beds, from material settling out of the flow, potentially with rip-up clasts and mud intraclasts or laminae (Morton et al., 2007). The high energy depositional wave can overtop beach berms and enter coastal marshes, depositing sediment in a wedge shape thinning and fining inland, 100s of meters from the beach (Morton et al., 2007). Studies in Chile and Japan have shown that deposits are generally thicker in low-laying areas (such as marshes), and thinner on topographical highs (Morton et al., 2011; Richmond et al., 2012). The deposits are commonly preserved in low laying, marshy or ponded areas, as they provide a means of capturing the sediment between plants and roots, protecting it from wave erosion at the beach front, and ultimately preserving it in the geologic record (Morton et al., 2007).

There are three main settings in Cascadia where deposits are preserved: estuaries, coastal lakes and back-barrier wetlands. All these environments are low energy, with deposits above and below a tsunami deposit distinctly different than the tsunami deposit itself (Peters et al., 2007). In a tidal marsh setting, tsunami deposits will consist of sandy mud overlaying peat or organic-rich mud (Peters et al., 2007). If the peat is not well developed at the time of deposition, the tsunami deposition over the marsh substrate may result in a less obvious deposit between overlaying and underlaying materials (Peters et al., 2007). A layer of organic debris or massive mud may overlie the sand layer (Peters et al., 2007). All published Cascadia tsunami deposits in the Puget Sound have consisted of silty and clayey sand layers found within the top $3 \mathrm{~m}$ of the coastal marshes (Williams and Hutchinson, 2000; Williams et al., 2005; Hutchinson et al., 2013).

The morphology of a tsunami deposit is distinguishable from thick storm deposits which do not extend much laterally beyond beach berms (typically 1-3 meters) and consist of thick $(>25 \mathrm{~cm})$ muddy sand beds between peat layers (Williams and Hutchinson, 2000; Williams et al., 
2005; Morton et al., 2007; Hutchinson et al., 2013). Even though storm waves can run up significant distances, they do not typically have enough power to deposit material as far inland as a tsunami and generally are characterized by an abruptly-ending thick, massive, wedge (Morton et al., 2007). Tsunami deposits generally have a sedimentary fabric created by a single flow direction from initial inundation, potential secondary direction of flow from the backwash outflow, and settling from suspension preserved in the stratigraphy as normal grading (Morton et al., 2007; Wassmer et al., 2010, 2015; Wassmer and Gomez, 2011; Kain et al., 2017). Storms typically display a degree of organization containing multiple sets of laminae and cross-beds, due to back and forth swash movement and inconsistent flow (Morton et al., 2007; Wassmer et al., 2010, 2015; Wassmer and Gomez, 2011; Kain et al., 2017).

\subsection{Previous Tsunami Deposits in Oregon and Washington}

\subsubsection{Oregon and Washington Outer Coast}

Marshes on the outer coast of Washington and Oregon provide the highest resolution record of past CSZ tsunami inundation, due to susceptibility from CSZ tsunami inundation. Tsunami deposits are preserved and correlate to turbidite events (Goldfinger, 2012; Witter et al., 2013). The buried soils at Willapa Bay and surrounding area are generally used as a proxy for the late Holocene marsh tsunami record for the CSZ, with each buried soil representing a coincident tsunami event. As an example, soil S correlates to earthquake event S. Willapa Bay likely contains at least $6 \mathrm{CSZ}$ tsunami events, preserved as buried soils that were heavily inundated during tsunami genesis and coastal subsidence (Atwater and Hemphill-Haley, 1997).

These buried soils are as follows (Atwater and Hemphill-Haley, 1997):

Soil J: Occurred between 3320-3500 years B.P.

Soil L: Likely dates to 2800-3300 years B.P. 
Soil N: Dates well to 2400-2780 years B.P.

Soil S: Exposed in Willapa Bay and Grays Harbor, and other marshes with smaller tidal ranges. Likely occurred between $1500-1700$. This could also possibly be between 1600-1900 years B.P. from additional ${ }^{14} \mathrm{C}$ dates which are not statistically well constrained.

Soil U: Widespread in WA state, likely occurred between $1130-1350$ years B.P.

Soil W: Likely 900-1300 years B.P.

Soil Y: Likely associated with 1700AD event

\subsubsection{Along the Strait of Juan de Fuca}

Over 60 localities from N. California to Southern Vancouver Island have been determined to have paleotsunami evidence from Cascadia earthquakes (Peters et al., 2007). Local to the Puget Sound, CSZ tsunami deposits have been identified in cores taken from Discovery Bay, Salt Creek and Swantown marsh (Figure 2). This suggests that historic, low-lying coastal marshes have high likelihood of preservation of CSZ tsunami deposits (Williams and Hutchinson, 2000; Williams et al., 2005; Peters et al., 2007; Bourgeois, 2009), due to the morphology of tsunami run-up and sediment transport inland. These were identified as tsunami deposits based on their micro sediment structures, presence and classification of marine microfossils (diatoms), ${ }^{14} \mathrm{C}$ dating, and lateral run-up extent from the beach inland. Used as a proxy for comparing dates of these deposits is the record from Willapa Bay, OR which contains buried soils that correlate to the longer-term turbidite record off the coast of Washington and Oregon (Atwater and Hemphill-Haley, 1997; Goldfinger, 2012). 


\subsubsection{Salt Creek, WA}

Located on the southern shore of the strait of Juan de Fuca, Salt Creek Marsh is a estuarine marsh, which contains two thin sand layers interpreted to be the product of Cascadia tsunami propagation and inundation (Hutchinson et al., 2013). These layers extend approximately $60 \mathrm{~m}$ along one edge of the creek, and $800 \mathrm{~m}$ from the mouth of the creek.

Evidence of marine diatoms suggest tsunamigenic origin. ${ }^{14} \mathrm{C}$ dating of the two sand sheet ages, with an estimated age for the upper sand dating 1560+/-30 ( 2 sigma range), with an estimated upper limit of $1790+/-30$. The lower sand layer has a maximum limiting age is $2440+/-30$ years B.P. They correlate the upper sand to buried soil S (and CSZ earthquake event S) found in Willapa Bay (Atwater and Hemphill-Haley, 1997).

\subsubsection{Discovery Bay, WA}

Discovery Bay is an inlet near Sequim, WA, just west of Port Townsend, located on the southern coast of the Strait of Juan de Fuca (Site B, Figure 2). This bay consists of a tidal flat that is ponded at high tide and exposed at low tide, and fed by freshwater from a fluvial outlet (Williams et al., 2005). A local home was flooded at this location from the tsunami produced by the Alaskan earthquake in 1964, suggesting that this location is particularly sensitive to tsunami inundation, even from distant sources (Williams et al., 2005).

Nine distinct sandy deposits are found in Discovery Bay up to $3 \mathrm{~m}$ below the surface, suggesting a rich paleotsunami history. Many of these deposits date to inferred CSZ event from turbidites and the record in Willapa Bay. The top 4 beds are interpreted to be CSZ tsunamis, with beds 5 and 6 being likely tsunamis and beds 7, 8 and 9 being possible tsunamis (Williams et al., 2005). All sand beds identified at Discovery Bay contain marine diatoms (Williams et al., 2005). However, the oldest of the deposits, beds 8-9, are unclear in age constrains, making them more 
difficult to correlate to turbidite events and other local marsh paleotsunami deposits. Beds 6 and 7 can both potentially be correlated to Soil S (and earthquake S) at Willapa bay.

These beds are radiocarbon dated as follows:

Bed 1: Likely dates to the 1700 event, $310-0$ cal. years BP.

Bed 2: 300-500 cal. years B.P.

Bed 3: 790-540 cal. years B.P.

Bed 4: $1270-960$ cal. years B.P

Bed 5: 1300-1060 cal. years B.P, inferred to likely overlap with inundation producing buried Soil U from CSZ Earthquake U from Willapa

Bed 6: 1820-1560 cal years B.P. or 2120-1930 cal. years B.P.

Bed 7: 1710-1330 cal. years B.P., inferred to likely overlap with the buried soil S from CSZ earthquake S.

Bed 8: 2100-1400 cal. years B.P.

Bed 9: 2750-2150 cal. years B. P.

\subsubsection{Swantown Marsh, WA}

Swantown marsh is on the west coast of Whidbey Island at the eastern end of the Strait of Juan de Fuca (Site C, Figure 2). The marsh faces WNW, meaning it is directly exposed to incoming influences of the Pacific Ocean (Williams and Hutchinson, 2000). Swantown has at least two CSZ tsunami depositional layers, dated with radiocarbon to be 1160-1350 cal. years B.P. and 1400-1700 cal. years B.P. The authors also concluded two more potential age ranges for tsunamis, around 1810-2060 cal. years B.P. and 1830-2120 cal years B.P., but these are potentially from sources other than the CSZ (Williams and Hutchinson, 2000). Within $25 \mathrm{~km}$ of the marsh are three local fault traces: Darrington-Devils Mountain, Southern Whidbey Island, 
and Leech River faults, and these could be responsible for these two older deposits (Williams and Hutchinson, 2000).

\subsubsection{Terrell Creek estuary}

The Birch Bay upper crustal fault is believed to be the source of a very thin $(1 \mathrm{~mm})$ tsunami deposit found in Terrell Creek estuary, WA (Kelsey et al., 2012). This deposit is believed to be caused by the Birch Bay fault where it traces off shore, adjacent to the Terrell Creek estuary (Kelsey et al., 2012). Though this is not a CSZ tsunami deposit, it is an example of a tsunamigenic source along an upper crustal fault, which exist locally to the north Puget Sound.

\subsection{Current Mitigation planning in Whatcom and Skagit Counties}

The 2015 Whatcom county hazard mitigation plan uses the Walsh et al. (2004) tsunami models as the basis for planning. The 2004 models predict grounding of ships in the harbor at low tide and, at higher tides, up to three meters of inundation into lower elevation downtown areas ("Whatcom County Natural Hazards Mitigation Plan," 2015).However, this prediction is based on older tsunami modeling, and newer models suggest the potential for inundation in Bellingham and other populated is actually greater and more spatially varied (Eungard et al., 2018). Large subduction zone earthquakes in the last 15 years have refined our understanding of splay faulting, and the potential for propagation of the fault through the accretionary wedge and to the sea floor, increasing tsunami height. Further developments in research and data sets factored into tsunami models for the CSZ events calls for revised models to be used in mitigation planning, such as the models produced by Eungard et al. (2018).

Skagit county's most recent natural hazard mitigation plan was updated in 2014 and claims "there is no written historical record of a damaging tsunami occurring in or affecting Skagit County" but does report that "geologic evidence of tsunamis has been found in Cultus 
Bay on Whidbey Island and at West Point in Seattle" ("Skagit County Natural Hazard Mitigation Plan,” 2014). They claim that tsunamis still pose a hazard to coastal areas such as the San Juan Islands and Anacortes. Skagit County uses the Walsh et al. (2004) models to make hazard assessment and mitigation plans and as a basis to suggest that there would be minimal effect from tsunami inundation along Skagit County coastal areas. The city of Anacortes, specifically, ranks tsunami hazard as a low risk, low probability issue currently facing the residents. While tsunamis may pose a less likely threat relative to other natural disasters such as flooding, which has a shorter recurrence interval and better understood effects, ("Skagit County Natural Hazard Mitigation Plan," 2014), the assessment of inundation risk is made based on older tsunami models (Walsh et al., 2004) which predict less spatial extent of inundation than more recent models (Gica and Arcas, 2016; Eungard et al., 2018). In addition to tsunami hazard, the Skagit County Hazard Mitigation Plan mentions the possibility of a "seiche", a large surge of water by earthquake waves forms a set of standing waves and causes the much larger than normal waves to arrive on shore, even where tsunami inundation is not expected ("Skagit County Natural Hazard Mitigation Plan,” 2014). Though it is only mentioned in Skagit County's plan, likely due to the small inlets within Skagit County, it is possible that seiches are a threat to a number of communities along the coast of the Puget Sound where a many constrictions can retard the flow of water out to the sea and promote development of a seiche.

\subsection{GeoCLAW Tsunami Modeling}

GeoCLAW software is used for modeling tsunami propagation and inundation (Gonzalez et al., 2011), by solving the depth averaged, non-linear shallow water wave equations (Leveque et al., 2010; Gonzalez et al., 2011; Mandli et al., 2016). For this model, sea floor deformation, calculated using Okada's 1985 method for slip on rectangular faults is used as an input and 
models inundation produced from that fault-slip source. The parameters chosen, such as initial sea level, and earthquake initial boundary conditions, specify sea floor deformation and define the incoming wave (Gonzalez et al., 2011; Mandli et al., 2016). To calculate these factors, depth of undisturbed water before the wave arrives is chosen as a model input, and sea level/larger storm swells/high tides can be used to define these initial conditions. Based on water depth, the flow velocity of the propagating wave can be determined (Gonzalez et al., 2011). Tsunami waves, once onshore, do not act linearly and are less predictable; so direct changes in inundation flow depth will vary spatially (Gonzalez et al., 2011). However, changes in tidal level can be used as a proxy for different sea level rise scenarios. GeoCLAW was used in this study to produce high resolution (1/3 arc second resolution) models for the field areas of focus, and the Witter et al. (2013) Bandon, OR sources were used to assess the different potential tsunami scenarios possible.

\subsection{Magnetic Fabrics of Tsunami Deposits}

Sedimentary fabrics reveal information about the hydrodynamic conditions during deposition (Wassmer et al., 2010; Wassmer and Gomez, 2011; Kain et al., 2017). A flow direction may be detected in the tsunami beds if the current for the tsunami is high (Wassmer et al., 2010; Kain et al., 2017). This flow regime could manifest as three potential sedimentary fabrics. If current was slow, then grains will be aligned in the direction of flow, with the grain long axis $\left(\mathrm{K}_{\max }\right)$ aligning in a dominate flow direction (Taira and Masuda, 1989; Boggs, 2011). If current was fast, than grains may be aligned perpendicular to the direction of flow, and will have varied inclination angles due to viscous collisional (turbulent) flows (Boggs, 2011). With turbulent flow, the $\mathrm{K}_{\max }$ axes will be oriented perpendicular to the expected direction of flow (Taira and Masuda, 1989), indicating how the tsunami moved inland as it inundated the marsh. If 
inundation was followed by ponded water, the deposits could have a fining upper sequence deposited from settling, producing a fabric with random orientations of the long axes and minimum axes perpendicular to the settling surface (Taira and Masuda, 1989; Boggs, 2011). The grain short axis $\left(\mathrm{K}_{\min }\right)$ orientations are referred to here as imbrication angles, which is the difference between the $\mathrm{K}_{\min }$ inclination reported and 90 degrees.

Fluvial deposition will preferentially orient grains with flow; alignment of grains can produce mineral fabrics that are characteristic of sediment transport mechanisms (Taira and Masuda, 1989), which can be measured as magnetic fabrics. When placed in a weak field, the grain long axis orientation, commonly the long axis of an oval shaped grain, produces a maximum $\left(\mathrm{K}_{\max }\right)$ susceptibility, producing the strongest response to the field. The intermediate axis $\left(\mathrm{K}_{\mathrm{int}}\right)$, the second longest grain axis, and minimum axis $\left(\mathrm{K}_{\min }\right)$, the shortest grain axis, produce less intense responses to the field than the $\mathrm{K}_{\max }$, as they are not as magnetically susceptible in response to a magnetic field. Due to the differences in the depositional flow regimes of storm and tsunami deposits anisotropy of magnetic susceptibility (AMS) fabric analysis can be used to differentiate the axis orientations, if a clear flow regime is detectable (Wassmer et al., 2015). Tsunami deposits will generally have a clearer flow direction retained in the sediment fabric due to the alignment of the long axes with or perpendicular to flow and little expected backwash to alter grain alignment. However, the general expectation that a flow regime is preserved can be complicated by local obstacles or fast, collisional flow. In previous studies (Wassmer et al., 2010, 2015; Wassmer and Gomez, 2011) tsunami deposit AMS results show a clustering of the AMS axes, with the $\mathrm{K}_{\text {mins }}$ being clustered perpendicular to the settling surface (flat or imbricated), and $\mathrm{K}_{\max }$ magnetic grain orientation commonly spread in orientations parallel or perpendicular to flow and parallel to the bedding plane, or presenting in random 
orientations parallel to the bedding plane, suggesting deposition from settling (Taira and Masuda, 1989; Wassmer et al., 2010). In contrast, storm wave AMS fabrics are typically more collisional due to multidirectional flow from the back and forth swashing motion, and highly collisional flows show less clustering of the $\mathrm{K}_{\min }$ perpendicular to the settling surface, and less clustering of $\mathrm{K}_{\max }$ and $\mathrm{K}_{\text {int }}$ directions making a flow direction more difficult to detect (Taira and Masuda, 1989). Magnetic fabrics in deposits from the 2004 Indonesian tsunami corroborated with the eyewitness accounts, suggesting this could be a feasible method for measuring flow direction for tsunami deposits (Wassmer et al., 2010).

\subsection{Paleo Secular Variation Dating}

The global magnetic field directions and paleointensity varies geographically but has been measured and documented by instruments for the last 150 years in North America, and paleosecular variation (PSV) records from igneous and sedimentary rocks are available in detail for older periods of time (Hagstrum and Champion, 2002). Based on geographical location, the paleosecular variation of the geomagnetic field can be used to determine the age of a section of sedimentary strata. Hagstrum et al., (2004) used this method to determine the regional PSV record for the Pacific NW from sediments that span 2000 years of Cascadia tsunami deposits in Discovery Bay (top 5 beds), and obtained PSV records from the Snohomish River which are believed to have preserved a Seattle Fault earthquake from $\sim 900$ cal. years B.P. Paleosecular variation dating can be used as a compliment to the ${ }^{14} \mathrm{C}$ dates and may provide both a higherresolution age of the cores when factored into a sequence model, and be directly compared with the geomagnetic field directions recorded in other sections that contain deposits from tsunami events locally. 


\subsection{Field Sites}

\subsubsection{Ship Harbor, Anacortes, WA}

Ship Harbor marsh faces NNW on the north-western tip of Fidalgo Island, WA, in the city of Anacortes (Figure 1 and 3). This marsh is bordered to the west by the Anacortes Ferry terminal and bordered on the north side by the Anacortes Interpretive Preserve and beach, which contains the old foundations and docks of the cannery built in the mid to late 1800 s ("Intro to Anacortes History"). Although Fidalgo Island has been home to the Samish and Swinomish people for thousands of years it was settled in the early 1800 s by westerners, and by 1890 a cannery and railroad system was built on the north side of the marsh. The marsh is primarily fresh water fed by rain, and has no major source of surface fluvial input. The barrier beach extends the entire width of the marsh with no tidal channels, separating the marsh from the ocean. The western most part of the marsh is likely the most "historical" long standing marsh area, as suggested by the 1889 T-sheets available (Gilbert, 1885). The building of the railroad berm along the north-west edge of the marsh likely separated the marsh completely from the beach, causing a potential shift in the dominate vegetation in the marsh. Pilings where built throughout the marsh in order to dry nets, and aerial photos show images of a ditch having been dug through the marsh at some point before it was left to return to its natural state. Today, the pilings stand about $.5 \mathrm{~m}$ high, and were observed in the field.

Ship Harbor marsh has an average elevation of $3-4 \mathrm{~m}$, based on LiDAR produced using the NAVD 88 vertical datum ("North Puget USGS 2006 DTM 43”). The typical tidal range for Ship Harbor, according to a permanent tide gauge at Friday Harbor, WA, can be $-2 \mathrm{~m}$ to $+1.5 \mathrm{~m}$ change from mean sea level (“Tide Predictions - NOAA Tides \& Currents"). 
The L1 based model predicts inundation at this site of up to $3.4 \mathrm{~m}$, extending approximately $330 \mathrm{~m}$ inland, with inundation predicted throughout the marsh (Gica and Arcas, 2016; Eungard et al., 2018). Based on the stratigraphy of nearby marshes, peaty intertidal sediments beneath this marsh are thin $<0.5 \mathrm{~m}$, and thicker sediment layers likely exist near the middle/back part of the marsh or in the pond (MacInnes, 2018).

The current marsh surface is seasonally ponded for most of the year (October - July), and dries in the summer. The plants, year-round, consist mainly of cattails and bulrushes which cover the entire marsh and stand around 2-2.5m in height. Duckweed is present covering areas where soils are saturated most of the year. The front part of the marsh consists of shrubby trees, blackberry and rose hip bushes.

\subsubsection{Shannon Point/Cannery Lake, Anacortes}

Cannery Lake is a coastal lake located in north-west Anacortes, adjacent (west) to the Anacortes ferry terminal. The area is mapped in the $1889 \mathrm{~T}$-sheets as an estuary, prior to the build of the railroad berm, inducing ponding and likely formation of the lake (Gilbert, 1885). There is predicted inundation of the lake up to $1.5 \mathrm{~m}$, with potential for preservation of the intertidal flat materials under the current reservoir/lake. We attempted to core with the gouge auger and the vibracorer here but were unsuccessful at retrieving anything below $1 \mathrm{~m}$ depth. This field site was eliminated from this study.

\subsubsection{Eliza Island}

Eliza island is located off the southwest tip of Lummi Island, Whatcom County, WA. It has a total land area of 158acres ("Eliza Island plan") and consist of 139 property subdivisions owned by private families and the Eliza Island Beach Club, which is a board of land owners. The site of interest on Eliza is located in the middle, low-elevation part of the island, just west of the 
airstrip which runs roughly NW-SE on the east side of the marsh (Figures 1 and 4). The marsh itself is ponded seasonally and located around a pond which is wet year-round.

Average elevation of the marsh is 1.8-2.5m ("San Juan 2009 DTM 12"). There is a large beach berm, approximately 3m in height ("San Juan 2009 DTM 12”), on the north and south sides of the middle of the island. Tidal range for Eliza are typically $-2 \mathrm{~m}$ to $+1.5 \mathrm{~m}$ above mean sea level ("Tide Predictions - NOAA Tides \& Currents"). There are no channels connecting the marsh to open water. The beach berm is approximately $30 \mathrm{~m}$ from the closest collected core (Figure 4). The north side of the marsh is approximately $145-190 \mathrm{~m}$ from the beach.

The marsh has at least $1.5 \mathrm{~m}$ of predicted inundation based on the Walsh et al. (2004), Gica et al. (2016) and Eungard et al. (2018) models. The marsh is present in the 1889 T-sheets, suggesting a good environment for paleotsunami deposit preservation (Gilbert, 1885). The area of interest on Eliza Island is a federal jurisdiction wetland, and the island's shorelines are protected by the county due to eelgrass populations and other protected plant communities. Eliza Island is considered a known geologic hazard tsunami zone in Whatcom County ("Whatcom County Natural Hazards Mitigation Plan,” 2015).

Plants identified in the immediate area consist of Salicornia Virginica (slender pickleweed), a succulent segmented grass which inhabits the areas closest to the central pond, Oenanthe sarmentosa (water parsley), Eleocharis acicularis (needle spike-rush), and Carex aperta (Columbia sedge) (Guard et al., 2010). These plants cover the entirety of the marsh. 


\section{Field methods}

\subsection{Gouge auger transects}

Data collection consisted primarily of gouge auger coring and vibracoring to characterize and subsample subsurface features and reconstruct paleoenvironments at both field sites. All field work was completed between mid-August 2018 and late September 2018. During the summer months, both field sites are substantially drier, making it easier to core and easily traverse each site. Prior to collecting vibracores, a $1 \mathrm{~m}$ x 60mm diameter Elijakemp gouge auger with two $1 \mathrm{~m}$ extensions and handle with beating head was used for most of the exploration and transect data for both field sites. A $1 \mathrm{~m}$ soil probe with up to $4 \mathrm{~m}$ of extensions was used for initial exploration of depths and presence of sand layers. Field exploration consisted of collecting auger pushes in 5-15m spaced points along several transects spanning through parts of the marsh, especially focused on areas that showed potential tsunamigenic deposits (Figures 3 and 4). In total, 33-36 auger cores were collected at each site, and for each core sediment type, size, color, grain size, rounding, clay content, and visual organic content was documented (Appendix 1). Field photos were taken of most auger cores.

A Trimble explorer 6000 or a Garmin 64 s was used to mark points and waypoints in the field. When possible, a topographic profile was also completed (only in Ship Harbor).

\subsection{Vibracore collection}

A vibracorer was used to collect nine cores: three from Eliza Island, and six from Ship Harbor. Vibracores were collected using 3" aluminum irrigation tube. The aluminum tube was cut into $8 \mathrm{ft}, 10 \mathrm{ft}$ and $13 \mathrm{ft}$ segments, based on desired sampling depth and vibrated to depth by mounting a customized, heavy vibrating head at the top of the pipe. 
The inside of the core pipe was wetted before collection to minimize compaction. Cores were oriented and marked with magnetic North during collection using a Brunton compass. Cores were oriented for magnetic data correction. A large clamp is positioned around the core pipe and connected to a cement mixing cable, which is connected to a modified gas-powered motor. When the motor is started, a mechanism spins the inside of the cable, effectively vibrating the clamp and the pipe and using the operators' body weight, driven into the ground until desired depth or refusal. Inner and outer measurements of the remaining core pipe are taken before retrieval to calculate compaction for each core (Table 1).

To retrieve the core, the pipe is filled with water to the top, capped with a plumber's cap to create a pressurized seal, wrapped with carpenters wrapping and retrieved with a jack. In the field, core tubes were then marked with name and orientation, labeled, and some were cut into segments ranging from 1-1.5m for transport.

\subsection{Field Methods}

Initial exploration was spent surveying as much of the marsh as possible with the gouge auger. Subsequent days were spent focusing on locations of interest within each marsh, found to have preferentially preserve the long-term stratigraphic record.

Several transects were completed in Ship Harbor (Figure 3): a large transect spanning approximately NW to SE, an several smaller transects extending to the SE, SW, and from East to West. Vibracores were collected at several different locations throughout the marsh, in locations representative of the overall stratigraphy seen in the gouge auger data.

On Eliza Island, cores were collected around the central pond in the wetland (Figure 4), adjacent to a well-sorted gravel-dominated mixed-sediment beach directly south. The central pond is armored on the bottom with gravels between $1-5 \mathrm{~cm}$ in diameter, sub-rounded to well 
rounded. Along the north side of the pond is a slope, which leads away from the pond into a grassy field. Eliza island had four transects completed using a gouge auger: two spanning EastWest and two, one of which was short (30m), spanning North-South. Points for auger collection where chosen based on location and ability to collect. Most cores were collected in the marsh around a pond that remains saturated year-round, and is the topographic low in the marsh. Using published inundation models and gouge auger data, three vibracores locations were selected for Eliza Island, one on the North side of the pond, in a predicted inundation zone, and two at a lower elevation on the South side of the pond.

\section{Lab Methods}

\subsection{Sediment vibracore analysis}

Vibracores were split at WWU for analysis. The North mark on the core pipe, made in the field, was used as a reference to measure and mark East, West, and South directions, running a line up either side of the core. Using a set of metal shears, two opposite sides were split, along the east and west marked lines, removing a ribbon of aluminum from the cores. A thin stainlesssteel wire was used to separate the halves, and when difficult, a knife was used. Immediately after splitting a core, each half was photographed using a Nikon DSLR camera and a stage with lights, as well as a reference measuring tape.

The cores, once photographed, were then described to characterize sediment type, based on color using a Munsell color book, grain size and visual sand and mud \%, textures and interpreted stratigraphic contacts and subdivisions (Appendix 2). Cores were stored in a refrigerator, with each half wrapped in plastic wrap and placed back together, capped on each end, and taped. 
To calculate compaction, the inner measurement and outer measurements made in the field are subtracted from one another and the difference, divided by the total core length minus the outer field measurements, calculating the amount of compaction per centimeter present within the core (Table 1). If material was removed prior to coring, this was subtracted from the inner field measurement before calculating compaction. These compaction factors were used to calculate the actual subsurface depths of each bed identified in the core (Appendix 2).

\subsection{Organic Content}

Four vibracores were analyzed for organic content using LacCore standard organic content loss on ignition (LOI) procedure (Myrobo et al., 2013). Samples were collected at $10 \mathrm{~cm}$ intervals down the length of the cores (VCS2, VCS6, VCEI2, VCEI3), starting stratigraphically below the peat (almost 100\% organic) sections. Crucibles were cleaned with deionized (DI) water and left to dry overnight in a $150^{\circ} \mathrm{C}$ oven. The crucible dry weight was measured, and then a wet sample from the core was placed in the crucible. The crucible was weighed again, and then left in a $100^{\circ} \mathrm{C}$ oven overnight. The samples were then weighed for pore water percent. They were then placed in a $550^{\circ} \mathrm{C}$ oven, held at temperature for four hours, and then cooled in the oven. The samples were weighted again to calculate organic content percent. Organic content was calculated using $=($ dry sample weight $)-($ final post -550 weight $) * 100$ to get a percentage organic content.

\subsection{Particle size analysis}

\subsubsection{Fine grained fraction, $<0.5 \mathrm{~mm}$}

Grain size distribution was measured on the WWU Geology Department Malvern Mastersizer instrument. Samples within cores VCS2, VCS6, VCEI2 and VCEI3 in were analyzed in $3-15 \mathrm{~cm}$ sections within each stratigraphic unit present. 
To prepare sediments for analysis, extensive pre-treatment was involved to remove organics and biogenic silica (diatoms). LacCore standard operating procedure (SOP) (Triplett and Heck, 2013) and SOPs from previous users of the Mastersizer were used as a reference for how to complete these pretreatments. Samples were digested for organics using 35\% hydrogen peroxide and a warm sonicating bath. The samples were then left to complete digestion for 4 or more days under a fume hood. Samples were centrifuged and decanted several times with new DI water additions each time to dilute the hydrogen peroxide until very dilute. Samples were treated next with $1 \mathrm{M}$ sodium hydroxide to remove biogenic silica, using a warm sonicating bath. The reaction was halted with hydrochloric acid, and samples were centrifuged and rinsed several times till dilute. Samples were filled with DI water and fixed with sodium hexaphosphate dispersant to prevent clay flocculation prior to and during analysis.

Samples were run using a Fraunhofer model SOP ("Mastersizer 2000 User Manual MAN0384 Issue 1.0,” 2007) taking three measurements from an aliquot ranging between 1$50 \mathrm{~mL}$. The pots were mixed for 20 seconds, and treated with pre-measurement ultrasonic for 10 seconds to reduce flocculation of clays. Results are an average of the three measurements, and used to determine a grain size distribution within a section of stratigraphy.

\subsubsection{Median grain size $>0.5 \mathrm{~mm}$}

For samples which are dominantly sand and gravels, the Mastersizer is not appropriate as it cannot accurately measure any materials greater than $0.5 \mathrm{~mm}$ in diameter. Settling tests were instead used as a simple way to accurately measure the percent of sand, silt and clay within a deposit. The soil settling procedure from the University of California, Agriculture and Natural Resources was used ("Sedimentation Test of Soil Texture"), which bases the sediment size fall 
velocities on Stokes law related to the size and Reynolds number of spherical particles in a slurry (Howard, 1983; Zhiyao et al., 2008).

Approximately 6-10 cubic cm of material were used for each settling test, sampled from core intervals that could not be analyzed using the Mastersizer, except those comprised of mostly organics. Materials were placed in a $6 \mathrm{oz}$ container, filled with $180 \mathrm{~mL}$ of water, shaken, and left to settle for 24 hours. The total thickness of settled sediment was measured, then container shaken again. A ruler was used to measure the thickness to $.5 \mathrm{~mm}$ precision. After 30 seconds of settling, the sand measurement is taken. After 30 minutes, the depth of silt was measured. The containers were then shaken a last time, and left to settle for another 24 hours. This give the clay measurement height. These measurements were subtracted from one another to produce percentages of sand, silt and clay, and a USDA soil triangle was used to estimate the sediment soil types present.

\section{$4.4{ }^{14} \mathrm{C}$ radiometric dating subsampling}

One core from each site with interpretable stratigraphy and present sand sheet(s) was chosen for ${ }^{14} \mathrm{C}$ dating. Because of the clear presence of a potential tsunami-related deposit at Ship Harbor, dating was primarily focused on this site.

For Ship Harbor, eight detrital plant macrofossils where selected from core VCS2: $61.8 \mathrm{~cm}$ and $12.85 \mathrm{~cm}$ above, $41.2 \mathrm{~cm}$ and $68.3 \mathrm{~cm}$ below, and four from within the sand-sheet between $230.7-254.5 \mathrm{~cm}$ corrected depth (156.5-175cm compacted depth) (Table 2), further labeled as Ship Harbor bed 1, or sand-sheet SHb1. This deposit contains shells, abundant sand, with an organic-rich section approximately $10 \mathrm{~cm}$ thick at the top (from $156-166 \mathrm{~cm}$ compacted depth, Figure 5). This organic rich debris layer is referred to in notes as the "trash layer". 
Samples were prepared for analysis at WWU by rinsing each sample with DI water and leaving to air dry within glass vials with caps set on top to prevent dust contamination, and left under a heat lamp for 3-5 days. Samples were examined under a dissecting microscope and cleaned with tweezers to remove unwanted organics, sand, mud, and surface debris. The samples were weighed to ensure a minimum $1 \mathrm{mg}$ sample weights, and sent to Woods Hole Oceanographic Institute, NOSAMS for analysis.

OxCal was used to calibrate the radiocarbon dates reported from NOSAMS for cores VCS2 and VCEI2. An age range for sand-sheets SHb1 and EIb2 was calculated by placing radiocarbon dates into $\mathrm{OxCal}$ sequence model, which makes no assumptions about relative stratigraphic depth within a single bed assumed to be deposited as a single event.

\subsection{AMS analysis}

After the initial split of the vibracores, oriented samples were collected for magnetic studies. Ten cubic centimeter sample cylinders where used to collect magnetics samples at $5 \mathrm{~cm}$ intervals. If collecting at such an interval was not possible due to the presence of large gravels, organic fragments, or signs of alteration or oxidation, samples were collected in alternate locations close by.

A KYL3-S Kappabridge Susceptometer was used with a rotating arm sample holder. The Kappabridge produces a low intensity magnetic field, and measures the response of the induced magnetization of the sample. The arm spins the sample in 360 degrees in three orthogonal positions and measures to determine the strongest signal direction. AMS measures the induced magnetization of the entire sample, paramagnetic, diamagnetic, and ferromagnetic constituents, to determine the bulk magnetic orientation of grains. Empty holders and background noise were measured prior to each analysis to ensure no major source of error were present. 


\subsection{Rock Magnetism Experiments}

Three types of rock magnetism experiments were performed: hysteresis loops, isothermal remnant magnetization (IRM) backfield measurements, and temperature vs susceptibility (high and low), to determine the magnetic constituents present throughout the cores at each site. Magnetic mineral constituents are important to identify prior to paleosecular variation dating to determine ability to complete demagnetization using alternating field (AF) demagnetization and the steps necessary during demagnetization.

\subsubsection{Hysteresis}

Hysteresis experiments measure the remnant and saturation magnetizations and the coercivity values of an unoriented portion of sample (Tauxe, 2018). This analysis used a Princeton Magnetics 4500 vibrating sample magnetometer (VSM) capable of producing a field up to 2.2 Tesla (T). Hysteresis experiments were made using a peak field of $1.0 \mathrm{~T}$, and between 50-60 field steps. The hysteresis data were corrected for high-field slope (due to the paramagnetic and diamagnetic phases in the sample) before determination of saturation moment (Ms), saturated remnant moment $(\mathrm{Mr})$, and coercivity $(\mathrm{Hc})$, and these results were massnormalized to determine magnetization values for Ms and Mr. These variables reveal the types of magnetic minerals present and the field steps of AF demagnetization necessary to demagnetize the sample.

To prepare samples for hysteresis and IRM, a small portion of sample weighed and placed in a gelatin capsule and compressed to be used in the VSM. Samples were prepped for all depths in the cores where AMS samples were collected. 


\subsubsection{Isothermal Remnant Magnetization (IRM)}

IRM is a measurement of the magnetization of a sample during increased step-wise field, but immediately after exposure to the field while the field is off. IRM measures the remanence of the ferromagnetic constituents, including those with short relaxation times. As the sample is exposed to a higher field, it will reach saturation if the coercivity is low (Tauxe, 2018). The field is then switched in direction starting from zero field, and the back field is measured. The backfield provides information about the coercivity of remanence of the sample (Hcr), providing further insight into the type and size of the magnetic minerals present, which can affect the demagnetization process during paleo secular variation dating (Tauxe, 2018). IRM is completed using the same sample prepped for hysteresis, and a demagnetization of the sample is completed before IRM if the sample was previously measured for hysteresis with the VSM.

\subsubsection{Temperature vs Susceptibility}

The KLY-3 Kappabridge was used to measure the temperature vs susceptibility curve for key samples, representing the different overarching stratigraphic units, from cores VCS2, VCS6, VCEI2 and VCEI3. To prepare samples for temperature vs susceptibility, samples were dried in a $100^{\circ} \mathrm{C}$ oven overnight, crushed with a mortar and pestle and weighed. The powdered sample is placed in a glass tube, inserted with a temperature probe, and set into a specific attachment for the Kappabridge. The empty holder was measured, and the curve produced is smoothed and applied as a background noise correction for the temperature vs susceptibility curve, to account for noise from the sample holder. The data for high and low temperature samples was bulk susceptibility normalized for analysis.

Low temperature vs susceptibility measurements were taken for key samples from VCS2 and VCEI2. Liquid nitrogen is used to cool the sample to $-174^{\circ} \mathrm{C}$, and measured over time as the 
sample warms to room temperature. Low temperature experiments provide information about the strength of the paramagnetic constituent(s) present, to justify the use of an automatic correction for the paramagnetic constituents in the hysteresis loop correction. If a strong paramagnetic signature is not present, a hysteresis correction may not be the correct course of action, as the lack of saturation than is caused by the magnetic minerals present instead of the paramagnetic constituents.

High temperature vs susceptibility is diagnostic of the ferromagnetic minerals in the sample, providing information about the necessary steps for demagnetization during paleo secular variation dating data collection. As a sample is heated, the ferromagnetic constituents will continue to maintain a consistent susceptibility until reaching the Curie temperature, where susceptibility decreases drastically. The Curie temperature is characteristic of the ferromagnetic constituents present within a sample. The sample tube is connected to Argon gas, which creates an Argon atmosphere to minimize oxidation and mineral neoformation during heating. The sample is incrementally heated to $700^{\circ} \mathrm{C}$ and then incrementally cooled using DI water surrounding the tube. Measurements are conducted at a regular interval through the entire process.

\subsection{Paleosecular variation dating (PSV)}

To determine the orientation of the geomagnetic field recorded by these sediments, each sample that was collected for AMS from cores VCS2 and VCEI2 was then was demagnetized in steps and measured to observe the demagnetization behavior. Alternating field (AF) demagnetization was performed in 6 or more steps, up to $60 \mathrm{mT}$ or greater (up to $200 \mathrm{mT}$ ), in three orthogonal positions. Samples were measured between demagnetization steps using the $2 \mathrm{G}$ DC-SQUID Magnetometer. AF demagnetization was performed in three positions, in the same 
order each time: $+\mathrm{XYZ}$. This was done for all samples from VCS2 and for all but six samples from VCEI2 which were demagnetized in a set of 6 different orders to limit potential bias from the AF demagnetizer: +XYZ, +YZX, +ZXY, -XYZ, -YZX, -ZXY. Notable differences in the data results are not observed between these methods.

A pilot study was completed for VCS2 and VCEI2 to understand the response to demagnetization of each unit present from the cores at each site. The pilot study focused on areas that are clay rich, sand rich and gravel rich to differentiate the behaviors within the overarching stratigraphic units and observe viability of PSV dating. Samples were kept in a shielded room during demagnetization to prevent an overprint of magnetization from the Earth's magnetic field.

\subsection{GeoCLAW Tsunami Modeling for Ship Harbor and Eliza Island}

Since no CSZ megathrusts earthquakes have occurred in the modern, instrumented era, it is difficult to determine source parameters of characteristic CSZ megathrust events. Tsunami inundation models are used to assess the likelihood of any sandy deposit being the product of a CSZ earthquake tsunami. The rupture parameters produced in Witter et al. (2013) are some of the most recent set of potential earthquake parameters to apply to tsunami models. GeoCLAW was used to run some basic tsunami wave height models using Witter et al. (2013) L1, L2, M1, M2 and SM1 earthquake scenarios, and the Seattle Fault earthquake scenario at mean sea level. This differs from the L1 model plots produced from Gica and Arcas (2016) and Eungard et al. (2018) which are based on mean higher high water (MHHW). Models were run using ClawPack 5.4.1 run on Linux through an Ubuntu virtual machine.

Slip parameters used as inputs are from the Witter et al. (2013). Peak slip is assumed at $42.94^{\circ}$ latitude. L1 assumes splay faulting, with $22 \mathrm{~m}$ of peak slip, $5.8 \mathrm{~m}$ maximum offshore uplift, 3.5m of offshore subsidence. L2 assumes shallow faulting producing $21.8 \mathrm{~m}$ peak slip, 
4.9m max offshore uplift and 3.3m maximum offshore subsidence. M1 assumes splay faulting with $14.4 \mathrm{~m}$ peak slip, $3.8 \mathrm{~m}$ max offshore uplift and $2.4 \mathrm{~m}$ maximum offshore subsidence. SM1 assumes splay faulting with $9.5 \mathrm{~m}$ peak slip, $2.6 \mathrm{~m}$ max offshore uplift, and $1.6 \mathrm{~m}$ max offshore subsidence.

GeoCLAW outputs are produced as time frame images and predicted total water level change. Each model scenario was run by defining locations for outputs of the model, such as water level and wave height, based on latitude and longitude observation points placed along the near-shore. For Ship Harbor, a single point measurement location was placed in front of the marsh, while for Eliza a tide gauge was placed in the bays to the North and South of the island to observe spatial differences in the change of water height as the simulated tsunami moved into Bellingham Bay on either side of the island. Mean sea level is used in these model scenarios, so tides are not considered for the basic model outputs. Open source bathymetry and topographic data was used as a base parameter for all models, with the coarser resolution being used for earlier time intervals, prior to tsunami propagation into areas of interest using etopo 1 , and the finer resolution after about 1.5 hours of run time being porttownsend_nadv88_2011 available at $<$ https://catalog.data.gov/dataset /port-townsend-washington-coastal-digital-elevation-model $>$. Six levels of resolution were chosen for different time intervals, with each step producing 18 frames for a total of 7 hours, with the first hour being modeled at the coarsest resolution, since tsunami arrival at the field sites of interest does not happen in this initial first hour. Subsequent steps are run with the higher resolution topography to monitor land-fall of the tsunami and to better resolve the spatial extent of inundation.

Tidal variability in the Puget Sound can be quite large, on the magnitude of $0.5-3 \mathrm{~m}$ daily variations, according to the harmonic tide gauge positioned by NOAA Co-ops at Port Townsend, 
and secondary (temporary) gauges positioned around Anacortes. Models of the L1 and M1 scenarios were run to determine the effect of tidal variation on inundation into Ship Harbor and Eliza Island. Initial sea level parameters are default set to mean sea level, then manipulated to $+/-$ $1 \mathrm{~m}$ increments to evaluate response to tidal variations. $\mathrm{L} 1$ scenario was run with a $-1 \mathrm{~m}$ and $-2 \mathrm{~m}$ tidal variation, while $\mathrm{M} 1$ was run with a $+1 \mathrm{~m}$ tidal variation. Each run produces outputs at specified time steps set in the modeling parameters, as well as plots of water height above the chosen sea level prior to arrival on land at designated observation points in the model.

\section{Results}

\subsection{Sedimentary core results and particle size analysis results}

Stratigraphic units were classified based on position within the stratigraphy of the core(s), grain size, color, texture, and presence of macroscopic features. Particle size analysis results were used to classify the dominant sediment or soil grain sizes present (Tables 3 and 4). Particle size, thickness of units and presence of shells/sand/gravels were used to correlate units between cores.

\subsubsection{Particle Size analysis results}

Both methods of particle size analysis produced a percentage of sand, silt and clay for each section of stratigraphy (Table 3 and 4). One result was omitted from VCEI2 due to a mechanical error during Mastersizer analysis (detachment of the feeder tube from the instrument arm to the prep tank), marked in yellow in Table 4. Homogeneity of the upper part of core VCEI2 suggests that this omitted sample, core VCEI2 depths 102-112, is similar to the section above and is also likely a silt loam. 
Grain size distribution from the Mastersizer shows a bimodal distribution, with a mean peak distribution in the silt/clay/fine sand fraction and a smaller peak in the medium to coarse sand fraction. This secondary peak is due to diatom presence and is not representative of the overall grain size distribution. Smear slides confirm the presence of diatoms, typically between 25-50 micrometers in size within samples, indicating that there was an incomplete diatom digestion during preparation. This second, larger particle size peak is not considered in the overall particle size classification, as it does not represent the bulk of the sample.

\subsubsection{Ship Harbor Data Assessment}

There is a consistent stratigraphy to the western-most part of the marsh. The top of each core collected along transects $\mathrm{T} 1 \mathrm{a}$ and $\mathrm{T} 1 \mathrm{~b}$ (Figure 3) consists of peat ranging from $\mathrm{H} 1-\mathrm{H} 9$ humification. The peat extends through the entire marsh and ranges from $60-120 \mathrm{~cm}$ thick. On the west side of the marsh, the peat gradually transitions to grey-green clay-rich mud (Figure 5), with generally less than $5 \%$ of fine to very fine sand. The clay is stratigraphically extensive and thickens to the south (Figure 6 ). The mud is composed primarily of silt $(\sim 50-60 \%)$ and clay ( $30-40 \%)$, suggesting a history of ponded water (lagoon) or intertidal marsh. Thickening of subsurface mud southward suggests long-standing ponded water at the land-ward extent of the marsh, similar to present-day conditions.

The northern most part of the marsh surveyed in this study has a uniform stratigraphy both north and south of the railroad berm, well represented by core VCS3 (Appendix 2). The top $80 \mathrm{~cm}$ consist of peat, above clay-rich mud around $42 \mathrm{~cm}$ thick (Figure 6). Below the peat and mud is a thick section of sand and gravels from $145.1 \mathrm{~cm}$ to $225.6 \mathrm{~cm}$ depth. Stratigraphically below $225.6 \mathrm{~cm}$ depth is a $33 \mathrm{~cm}$ thick mud to $258.9 \mathrm{~cm}$ depth. From 258.9 to the bottom is sand. 
It is unclear if the bottom sand here is discrete, or extends further down, as there are no data collected from lower depths.

One well-defined sand-sheet $\mathrm{SHb} 1$, is present though the western edge of the marsh, thinning inland and primarily composed of sand, with a lateral extent of 50+m (Table 5, Figures 5 and 6). The sand-sheet is first detected closest to the beach as a discrete unit in gouge auger core S13 (Figure 3) as a clear stratigraphic unit, $26 \mathrm{~cm}$ thick between $233-259 \mathrm{~cm}$ depth within mud, and is traceable south in cores VCS2 (Figure 5), VCS6 and VCS4 (Figure 6), as well as gouge auger cores that reach a depth of at least $2.5 \mathrm{~m}$. The sand commonly contains shell fragments, with core VCS2 containing a whole mollusk shell, and a few conular mollusk shells (Figure 5 and 7). Sand-sheet SHb1 in core VCS2, from depths $230.7-254.5 \mathrm{~cm}$ is a massive sand bed containing $40 \%$ fine sand, $10 \%$ shell fragments and coarse sand, $20 \%$ organics (concentrated into the top $10 \mathrm{~cm}$ of the deposit) and $40 \%$ silt-rich mud, with an abrupt lower contact (Figure 5). Particle size analysis reveals that the mud in units above and below sand-sheet SHb1 contains 4$5 \%$ fine sand in silt and clay (Table 3).

Moving south along transect T1a and T1b (Figure 3), VCS6 contains sand-sheet SHb1 from $214.5-234.0 \mathrm{~cm}$, as a discrete bed with graded sand and organics present, containing $55 \%$ sand, between silt loam beds containing 3.5-5.8\% sand (Table 3). To collect core VCS6, $45.7 \mathrm{~cm}$ of material was first removed from the top of the marsh, necessary for the vibracoring process to be successful. The difference in stratigraphic depth between the position of sand-sheet SHb1 in cores VCS2 and VCS6 could be due to the variation of the amount of peat and modern rooting systems of the marsh plants; the difference in stratigraphic depth could also be due to paleotopography differences, with VCS6 being $\sim 15 \mathrm{~m}$ closer to the edge of the marsh. 
Identification of the conular shells from within the VCS2 (Figure 7) appears to be Neostylidium eschrichtii or Lirobittium attenuatum, both within the Cerithiidae family and Bittinae subfamily, due to the number of shell groves, tiers, smoothness, color, and size. Both gastropods have been found along Anacortes beaches by the Pacific Northwest Shell Club ("Pacific Northwest Marine Mollucan Biodiversity," 2019). Though uncommon, they are present in the Pacific Northwest and Puget Sound, and have been seen on recent beaches near Ship Harbor ("Pacific Northwest Marine Mollucan Biodiversity," 2019). Both organisms live in intertidal and subtidal waters up to $55 \mathrm{~m}$ depth, but are commonly found under rocks and the shells are commonly inhabited by hermit crabs ("Pacific Northwest Marine Mollucan Biodiversity,”2019). Intertidal mollusk shells suggest inundation from the beach or intertidal region as a potential source of deposition of SHb1.

At the most landward extent of sand-sheet SHb1 to the south, along transect T1b (Figure 3, Table 5), gouge auger core S33 contains shells in mud at the depth that correlates to sandsheet SHb1, however, did not contain a higher sand percentage detectable in the field, indicating that it may or may not correlate with SHb1.

Correlation of sand-sheet SHb1 can potentially be extended north along transect T1a (Figure 3) through gouge auger cores S17, S18 and S19, and core VCS3 (Table 5), though gouge auger cores collected in this area end with unconsolidated and poor recovery, making correlation difficult. Gouge auger core S18, from $121-211 \mathrm{~cm}$ and $\mathrm{S} 19$, from $186-245 \mathrm{~cm}$, contain a massive sand bed with abundant organics and an abrupt lower contact with sand-poor mud. This may correlate with the bed in core VCS3 from 145.1-225.6 cm, and potentially connect with sandsheet SHb1 in gouge auger core S13 to the south (Figure 3). The sand units in gouge auger cores S18, S19 and core VCS3 (Figure 6) are significantly thicker than sand-sheet SHb1 in VCS2 and 
start stratigraphically higher, but end at a similar depth. Presence of shell fragments, graded sand and gravels, stratigraphic depth, and an abrupt contact at the base, suggest that sand-sheet SHb1 could be the larger bed within these core VCS3, or at the base of the larger bed of from 197.4$225.6 \mathrm{~cm}$.

Interpreting stratigraphy eastward of VCS2 presents a challenge for several reasons. The stratigraphy to the east of VCS2, along transect T2 (Figure 3), through cores S29, S25, VCS5, $\mathrm{S} 28$, and S27 is more convoluted and difficult to correlate, due to the presence of sand and gravel beds that are not clearly stratigraphically continuous. Moving east from core VCS2, gouge auger core S29, closest to VCS2, contains peat and sand-poor mud overlaying sand from $241-261 \mathrm{~cm}$, with an unconsolidated return from $262-270 \mathrm{~cm}$ and unconsolidated clay-rich material at the base. If there were difference in paleotopography this bed could be sand-sheet SHb1. Continuing east, S25 is more convoluted, as there was a loss of material within the barrel between 197-204 and 214-220. Gouge auger core S26 contains several beds of sand and organics, from 98-104.5, 114139.5 , and $167-176 \mathrm{~cm}$, with poor return beyond $176 \mathrm{~cm}$ depth. The presence of a sand beds from 114-139.5 and $167-176 \mathrm{~cm}$ could correlate to the higher sand percentage of core VCS2 between 151.4-168cm and $181.1-188.8 \mathrm{~cm}$ respectively. Within core VCS5, a discrete sandy section from $170.1-190.6 \mathrm{~cm}$ is followed by a section of mud from $190.6-197.4 \mathrm{~cm}$, above sand and gravels at the base (Figure 6). Due to similarities in stratigraphy, the section in core VCS5 from 170.1190.6cm could correlate to sand-sheet SHb1, or to the sandier bed from 181.1-188.8 in VCS2, and an upper sandy bed from VCS5 from $151-155.8 \mathrm{~cm}$ could correlate to the sandier bed in VCS2 from $151.4-168 \mathrm{~cm}$. The upper two beds described here may be laterally continuous to the east, suggesting the presence of more than one sand-sheet, though poor return on gouge auger pushes make this correlation less clear. 
Gouge auger core S27, the easternmost point along transect T2, contains a graded sand bed directly below peat, similar to gouge auger core S26, starting at $87 \mathrm{~cm}$ depth and extending to $104.5 \mathrm{~cm}$ depth, followed by sand from $104 \mathrm{~cm}$ downward, and $40 \%$ organics. Lack of return beyond $185 \mathrm{~cm}$ depth makes it unclear if this bed is discrete or continues further. Other gouge auger pushes in the eastern portion of the marsh (S1-S4) consisted of peat directly above sand (Appendix 1).

\subsubsection{Eliza Island Data Assessment:}

South of the pond (Figure 4), stratigraphy of gouge auger and vibracores consists of peat between $60-72 \mathrm{~cm}$ thick above silt loam, which dominates below the peat except in sand-rich sections between 155-188cm depth (Appendix 1 and 2). In stratigraphic sections rich in sand, the sediment type transitions from silt loam to a loam or sandy loam, and is further labeled sandsheet EIb2 (Table 6). This lower sandy section appears to be laterally extensive across the marsh from the south extending to the north (Table 6). Below the silt-loam, there is a transition to a very light blue mud, high in clay content, which commonly made up the base of the gouge auger cores and vibracores.

On the north side of the pond, the top of the marsh is organic rich soil (such as in core VCEI3, Appendix 2) approximately 49cm thick. The topsoil contains 30-50\% gravels, which made collecting vibracores and gouge auger pushes difficult in the field, limiting collection locations. Below the topsoil, the stratigraphy is dominated by silt loam, with sections of higher sand percentage being loam or sandy loam.

East of the pond, the stratigraphy furthest north (gouge auger core EI7, Figure 4) is similar to core VCEI3, consisting of topsoil from $0-30 \mathrm{~cm}$, followed by alternating sections of sand-poor mud and sandy loam, with abundant gravels throughout. An upper sand-sheet EIb1 is 
detectable through this portion of the marsh (Table 6). Moving south, with gouge auger core EI24, the lower section of core consist of a light blue-grey clay. Gouge auger and vibracores show pockets of sand present throughout the marsh, consisting of angular well sorted coarse sand, white and black in color.

\subsection{Organic Content}

In reporting the organic content (Table 7 and Table 8) corrected depths are reported. For sections of stratigraphy between two organic content results, percentages were averaged to assume the organic content for the section (Table 7 and Table 8).

\subsubsection{Results Ship Harbor}

Organic content is consistent between cores VCS2 and VCS6. Both cores have a generally higher organic content at the top, where peat transitions to clay. Organic content within clay sections ( $\sim 100-215 \mathrm{~cm}$ and $\sim 252-289 \mathrm{~cm})$ range from $10-14 \%$ organics (Table 7$)$. Within sand and gravel dominated stratigraphic beds, organic content decreases to 2-9\%. Just above sand-sheet SHb1 in core VCS2, the organic content increases to $22-23 \%$. The increase is likely due to the organic-rich layer associated with the top of sand-sheet SHb1.

\subsubsection{Results Eliza Island}

Eliza Island cores VCEI2 and VCEI3, taken on opposite sides of the pond (Figure 4) range between 1-11.8\% organics (Table 8 ). In core VCEI2 there is a high percentage of organics at $171.7 \mathrm{~cm}$, similar to the base depth of the laterally extensive sand-sheet EIb2. Organic content increases in VCEI3 around $114.1 \mathrm{~cm}$ depth, which does not correlate to either sand-sheet EIb1 or EIb2. 


\section{$5.3 \mathrm{C}^{14}$ dating}

Because wood can persist in an environment and may be older than a deposit it is found in, and all samples selected were wood and plant macrofossils, all samples likely represent maximum ages.

\subsubsection{Ship Harbor Results}

Materials were selected to constrain the age of sand-sheet SHb1 within core VCS2. Four samples were dated from sand-sheet SHb1: three dates are from the organic-rich layer of wood and sticks at the top of sand-sheet SHb1 and one $20 \mathrm{~cm}$ lower, from within the sand-rich section of the deposit (Figure 5). Stratigraphically, the reported dates vary sequentially with respect to depth in the cores (Tables 9). Within the organic-rich top of sand-sheet SHb1, a variation of about 600 years between dates from samples stratigraphically close to one another suggest that older material was likely transported with younger material during deposition. Four dates, two above and two below sand-sheet SHb1, were selected to better constrain the age of the bed within the core. Dates predict the age of sand-sheet SHb1 to be 1802-1730 cal. yrs BP (Table $10)$.

\subsubsection{Eliza Island}

For Eliza Island, VCEI2 has a single bed, EIb2, which consist of graded sand overlaying an organic-rich section (Appendix 2). Dates from VCEI2 were much older than expected (Table 9 and 11), with the youngest date at $143.1 \mathrm{~cm}$ depth being 4248 years B.P., and the oldest calibrated date for the bottom $(176.2 \mathrm{~cm})$ of the core ranging between 5274-4980 years B.P. (Table 11). The sequence model results suggest that the date of EIb2 ranges between 4820-4669 cal. years BP (Table 11). 


\subsection{AMS analysis}

Magnetic fabrics are coaxial to sedimentary fabrics, as commonly in sedimentary minerals crystal habit and grain shape determine the maximum, intermediate and minimum susceptibility axes (long grain axis commonly is parallel to $\mathrm{K}_{\max }$, short-axis or basal-plane of phyllosilicates is parallel to $\mathrm{K}_{\mathrm{min}}$ ). Susceptibility values of the mean tensors can be compared to determine the dominate fabric type present within a deposit. Triaxial fabrics typically represent fabrics with three distinct axes orientations for $\mathrm{K}_{\max }, \mathrm{K}_{\mathrm{int}}$, and $\mathrm{K}_{\min }$, with $\mathrm{K}_{\max }$ having the strongest susceptibility, $K_{\text {int }}$ having the second strongest, and $\mathrm{K}_{\min }$ the weakest. Prolate fabrics have a high susceptibility in the $\mathrm{K}_{\max }$ direction with susceptibilities along the $\mathrm{K}_{\text {int }}$ and $\mathrm{K}_{\min }$ axes being similar (making them more difficult to distinguish from one another, and producing a higher error along those axes during measurement). Oblate fabrics have similar susceptibilities in the $K_{\max }$ and $K_{\text {int }}$ directions, with lower susceptibility of the $\mathrm{K}_{\min }$ typically perpendicular to the settling surface produced when material settles out of suspension. Mean susceptibility axes, or mean tensors, are reported as declinations and inclinations, and represent the mean orientation of each axis within the grains, corrected for the geographic orientation of the sample in space. Errors recorded from the AMS data provided initial insight into the strength of the fabric during analysis, and were used to determine data accuracy during analysis (Tables 12 and 13).

AMS results were grouped by stratigraphy, so an overall fabric could be determined for each unit present, and reported as both equal angle stereonet projections of the $\mathrm{K}_{\max }, \mathrm{K}_{\text {int }}$ and $\mathrm{K}_{\text {mins }}$ (Figure 8a-d) and as mean tensors (Tables 14 and 15). Anisoft (AGICO) was used to calculate parameters related to the AMS ellipsoid shape: lineation (L, $\left.\mathrm{K}_{\max } / \mathrm{K}_{\mathrm{int}}\right)$, foliation (F, $\mathrm{K}_{\mathrm{in}} / \mathrm{K}_{\min }$ ), corrected degree of anisotropy (Pj) relating to the strength of the magnetic fabric, and 
shape parameter $\mathrm{T}(0<\mathrm{T}<1$ the fabric is oblate and dominated by settling, $-1<\mathrm{T}<0$ than the fabric is prolate and dominated by traction or flow) (Table 16).

\subsubsection{Ship Harbor AMS results}

Ship harbor AMS results from core VCS2 and VCS6 are grouped for analysis by stratigraphic designations of peat, sand-poor silt loam (Clay Upper and Clay Lower, upper for above SHb1 and lower for below SHb1), sand-sheet SHb1, and basal gravel/sand in Figure 8a-b. Sample locations are displayed in Figure 8e and 8f. Combined results from sand-sheet SHb1 are presented to analyze if a flow regime is detectable. Clay-rich beds above and below sand-sheet $\mathrm{SHb} 1$ are grouped together, as they are interpreted to be the same paleoenvironment pre and post sand-sheet SHb1 deposition.

AMS parameters of lineation $(1.00<\mathrm{L}<1.04)$, foliation $(1.002<\mathrm{F}<1.08)$, corrected degree of anisotropy $(1.02<\mathrm{Pj}<1.11)$, and alignment parameter $(-0.7<\mathrm{T}<0.94)$ vary vertically within the core and between stratigraphic designations, but also have some variability within stratigraphic sections. The L, F and T values suggest that there are both prolate and oblate fabrics present within the stratigraphy, with sand-poor silt loam sections being generally oblate $(\mathrm{T}>0)$ and peat and sand-sheet SHb1 sections being generally prolate $(\mathrm{T}<0)$. A generally high $\mathrm{L}$ value, around one, suggests the sand sheet $\mathrm{SHb} 1$ has a triaxial fabric.

Low $\mathrm{L}$ values and poor grouping of the $\mathrm{K}_{\mathrm{int}}$ and $\mathrm{K}_{\max }$ (Figure 8a and Figure 8b), suggest a weak depositional fabric within the peat sections. The values for the peat sections should be questioned, as there is high error $(\sim 100 \%)$ recorded for these samples (Table 12$)$ suggesting that no real fabric is detectable.

Within the sand-poor silt-loam sections above and below sand-sheet SHb1 (Figure 8a and $8 b), K_{\text {mins, }}$ with a few exceptions, have low imbrication between 0-20 degrees, and distribution of 
$\mathrm{K}_{\max }$ and $\mathrm{K}_{\text {int }}$ with variable declinations and low inclination angles generally between 0-20 degrees (Figure 8a and 8b). When grouped, the silt loam sections produce an oblate fabric, with a grouping of $K_{\operatorname{mins}}$ at 90 degrees inclination, suggesting that these samples have mostly likely formed as a depositional fabric. The $\mathrm{T}$ values for these samples are generally between 0 and 1 , however several samples are between 0 and -1 . Most $\mathrm{T}$ values are positive, suggesting an oblate fabric.

Sand-sheet SHb1, in both cores, presents as a commonly triaxial fabric when plotted on a Flinn diagram (Figure 8g), with some samples plotting as more oblate or prolate. Three samples fall near the 1:1 line on the Flinn diagram, suggesting that there are some strongly triaxial samples from within sand-sheet SHb1. Seven of the thirteen samples from VCS2 and VCS6 identified as being from sand-sheet $\mathrm{SHb} 1$ have $\mathrm{T}$ values between -1 and 0 , suggesting that more than half the samples present a prolate fabric, meaning likely deposition from flow. Combined result for sand-sheet SHb1 (Figure $8 \mathrm{~h}$ ) produced a general grouping of $\mathrm{K}_{\operatorname{mins}}$ with imbrication between 0-30 degrees, with some outliers.

The lower section of sand-sheet SHb1 in core VCS2 (samples 174, 172.5, 168.5, and 166) shows varied $K_{\operatorname{mins}}$ with high imbrication angles (Figure $8 \mathrm{~h}$ ). Above these, sample 163.5 shows $\sim 35$ degrees of imbrication in the southern direction. The top of sand-sheet SHb1 in core VCS2 shows almost 0 degrees imbrication.

Samples from sand-sheet SHb1 in VCS6 (samples 168.8, 167, 161.8) show 0-20 degrees imbrication in the northern direction (Figure $8 \mathrm{~b}$ and $8 \mathrm{~h}$ ). Above these, samples 163s, 161s, 160s and 157s have high imbrication angles between 30-50 degrees but not in any one direction. 


\subsubsection{AMS mean tensor results Eliza Island}

VCEI2 and VCEI3 were grouped into different stratigraphic sections similar as for Ship Harbor: soil/peat, clay-rich sand-poor sections (green) and sand-sheet deposits (blue) (Figure 8ad). The peat in VCEI2 had a very high error, between $29-500 \%$, suggesting very weak anisotropy. Mean tensors for each stratigraphic unit was calculated (Table 15).

Clay-rich section $K_{\operatorname{mins}}$ have imbrication from 0-25 degrees (Figure 8c and 8d). $K_{\max }$ and $\mathrm{K}_{\text {int }}$ declinations are variable, and have low inclinations (Figure $8 \mathrm{c}$ and $8 \mathrm{~d}$ ), forming an oblate fabric. An oblate fabric is supported by the $\mathrm{T}$ values which are generally higher than 0 (Table 16). Both cores sampled were collected close to the pond, in areas that are seasonally ponded, depositing material from suspension, supported by the dominantly oblate fabric.

AMS results from sand-sheet EIb2 from cores VCEI2 and VCEI3 show a grouping of $\mathrm{K}_{\mathrm{mins}}$ approximately around the origin, but varying in imbrication from 5-20 degrees, with a few outliers having imbrication $\sim 50$ degrees. Combined results from sand-sheet EIb2 (Table 15) $\mathrm{K}_{\max }$ directions appear to be well grouped to the Southwest, between 200-270 degrees. EIb2 in VCEI2 generally has $\mathrm{T}$ values greater than 0 , however, in VCEI3, the $\mathrm{T}$ values are generally less than zero. Core VCEI2 has clear normal grading at the top of sand-sheet EIb2, however normal grading is not visually present within core VCEI3 for the sand-sheet.

\subsection{Rock Magnetism Results}

\subsubsection{Bulk Susceptibility}

\subsubsection{Ship Harbor}

Cores VCS2 and VCS6 have similar susceptibility values from -9.82E-06 to 7.05E-04 throughout (Figure 9a, Table 17). Peat sections have very low, close to zero, susceptibility. At the transition to clay, there is an increase in susceptibility to $\sim 0.25 \mathrm{E}-04$. This is consistent until 
sand-sheet SHb1, where susceptibility increase to $\sim 2.0 \mathrm{E}-04$ in both cores. At the base of VCS2 the susceptibility increases rapidly in the basal section of gravels. Core VCS6 does not have an increase in susceptibility towards the bottom extent, but is also missing the lower basal gravels layer.

\subsubsection{Eliza Island}

Cores VCEI2 and VCEI3 vary in bulk susceptibility by a factor of 10 (Table 18, Figure $9 \mathrm{~b}$ ), ranging from close to zero to $2.0 \mathrm{E}-03$. Bulk susceptibility for both cores increases from $\sim 0.5 \mathrm{E}-04$ to $2.0 \mathrm{E}-04$ between $110-120 \mathrm{~cm}$ depth, and around $150 \mathrm{~cm}$ depth to $2.0 \mathrm{E}-04$, near the top of EIb2. VCEI3 has a generally very low susceptibility, between $73-175 \mathrm{~cm}$, increasing around $175 \mathrm{~cm}$ depth up to $2 \mathrm{E}-03$.

\subsubsection{Hysteresis}

The corrected Hc value for each sample is important when demagnetizing samples for PSV dating. Corrected hysteresis loops show low coercivity and saturation within a 1T field (Figure 10). Corrected coercivity values from both field sites are generally low, typically less than $150 \mathrm{mT}$, but for most samples less than 60mT (Table 17 and 18). The low coercivity suggests that the main magnetic constituent is magnetite at both field sites (Tauxe, 2018). The presence of magnetite is also confirmed by the temperature vs susceptibility experiments completed. Hysteresis loops from core VCS2 contain a fairly high level of error, likely due to presence of water within the samples.

\subsubsection{IRM}

IRM was completed on select samples, and at least one sample from each stratigraphic unit was measured for the four cores VCS2, VCS6, VCEI2 and VCEI3. The IRM was saturated for all samples measured (Figure 11, Tables 17 and 18), suggesting that the samples have a 
saturation magnetization below 1T, which is the maximum field applied in the IRM experiments. Saturation during IRM determines the magnetic saturation value (Ms), which helps identify the type and size of the magnetic minerals present. The IRM saturation and coercivity values further suggest that magnetite, which has a very low coercivity typically between $30-120 \mathrm{mT}$ (but up to $300 \mathrm{mT}$ ), is the main ferromagnetic constituent for both Ship Harbor and Eliza Island (Tauxe, 2018).

\subsubsection{Temperature vs Susceptibility}

Two to three samples from representative deposits were selected from cores VCS2, VCS6, VCEI2, and VCEI3 each to measure the Curie temperature. Samples from cores VCS2 and VCEI2 were selected to complete low temperature susceptibility experiments, as these cores were the focus for PSV dating.

All samples, except VCEI2n at $80 \mathrm{~cm}$ show a Curie temperature ranging from $550-600^{\circ} \mathrm{C}$ (Figure 12, Table 19). The $80 \mathrm{~cm}$ sample for VCEI2 has an ambiguous result, as there is a very weak signal. A Curie temperature between $550-600^{\circ} \mathrm{C}$ suggests the main magnetic constituent is magnetite for both field sites (Tauxe, 2018). This corroborates the IRM and hysteresis data.

Low temperature vs susceptibility experiments show a dramatic decrease in susceptibility between -200 and $-170{ }^{\circ} \mathrm{C}$ (Figure 13). This dramatic decrease is related to increase in susceptibility of paramagnetic constituents at low temperatures. The decrease suggests that there are strong paramagnetic constituents present in cores from both sites, and that a paramagnetic correction can acceptably be made for hysteresis data.

\subsection{Paleosecular variation dating results}

PSV dating was performed with the intention of refining the age sequence models produced from ${ }^{14} \mathrm{C}$ dates to better constrain the dates for sand-sheets $\mathrm{SHb} 1$ and EIb2. Examples 
of demagnetization Zijderveld diagrams are displayed in Figure 14. Reported declinations, inclinations, and ${ }^{14} \mathrm{C}$ dates were all used to match declinations and inclinations reported from demagnetization data (Tables 20 and 21) with the PSV curves from Hagstrum and Champion (2002) (Figure 15). The regional reference curve was calculated from the latitude and longitude of the field sites using the highest quality data with the lowest error from volcanic flows in the western US, reported as years before 2000A.D. (Hagstrum et al., 2004). For Eliza Island, the dates from Hagstrum et al. (2004) were supplemented with later dates and virtual geomagnetic poles (VGPs) from Hagstrum et al. (2002) to create a longer predicted record (Figure 16). The virtual geomagnetic poles (VGPs) reported were converted to expected declinations and inclinations for each field site using Butler (1992) equations for the expected magnetic field direction (Appendix 4). Alpha 95\% confidence envelopes were calculated equations from Butler (1992) for calculating the 95\% confidence envelopes (Appendix 4), labeled delta-I and delta-D for inclination and declination respectively. Puget Sound tsunami buried soil VGPs from Hagstrum et al. (2004) were also converted to inclinations and declinations for both field site latitudes and longitudes, to directly compare to the regional reference curve and field data in this study. Date ranges for each sample were estimated using an OxCal sequence model for each site, with error bars to represent the range of dates reported along the y-axis and the mean absolute deviation (MAD) reported for each component as the error along the $\mathrm{x}$-axis (Figures 15 and 16). Because OxCal reports dates as years B.P. using the datum of 1950, estimated ages had 50 years added to them to match the PSV dates reported as years before 2000B.C. Samples which intersect the PSV expected curve were used to estimate dates for those core locations, based on inclination or declination of the sample. 


\subsubsection{Ship Harbor}

Sample results show vertical variability in declinations and inclinations of the primary components throughout the cores (Table 20). Each sample is estimated to represent $\sim 50$ years of deposition, based on calculated rates of deposition ( $\sim .15 \mathrm{~cm} /$ year $)$ and rates of compaction for the vibracores (Table 1), so each sample was treated as a single PSV component.

Samples are plotted in Figure 15 with the Hagstrum (2004) soil samples and the Hagstrum (2002) PSV calculated curve. Six samples intersect with the declination or inclination PSV expected curve, all within the upper clay unit above sand-sheet SHb1.

To account for inclination shallowing from vibracore compaction in core VCS2, an inclination correction was done, using equation 1 from (Tauxe et al., 2008): $\tan \left(I_{r}\right)=(1 / \mathrm{f}) \tan \left(\mathrm{I}_{0}\right)$ where $I_{r}$ is corrected inclination, $\mathrm{f}$ is the flattening factor for magnetite, and $\mathrm{I}_{\mathrm{o}}$ is the sampled inclination.

\subsubsection{Eliza Island}

Results show vertical variability in declinations and inclinations of the primary components throughout the cores. Table 21 reports declinations and inclinations calculated. Figure 16 shows that of the samples plotted, five intersect with the PSV declination or inclination curves.

Some issues with demagnetization data arose during the demagnetization process within the lower section of VCEI2. Demagnetization plots (Figure 14) show a curving of the component away from the origin for VCEI2 reference depth: $152 \mathrm{~cm}$. Work by Snowball (1997) suggests that this effect could be due to the presence of gregite or another sulfide mineral gaining a gyroremenant magnetization from the AF demagnetization process, creating a secondary component. However, the Hc values for these samples are not higher than others, which 
contradicts the potential for sulfide minerals, which should have a higher Hc value (Tauxe, 2018). Due to the odd demagnetization behavior and potential for sulfides, these results have been omitted from the PSV dating analysis for this site.

\subsection{GeoCLAW Modeling results}

The L1 scenario (Table 22), the largest earthquake scenario considered in this study, predicts an increase in water height above mean sea level greater than $4 \mathrm{~m}$ at the tide gauge in front of Ship Harbor, and almost $2 \mathrm{~m}$ at the tide gauges placed near Eliza Island (Figure 17). The L1 scenario produces the largest inland extent of inundation within Ship Harbor, up to 325m inland during the initial wave (Figure 17). L1 only inundates the outer sections of Eliza Island, varying greatly from the MHHW simulation produced from Walsh et al. (2004), Gica and Arcas (2016), and Eungard et al. (2018), which predicts inundation large enough to overtop the beach berm and inundate the central marsh and pond. Spatial variations in modeling could also be due to the use of a MHHW datum run in the models using MOST relative to MSL used with GeoCLAW, or from different assumptions of surface roughness and wave physics parameterized for modeling. An L2 scenario was also run, which predicts a $3 \mathrm{~m}$ tidal gauge increase, and inundation into Ship Harbor less extensive than the L1, but still approximately half the lateral extent of the marsh $(\sim 150 \mathrm{~m})$, and no inundation into Eliza Island marsh.

The moderate M1 scenario (Table 22), considered the most statistically likely scenario (Witter et al., 2013), was modeled to compare to the L1 hazard planning models (Figure 18). At Ship Harbor, the M1 scenario predicts a maximum water level at the observation point just under $3 \mathrm{~m}$, producing inundation into the northern part of the marsh to at least $1 \mathrm{~m}$, with a lateral extent inland around $130 \mathrm{~m}$, and predicts several smaller waves through the 5 hours following the slip event and propagation into the Puget Sound (Figure 18). At Eliza Island, the M1 scenario 
registered to $1.5 \mathrm{~m}$ height at the tide gauges for the initial wave, as well as for a secondary wave just before hour 5. The M1 inundates outer parts of Eliza Island, but does not predict overtopping the beach berm or inundation of the central marsh and pond.

The M2 scenario (Table 22) was also run to look at differences between the two most statistically likely scenarios (Witter et al., 2013). M2 does not factor in splay faulting, and thus produces a smaller amount of sea floor displacement and inundation. M2 model results are summarized in Figure 19, and show a similar inundation as the M1 scenario, only varying in the water height change. The M2 scenario predicts just under $2 \mathrm{~m}$ of water height change, and $\sim 100 \mathrm{~m}$ of lateral extent landward, at Ship Harbor, and just over $1.5 \mathrm{~m}$ of change south of Eliza Island. Inundation at both locations is similar to M1, with just over a meter of inundation in the northern $100 \mathrm{~m}$ of Ship Harbor marsh, and along outer sections of Eliza Island.

The small SM1 scenario (Table 22) is considered one of the most historically common scenarios according to Witter et al. (2013). This was important to consider, as it is one of the smaller potential scenarios for CSZ events. For Ship Harbor, the tide gauge registers just over $1.5 \mathrm{~m}$ increase in water column height, producing up to $1 \mathrm{~m}$ of inundation along the beach and northern-most extent of the marsh, with $\sim 100 \mathrm{~m}$ of landward extent (Figure 20). The SM1 predicts no inundation at Eliza Island.

A Seattle Fault scenario from Koshimura et al. (2002) was run to see what the effect of a well understood upper crustal fault would have for producing inundation for both field sites. Based on seismic reflection data, the Seattle Fault is interpreted as a south-dipping thrust fault, with a potential total rupture area of $4420 \mathrm{~km}^{2}$, and produces $\mathrm{M}_{\mathrm{w}}=7.6$ to 7.7 earthquakes (Koshimura et al., 2002). The model separates the fault into 12 total segments varying in length and width, six along the upper steeper dipping section, and six below in the more gently dipping 
fault zone. Total slip along each segment is predicted to be $2-8 \mathrm{~m}$ total, with greater slip along the upper portion of the fault. Based on model results, minimal inundation is predicted for both Ship Harbor and Eliza Island (Figure 21). At Ship Harbor, the Seattle Fault scenario produces just more than a $20 \mathrm{~cm}$ increase in the water column height, while Eliza Island only produces $10 \mathrm{~cm}$ at the south observation point, and less than $10 \mathrm{~cm}$ at the north observation point.

\subsubsection{Tidal Variations on the $\mathrm{L} 1$ and $M 1$ scenarios}

The L1 run with $-1.0 \mathrm{~m}$ tide at the time of tsunami propagation (Figure 22) predicts a total increase in water level height of the first wave to $3.5 \mathrm{~m}$ and a landward extent of inundation to $324 \mathrm{~m}$. This results in inundation of Ship Harbor marsh the entire extent of the marsh, with lingering water in the marsh for a number of hours after the initial wave (Figure 22). Model results for Eliza Island are similar to the M1 scenario results.

The L1 run with $-2.0 \mathrm{~m}$ low tide (Figure 23) predicts an increase of water height at the observation point at Ship Harbor for the first wave of $2.5 \mathrm{~m}$ and inundation is limited to the northern $94 \mathrm{~m}$ of Ship Harbor marsh. This appears to be similar to the mean sea level prediction for the M1 scenario.

The M1 was run with a high tide $(+1 \mathrm{~m})$ variation (Figure 24$)$, as it does not inundate the full extent of Ship Harbor marsh at mean sea level. With a $+1 \mathrm{~m}$ tide (Figure 24), the observation point at Ship Harbor predicts almost $4 \mathrm{~m}$ of water height increase, and an inundation extent of 300m landward in Ship Harbor marsh. Eliza Island is still not effectively inundated. 


\section{Discussion}

\subsection{Interpreting Ship Harbor Stratigraphy, AMS and Modeling}

\subsubsection{Stratigraphy}

Ship harbor is a marsh primarily fed by fresh-water run-off and rain, with no modern tidal channels (Figure 3). The marsh consists of the beach barrier and central pond; the barrier beach extends E-W along the front of the marsh, protecting the entire extent of marsh from regular tidal or wave influences (Figures 1 and 3), and the marsh is seaward (north) of a pond, which likely formed in response to the sandy barrier beach. There are no large streams feeding into the marsh, so fluvial sediment supply is limited. Though the front of the marsh has been heavily impacted by human modification in the last 160 years, including ditching and drainage for building of a railroad berm, the marsh appears generally undisturbed in the subsurface, and this is reflected in the stratigraphy and ages from the cores that were collected (Figure 5).

Simplified stratigraphic sections (Figure 5 and 6 and Appendix 2) show that the stratigraphy of the back-marsh transitions from a gravel-rich sand at the base of $2.5-3 \mathrm{~m}$, grading upwards to silt loam, which gradually transitions into peat, marking a gradual infilling of Ship Harbor marsh over the late Holocene. The color of the mud and humification of peat, suggests a water-logged anoxic subsurface. The silt loam is thickest in the south above and below sandsheet SHb1 and thins to the north both above and below sand-sheet SHb1 (Figure 25). The mud is occasionally interbedded with sand lenses, but is generally sand-poor, consisting mostly of massive silt loam. The silt loam is interpreted to be a low marsh or lagoon paleoenvironment due to lithology, texture, color, organic content, and current marsh conditions (Nichols, 2009). The modern marsh surface is dominated by peat formation, with minimal discernable sediment deposition occurring within the marsh today. 
From stratigraphy (Figure 5, Figure 6, Figure 25a), lateral extent (Table 5, Figure 25a and 25b), and presence of intertidal mollusk shells (Figure 5 and Figure 7), sand-sheet SHb1 was likely created during inundation of ocean water. Sand-sheet SHb1 has a lateral extent of at least $50 \mathrm{~m}$ south of VCS2 (Table 5), and potentially extends another 50+m north along transect T1a (Figure 25b and Figure 3). An organic rich layer of twigs and bark at the top of SHb1 is interpreted to be organic debris carried from the beach and front marsh and deposited during inundation. SHb1 contains shell fragments in cores VCS2, S14, S15, including half a bivalve mollusk shell, and multiple whole conular mollusk shells (Figures 5 and 7). The presence of intertidal mollusk shells further suggests that materials were transported during inundation from the intertidal or beach.

SHb1 is first clearly detected $200 \mathrm{~m}$ south of the modern beach berm, with $50 \mathrm{~m}$ lateral extent to the south (Table 5 and Figure 25a). A tsunami has the energy to drive water inland for several hundred or more meters when coastal topography is relatively flat, and as a consequence inland sediment transport distances can be $200+\mathrm{m}$. Storm waves typically limit sediment transport to a few hundred meters at most, ending abruptly, and have a higher degree of internal stratification and sets of mud laminae (Morton et al., 2007). Though both storms and tsunami processes theoretically can drive materials the distance of the marsh, it is unlikely with the beach barrier and lack of tidal channels that lateral extent of inundation into the marsh by storm waves would deposit this far into the marsh. Terrestrial fluvial origin of sand-sheet SHb1 can be ruled out due to lateral extent and land-ward thinning, and lack of fluvial sources into the marsh.

Presence of mollusk shells from intertidal areas, general thickness less than $26 \mathrm{~cm}$ (potentially up to $90 \mathrm{~cm}$ ) and thinning landward (to the south), high percentage of sand, abrupt lower contact, massive and graded sand structures, and detectable extent of $50 \mathrm{~m}$ but potentially 
up to $100 \mathrm{~m}$, are all stratigraphic evidence that suggest that sand-sheet $\mathrm{SHb} 1$ is likely the result of tsunamigenic inundation in Ship Harbor marsh.

Sand-sheet SHb1 can possibly be correlated to the north along transect T1a (Figure 25b). Because maximum thicknesses reported for tsunami deposits globally is $1 \mathrm{~m}$, but typically most are less than $25 \mathrm{~cm}$ thick (Morton et al., 2007), and the presence of intertidal mollusk shells, the whole bed from 145.1-225.6cm within core VCS3, and the similar-depth beds in gouge auger cores S18 and S19 could be correlated to sand-sheet SHb1. However, an alternative interpretation is that the large sand bed present in cores S18, S19 and VCS3 could be the remains of a historic barrier beach that was positioned further south in the marsh, located approximately in the location of VCS3. Lateral migration of the beach front to the north over time could account for this. However, this is unlikely, as lateral migration seaward is common with sea level fall, which has not occurred in the Puget Sound over the late Holocene, except by potential means of isostatic rebound. Even if this is true, sand-sheet $\mathrm{SHb} 1$ would still represent inundation into the marsh from the ocean, and require toppling of the paleo-beach berm and inundation to a lateral extent greater than $50 \mathrm{~m}$.

\subsubsection{Peat accumulation in Ship Harbor marsh}

Stratigraphy in Ship Harbor is covered with, on average, a meter of peat. $106 \mathrm{~cm}$ of peat is present at the marsh surface at VCS2, and $127 \mathrm{~cm}$ of peat has accumulated at VCS6. Peat accumulation is understood to occur at a maximum rate of $2 \mathrm{~mm} /$ year globally (Borgmark, 2016), and in the Puget Sound is measured to be closer to $0.62 \mathrm{~mm} /$ year (Kulzer et al., 2001). Even at $2 \mathrm{~mm} /$ year, a meter of peat should represent $\sim 500$ years of accumulation. Based on the calibrated

${ }^{14} \mathrm{C}$ dates, the difference in depth between samples VCS2n_RC28 and VCS2n_RC28 is $48.9 \mathrm{~cm}$, with a maximum age difference of 450 years, and a minimum age difference of 184 years. Based 
on the ${ }^{14} \mathrm{C}$ dates, the sedimentation rate within the silt and clay dominated beds likely ranges between $0.11 \mathrm{~cm} /$ year and $0.27 \mathrm{~cm} /$ year, with an average of $0.19 \mathrm{~cm} /$ year, or $1.9 \mathrm{~mm} /$ year. ${ }^{14} \mathrm{C}$ dates indicate that at $168.2 \mathrm{~m}$ depth the core is $1546-1414$ cal. years B.P. Because ${ }^{14} \mathrm{C}$ dates are reported as years B.P. from the datum of 1950 , this location in the core is likely closer to $1614-$ 1482 years prior to the sampling date. Assuming $1.9 \mathrm{~mm} /$ year of for $62.2 \mathrm{~cm}$ of clay, and $2 \mathrm{~mm} /$ year for $106 \mathrm{~cm}$ of peat, the base of the peat should have started forming around 530 years ago, prior to the first western settlers arrived. The cause of a shift in the environment at Ship Harbor from a lagoon or low marsh environment to a peat marsh is unclear. Lateral migration of the front of the marsh could have occurred with sea level fall, or isostatic rebound (uplift).

\subsubsection{AMS results}

Sand-poor silt loam beds above and below SHb1 show an overall oblate fabric, representative of clays and silts settling out of suspension (Figures $8 \mathrm{a}$ and $8 \mathrm{~b}$ ). Most samples represented in this set have a $\mathrm{T}$ value above 0 (Table 16), supporting a dominantly oblate fabric. The oblate fabric and grain size distribution together support a low energy lagoon-like paleoenvironment, with clay and silts settling out of suspension. Oblate fabrics above and below sand-sheet SHb1 support that the environment was a calm depositional environment pre and post sand-sheet SHb1 deposition.

$\mathrm{K}_{\max }$ and $\mathrm{K}_{\operatorname{mins}}$ from sand-sheet $\mathrm{SHb1}$ are highly varied, making a definitive flow regime difficult to interpret. Collision of grains can vary the $\mathrm{K}_{\max }$ direction greatly, as the strength of flow and the amount of grain collisions that occur effect the alignment of the grain long-axis with flow (Taira and Masuda, 1989; Tauxe, 2018). $\mathrm{K}_{\operatorname{maxs}}$ are highly varied for samples throughout sand-sheet SHb1, but have some grouping oriented in the 90-degree plane or around the 0-degree plane. Flow direction of inundation, based on models and geography of the marsh, 
is expected to be from the north/north-east direction, flowing toward south/south-west. If the run-up phase had a strong enough current, some sections of the bed could be aligned with flow from the north, while some are oriented to the east, perpendicular to flow, during collision or rolling. Core VCS2 shows $\mathrm{K}_{\min }$ imbrication to the $\mathrm{SW}$, suggesting a possible flow direction to the SW (Figure 8a). The projection of AMS data for sand-sheet SHb1 in core VCS6 shows a much clearer flow regime than core VCS2, with most samples from the north half of the core reporting a mean tensor of Kmax $\sim 108$ degrees, Kint $\sim 200$, and a Kmin imbrication between 025 degrees (Table 14, Figure 8b). This could indicate a flow to the south, or a strong back-wash phase to the north. However conclusive flow direction cannot be made due to the scatter for the $\mathrm{K}_{\max }$ and $\mathrm{K}_{\operatorname{mins}}$ when data is combined from both cores by depth (Figure 8i). The massive bedding of sand-sheet SHb1, and lack of stratified bedding structures, supports viscous collisional flow as a sediment transport mechanism.

\subsubsection{GeoCLAW modeling and potential of CSZ source for SHb1}

The presence of a tsunami deposit in Ship Harbor marsh helps validate the L1 based models used for hazard planning, as the L1 model parameters predict enough inundation in Ship Harbor marsh to produce a tsunami deposit such as the one identified in this study.

Using models at Ship Harbor to predict future inundation may be more accurate than for past inundation predictions due to a shift in the environment and topography over the last few hundred years from human modification to northern extent of marsh. The current barrier beach berm is approximately $2.4 \mathrm{~m}$ above sea level and the typical marsh elevation is less than $3 \mathrm{~m}$. GeoCLAW models of tsunami inundation predicted for the L1 and L2 earthquake scenarios easily overtop the beach berm and inundate the marsh to the full lateral extent of $325 \mathrm{~m}$ (Figure 17). However, the smaller seismic scenarios with initial parameters at mean sea level, such as the 
M1 and M2, do not (Figures 18 and 19). Current topographic data of the marsh includes the railroad berm, which is $3 \mathrm{~m}$ above local surface elevation and could prevent future inundation from reaching the back part of the marsh. The modern railroad berm may act as a topographical barrier for modern models, and may cause an underprediction of inundation for the past, prior to the build of the railroad.

Tsunami inundation and impacts appear sensitive to water level from tidal changes and storm surge, made clear by the tidal variations of the L1 and M1 models. (Figures 22, 23, and 24). The L1 modeled at $-2 \mathrm{~m}$ low tide only inundates the most northern part of the marsh (Figure 23). The M1 with a $+1 \mathrm{~m}$ high tide does inundate the entire lateral extent of Ship Harbor marsh (Figure 24). These models suggest that typical tidal ranges in the Puget Sound (between 1-3m) can greatly affect the potential of tsunami inundation at Ship Harbor, and may explain why only one clear sand-sheet can be detected.

\subsection{Interpreting Eliza Island marsh}

\subsubsection{Stratigraphy}

The typical stratigraphy of Eliza Island, at the base consists of clay-rich blue mud, which has a sharp transition to lithic fragments, below a large bed of graded gravels and sands, followed by sand-poor grey-green mud, with soil or peat at the top (Appendix 2). Skagit county soil surveys labels the marsh as Sharlcar mud, which consists of deep, very poorly drained soil, formed in herbaceous deposits above alluvium and glaciofluvial deposits. The basal unit here could be interpreted to be part of glaciomarine drift plane soils formed during glacial retreat, but the origin is unclear.

Overall, Eliza Island stratigraphy suggests that there has been a shift in the environment sometime between 4500-6000 years ago and has been relatively steady since then. The modern 
marsh environment has abundant gravels covering the floor of the pond and present in pond outcrop exposures, suggesting that gravels and sands can enter the marsh regularly from the beach, despite the large and extensive beach berms present. Anthropogenic sources may also be a reason for the presence of gravels and pebbles in the pond. Two sand sheets appear to be laterally extensive throughout the marsh (Figure 26), and from the grading of the sand and presence of gravels suggest deposition during ocean water inundation. EIb2, present in VCEI2 and VCEI3 between depths $142.5-174 \mathrm{~cm}$ and $155.6-166.8 \mathrm{~cm}$ respectively is not conclusively of tsunamigenic origin; however, because of lateral extent and presence, it is possible that the sand was deposited during inundation events.

\subsubsection{AMS data Eliza Island}

The sand-poor silt-loams from Eliza Island, according to the plots of Figure 8a and 8d, as well as the T values, suggest settling from suspension (Figure 8c and 8d, Table 16) and may suggest deposition in the pond adjacent to the cores collected.

T values larger than 0 , and visual grading of EIb2 in VCEI2 suggests settling from suspension, which is supported by the generally oblate fabric in Figure 8c and 8d. The grouping of the $\mathrm{K}_{\text {mins }}$ in VCEI2 (Figure 8c) suggest that there is a lack of clear imbrication, and no clear fabric indicating flow. The generally oblate fabric suggests that sands and gravels were carried into the marsh and then deposited out of suspension.

\subsubsection{GeoCLAW modeling and Eliza Island inundation potential}

Tsunami modeling for Eliza Island makes it unclear if inundation from CSZ tsunamis can breach the beach berm and inundate the central marsh. Of all GeoCLAW models run, no models predict toppling of the beach berm, even the largest L1 scenario. However, though inundation predictions are high, future inundation could be prevented due to the large beach berm present on 
the south and north sides of Eliza Island. Despite current height, the beach berm may not have been historically as tall. According to DTMs from Washington DNR, the south berm is $4.3 \mathrm{~m}$ above mean sea level (based on the NAVD88 vertical datum), lowering on the north side to an average marsh elevation of $2.4 \mathrm{~m}$ above sea level. On the north side of the marsh, the elevation of the beach berm is around $3.0 \mathrm{~m}$ elevation. If these beach berms have been modified by human action, which field observations suggest, then these berms may not have always been as high, meaning the potential for inundation into the marsh may have been more likely in the past.

\subsection{OxCal sequence modeling using PSV dates and $\mathrm{C}^{14}$ dates, other Paleotsunami deposits dated in the Puget Sound and potential sources for inundation other than the CSZ plate- boundary earthquakes.}

Seven PSV dates from Ship Harbor and five PSV dates from Eliza Island, were used to compare to the calibrated ${ }^{14} \mathrm{C}$ dates and were used as additional dates within the $\mathrm{OxCal}$ sequence model to predict a depositional age for SHb1 and EIb2 (Table 23a and 23b).

\subsubsection{Ship Harbor}

The OxCal sequence model with PSV dates incorporated reports a maximum age of SHb1 between 1804-1731 cal. years B.P. (Table 23a). Including supplemental dates from PSV analysis does not considerably change the dates of sand-sheet SHb1, suggesting that the PSV dates support the ${ }^{14} \mathrm{C}$ dates measured for core VCS2.

The most likely scenario of deposition is inundation from a tsunami event, and SHb1 modeled dates are close to the maximum ages of many of the sand sheets correlated to Earthquake S in the Puget Sound. Atwater et al. (1997) identified several soil sequences along the Oregon and Washington coast believed to be buried during past CSZ events. Soil S is widely exposed in a Willapa Bay, Grays Harbor, and several other estuaries with low tidal ranges 
(Atwater and Hemphill-Haley, 1997). Earthquake S, marked by the burial of soil S, is predicted to have occurred between 1500-1700 years B.P. based on two precise radiocarbon ages collected along the Niawiakum River (Atwater and Hemphill-Haley, 1997). However, dates from Nelson et al. (1996) suggest the age of earthquake S had a weighted mean of 1797+/-23 years B.P., corresponding to 1600-1900 years ago; however, statistical differences suggest that these later dates are problematic (Atwater and Hemphill-Haley, 1997). Earthquake S is potentially correlated with Bed 7 in Discovery bay, dated to 1330-1710 years ago (Williams et al., 2005). Hutchinson et al (2013) correlate the upper sand sheet deposited in Salt Creek marsh to earthquake S, dated $1560+/-30$ years B.P. with a maximum limiting age for the upper sand being $1790+/-30$ years B.P. In Swantown Marsh, earthquake S is correlated to the deposition of layer E2, with ${ }^{14} \mathrm{C}$ dates from $S$. maritimus tubers, which predict a calibrated minimum age of 1400-1700 years B.P (Williams and Hutchinson, 2000).

Earthquake $\mathrm{S}$ is calculated to have occurred after a long inter-seismic period, estimated to be 700-1300 years, due to spruce root fossils indicating prolonged high marsh and depth of soil formation (Atwater and Hemphill-Haley, 1997). The long interseismic period that preceded earthquake $\mathrm{S}$, and the presence of earthquake $\mathrm{S}$ dated deposits along the coasts of Oregon, Washington, the Puget Sound and Vancouver Island, suggest that earthquake S spurred a large tsunami able to inundate many areas of the Salish Sea. Based on the age of sand-sheet SHb1, the dates of other beds in the Puget Sound similarly dated to sand-sheet SHb1 and associated with earthquake $\mathrm{S}$, and the potential that earthquake $\mathrm{S}$ created a large tsunami, it is possible that sandsheet SHb1 was created during inundation from the tsunami produced by earthquake $\mathrm{S}$ along the CSZ plate boundary. Earthquake S is commonly associated with Goldfinger's turbidite T5 event, 
dated 1400-1740 cal. years B.P. which is modeled to be large with up to a 1000 year interseismic period prior to the full rupture (Goldfinger, 2012; Witter et al., 2013).

\subsubsection{Other potential sources tsunamis in the Puget Sound}

Though CSZ earthquakes are predicted to produce large tsunamis, there are many potential upper crustal faults in the Puget Sound lowlands with off-shore fault traces including the Darrington-Devils Mountain fault zone, South Whidbey Island fault zone, Seattle Fault, Sandy Point fault, and Leech Creek fault. Though these faults do not have reported earthquakes that are directly dated to sand-sheet $\mathrm{SHb} 1$, and because we cannot easily model the potential tsunamis from these faults, the possibility still exists that one or more of these faults could be the source of a tsunami that could produce inundation in Ship Harbor marsh.

The Darrington-Devils mountain fault zone (DDMFZ) is located approximately $25 \mathrm{~km}$ south of Ship Harbor (Figure 2), on the border between Fidalgo and Whidbey islands. Trenching along the DDMFZ identifies the fault as having dominantly right-lateral strike slip movement along a NW-SE strike, however, the deep dip of the fault around $90^{\circ}$ makes it difficult to determine if the vertical component is reverse or normal (Personius et al., 2014). ${ }^{14} \mathrm{C}$ dates from the trench suggests that the most recent earthquake to happen along the fault was $1,900+/-400$ years B.P. Connecting to the DDMFZ is the Leech River fault system (LRF), located on Vancouver Island and tracing to the east offshore. The LRF is $130 \mathrm{~km}$ long and has dip-slip motion and trenching reveals three rupture events (greater than Mw 6.0) in the last 9000 calendar years before present (Morell et al., 2018). Trench ${ }^{14} \mathrm{C}$ chronology reveals the most recent rupture likely occurred $\sim 1700$ +/- 100 years before present $(1630$ +/- 100 cal. years BP) (Morell et al., 2018). Though the dates from the DDMFZ and LRF overlap with the dates of SHb1, Ship Harbor faces away from both fault systems limiting direct propagation into the marsh; however, though 
not well constrained, diffraction around the islands is possible, and constriction of water in the Puget Sound between islands could increase wave velocity and height.

The Seattle Fault is approximately 100km south of Ship Harbor (Figure 2). Tsunami modeling done for this study suggests that the maximum increase in water level at Ship Harbor would be $20 \mathrm{~cm}$ (Figure 21). This would not be enough increase in the water column to overtop the beach berm at either field site, and is an unlikely source for sand-sheets SHb1 or EIb2.

The Southern Whidbey Island fault system (SWF) is located approximately $30 \mathrm{~km}$ south of Ship Harbor and strikes NW, tracing offshore west of Whidbey Island (Figure 2). Magnetic measurements, gravity anomalies, and borehole data all suggest that the fault has a transpressional history and has experienced strike-slip and thrust or reverse offsets (Johnson et al., 1996). Seismic reflection profiles and boreholes suggest that there has been displacement along the fault within the Quaternary, confirmed by identified liquefaction structures crosscutting Quaternary deposits. The SWF to the west and northwest is inferred to connect to the southern extent of the Leech River fault on Vancouver Island. It is possible that slip along these faults could produce tsunami inundation to local areas (Johnson et al., 1996). The timing of the most recent earthquake events along these faults are not well constrained (Johnson et al., 1996).

The Sandy Point fault (SPF) is approximately $35 \mathrm{~km}$ north of Ship Harbor marsh and has inferred slip which has offset Holocene landforms/deposits (Figure 2) (Kelsey et al., 2012). Kelsey et al. (2012) predict that there have been three coseismic uplift events in the last 6,000 years, with the most recent event occurring several centuries after 2060-2320 years B.P. It is possible that one or more of these faults created a tsunami during a Holocene slip events. However, it is unclear if any of these faults could generate enough vertical sea floor deformation to produce the observed inundation and deposit thickness of SHb1. All fault traces 
mentioned here except the Sandy Point fault are to the south of Ship Harbor marsh, limiting direct tsunami propagation into the north-facing Ship Harbor marsh. However, it is possible that wave propagation through the Puget Sound diffracts around the islands, and constriction of water in the Puget Sound between islands could increase wave velocity and height.

\subsubsection{Limited records of CSZ tsunamis in Ship Harbor}

It is problematic that earthquake Y (associated with buried soil Y in Atwater and Hemphill-Haley (1997)) representing the most recent 1700 AD CSZ earthquake, and other CSZ tsunami event deposits are not recorded in the stratigraphy at Ship Harbor. Over the last 4300 cal. years B.P. nine potential full-rupture CSZ events have occurred (Goldfinger, 2012; Witter et al., 2013). Of these nine events, only one event is modeled, based on recurrence interval, to have been a large event, while the rest are modeled to have been SM or M size events (Witter et al., 2013). Assuming mean sea level, this may explain why only one tsunami event is detectable within Ship Harbor marsh.

Earthquake Y ( $\sim 300$ years ago $)$ is understood to have been large, and likely comparable to earthquake S. Tidal differences in the models show that the L1 with $-2.0 \mathrm{~m}$ tide does not produce inundation further than the northern, seaward 100m of the marsh at Ship Harbor (Figure 23). Daily tidal fluctuations around Anacortes range between 1.3-2.35m ("Tide Predictions NOAA Tides \& Currents"), and models suggest that tide changes this size can influence the possibility of overtopping of the beach berm and inundation of the marsh. Tides may play a role in the potential and extent of inundation into the marsh during the most recent 1700 event, and could account for the absence of these deposits in Ship Harbor marsh. Tide hindcasting from the eastern Strait of Juan de Fuca predict that neap tides occurred during the inferred time of tsunami arrival in the Puget Sound (Mofjeld et al., 1997; Williams and Hutchinson, 2000). At low tides, 
as confirmed by modeling, it is possible that a tsunami may not have sufficient height to effectively overtop the beach berm- in this case this provides a viable explanation for lack of tsunami deposits from the last large CSZ event at Ship Harbor marsh. The most northern beachward extent of the marsh, were not surveyed in this study, due to limited access. Furthermore, the Skagit County soil survey from 1989 suggests that the whole area has been heavily altered by human development and fill, likely when the cannery and railroad were built in the 1800s. It is possible that the seaward marsh has preserved more deposits than found in the back of the marsh, if not too heavily disturbed from human modification.

\subsubsection{Eliza Island}

EIb1 and EIb2 are interpreted as potential inundation events into Eliza Island marsh. Dating of VCEI2, and the refined sequence model incorporating PSV dates, suggests that sandsheet EIb2 was deposited 4669-4820 years B.P (Table 23b). The dates for sand-sheet EIb2 do not correlate to the modern marsh record preserved on the outer coast or in the Puget Sound. However, it does relate to a large, full rupture event predicted by the turbidite record. Goldfinger et al. (2012) and additional ${ }^{14} \mathrm{C}$ dates from Witter et al. (2013) suggests that T10 occurred between 4590-4950 years B.P. T10 is predicted to have occurred after a very long post-seismic interval, and is estimated to be large. This evidence is the best to suggest that EIb2 may have been the result of CSZ tsunami inundation into Eliza Island marsh.

\subsection{Future work}

There are many areas of research, field work, and data collection that could be expanded upon to answer some lingering questions related to the conclusions made here.

Confirmation of SHb1 as a paleotsunami deposit requires additional study. Stratigraphy of the subsurface at the front of Ship Harbor marsh would be helpful for looking at the northern 
extent of the deposit and how the thickness varies spatially through the front $200 \mathrm{~m}$ of marsh between VCS4 and the modern beach, and if it is detectable within the modified marsh environment. Presence of a large section of sands and gravels in VCS3 could represent a paleo beach environment, present at the historic marsh front, or a larger deposit of beach berm over wash, or the deposition of multiple inundation events (be it storm or tsunami) which accumulated to produce a larger column of sand and gravels. More field work would be an ideal way to answer the lingering questions about spatial extent and detect other deposits not identified in this study.

Smear slides show that abundant diatoms are present within the cores. Diatom smearslide analysis and identification would be a great way to confirm ocean inundation caused the deposition of sand-sheet SHb1. Diatoms can be traced to their source when identified from within specific sections of the cores collected. An abundance of marine diatoms from within sand-sheets SHb1, EIb1 and EIb2 would confirm that ocean inundation created these sand sheets. Terrestrial diatoms, and general diatom make-up from beds above and below these sand-sheets would help confirm the past environments pre/post sand-sheet deposition.

Puget Sound upper crustal fault tsunami modeling is important to assess the potential of the faults to produce inundation at Ship Harbor. In order to provide the parameters for these models, trenching and other paleoseismic analyses need to be done to constrain the timing of the Holocene slip events along the faults. Large submarine landslides could also be a tsunamigenic source in the Puget Sound. Constraints on timing of collapses and slumps from the Fraser, Nisqually, Skokomish and Hood River canal deltas would provide better timing constraints on potential submarine landslides in the Puget Sound. 
Further AMS analysis of Ship Harbor data would help to constrain the flow regime for sand-sheet SHb1. Lack of tidal channel exposures made in situ AMS collection impossible, and compaction from coring could have impacted interpretation of sedimentary fabrics. Digging trenches/benches/holes within the marsh from which samples can be directly collected in situ would be a good solution to this, though potentially difficult do to the saturated subsurface of the marsh. 


\section{Work Cited}

Atwater, B.F., 1987, Evidence for Great Holocene Earthquakes along the Outer Coast of Washington State: Science, v. 236, p. 942-944.

Atwater, B.F., Carson, B., Griggs, G.B., Johnson, H.P., and Salmi, M.S., 2014, Rethinking turbidite paleoseismology along the Cascadia subduction zone: Geology, v. 42, p. 827830, doi:10.1130/G35902.1.

Atwater, B.F., and Hemphill-Haley, E., 1997, Recurrence intervals for great earthquakes of the past 3,500 years at northeastern Willapa Bay, Washington: U.S. G.P.O. ; Information Services [distributor], Professional Paper USGS Numbered Series 1576, http://pubs.er.usgs.gov/publication/pp1576 (accessed February 2019).

Atwater, B.F., Tuttle, M.P., Schweig, E.S., Rubin, C.M., Yamaguchi, D.K., and Hemphill-Haley, E., 2003, Earthquake recurrence inferred from paleoseismology, in Developments in Quaternary Sciences, Elsevier, v. 1, p. 331-350, doi:10.1016/S1571-0866(03)01015-7.

Board on Earth Sciences and Resources, Ocean Studies Board, Division on Earth and Life Studies, and National Research Council, 2012, Sea-Level Rise for the Coasts of California, Oregon, and Washington: Past, Present, and Future: Washington, D.C., UNITED STATES, National Academies Press, http://ebookcentral.proquest.com/lib/wwu/detail.action?docID=3379304 (accessed January 2018).

Boggs, S., 2011, Principles of Sedimentology and Stratigraphy: Boston, Mass., Pearson, 585 p.

Borgmark, A., 2016, Physical parameters and accumulation rates in peat in relation to the climate during the last 150 years:

Bourgeois, J., 2009, Chapter 3: Geologic Effects and Records of Tsunamis, in The Sea, Harvard University Press, Tsunamis, v. 15, p. 53-91.

Cherniawsky, J.Y., Titov, V.V., Wang, K., and Li, J.-Y., 2007, Numerical Simulations of Tsunami Waves and Currents for Southern Vancouver Island from a Cascadia Megathrust Earthquake: Pure and Applied Geophysics, v. 164, p. 465-492, doi:10.1007/s00024-006-0169-0.

Eliza Island plan: a component of the Whatcom County comprehensive plan :: North Corner Documents Collection, http://content.wwu.edu/cdm/ref/collection/ncde/id/347 (accessed October 2018).

Eungard, D.W., Forson, C., Walsh, T.J., Gica, E., and Arcas, D., 2018, Tsunami hazard maps of the Anacortes-Bellingham area, Washington - Model resluts from a 2500-year Cascadia subduction zone eathquake scenario: Washington Geological Survey Map Series 201802, p. 6 Sheets. 
Flück, P., Hyndman, R.D., and Wang, K., 1997, Three-dimensional dislocation model for great earthquakes of the Cascadia Subduction Zone: Journal of Geophysical Research: Solid Earth, v. 102, p. 20539-20550, doi:10.1029/97JB01642.

Gica, E., and Arcas, D., 2016, Tsunami Inundation Modeling of Anacortes and Bellingham, Washington due to a Cascadia Subduction Zone Earthquake:, $\mathrm{ftp}: / /$ newportftp.pmel.noaa.gov/tsunami/ForFrankGonzalez/Anacortes_Bellingham_Wash ington_Report.pdf.

Gilbert, J.J., 1885, T-1667: Puget Sound River History Project SheeNo. 1, Topography of Rosario Strait, WT, Deception Pass to Ship Harbor, 1885, http://riverhistory.ess.washington.edu/tsheets/t1667.html.

Goldfinger, C., 2012, Turbidite event history: methods and implications for Holocene paleoseismicity of the Cascadia subduction zone: Reston, Va., U.S. Dept. of the Interior, U.S. Geological Survey.

Gonzalez, F., LeVeque, R., Chamberlain, P., Hirai, B., Varkovizky, J., and George, D., 2011, Validation of the GeoClaw Model:

Guard, B.J., Christy, J.A., and Steen, T., 2010, Wetland plants of Oregon \& Washington: Auburn, WA; Edmonton, Lone Pine Pub.

Hagstrum, J.T., Atwater, B.F., and Sherrod, B.L., 2004, Paleomagnetic correlation of late Holocene earthquakes among estuaries in Washington and Oregon: Geochemistry, Geophysics, Geosystems, v. 5, p. n/a-n/a, doi:10.1029/2004GC000736.

Hagstrum, J.T., and Champion, D.E., 2002, A Holocene paleosecular variation record from 14Cdated volcanic rocks in western North America: Journal of Geophysical Research: Solid Earth, v. 107, p. EPM 8-1-EPM 8-14, doi:10.1029/2001JB000524.

Howard, P.M., 1983, National Engineering Handbook, Section 3, Sedimentation:, https://directives.sc.egov.usda.gov/OpenNonWebContent.aspx?content=18375.wba (accessed June 2019).

Hutchinson, I., Peterson, C.D., and Sterling, S.L., 2013, Late Holocene Tsunami Deposits at Salt Creek, Washington, USA:, http://onesearch.library.wwu.edu/primo_library/libweb/action/dlDisplay.do?vid=WWU\& afterPDS=true\&docId=TN_proquest $1566836989 \&$ loc $=$ adaptor,primo_central_multiple_f e (accessed January 2018).

Hyndman, R., and Wang, K., 1995, The rupture zone of Cascadia great earthquakes from current deformation and thermal regime: Journal of Geophysical Research, v. 1002, p. 2213322154, doi:10.1029/95JB01970.

Intro to Anacortes History, https://www.anacorteswa.gov/337/Anacortes-History (accessed May 2019). 
Johnson, S.Y. et al., 2004, Evidence for Late Holocene Earthquakes on the Utsalady Point Fault, Northern Puget Lowland, Washington: Bulletin of the Seismological Society of America, v. 94, p. 2299-2316, doi:10.1785/0120040050.

Johnson, S.Y., Potter, C.J., Miller, J.J., Armentrout, J.M., Finn, C., and Weaver, C.S., 1996, The southern Whidbey Island fault: An active structure in the Puget Lowland, Washington: GSA Bulletin, v. 108, p. 334-354, doi:10.1130/00167606(1996) 108<0334:TSWIFA>2.3.CO;2.

Kain, C., Wassmer, P., Goff, J., Chague-Goff, C., Gomez, C., Hart, D., Fierro, D., Jacobsen, G., and Zawadzki, A., 2017, Determining flow patterns and emplacement dynamics from tsunami deposits with no visible sedimentary structure: Earth Surface Processes and Landforms, v. 42, p. 763-780, doi:10.1002/esp.4020.

Kelsey, H.M., Sherrod, B.L., Blakely, R.J., and Haugerud, R.A., 2012, Holocene faulting in the Bellingham forearc basin: Upper-plate deformation at the northern end of the Cascadia subduction zone: ACTIVE FAULTING BELLINGHAM FOREARC BASIN: Journal of Geophysical Research: Solid Earth, v. 117, doi:10.1029/2011JB008816.

Koshimura, S., Hayashi, S., and Gokon, H., 2014, The impact of the 2011 Tohoku earthquake tsunami disaster and implications to the reconstruction: Soils and Foundations, v. 54, p. 560-572, doi:10.1016/j.sandf.2014.06.002.

Koshimura, S., Mofjeld, H.O., González, F.I., and Moore, A.L., 2002, Modeling the 1100 bp paleotsunami in Puget Sound, Washington: MODELING THE 1100 BP PALEOTSUNAMI: Geophysical Research Letters, v. 29, p. 9-1-9-4, doi:10.1029/2002GL015170.

Kulzer, L., Luchessa, S., Cooke, S., Errington, R., and Weinmann, F., 2001, Chapter 2: Physical Characteristics of Sphagnum-dominated Peatlands in Western Washington, in Characteristics of Low-Elevation Sphagnum-dominated Peatlands in Western Washington: A Community Profile, King County Department of Natural Resources, https://your.kingcounty.gov/dnrp/library//2001/kcr771/chapter2.pdf (accessed March 2019).

Leonard, L.J., Hyndman, R.D., and Mazzotti, S., 2004, Coseismic subsidence in the 1700 great Cascadia earthquake: Coastal estimates versus elastic dislocation models: GSA Bulletin, v. 116, p. 655-670, doi:10.1130/B25369.1.

Leveque, R., Berger, M., and Mandli, K., 2010, The GeoClaw Software for Geophysical Flows: AGU Fall Meeting Abstracts, v. 1, p. 1855.

MacInnes, B., 2018, Nelson and others notes and .KMZ files, written communication, 2018:

Mandli, K.T., Ahmadia, A.J., Berger, M., Calhoun, D., George, D.L., Hadjimichael, Y., Ketcheson, D.I., Lemoine, G.I., and LeVeque, R.J., 2016, Clawpack: building an open source ecosystem for solving hyperbolic PDEs: PeerJ Computer Science, v. 2, p. e68, doi:10.7717/peerj-cs.68. 
Mastersizer 2000 User Manual MAN0384 Issue 1.0, 2007, https://www.labmakelaar.com/fjc_documents/mastersizer-2000-2000e-manual-eng1.pdf.

Mofjeld, H.O., Foreman, M.G.G., and Ruffman, A., 1997, West Coast tides during Cascadia Subduction Zone tsunamis: Geophysical Research Letters, v. 24, p. 2215-2218, doi:10.1029/97GL02060.

Morell, K.D., Regalla, C., Amos, C., Bennett, S., Leonard, L., Graham, A., Reedy, T., Levson, V., and Telka, A., 2018, Holocene Surface Rupture History of an Active Forearc Fault Redefines Seismic Hazard in Southwestern British Columbia, Canada: Geophysical Research Letters, v. 45, p. 11,605-11,611, doi:10.1029/2018GL078711.

Morton, R.A., Gelfenbaum, G., Buckley, M.L., and Richmond, B.M., 2011, Geological effects and implications of the 2010 tsunami along the central coast of Chile: Sedimentary Geology, v. 242, p. 18, doi:10.1016/j.sedgeo.2011.09.004.

Morton, R.A., Gelfenbaum, G., and Jaffe, B.E., 2007, Physical criteria for distinguishing sandy tsunami and storm deposits using modern examples: Sedimentary Geology, v. 200, p. 184-207, doi:10.1016/j.sedgeo.2007.01.003.

Myrobo, A., Plank, C., Coleman, J., Shane, L., and Graber, D., 2013, Loss-on-Ignition Standard Operating Procedure:, http://lrc.geo.umn.edu/laccore/assets/pdf/sops/loi.pdf.

Nichols, G., 2009, Sedimentology and stratigraphy: Chichester, UK ; Hoboken, NJ, WileyBlackwell, $419 \mathrm{p}$.

North Puget USGS 2006 DTM 43 Washington State Department of Natural Resources Division of Geology and Earth Resources North Puget Sound USGS 2006 LiDAR LiDAR, http://lidarportal.dnr.wa.gov/\#48.19905:-122.34924:7.

Ozawa, S., Nishimura, T., Munekane, H., Suito, H., Kobayashi, T., Tobita, M., and Imakiire, T., 2012, Preceding, coseismic, and postseismic slips of the 2011 Tohoku earthquake, Japan: Journal of Geophysical Research: Solid Earth, v. 117, doi:10.1029/2011JB009120.

Pacific Northwest Marine Mollucan Biodiversity, 2019, Pacific Northwest Shell Club, http://www.bily.com/pnwsc/web-content/Index.html (accessed December 2018).

Personius, S.F., Briggs, R.W., Nelson, A.R., Schermer, E.R., Maharrey, J.Z., Sherrod, B.L., Spaulding, S.A., and Bradley, L.-A., 2014, Holocene earthquakes and right-lateral slip on the left-lateral Darrington-Devils Mountain fault zone, northern Puget Sound, Washington: Geosphere, v. 10, p. 1482-1500, doi:10.1130/GES01067.1.

Peters, R., Jaffe, B., and Gelfenbaum, G., 2007, Distribution and sedimentary characteristics of tsunami deposits along the Cascadia margin of western North America: Sedimentary Geology, v. 200, p. 372-386, doi:10.1016/j.sedgeo.2007.01.015.

Pollard, D., and DeConto, R.M., 2016, Contribution of Antarctica to past and future sea-level rise: Nature, v. 531, p. 591, doi:10.1038/nature17145. 
Priest, G.R., Myers, E., Baptista, A., Fleuck, P., Wang, K., and Kamphaus, R., 1997, Cascadia Subduction Zone Tsunamis, Hazard Mapping at Yaquina Bay, Oregon: State of Oregon, Department of Geology and Mineral Industries, 144 p.

Richmond, B. et al., 2012, Erosion, deposition and landscape change on the Sendai coastal plain, Japan, resulting from the March 11, 2011 Tohoku-oki tsunami: Sedimentary Geology, v. 282, p. 27-39, doi:10.1016/j.sedgeo.2012.08.005.

San Juan 2009 DTM 12 Washington State Department of Natural Resources Division of Geology and Earth Resources San Juan 2009 LiDAR LiDAR, http://lidarportal.dnr.wa.gov/\#48.65378:-121.93314:9.

Satake, K., Shimazaki, K., Tsuji, Y., and Ueda, K., 1996, Time and size of a giant earthquake in Cascadia inferred from Japanese tsunami records of January 1700: Nature, v. 379, p. 246-249, doi:10.1038/379246a0.

Sedimentation Test of Soil Texture, https://ucanr.edu/sites/UrbanAg/files/263165.pdf.

Skagit County Natural Hazard Mitigation Plan, 2014,.

Snowball, I.F., 1997, Gyroremanent magnetization and the magnetic properties of greigitebearing clays in southern Sweden: Geophysical Journal International, v. 129, p. 624-636, doi:10.1111/j.1365-246X.1997.tb04498.x.

Taira, A., and Masuda, F., 1989, Magnetic Fabrics and Depositional Processes, in Sedimentary Facies in the Active Plate Margin, Terra Scientific Publishing Company, Tokyo, p. 4377.

Tauxe, L., 2018, Essentials of Paleomagnetism: Fifth Web Edition: Scripps Institution of Oceanography, v. 5.

Tauxe, L., Kodama, K.P., and Kent, D.V., 2008, Testing corrections for paleomagnetic inclination error in sedimentary rocks: A comparative approach: Physics of the Earth and Planetary Interiors, v. 169, p. 152-165, doi:10.1016/j.pepi.2008.05.006.

Tide Predictions - NOAA Tides \& Currents, https://tidesandcurrents.noaa.gov/noaatidepredictions.html?id=9448772\&legacy=1 (accessed April 2019).

Triplett, L., and Heck, J., 2013, LacCore Grain Size Pretreatment SOP:, http://lrc.geo.umn.edu/laccore/assets/pdf/sops/Grain $\% 20$ Size $\% 20$ Pretreament $\% 20$ SOP $\%$ 202013.pdf.

Walsh, T.J., Titov, V., Mofjeld, H.O., and Gonzalez, F.I., 2004, Tsunami hazard map of the Bellingham area, Washington: modeled tsunami inundation from a Cascadia subduction zone earthquake: 
Wang, K., Wells, R., Mazzotti, S., Hyndman, R.D., and Sagiya, T., 2003, A revised dislocation model of interseismic deformation of the Cascadia subduction zone: Journal of Geophysical Research: Solid Earth, v. 108, doi:10.1029/2001JB001227.

Wassmer, P., and Gomez, C., 2011, Development of the AMS method for unconsolidated sediments. Application to tsunami deposits: Géomorphologie : relief, processus, environnement, v. 17, p. 279-290, doi:10.4000/geomorphologie.9491.

Wassmer, P.C., Gomez, C.A., Iskandasyah, T.Y.W.M., Lavigne, F., and Sartohadi, J., 2015, Contribution of anisotropy of magnetic susceptibility (AMS) to reconstruct flooding characteristics of a $4220 \mathrm{BP}$ tsunami from a thick unconsolidated structureless deposit (Banda Aceh, Sumatra): Frontiers in Earth Science, v. 3, doi:10.3389/feart.2015.00040.

Wassmer, P., Schneider, J.-L., Fonfrège, A.-V., Lavigne, F., Paris, R., and Gomez, C., 2010, Use of anisotropy of magnetic susceptibility (AMS) in the study of tsunami deposits: Application to the 2004 deposits on the eastern coast of Banda Aceh, North Sumatra, Indonesia: Marine Geology, v. 275, p. 255-272, doi:10.1016/j.margeo.2010.06.007.

Whatcom County Natural Hazards Mitigation Plan, 2015,.

Williams, H., and Hutchinson, I., 2000, Stratigraphic and Microfossil Evidence for Late Holocene Tsunamis at Swantown Marsh, Whidbey Island, Washington: Quaternary Research, v. 54, p. 218-227, doi:10.1006/qres.2000.2162.

Williams, H.F.L., Hutchinson, I., and Nelson, A.R., 2005, Multiple sources for late-Holocene tsunamis at Discovery Bay, Washington State, USA: The Holocene, v. 15, p. 60-73, doi:10.1191/0956683605hl784rp.

Witter, R.C., Zhang, Y., Wang, K., Priest, G., Goldfinger, C., Stimely, L., English, J., and Ferro, P., 2013, Simulated tsunami inundation for a range of Cascadia megathrust earthquake scenarios at Bandon, Oregon, USA: ResearchGate, doi:http://dx.doi.org/10.1130/GES00899.1.

Zhiyao, S., Tingting, W., Fumin, X., and Ruijie, L., 2008, A simple formula for predicting settling velocity of sediment particles: Water Science and Engineering, v. 1, p. 37-43, doi:10.1016/S1674-2370(15)30017-X. 
Figure 1. Context image of Washington State, Bellingham Bay, and field sites considered for this study. a: Image of western Washington state. CSZ appears as green line on left side of image, outer and inland coasts are labeled. b. Image of northern Puget Sound lowlands with current speed overlay from Gica and Arcas (2016). Labeled boxes are field sites of interest for this study: i. Eliza Island with predicted maximum inundation to $1.67 \mathrm{~m}$. ii. Cannery Lake, Anacortes. iii. Ship Harbor Marsh, Anacortes with predicted maximum inundation to $3.4 \mathrm{~m}$.
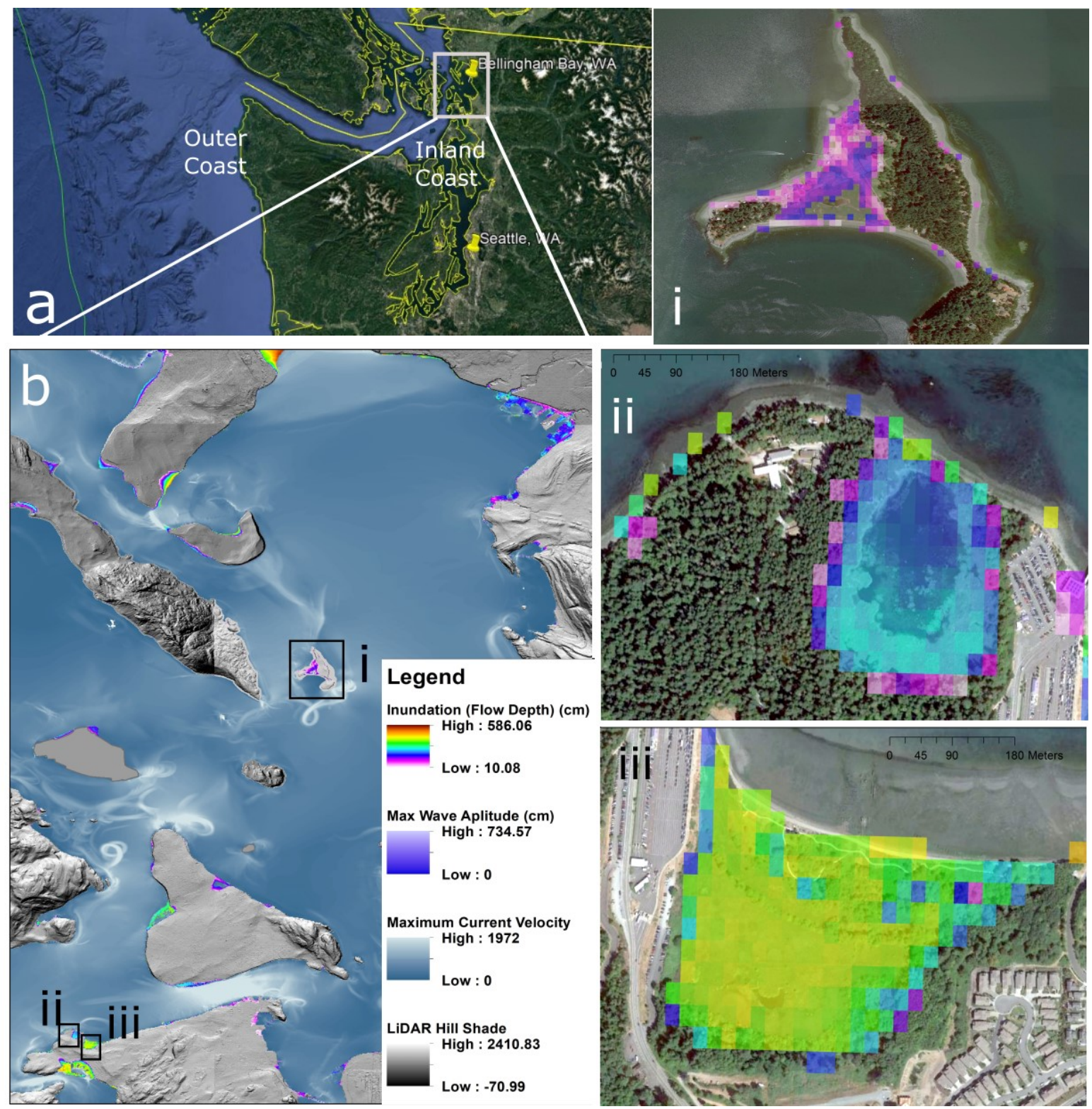
Figure 2. Map of North-west Washington, and images of Puget Sound marsh locations where CSZ tsunami deposits have been identified. Top left image is adapted from Kelsey et al. (2012) and displays the general outline of the Puget Sound and upper crustal fault locations in red with field locations of CSZ identified deposits are in blue boxes, labeled with letter or corresponding image. A: Salt Creek, B: Discovery Bay, C: Swantown Marsh. Key for shorthand: SPF: Sandy Point Fault, DMF: Darrington-Devils Mountain Creek Fault (which connects to the Leach River fault system off Vancouver, BC), UPF: Utsalady Point Fault. Imagery acquired from ArcGIS REST Services Directory. PugetSound_2009_30 cm_color_wsps_83h_img.

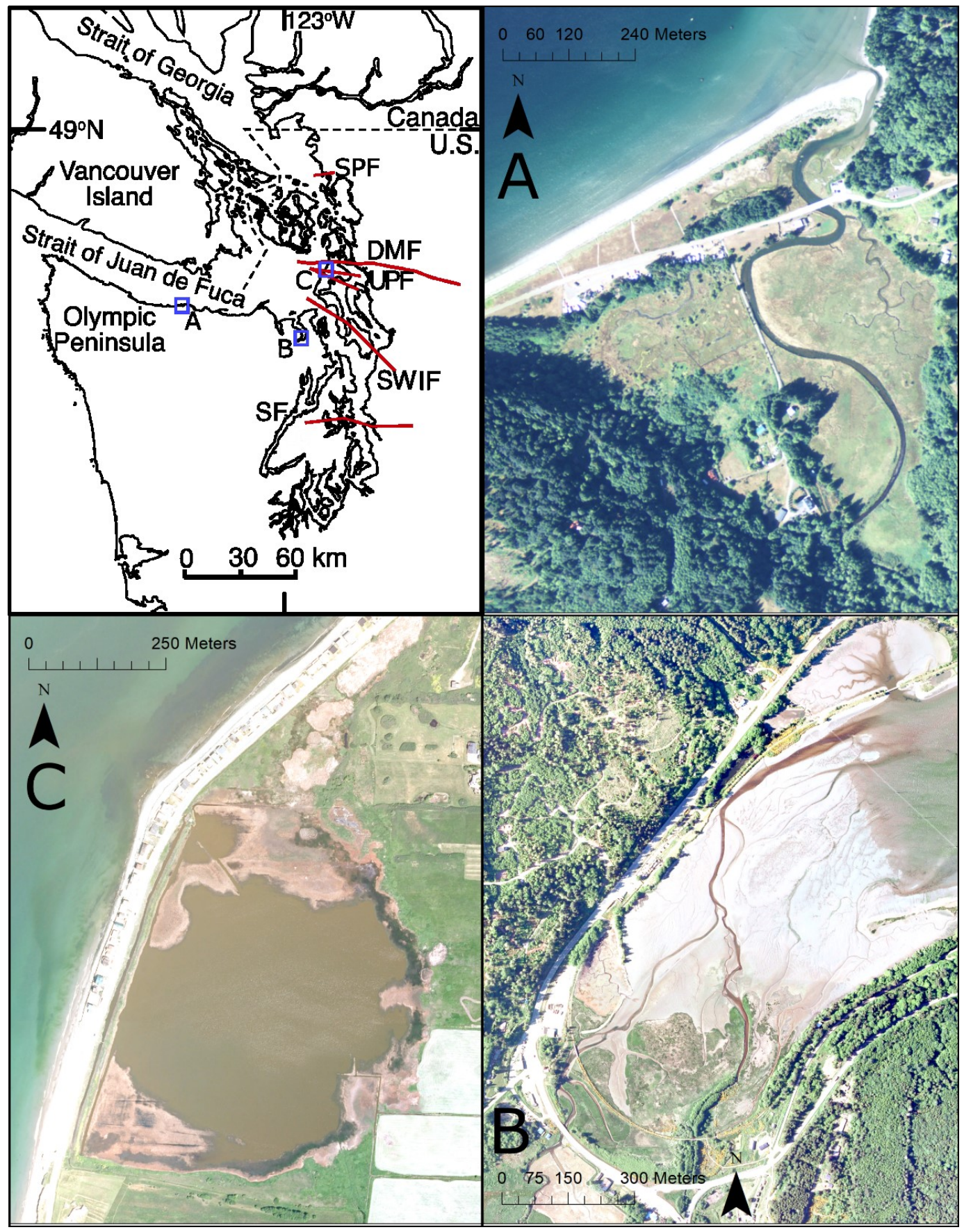


Figure 3. Image of Ship Harbor marsh, Anacortes, WA. Gouge-auger core locations in yellow, vibracore locations in red. Vibracores VCS1 and VCS2 are located under S30 and S12 respectively. Gouge auger cores are named relative to Appendix 2, and vibracores are labeled relative to Appendix 1. To the NE is the beach front, and to the $\mathrm{SW}$ is landward. Landsat aerial image from USGS public access.

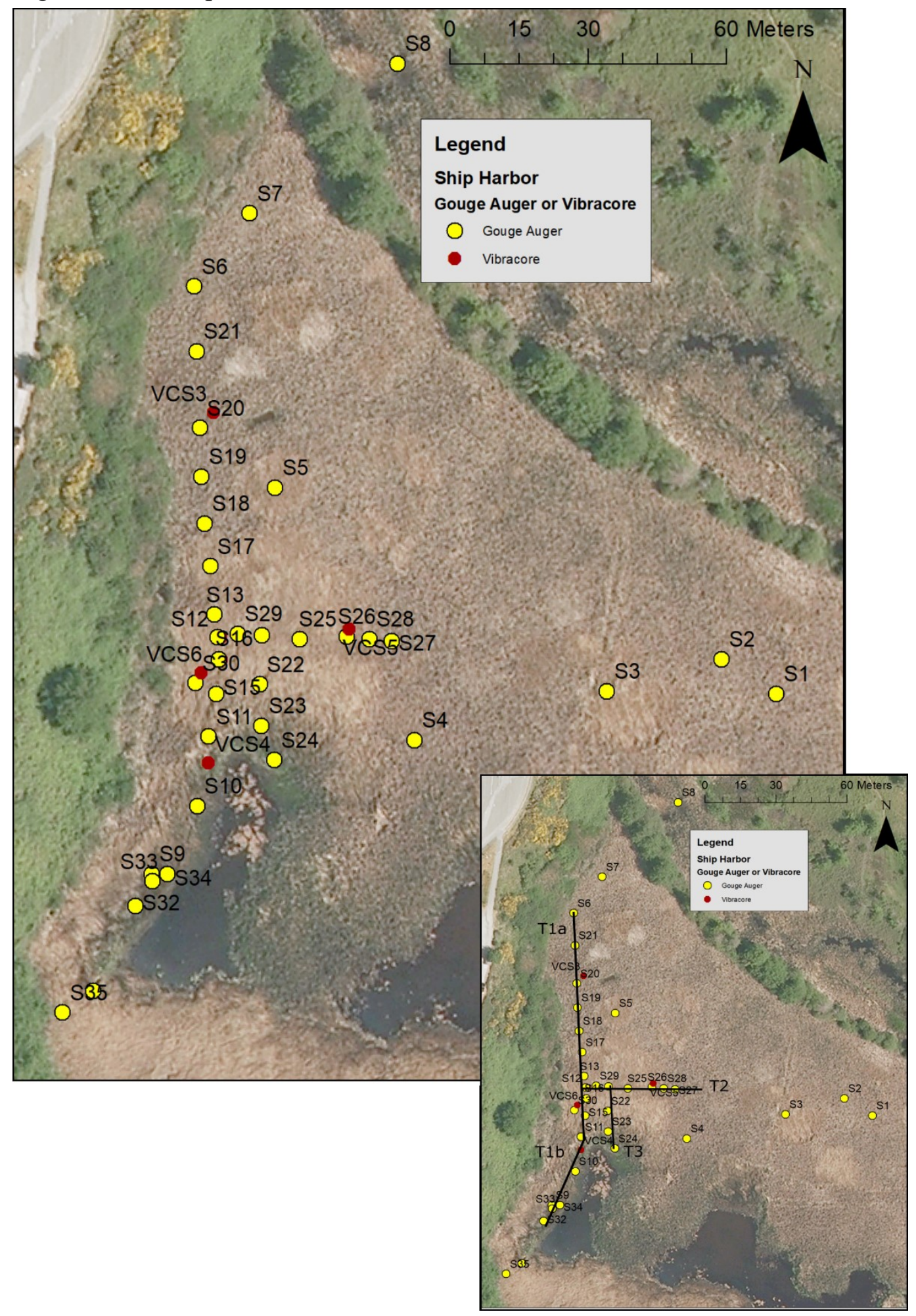


Figure 4. Image of Eliza Island Marsh, Eliza Island, WA. Gouge-auger core locations in yellow, vibracores locations in red. All points labeled with core name relative to appendix 1 and appendix 2. Beach fronts are located approximately south and NW of the central pond. A $2 \mathrm{~m}$ high beach berm boarders the marsh to the south. Aerial imagery acquired from USGS public access global imagery site.

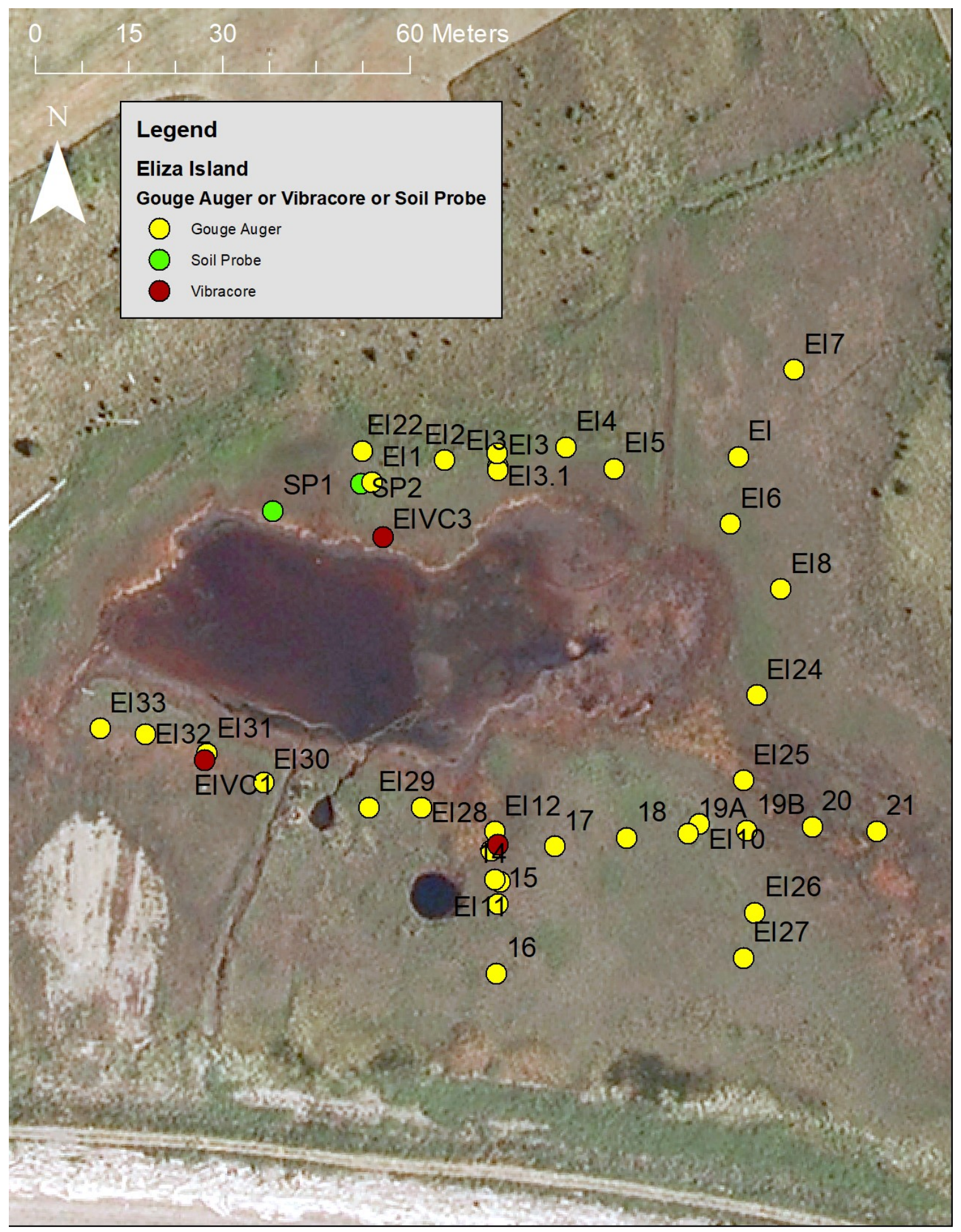


Figure 5. VCS2 core summary. Full image mosaic of core on right, with A. Upper transition from peat to mud. B. Sand-sheet SHb1 containing woody debris at top and mollusk shells within deposit. C. Lower section of gravels and organics. Left: Stratigraphic section of VCS2 with ${ }^{14} \mathrm{C}$ dates in cal. years BP given with $+/$ - error.
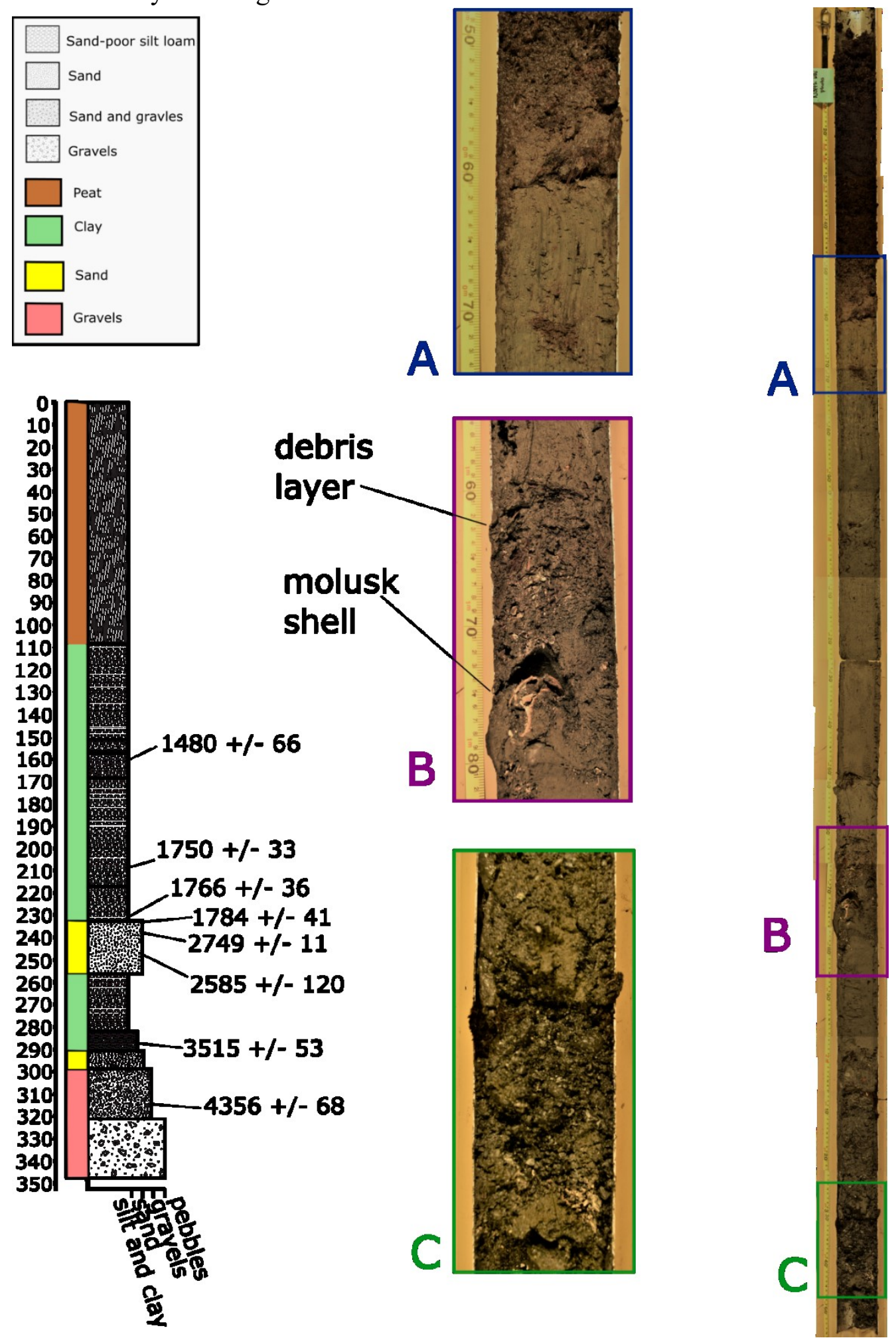
Figure 6. Stratigraphic sections of vibracores from Ship Harbor, described in appendix 2. Peat is generally $>80 \%$ organic material, ranging from $\mathrm{H} 1$ to $\mathrm{H} 9$ humification. Mud with some sand, and sand-poor mud are generally grey-green in color, and contain less than $30 \%$ sand, and $\sim 10 \%$ organics. Sand sections are greater than $40 \%$ sand, and sections of sands and gravels are $>40 \%$ gravels. Name of vibracore is at the top, and depth in centimeters is on the y-axis.

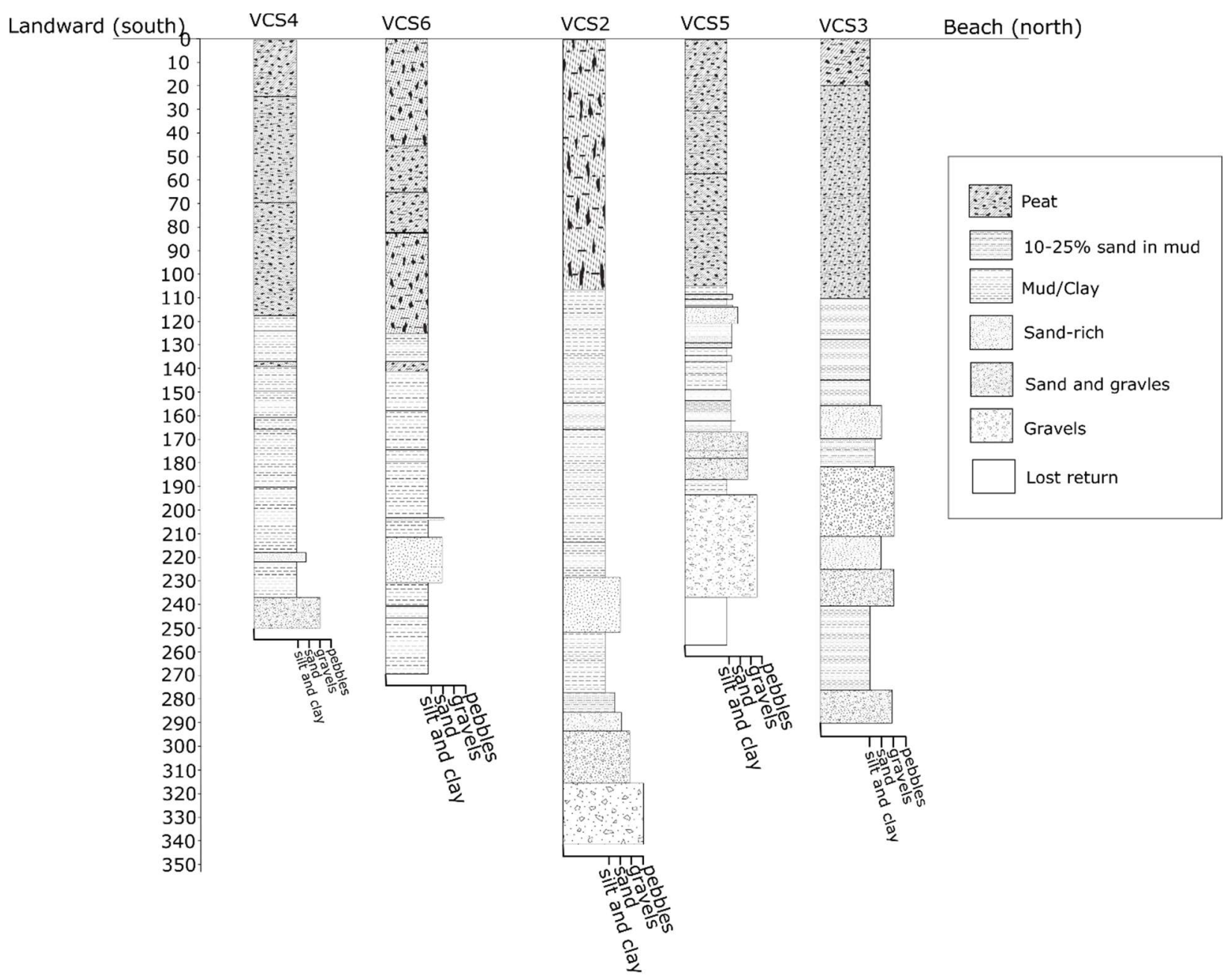


Figure 7. Left: Image of shell from sand-sheet $\mathrm{SHb} 1$ core reference depth: $165 \mathrm{~cm}$, with $\mathrm{mm} /$ centimeter measure below, Right: image of VCS2 layer SHb1 from which this shell was retrieved.

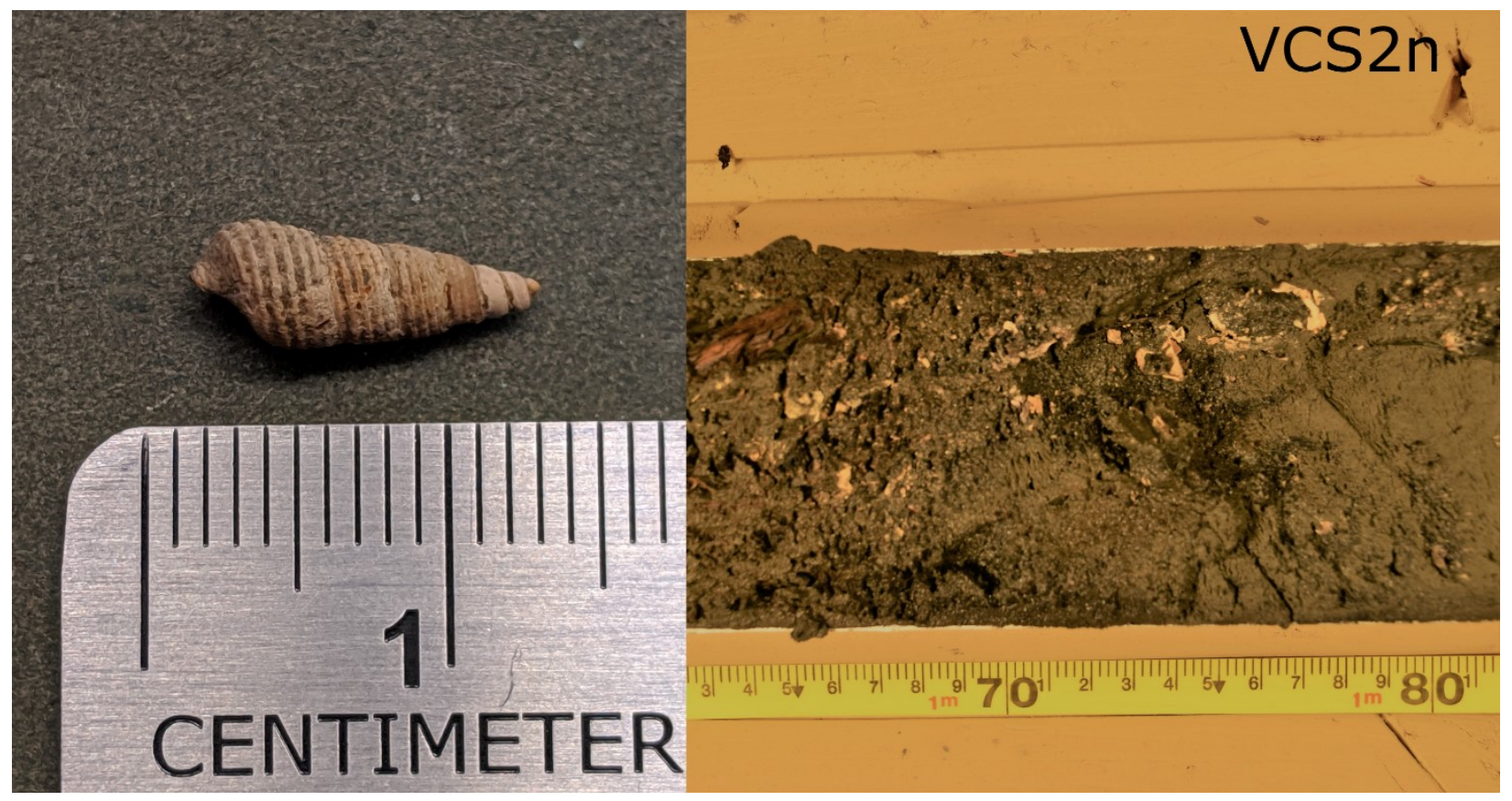


Figure 8a. Vibracore Ship Harbor 2 (VCS2) AMS results. Strat column displays depth in cm on the y-axis. Samples are organized by sediment type, indicated by color classifications of stratigraphic section. Brown: peat, Green: sandpoor silt and clay rich unit, yellow: sand, pink: gravels and sand. Lower hemisphere equal-area projections for sections display $\mathrm{K}_{\max }, \mathrm{K}_{\text {int }}$ and $\mathrm{K}_{\text {mins }}$ from AMS measurements, plotted in Anisoft. Circles are $95 \%$ confidence ellipses. A. Peat samples. B. Clay samples. C. Sand Samples. D. Lower gravel samples

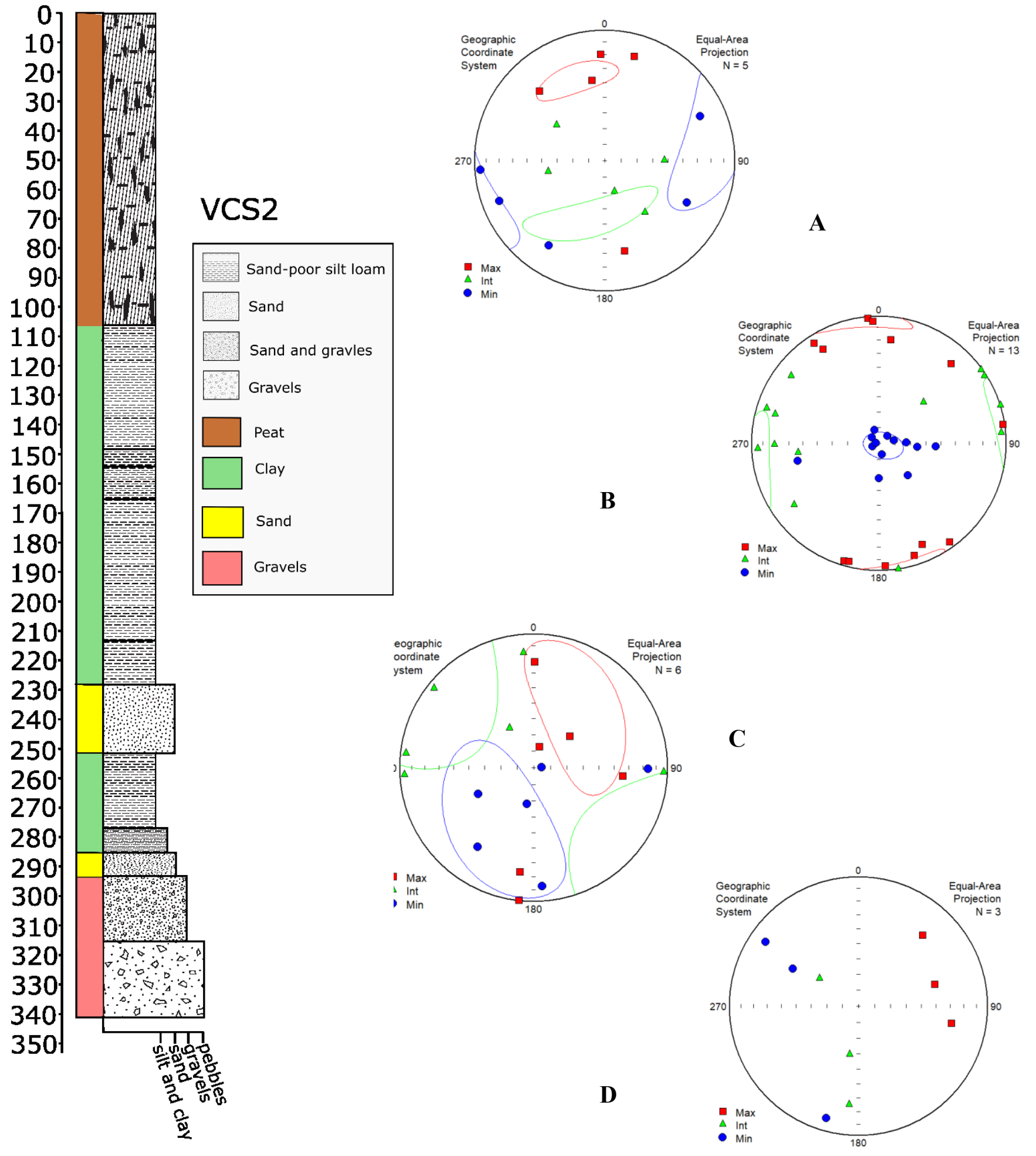


Figure 8b. Right: diagram of stratigraphic section for VCS6. Strat column displays depth in $\mathrm{cm}$ on the y-axis. Samples are organized by sediment type, indicated by color classifications of stratigraphic section. Brown: peat, Green: sand-poor silt and clay rich unit, yellow: sand, pink: gravels and sand. Lower hemisphere equal-area projections for sections display $\mathrm{K}_{\max }, \mathrm{K}_{\mathrm{int}}$ and $\mathrm{K}_{\operatorname{mins}}$ from AMS measurements, plotted in Anisoft. Circles are $95 \%$ confidence ellipses . A. Peat samples. B. Clay samples. C. Sand sample interpretation 1. D. Sand sample interpretation 2 .

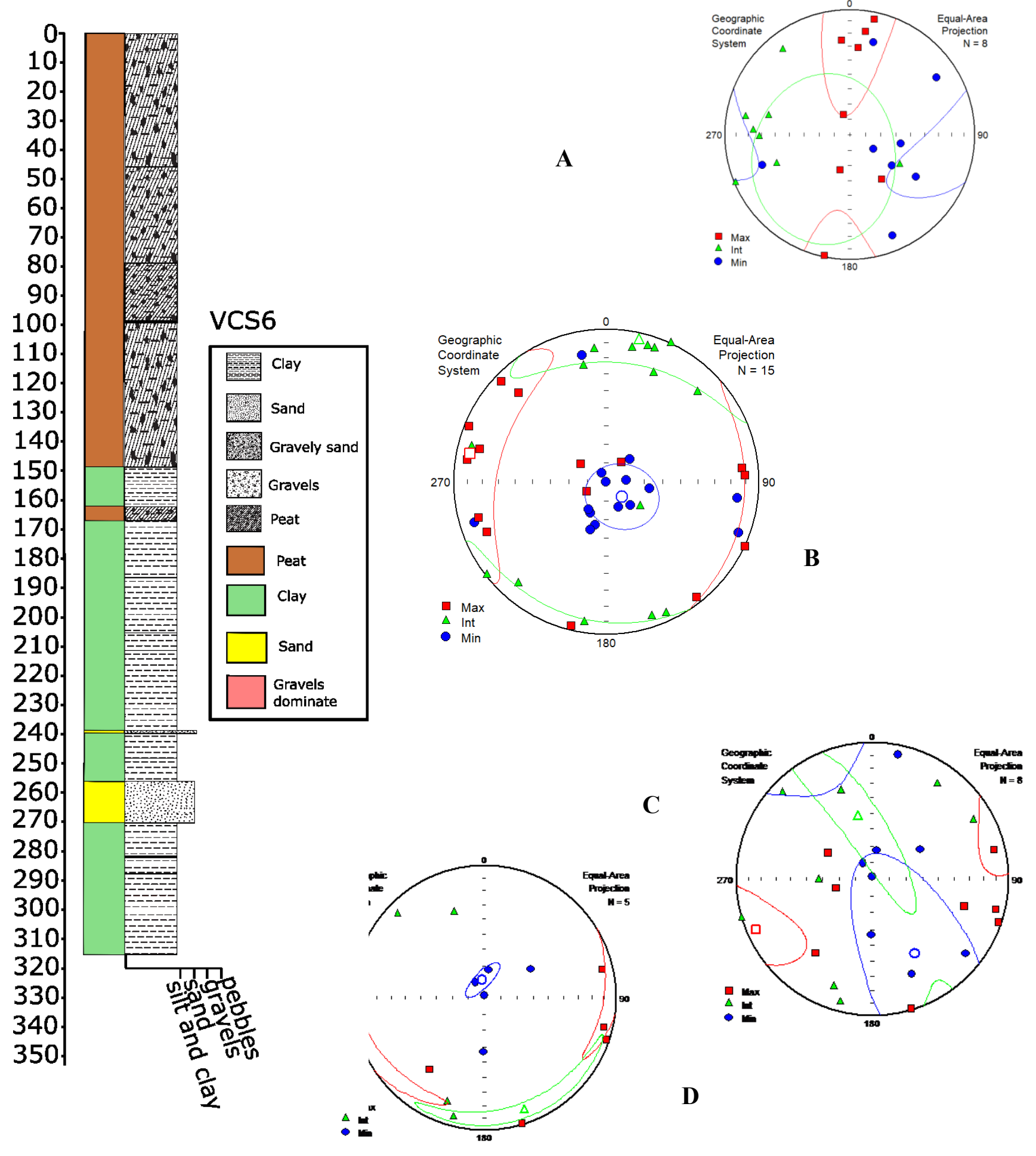


Figure 8c. Right: diagram of stratigraphic section for VCEI2. Strat column displays depth in $\mathrm{cm}$ on the y-axis. Samples are organized by sediment type, indicated by color classifications of stratigraphic section. Brown: peat, Green: sand-poor silt and clay rich unit, yellow: sand, pink: gravels and sand. Lower hemisphere equal-area projections for sections display $\mathrm{K}_{\max }, \mathrm{K}_{\mathrm{int}}$ and $\mathrm{K}_{\operatorname{mins}}$ from AMS measurements, plotted in Anisoft. Circles are $95 \%$ confidence ellipses. A: Peat samples (brown). B. Clay/Mud samples (green). C. Sand sheet samples (yellow).

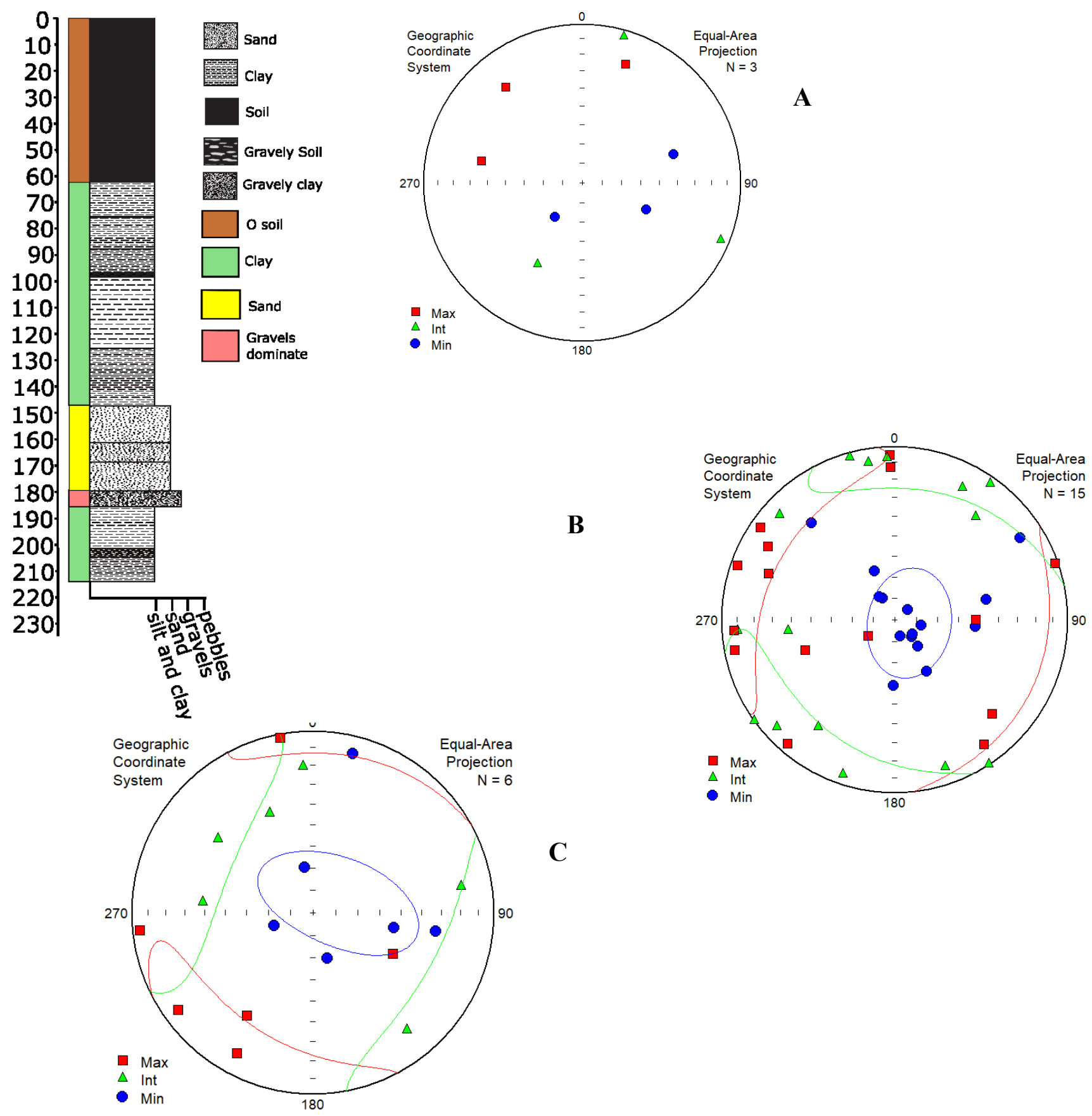


Figure 8d. Right: diagram of stratigraphic section for VCEI3. Strat column displays depth in $\mathrm{cm}$ on the y-axis. Samples are organized by sediment type, indicated by color classifications of stratigraphic section. Brown: peat, Green: sand-poor silt and clay rich unit, yellow: sand, pink: gravels and sand. Lower hemisphere equal-area projections for sections display $\mathrm{K}_{\max }, \mathrm{K}_{\text {int }}$ and $\mathrm{K}_{\operatorname{mins}}$ from AMS measurements, plotted in Anisoft. Circles are $95 \%$ confidence ellipses. A. Soil samples. B. Clay samples (green). C. Sand samples (yellow). D. Basal ravel samples (lower pink unit)

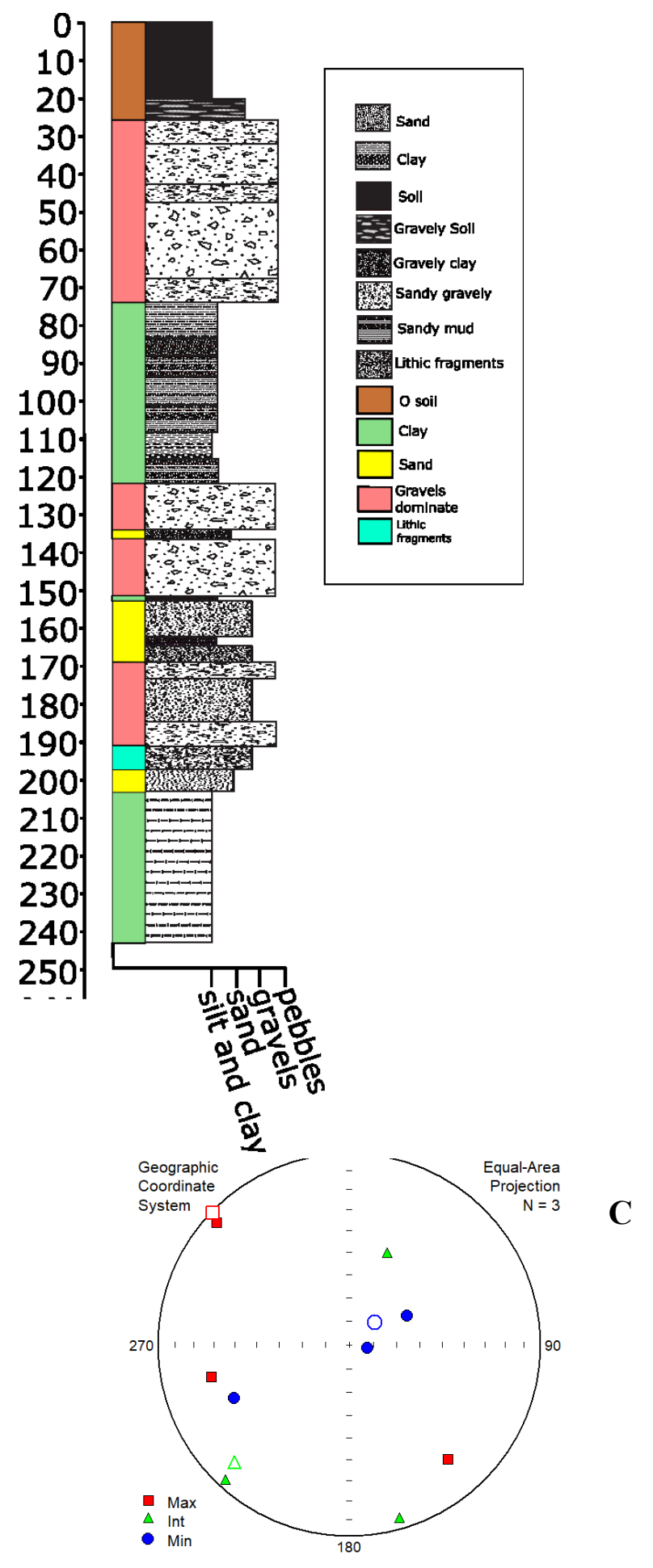

A

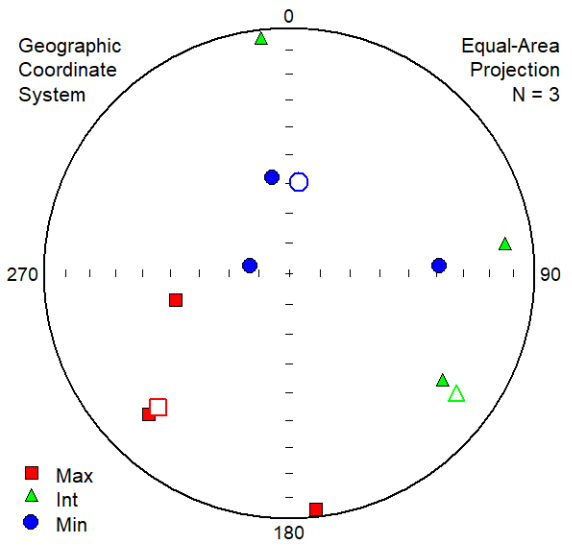

B

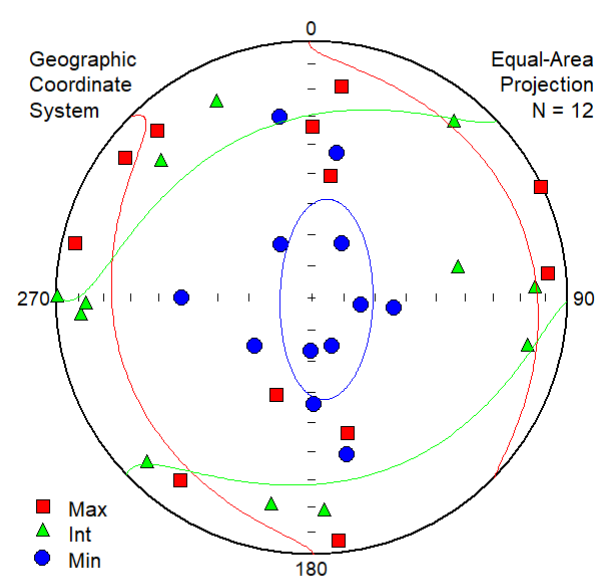

D

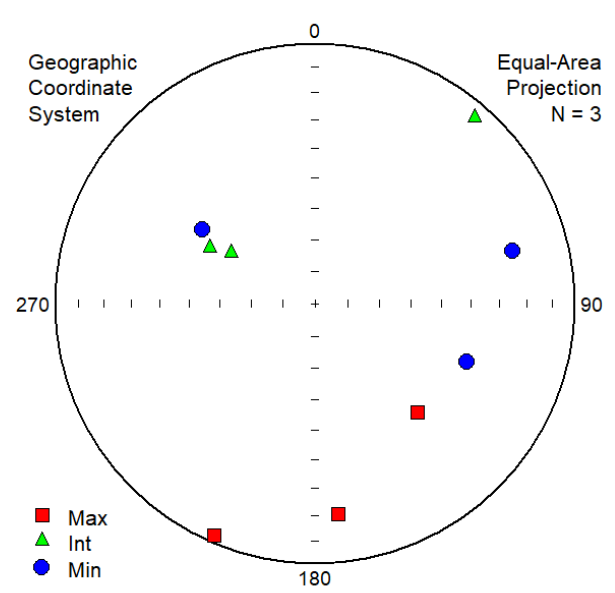


Figure 8e. AMS analysis sample locations of SHb1 from cores VCS2 and VCS6. Stratigraphy from VCS2 with oriented sampling locations, inset is portion of core identified as sand-sheet $\mathrm{SHb} 1$ with reference core depths labeled for samples collected. Reference depths correlate with the name of each sample. $\mathrm{Y}$-axis is the corrected depth for compaction in centimeters, specific sample labels are core reference depths (not corrected for compaction, but used in nomenclature for sample names).

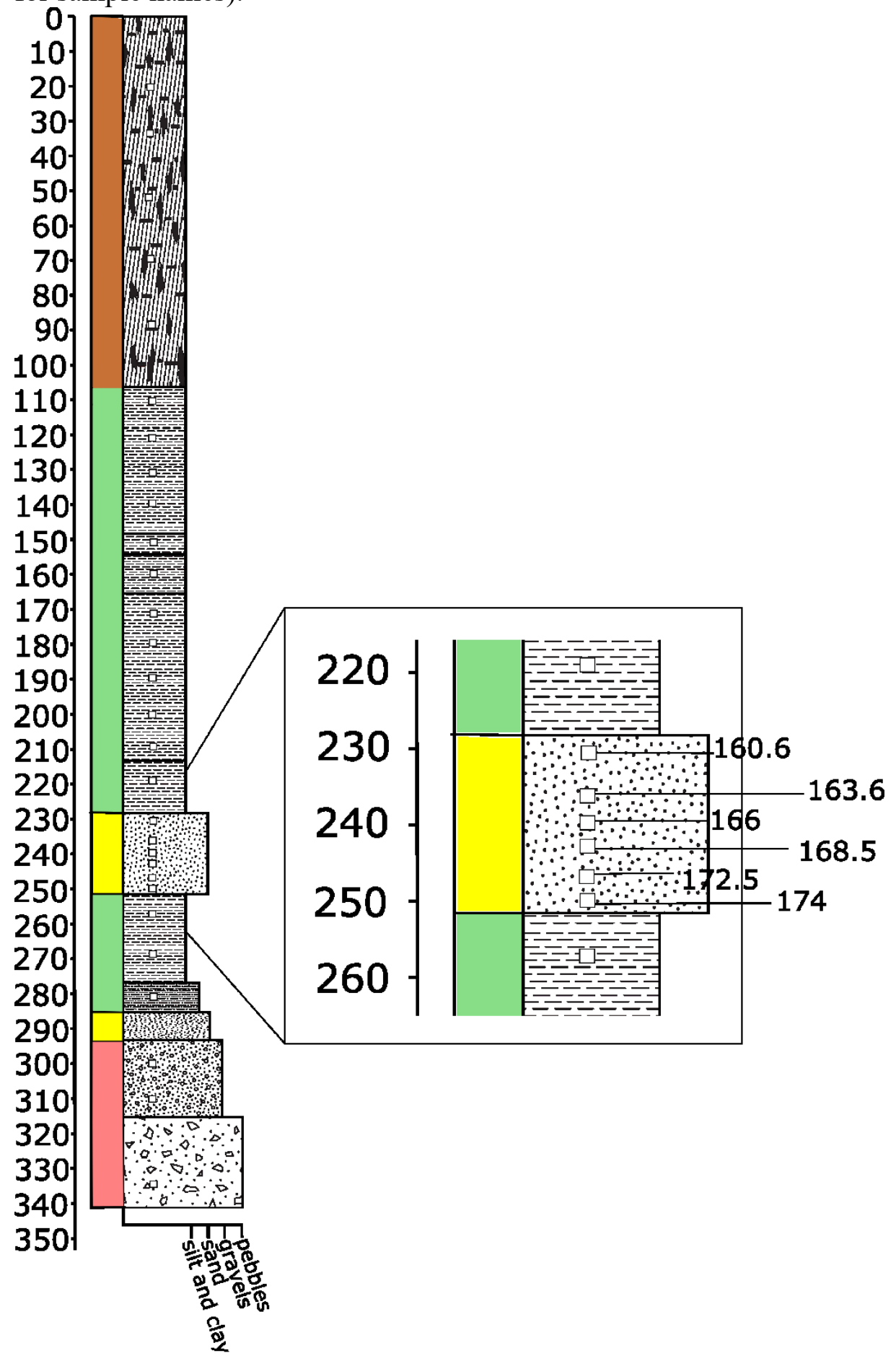


Figure 8f. Stratigraphy from VCS6 with oriented sampling locations for AMS and paleomagnetic data collection, inset is portion of core identified as sand-sheet SHb1. Y-axis is the corrected depth for compaction in centimeters. Within inset, specific sample labels (right) are core reference depths (not corrected for compaction, but used in nomenclature for sample names). Reference depths correlate with the name of each sample. Samples on right are from the south marked half of the core, and samples on the right are from the north marked half of the core. These two sets of samples are not collected in the same half but are depicted in such a way here.

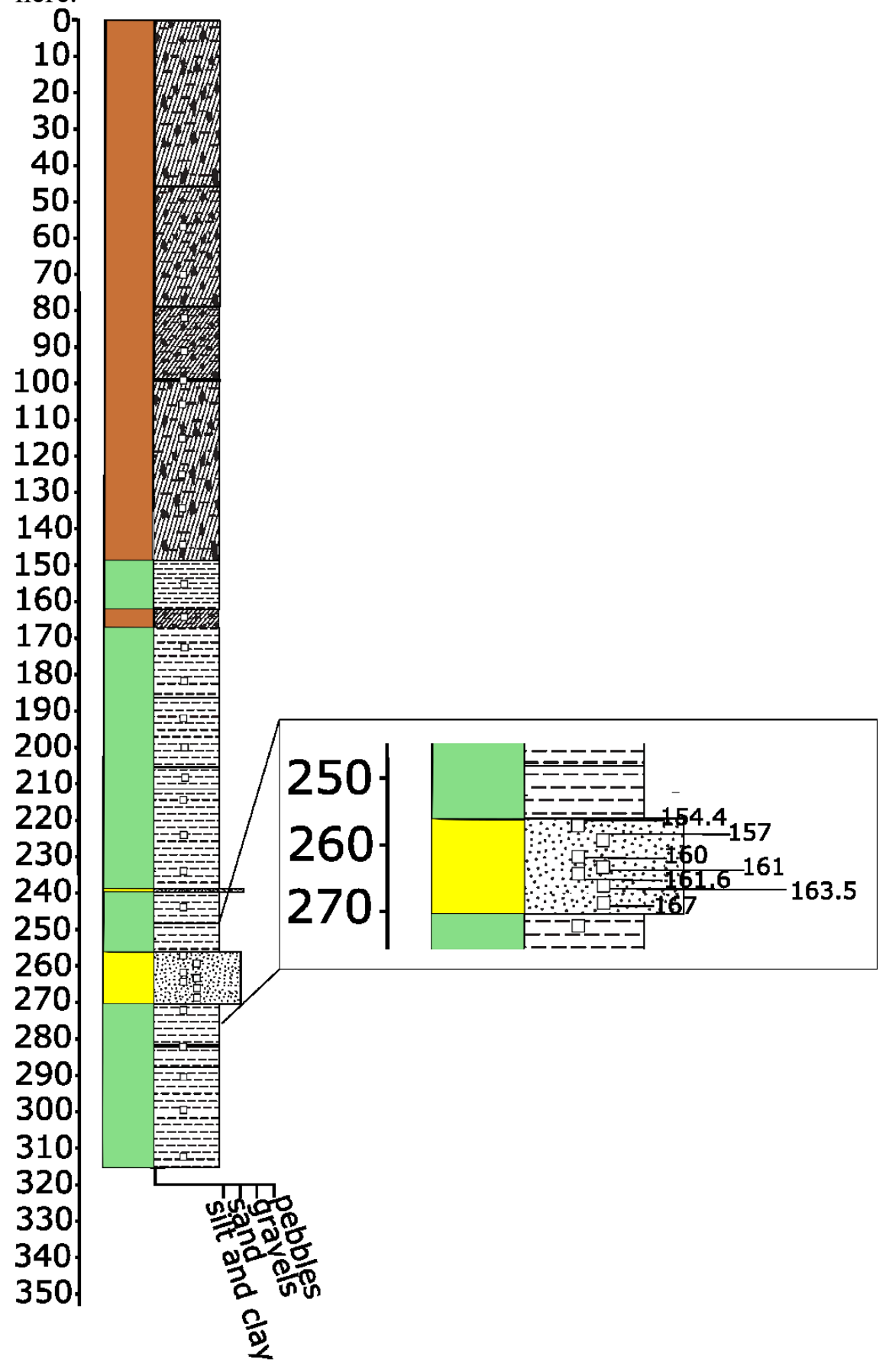


Figure 8g. Flinn diagram of samples from sand-sheet SHb1 in cores VCS2 and VCS6 plotted based on L and F parameters calculated in Anisoft. Y-axis is labeled L for lineation $\left(\mathrm{K}_{\max } / \mathrm{K}_{\mathrm{int}}\right)$ and $\mathrm{X}$-axis is labeled $\mathrm{F}$ for foliation $\left(\mathrm{K}_{\mathrm{int}} / \mathrm{K}_{\mathrm{min}}\right)$. Samples which plot above the orange line have measured prolate fabrics, suggesting a direction of flow is recorded, and samples below the line are measured as oblate fabrics, meaning they have less well defined $\mathrm{K}_{\text {int }}$ and $\mathrm{K}_{\text {min }}$ susceptibility axes.

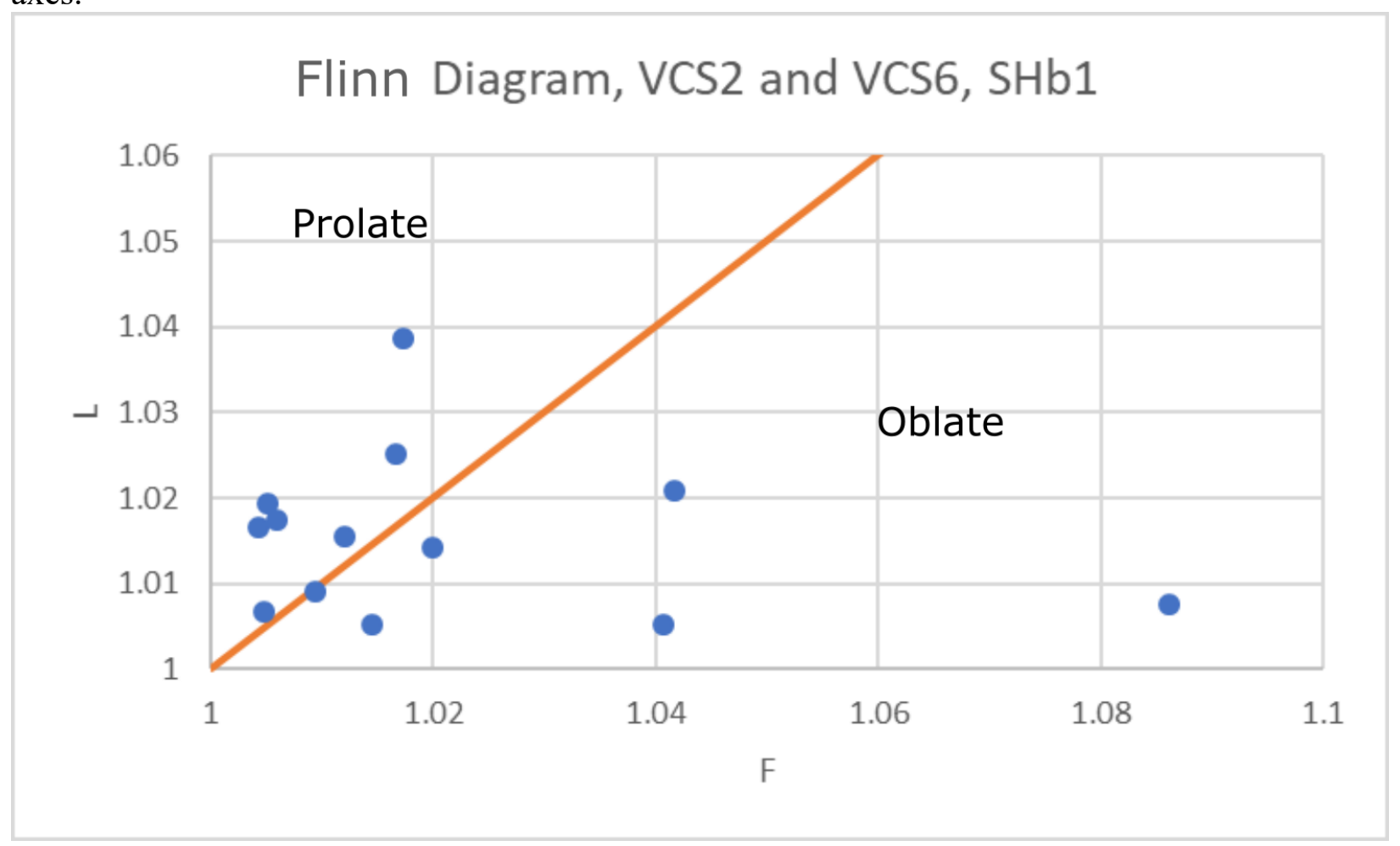


Figure 8h. Equal area stereonet northern-hemisphere projections of AMS results from SHb1, organized by depth within sand-sheet SHb1. Samples from the base of sand-sheet SHb1 reference depths: VCS2: $168.5 \mathrm{~cm}, 172.5 \mathrm{~cm}, 174 \mathrm{~cm}, \mathrm{VCS} 6: 167 \mathrm{~cm}, 168.8$. Middle referenced depths: VCS2: $163.5 \mathrm{~cm}, 166 \mathrm{~cm}$. Top reference depths: VCS2: $160.6 \mathrm{~cm}$, VCS6: $154.4 \mathrm{n}, 157 \mathrm{~s}$, 160n, 161.8n, 161s. D. Combined equal area stereonet projections of all samples from VCS2 and VCS6 for SHb1. E. Combined equal area stereonet projections with only $\mathrm{K}_{\text {maxs }}$ plotted.
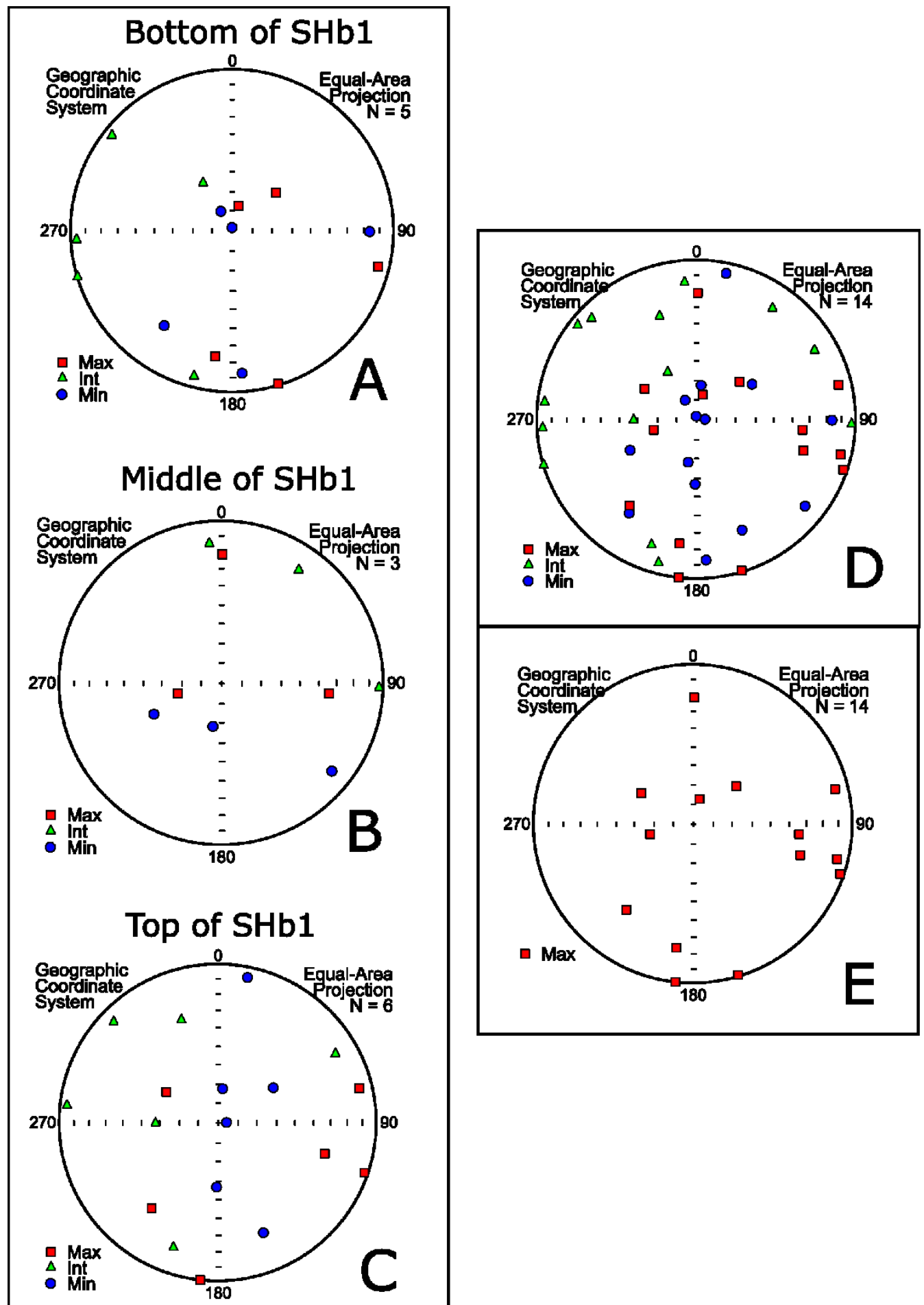
Figure 9a. Mass normalized bulk susceptibility results plotted with mass normalized corrected saturation magnetization (Ms) on secondary axis for Ship Harbor. Left is VCS2, right is VCS6. Top $\mathrm{x}$-axis is volume normalized bulk susceptibility, secondary $\mathrm{x}$-axis at bottom is mass normalized magentization. Both cores have an increase in susceptibility and magnetization within the (yellow) sand bed to $\sim .2 \mathrm{Kg} / \mathrm{m}^{3}$.
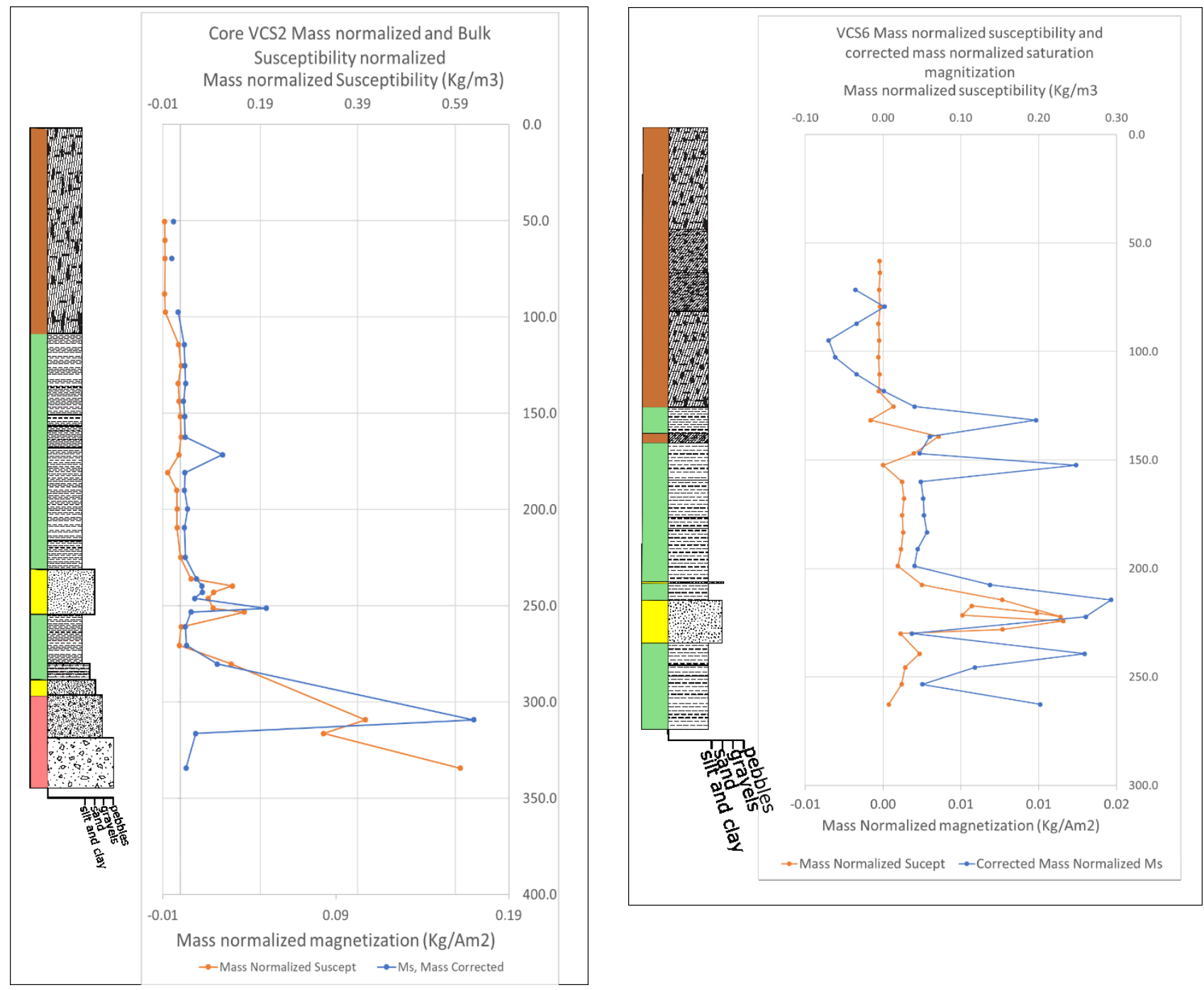
Figure 9b. Mass normalized bulk susceptibility results plotted with mass normalized saturation magnetization (Ms) on secondary axis for Eliza Island Left: core VCEI2, Right: core VCEI3. Both have an increase in susceptibility and magnetization within the (yellow) sand bed, identified as EIb2.

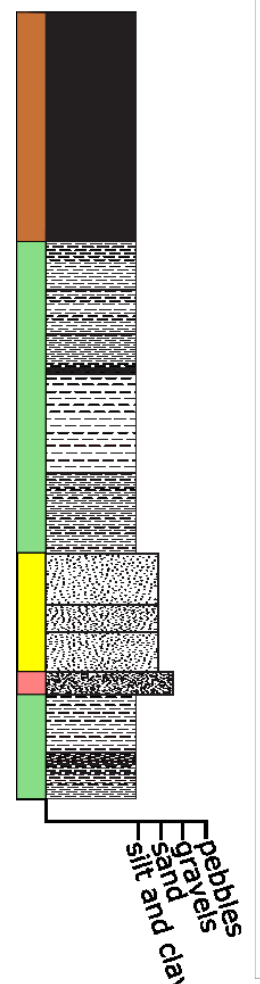

$-0.005$

0.005

0.015

0.025

Mass normalized corrected magnetization $\mathrm{Kg} / \mathrm{Am} 2$ - Mass Normalized Bulk Susceptibility $\rightarrow$ Mass Normalized Ms

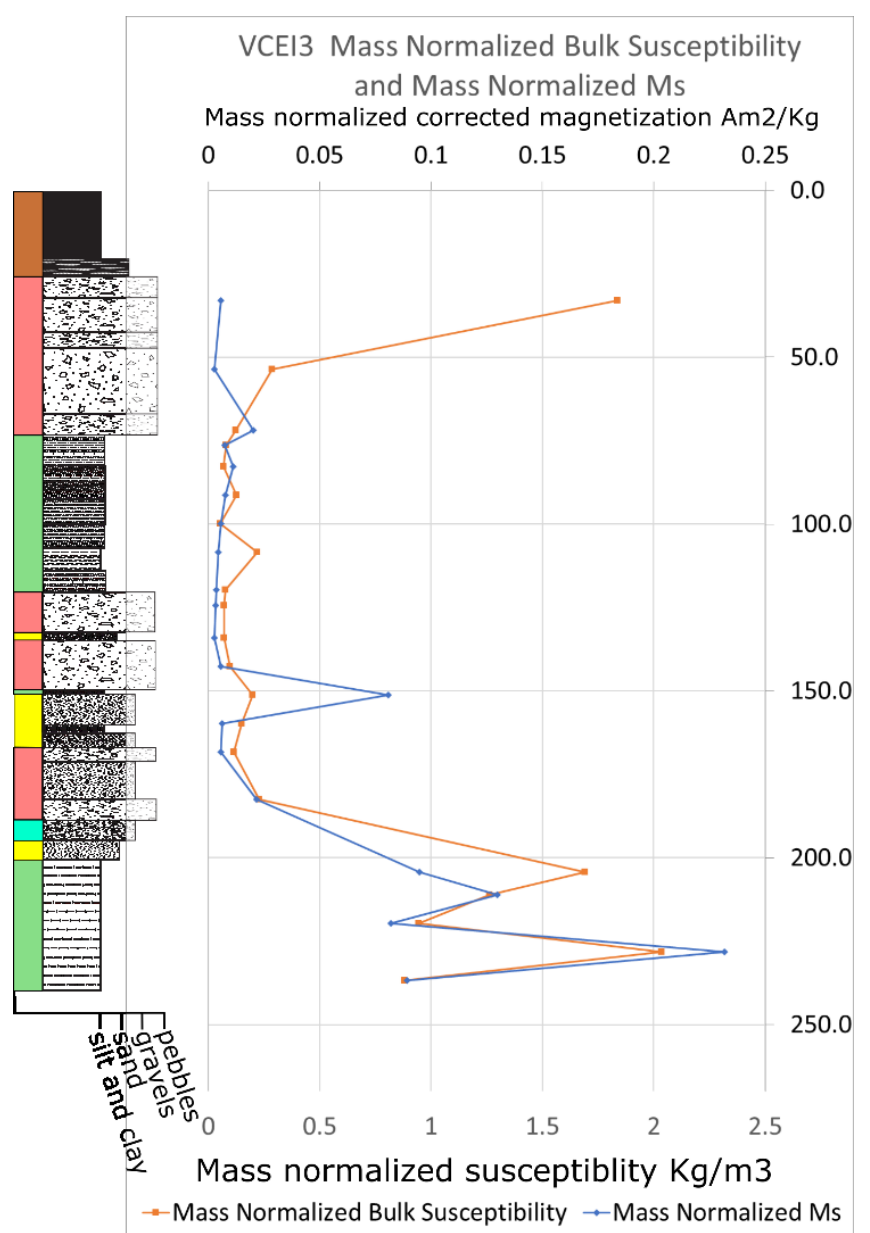


Figure 10. Figure of typical hysteresis for Ship Harbor and Eliza Island. Left is uncorrected, and right has a correction for the paramagnetic signal applied. A correction is only applied when saturation is present in the IRM data.
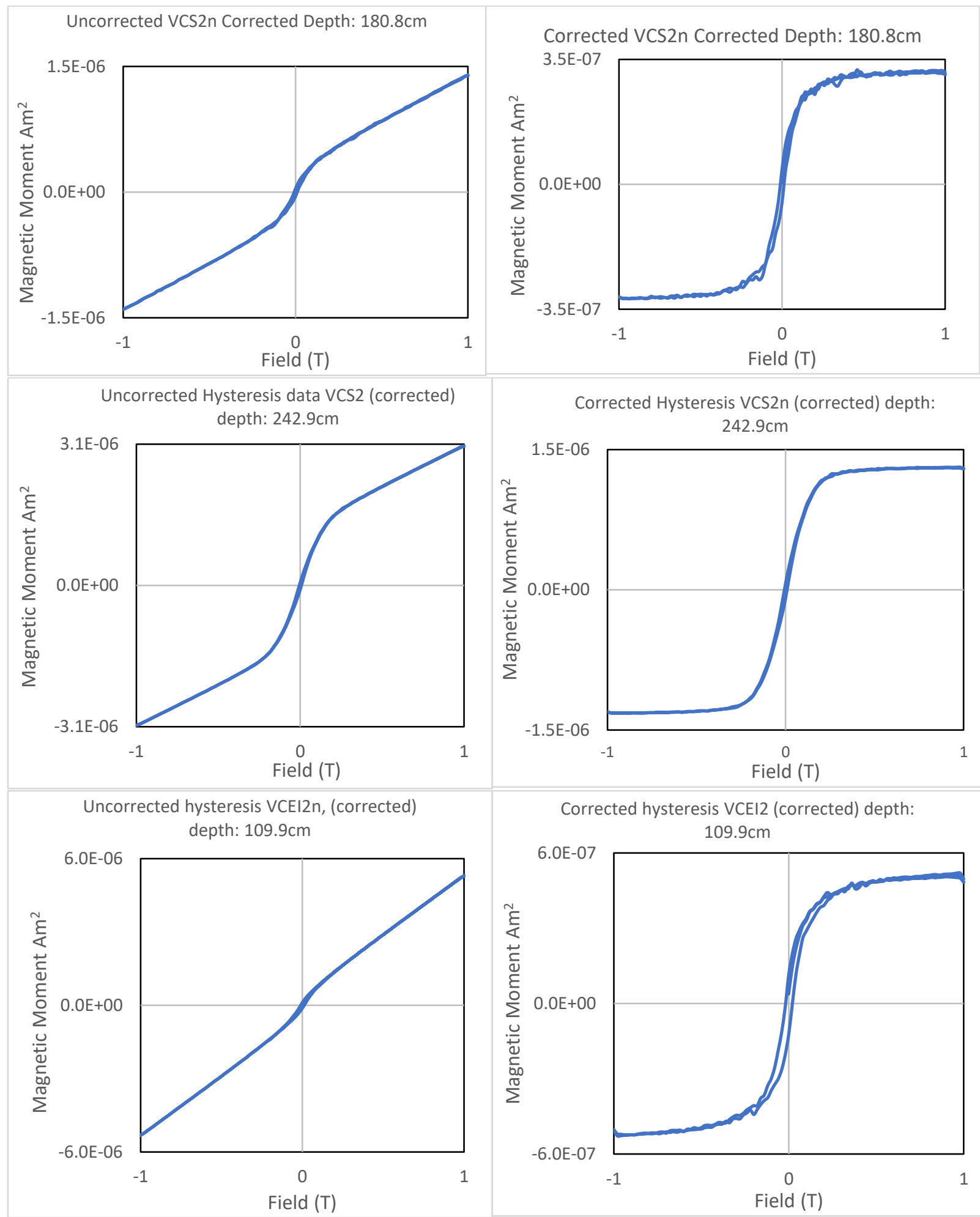

Corrected hysteresis VCEI2 (corrected) depth:

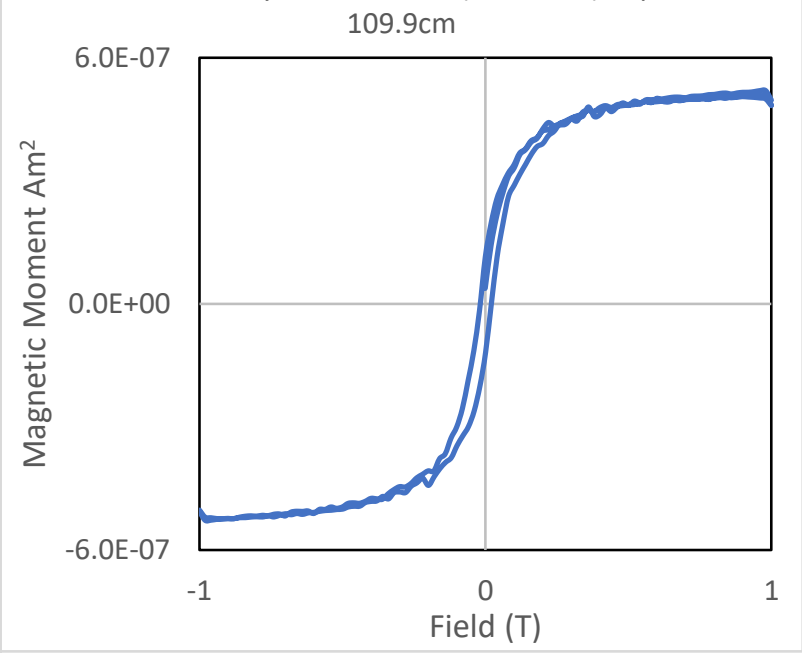



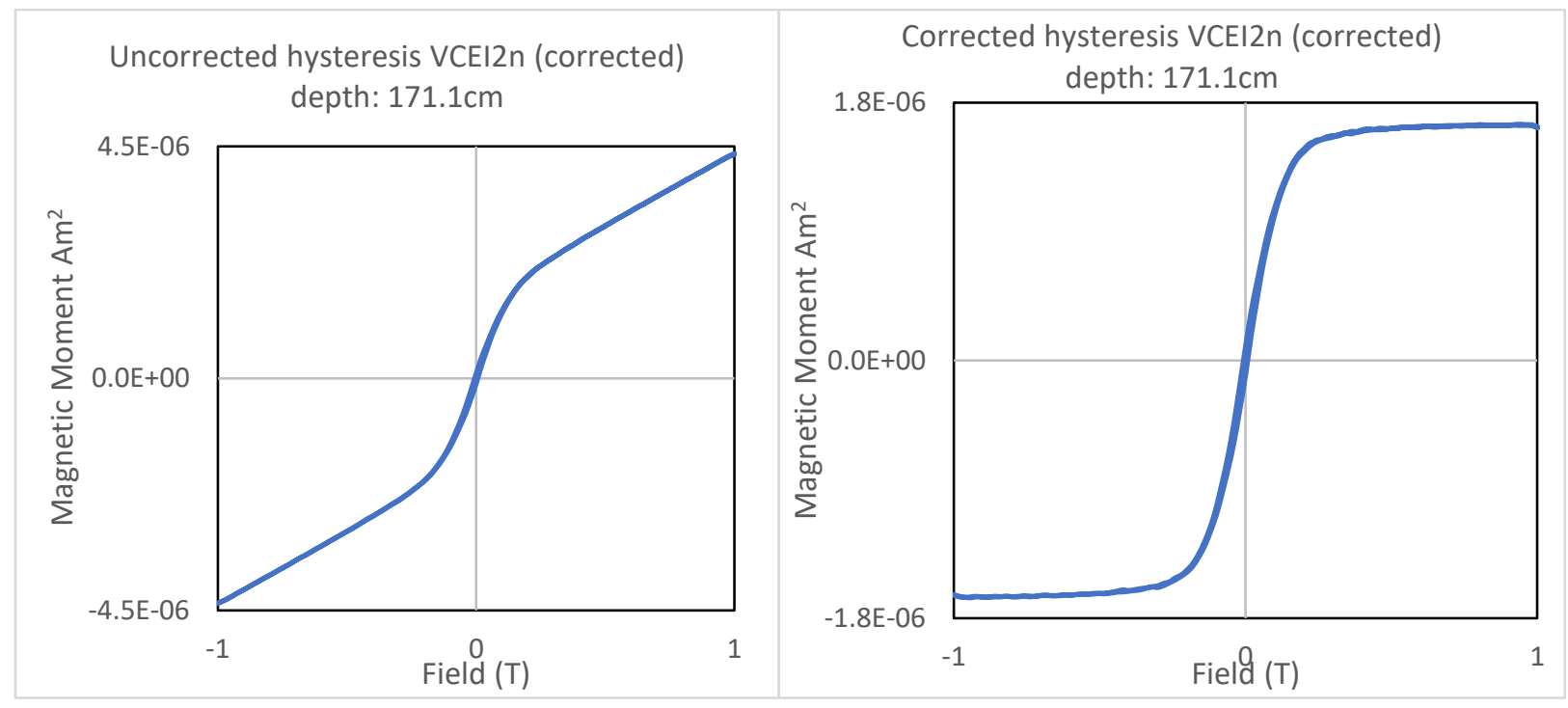

Figure 11. IRM results. IRM Data Examples from Ship Harbor and Eliza Island
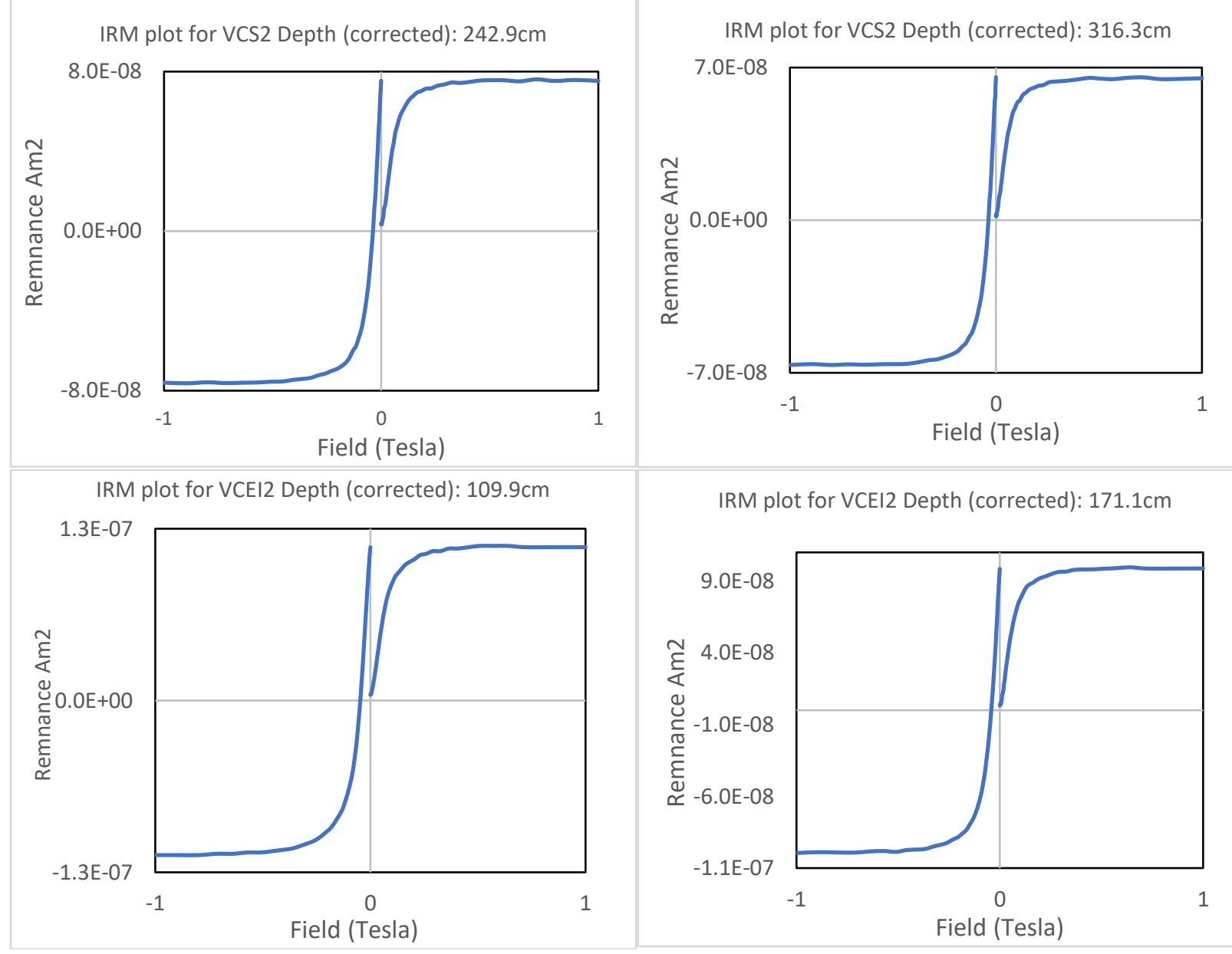
Figure 12. Typical temperature vs susceptibility curves. Y-axis is normalized bulk-
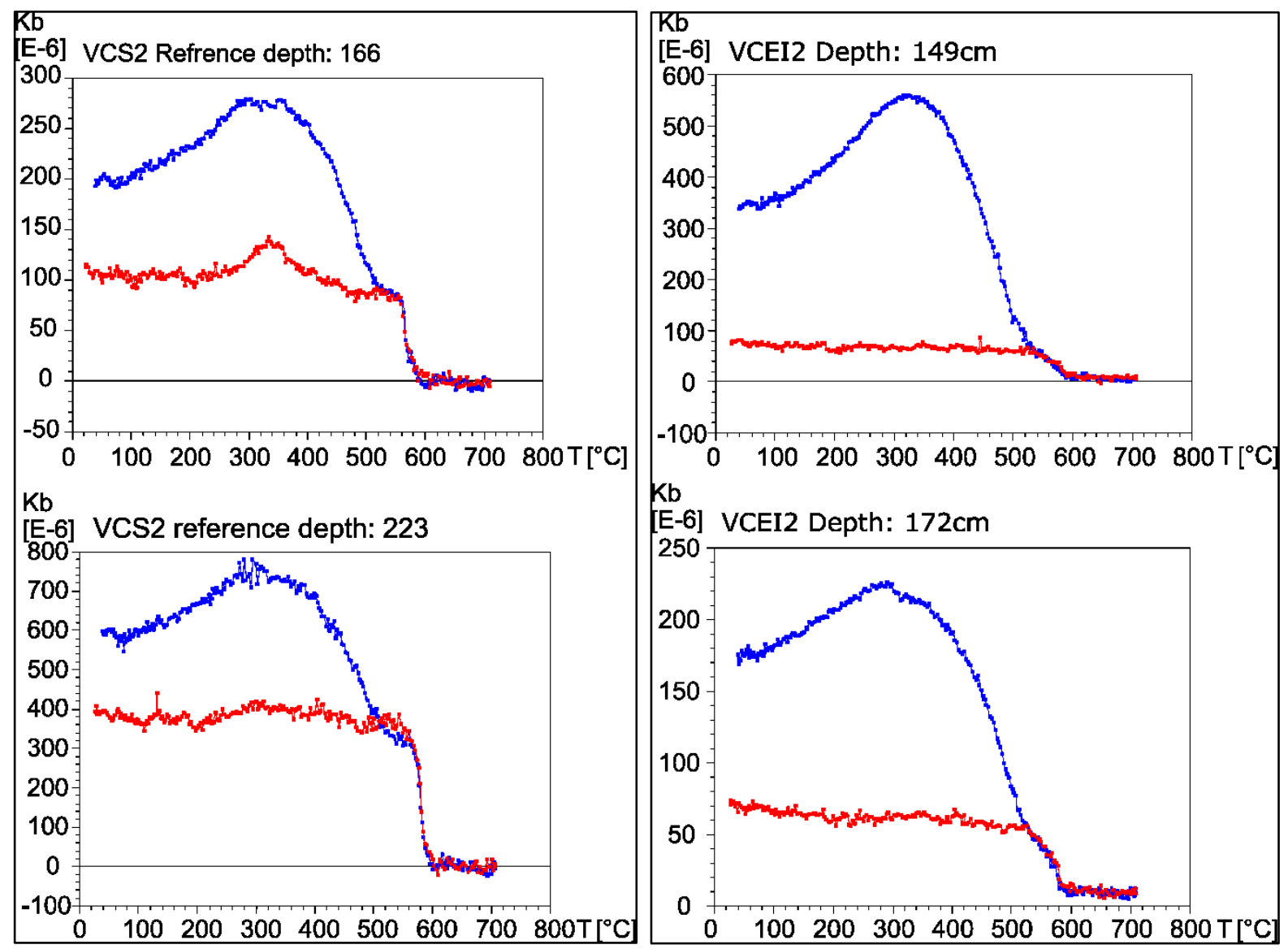
Figure 13. Graphs of typical low temperature vs susceptibility curve for VCS2 and VCEI2, corrected for the holder and room temperature bulk susceptibility, labeled with corrected depths in cores. Y-axis displays bulk corrected susceptibility, and $\mathrm{x}$-axis displays temperature in Celsius.
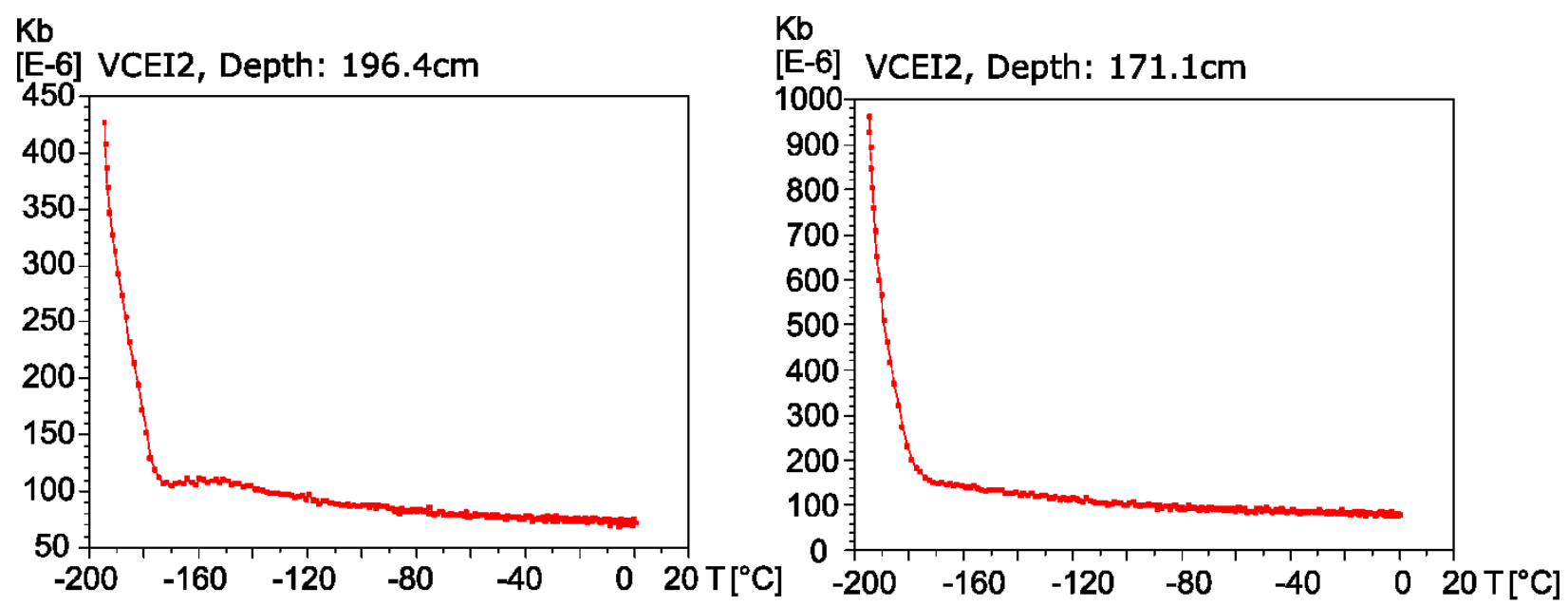

\section{$\mathrm{Kb}$}

[E-6] VCS2, Depth: $274.0 \mathrm{~cm}$

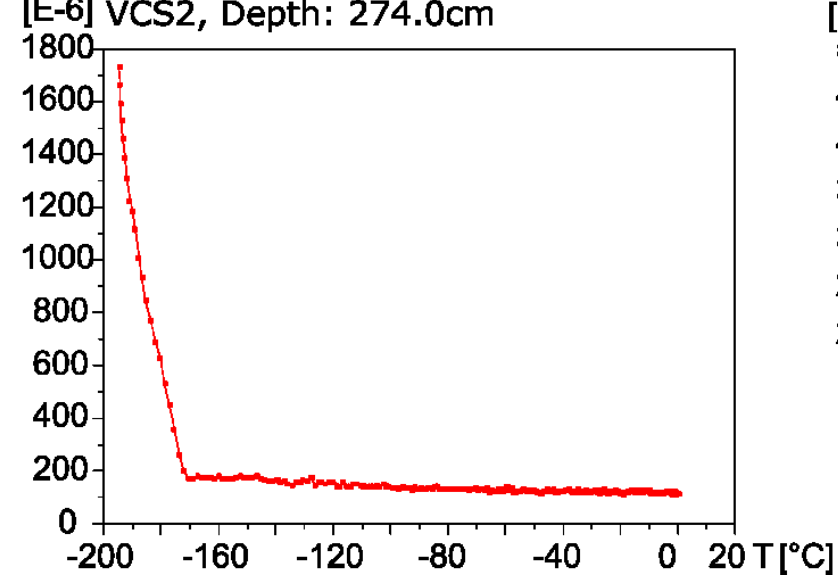

$\mathrm{Kb}$

[E-6] VCS2, Depth: $236.0 \mathrm{~cm}$

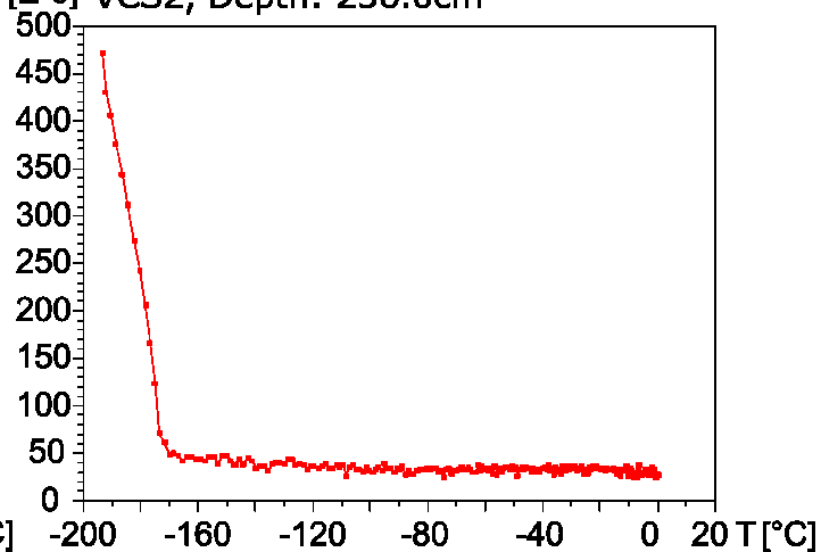


Figure 14. PSV Zijderveld examples from core VCS2 and VCEI2. Zijdervled diagrams are two dimensional displays of declination and inclination vector measurements made during the demagnetization process. The natural remnant magnetization is the point furthest from the origin, and as the sample is demagnetized the vector should continue towards the origin of the plot. Green dots are inclination projected in the X-Z plane, and blue dots are declination in the X-Y plane.

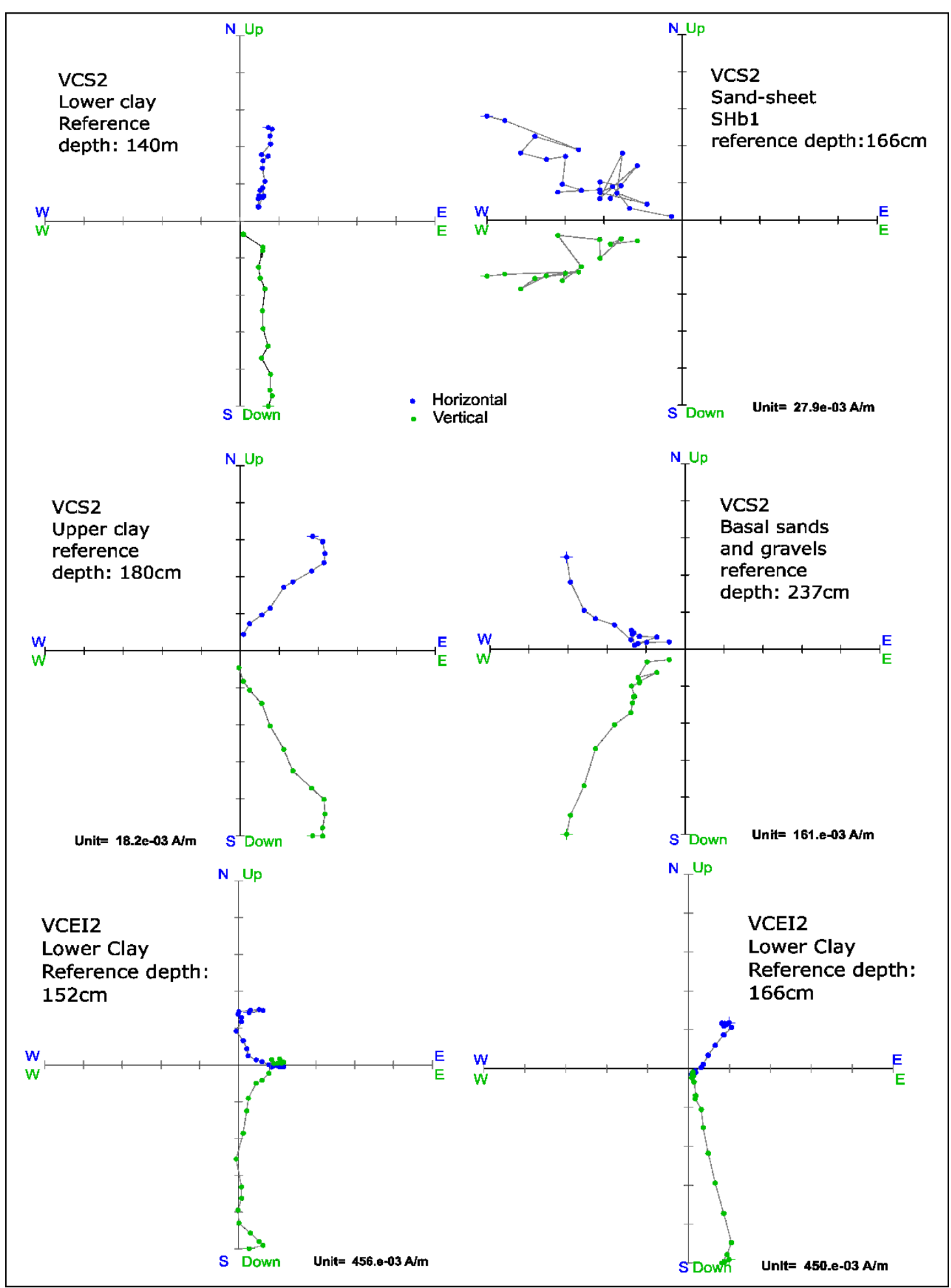


Figure 15. Figure of Ship Harbor PSV curves and plotted samples. Calculated delta-I and deltaD (Appendix 4) in pink displaying a 95\% confidence envelope, while the calculated (Appendix 4) regional reference curve is blue, is calculated based on the high-resolution PSV dates reported in Hagstrum et al. (2004) and the latitude and longitude of each field site. X-axis error bars based on MAD from calculated component, y-axis displays age errors determined by an OxCal sequence model. Inclinations are shallow (lower than expected) likely due to compaction during vibracoring.
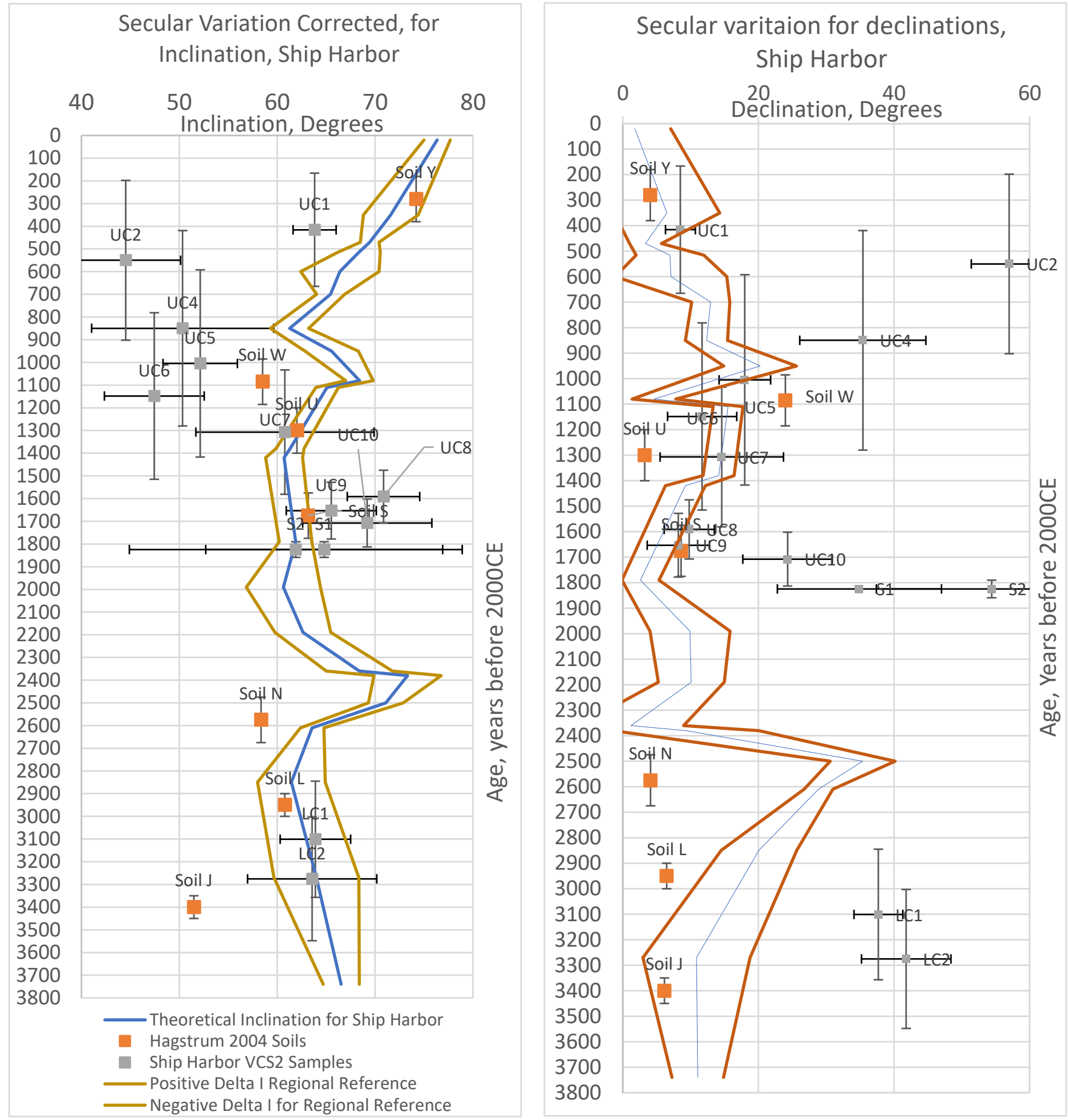
Figure 16. Eliza Island PSV curves and plotted samples. Calculated delta-I and delta-D (Appendix 4) in tan displaying a 95\% confidence envelope, while the calculated (Appendix 4) regional reference curve is blue, is calculated based on the high-resolution PSV dates reported in Hagstrum et al. (2004) and the latitutde and longitude of each field site. X-axis error bars based on MAD from calculated component, y-axis displays age errors determined by an $\mathrm{OxCal}$ sequence model. Inclinations are shallow (lower than expected) likely due to compaction during vibracoring.

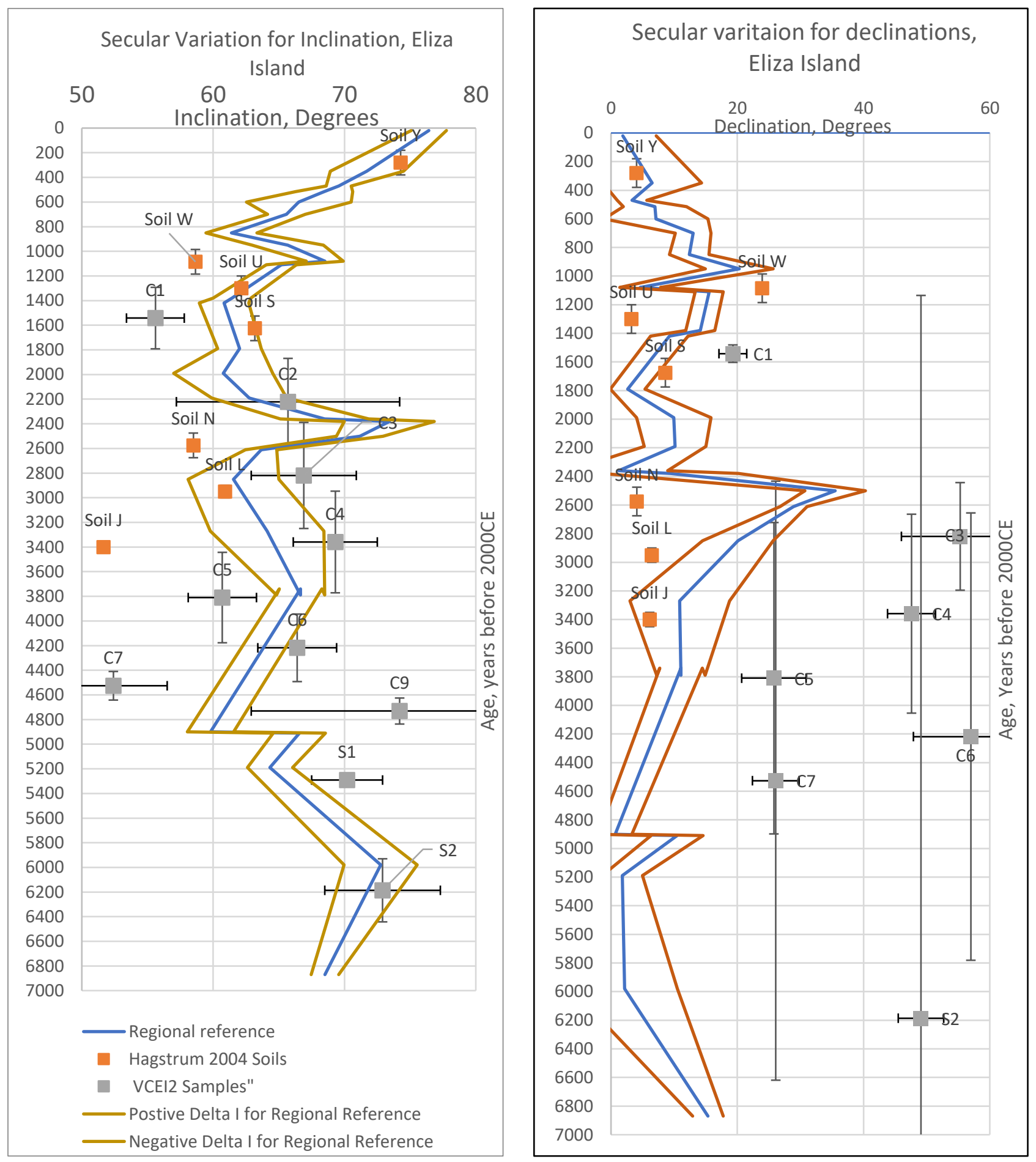


Figure 17. Model results from GeoCLAW, L1 scenario (Witter et al. 2013). First figure is of the northern Puget Sound showing how multiple pulses of waves move through the area in the five hours after initial wave propagation, with A-F representing different times during tsunami propagation. Field sites shown in next images are in boxes here, with tide gauges labeled. Tide gauge 1000 is used to predict wave height at Ship Harbor, and tide gauges 1001 and 1002 are used for Eliza Island. Latitude is displayed on the y-axis and longitude is displayed on the $\mathrm{x}$-axis. Image $\mathrm{A}$ is a course resolution, while images B-F are higher resolution, showing more features of the coast. The gauge on the right shows wave height, with a maximum of one meter displayed.
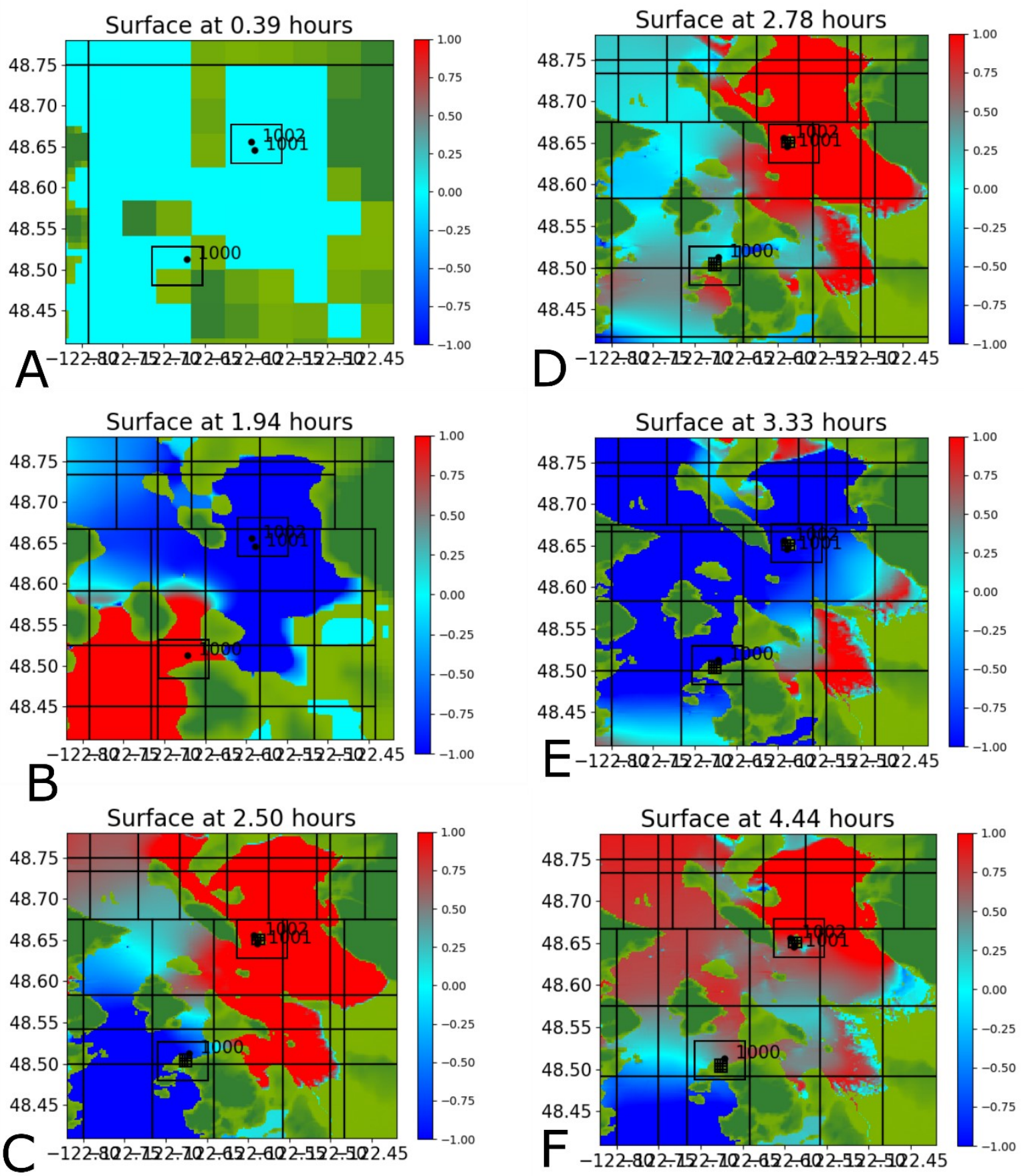
Figure 17. Continued from previous page. Ship Harbor L1 scenario. Tide gauge on top right displays the wave height just prior to landfall, and is labeled with corrospoding field site predictions. Initial wave (B) has a maximum amplitude of $4.5 \mathrm{~m}$ and inundates the clear extent of the marsh.
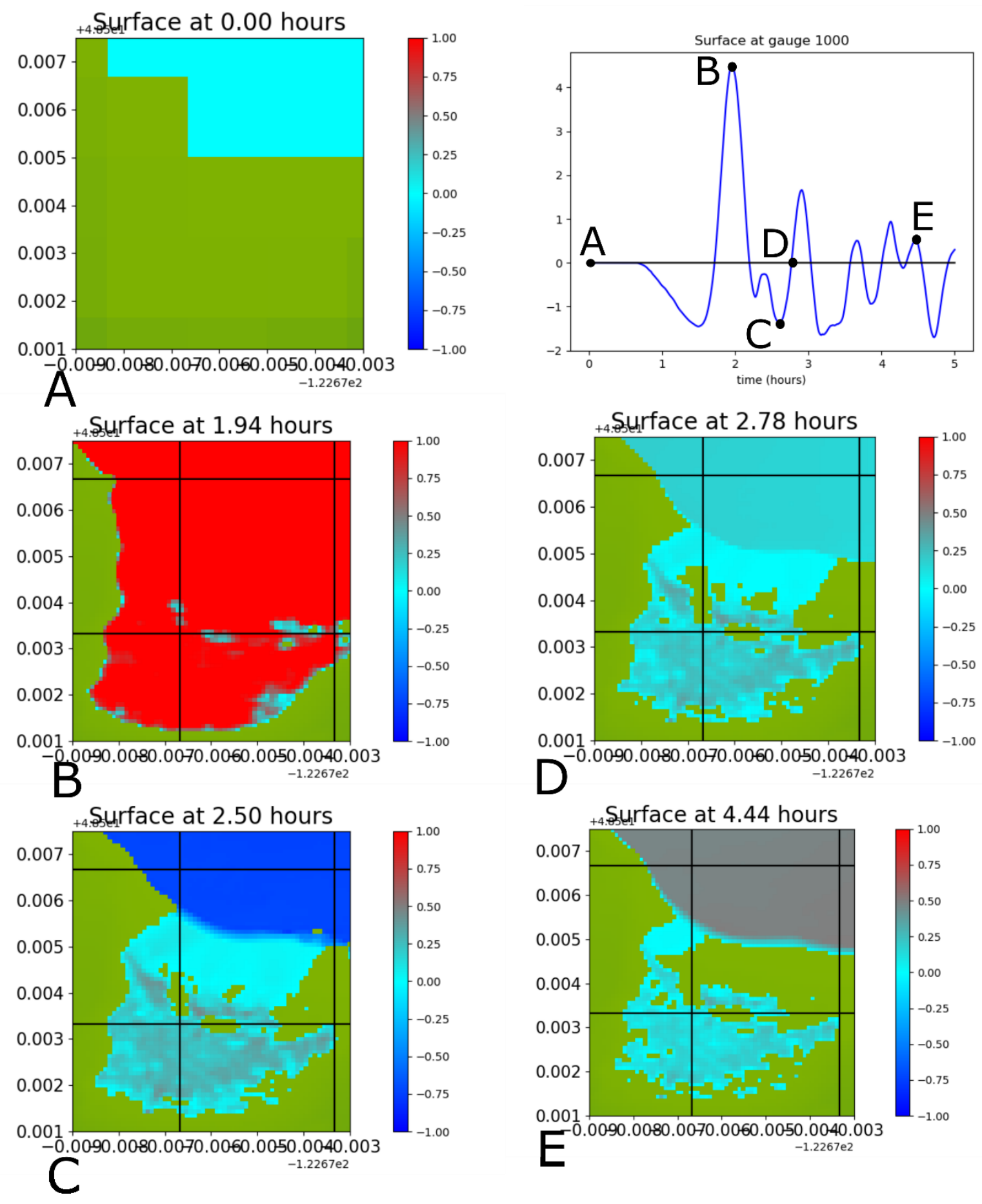
Figure 17. Continued from previous page, Eliza Island field site

\section{Eliza Island L1, mean sea level}
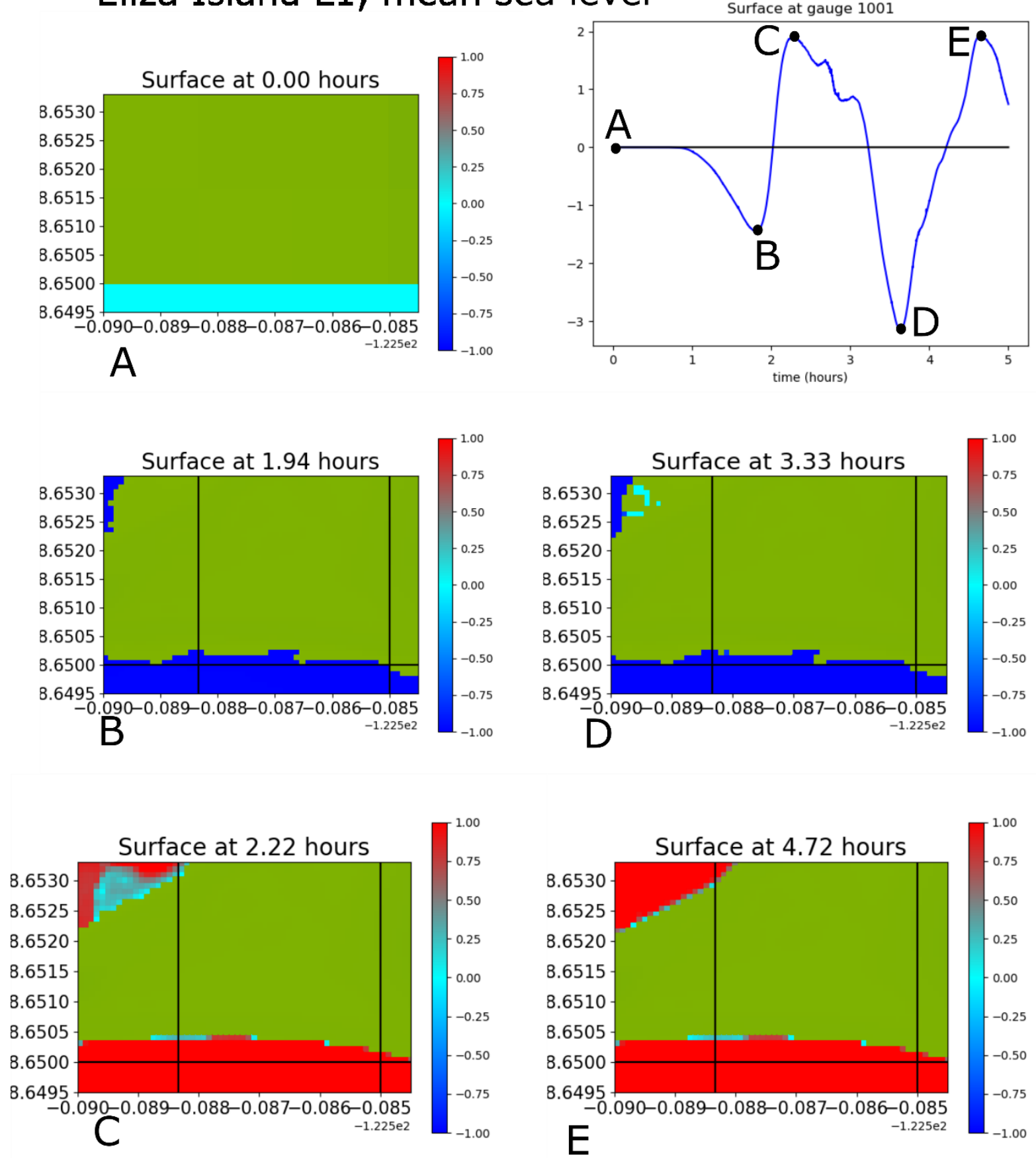
Figure 18. Model results scenario M1 (Witter et al. 2013). First figure is of Bellingham bay area, second is Ship Harbor, and third is Eliza Island.
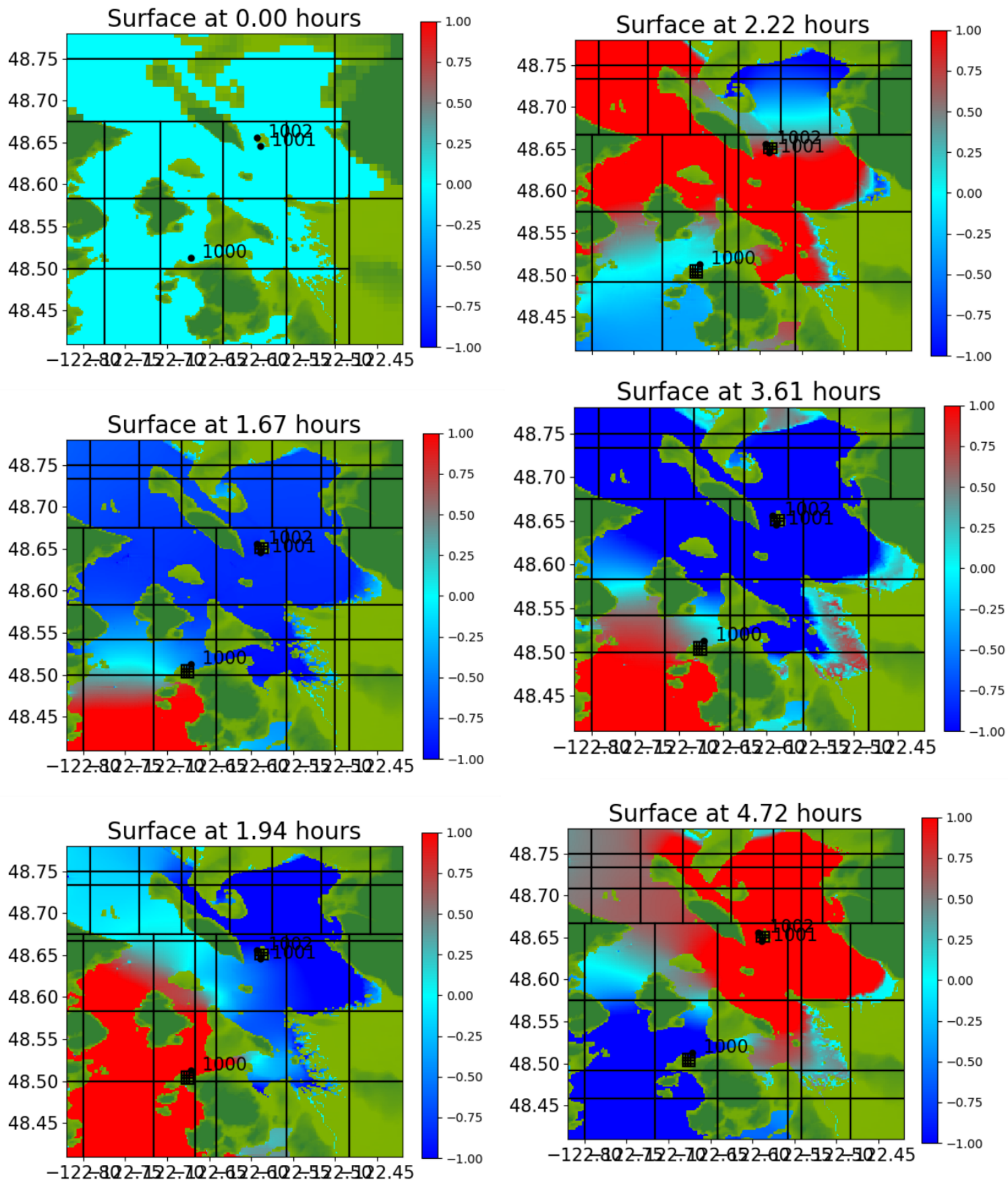
Figure 18. Continued from previous page

Ship Harbor, M1, mean sea level
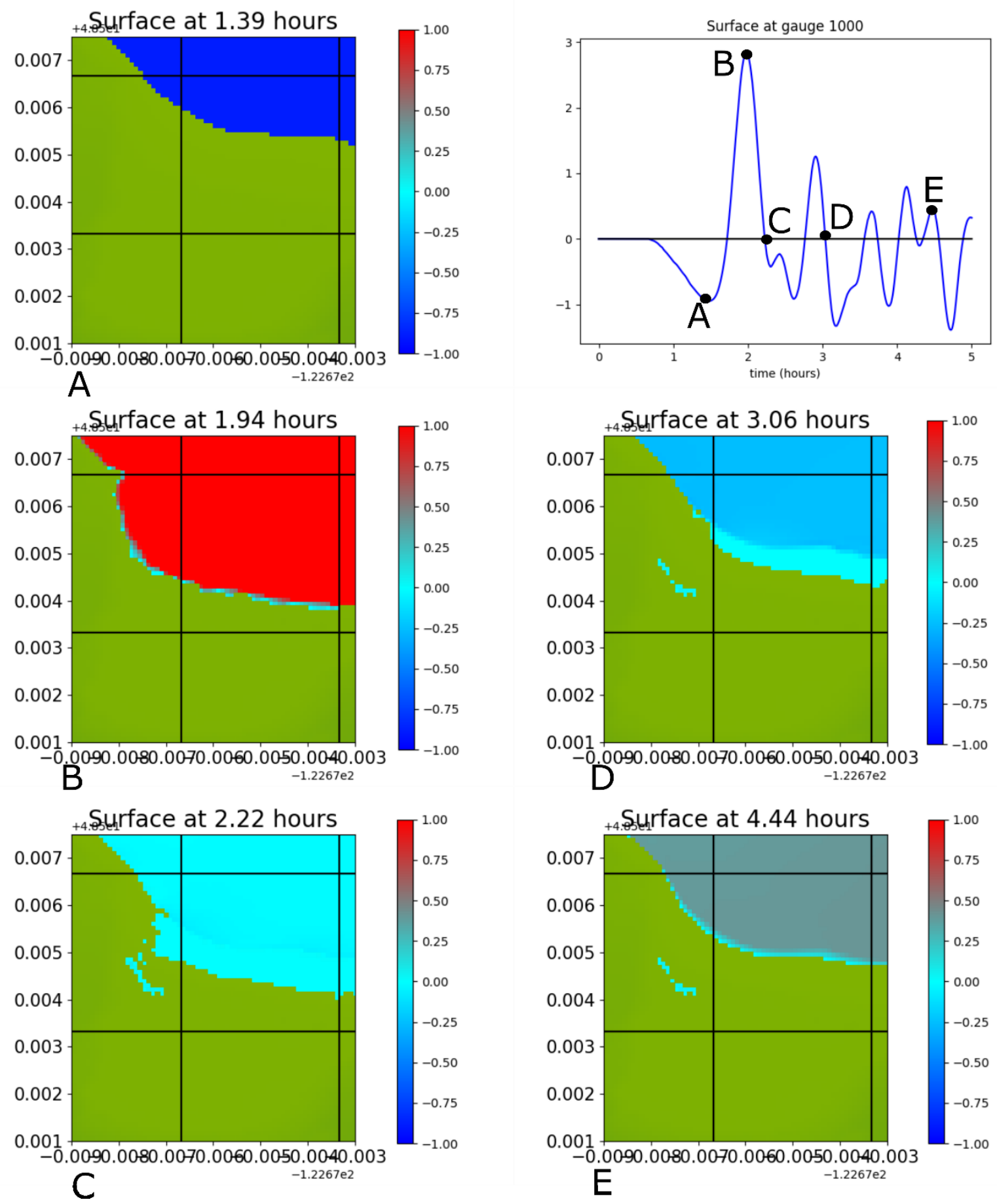
Figure 18. Continued from previous page

\section{Eliza Island, M1, mean sea level}
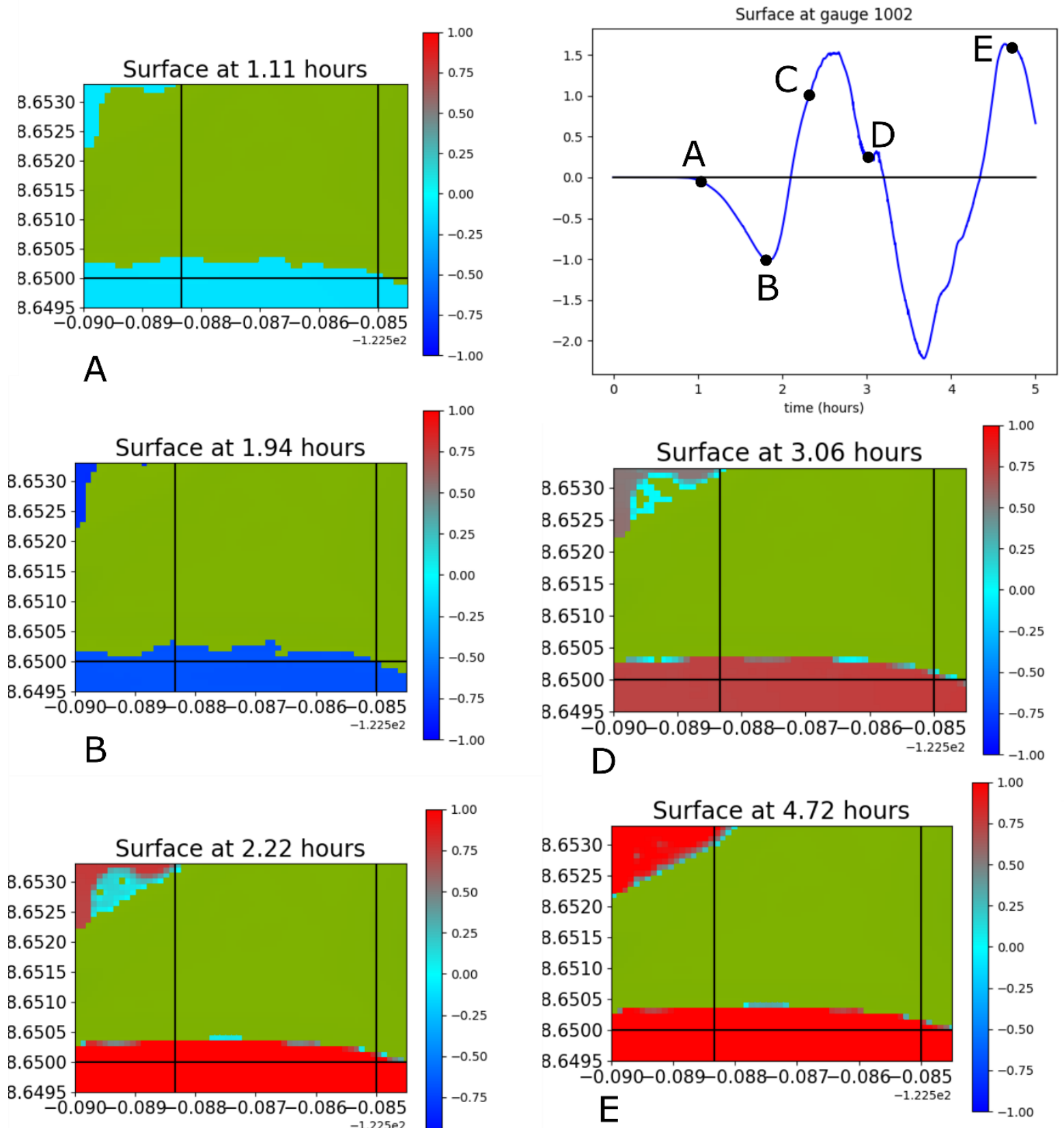
C 
Figure 19. M2 model results (Witter et al. (2013)) scenario. Location shown in figures 17 and 18.

\section{Ship Harbor, M2, mean sea level}
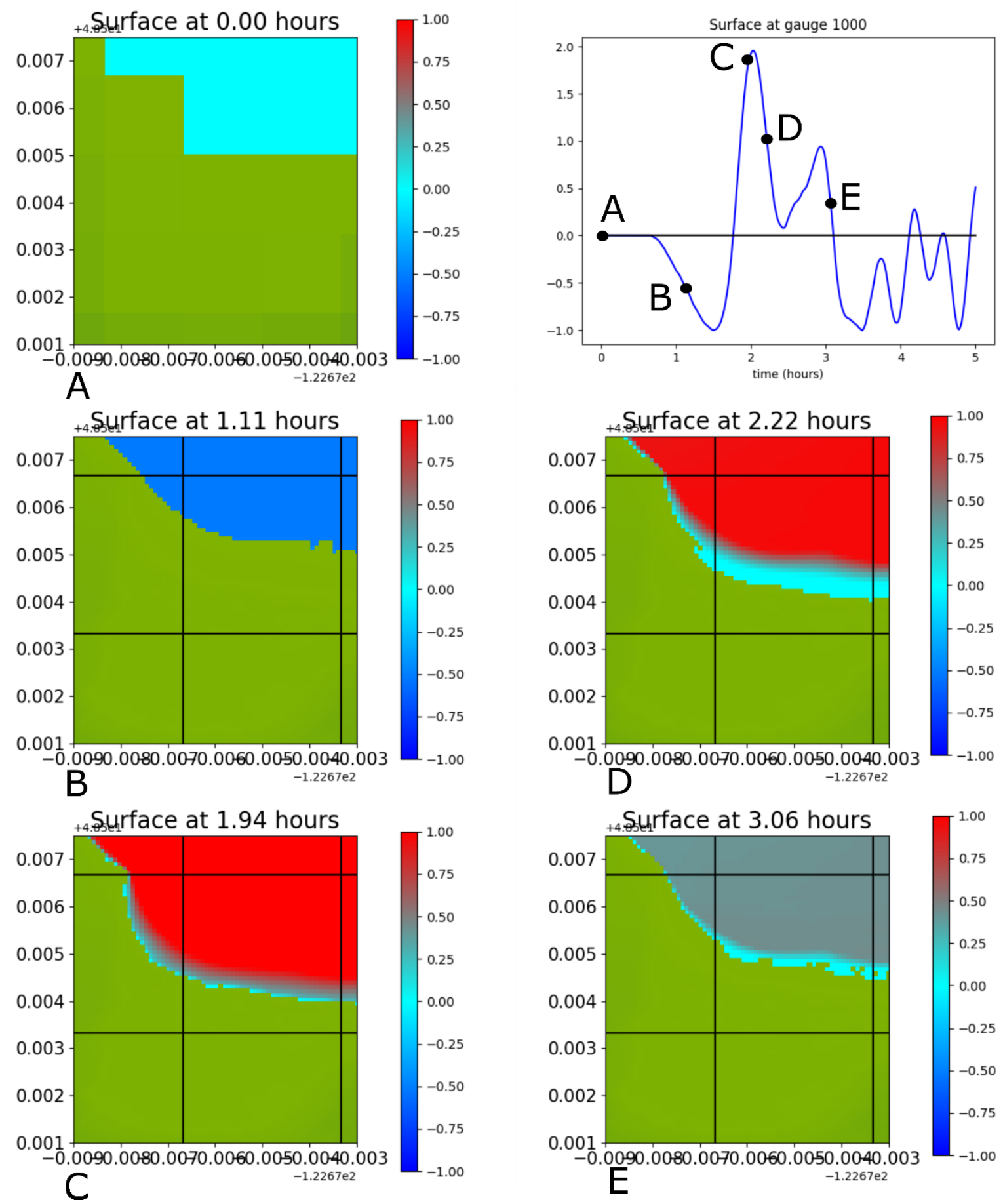
Figure 19. Continued from previous page

\section{Eliza Island, M2, mean sea level}
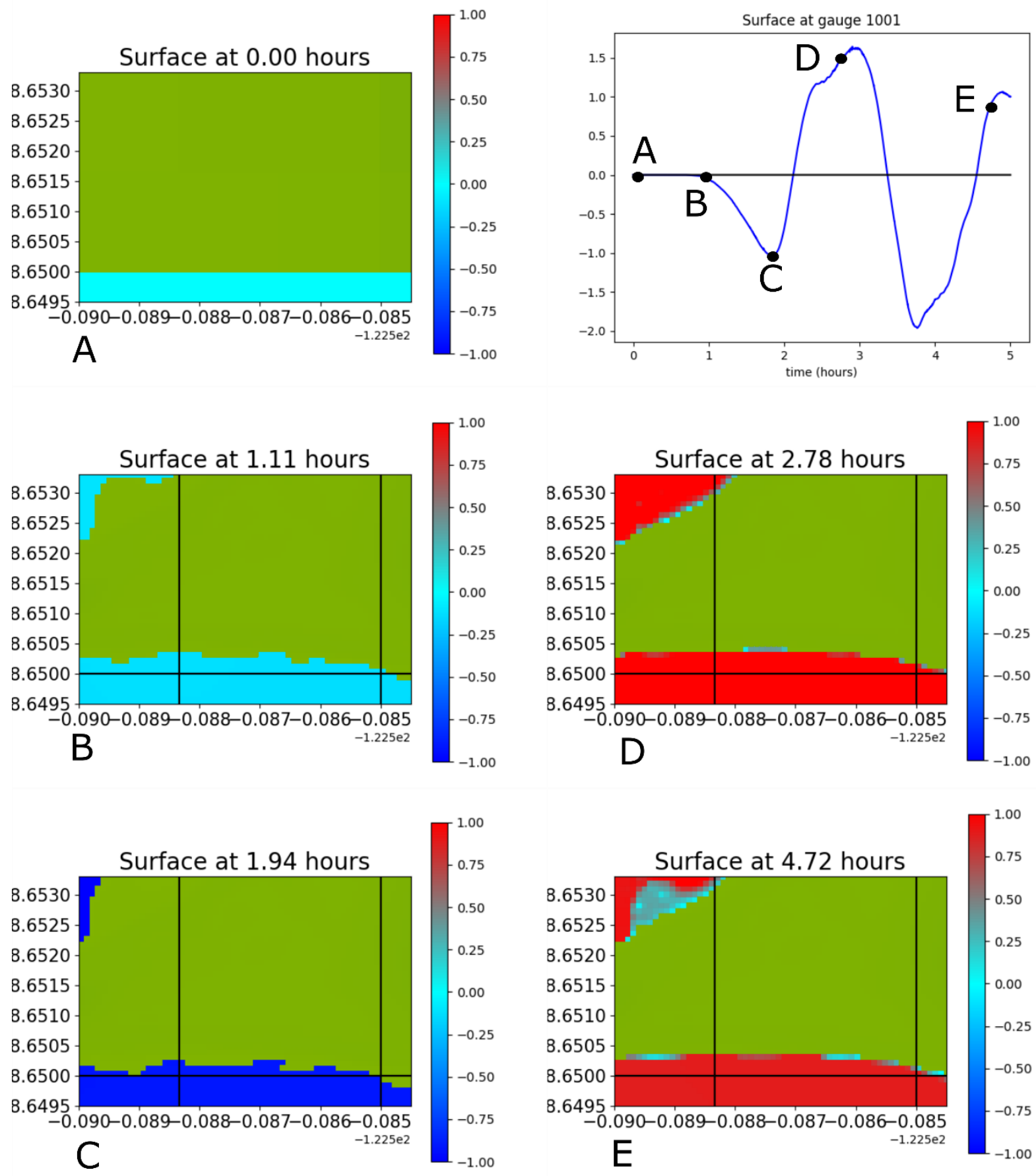
Figure 20. Model Results SM1 (Witter et al. 2013). First image of Ship Harbor, second is Eliza Island.

\section{Ship Harbor, SM1, mean sea level}
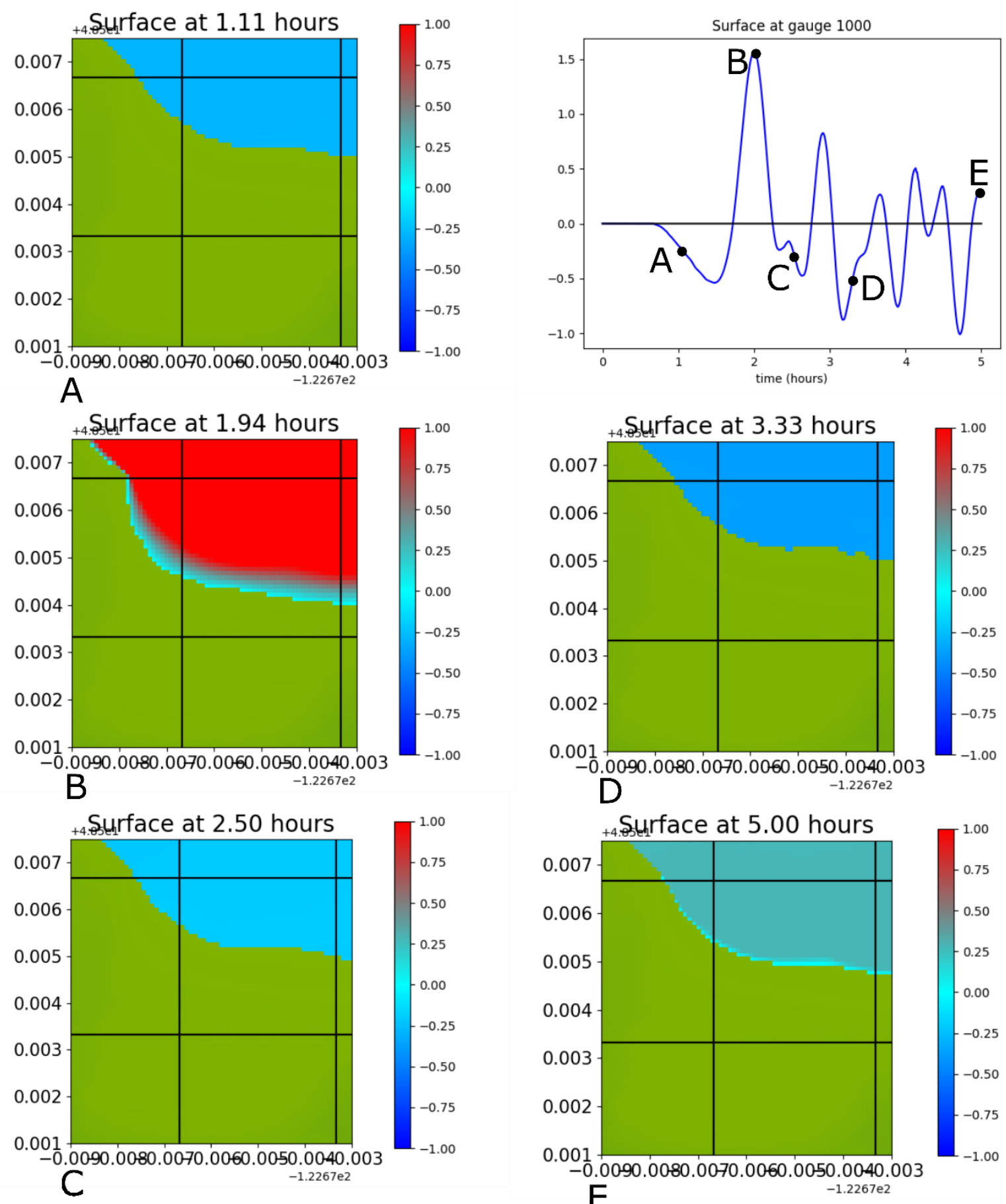
Figure 20. Continued from previous page

\section{Eliza Island, SM1, mean sea level}
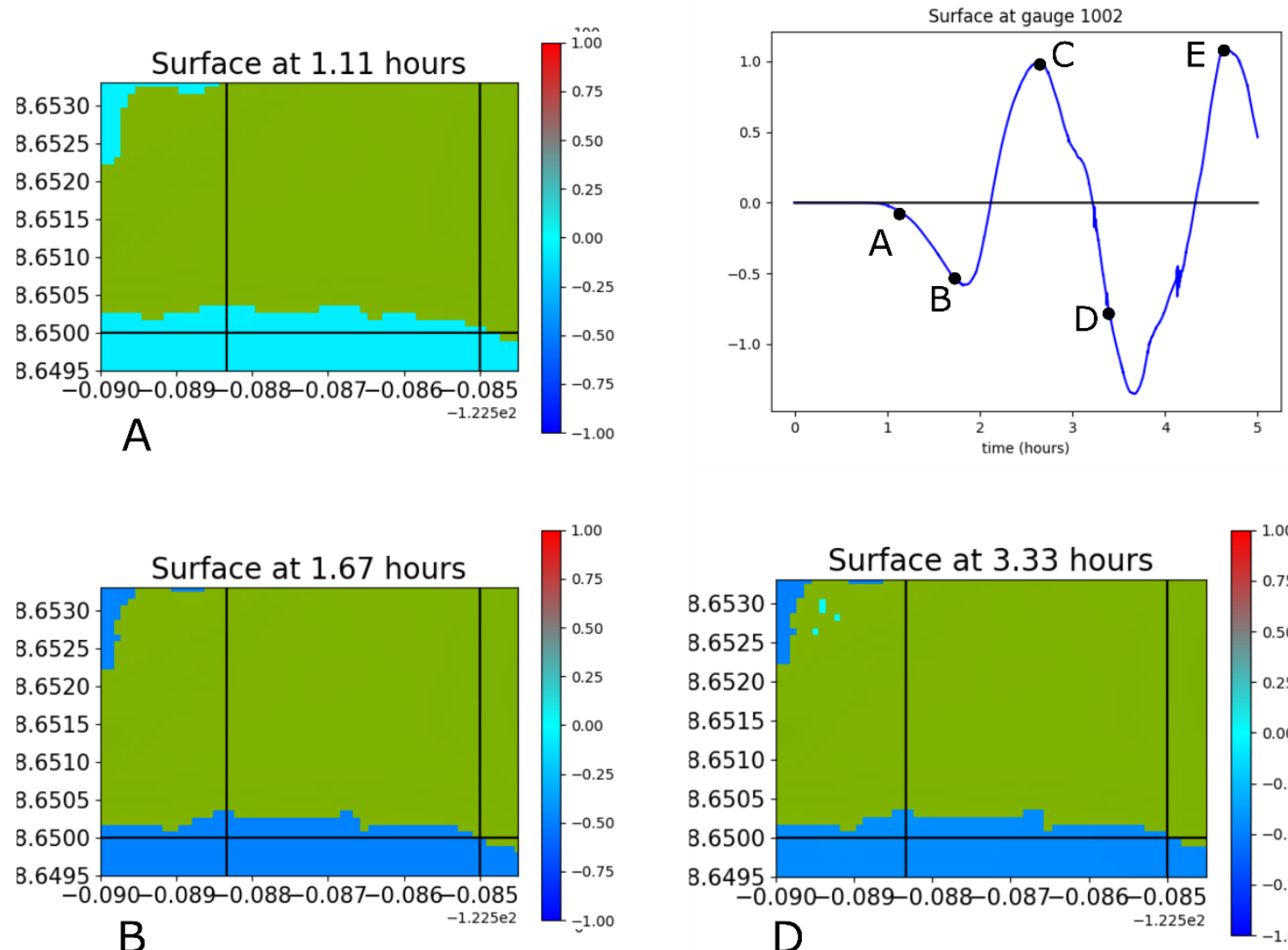

Eliza Island
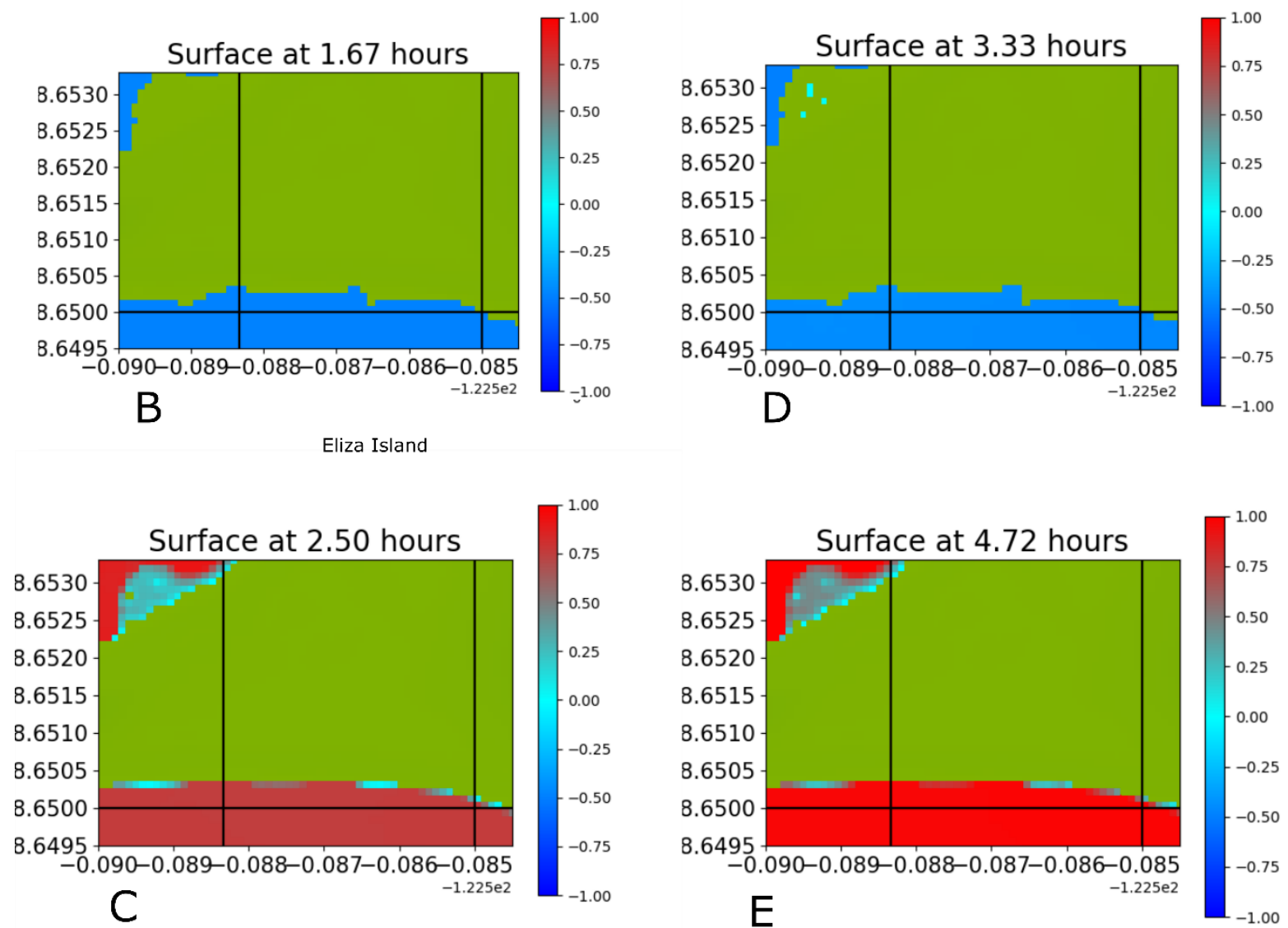
Figure 21. Model tide gauge results for the Seattle Fault Koshimura (2002) modeling parameters

\section{Seattle Fault Scenario}

\section{Ship Harbor}

Surface at gauge 1000

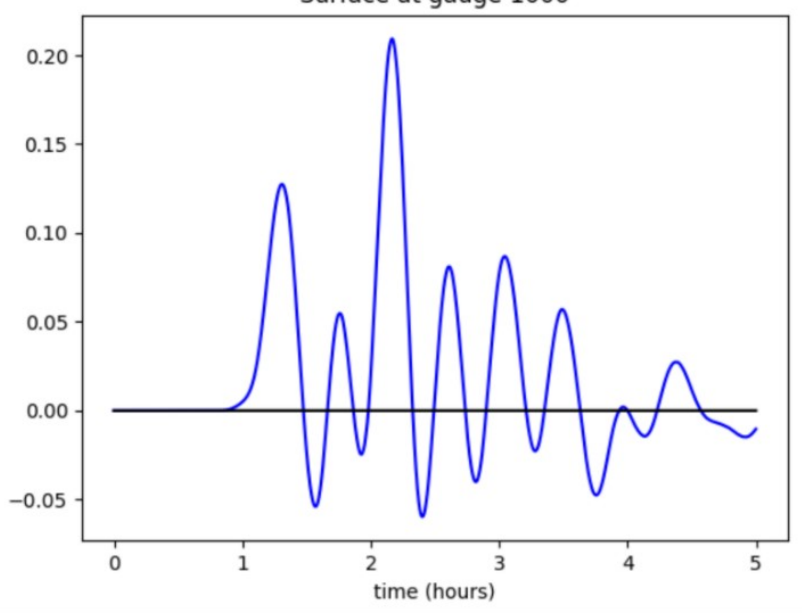

South of Eliza Island

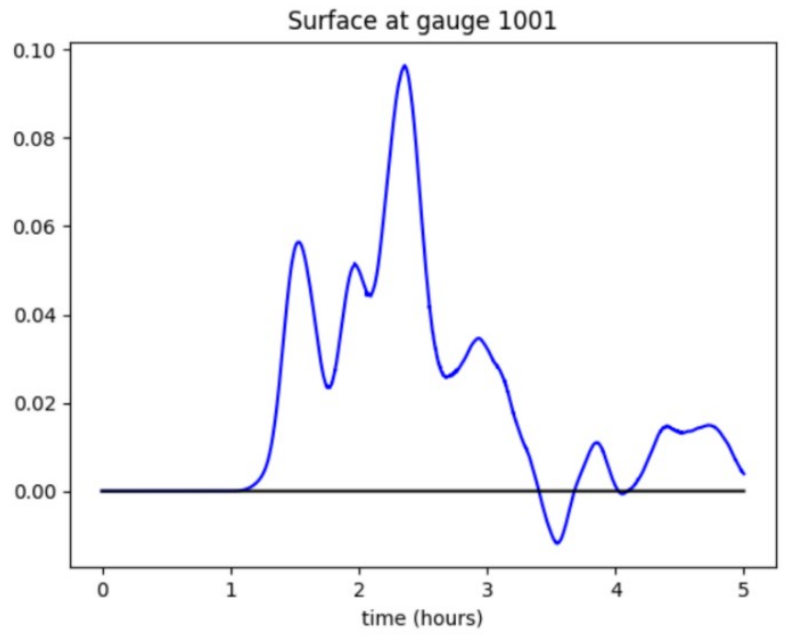

North Eliza Island

Surface at gauge 1002

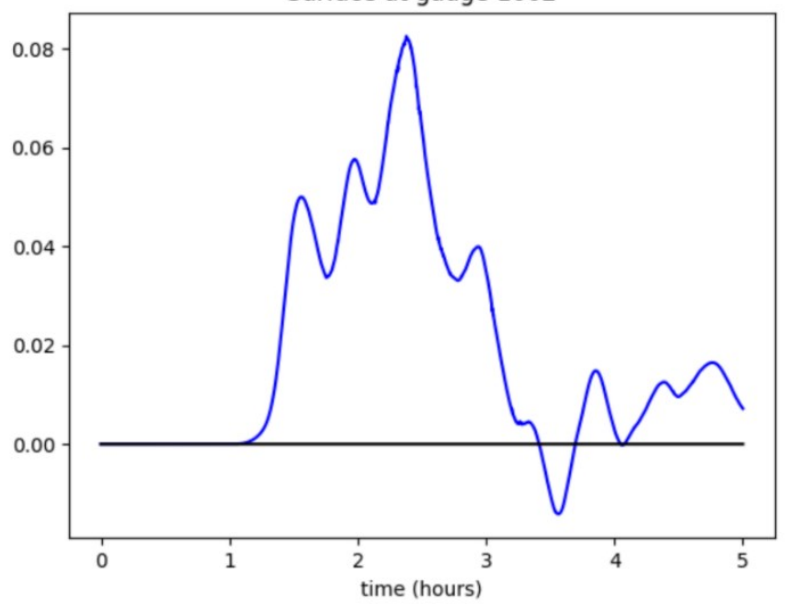


Figure 22. Model results L1 with -1m low tide
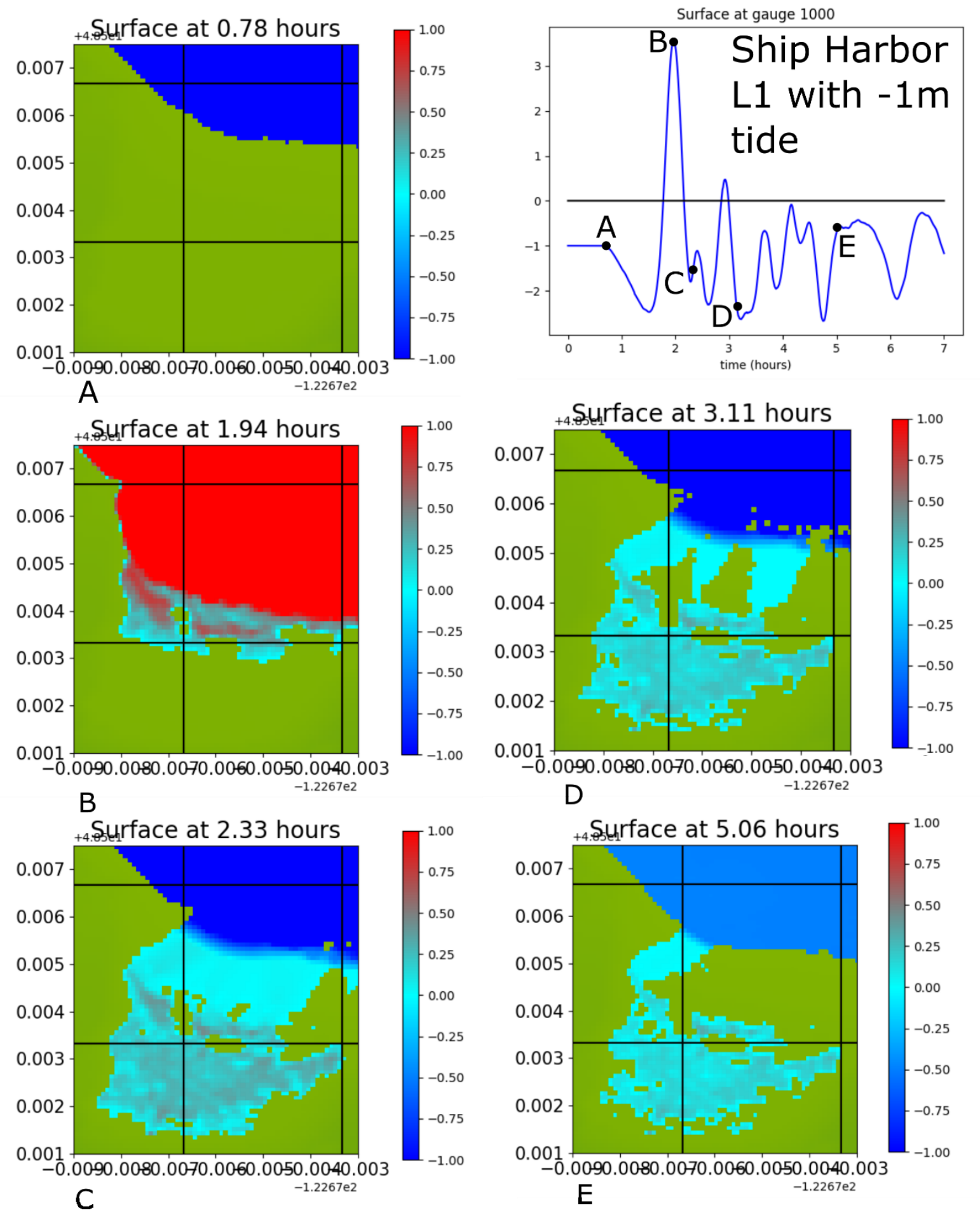
Figure 22. Continued from previous page, Eliza Island field site.

\section{Eliza Island}
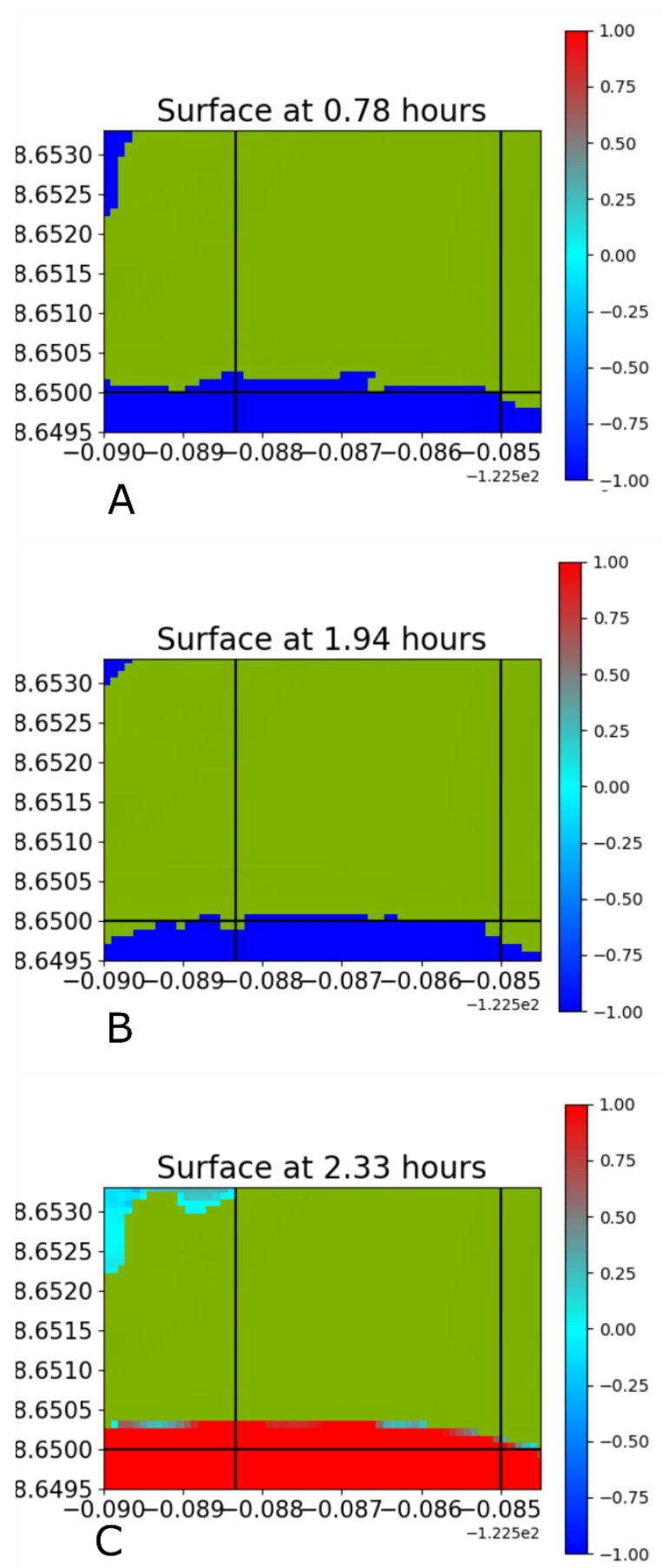

L1 with $-1 \mathrm{~m}$ tide
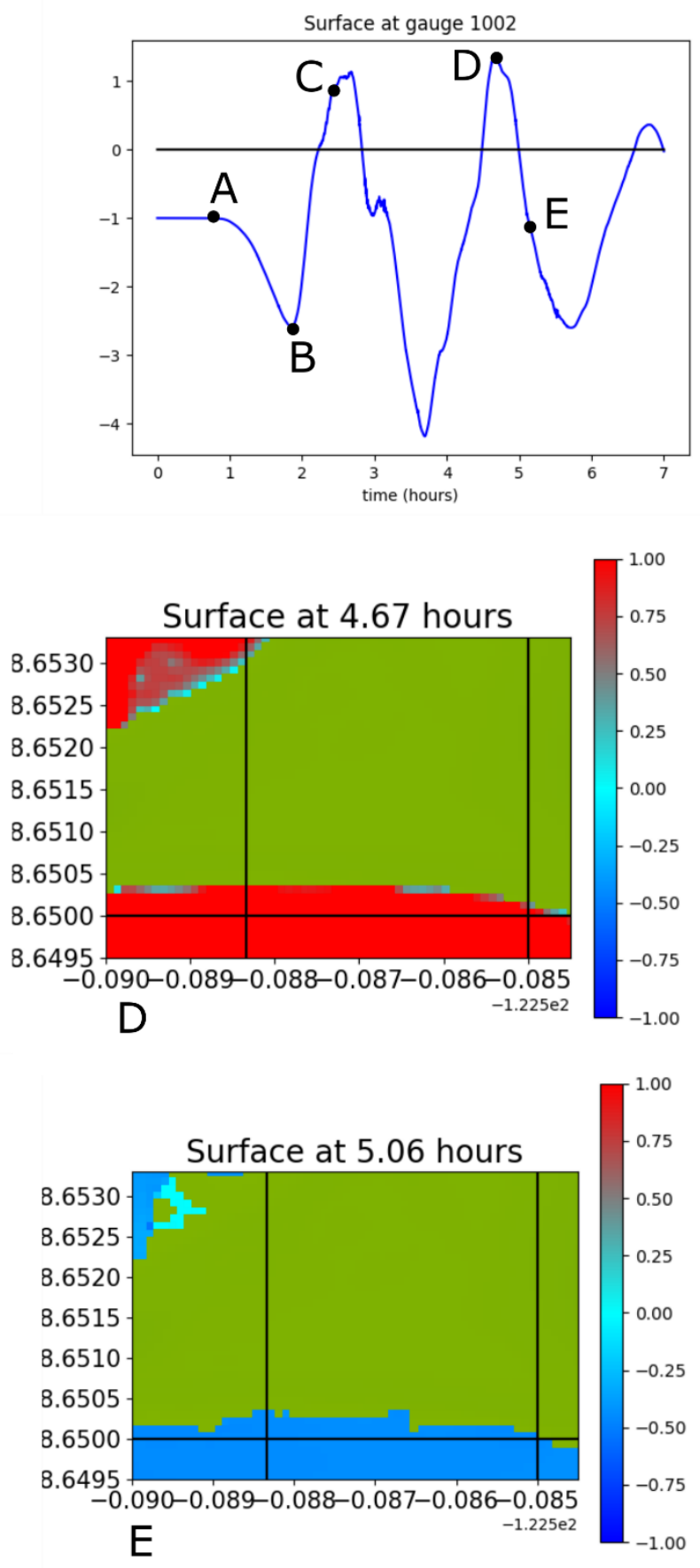
Figure 23. Model results L1 with -2.0m tide.

\section{Ship Harbor, L1, $-2 m$ tide}

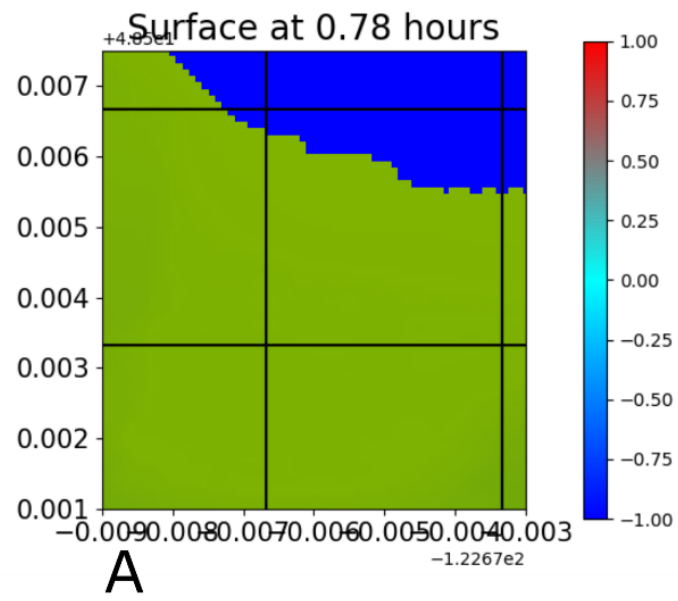

+4.Surferface at 1.94 hours

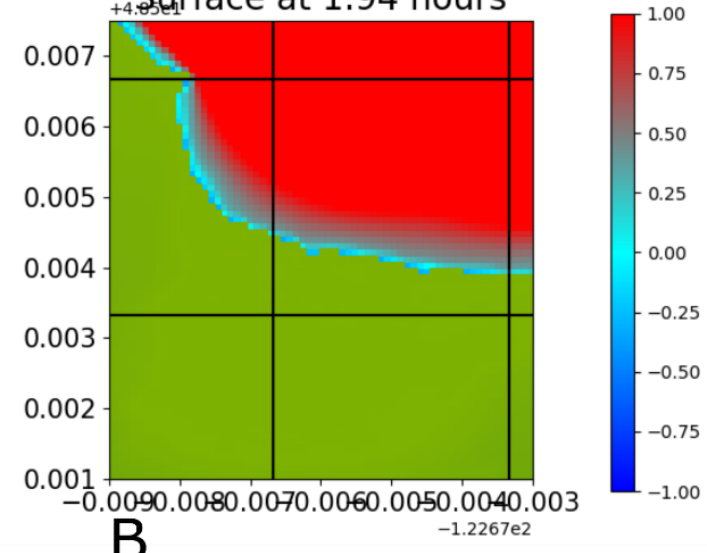

B

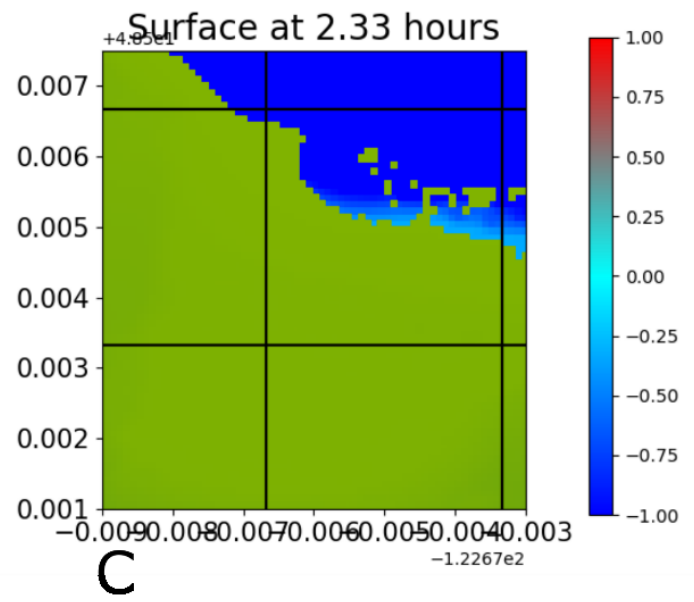

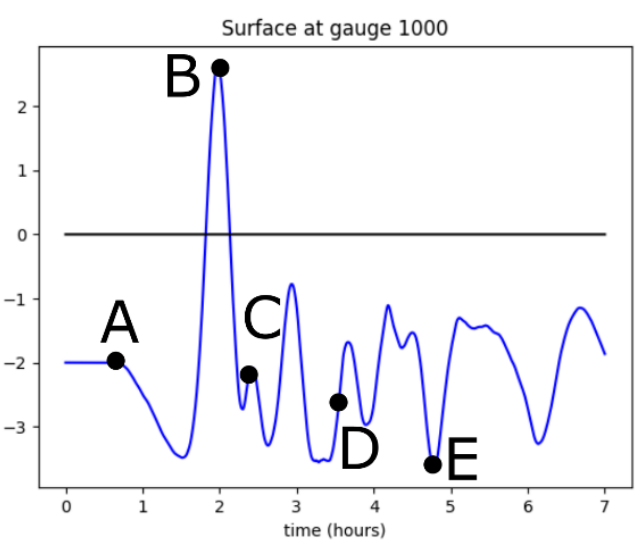
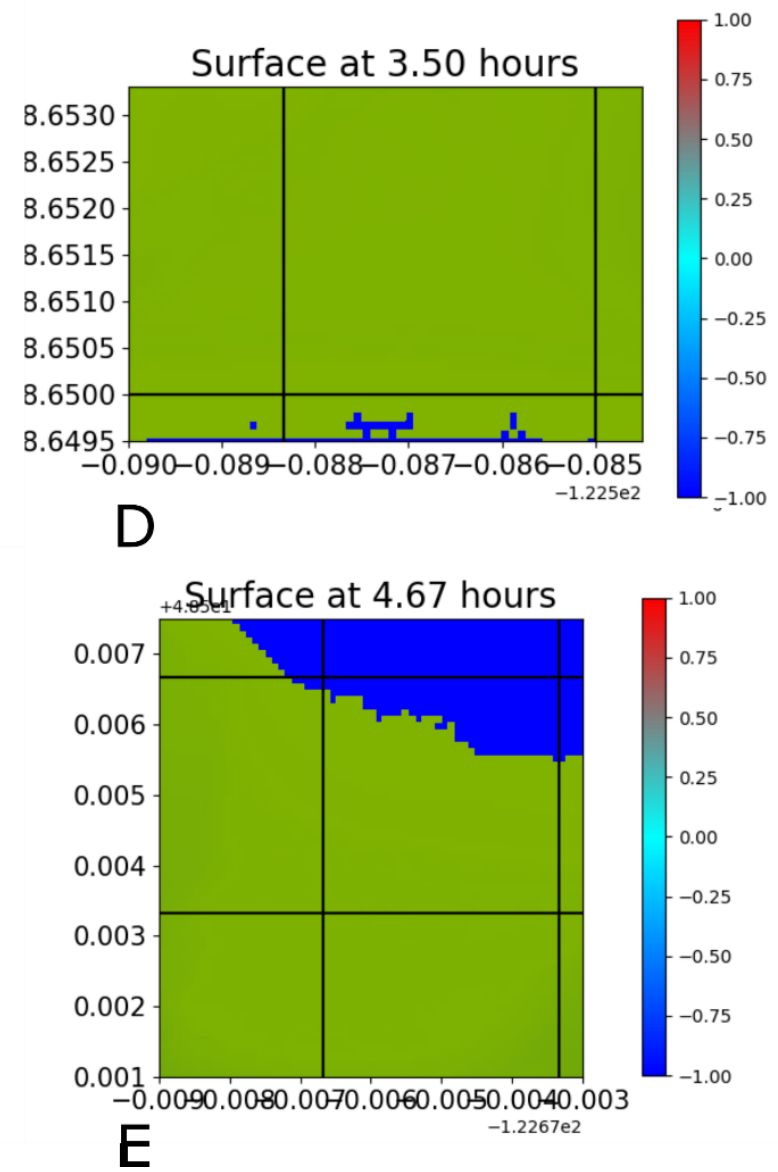
Figure 23. Continued from previous page

\section{Eliza Island, L1, -2m tide}
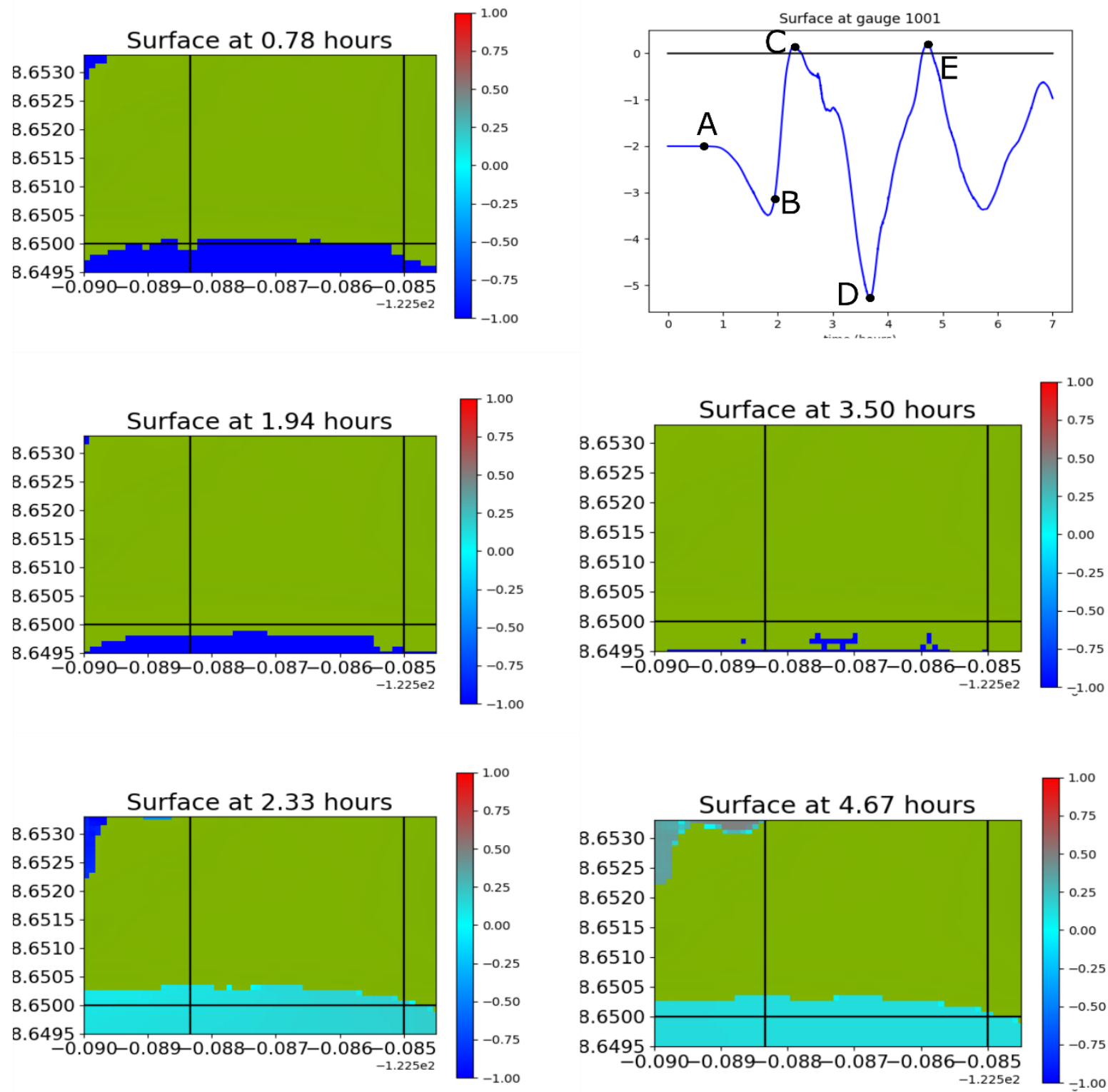
Figure 24. Model results from M1 scenario with $+1.0 \mathrm{~m}$ high tide

\section{Ship Harbor, M1, +1m tide}
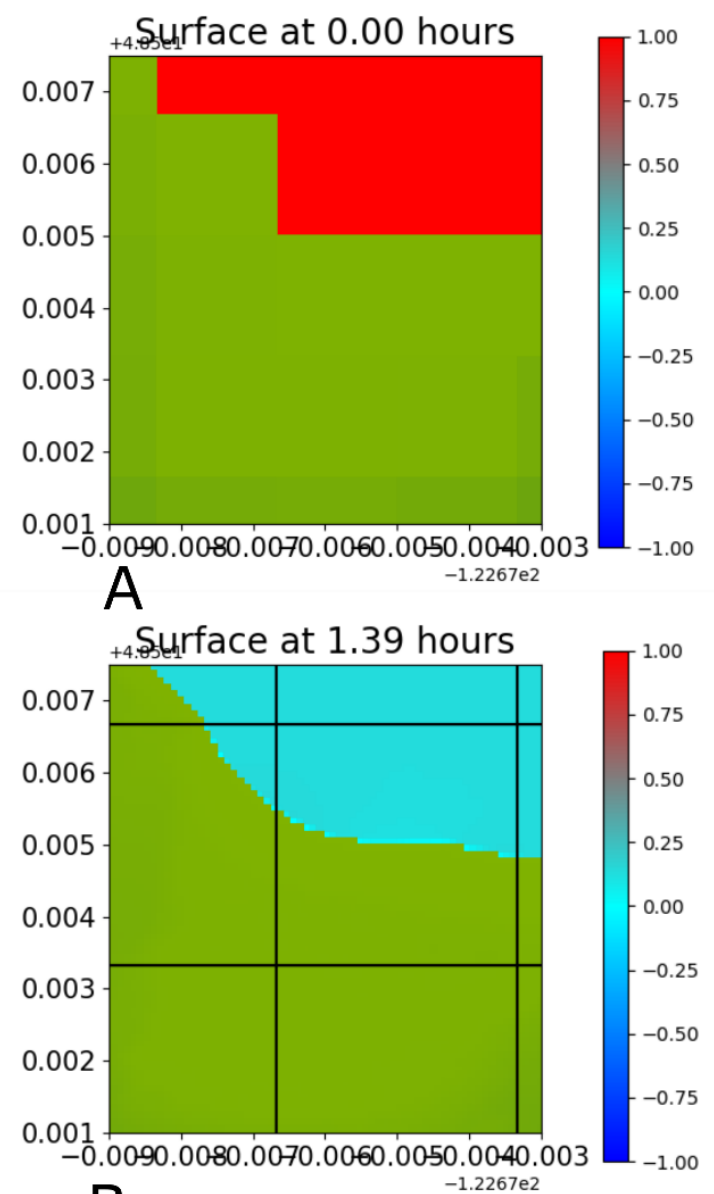

B

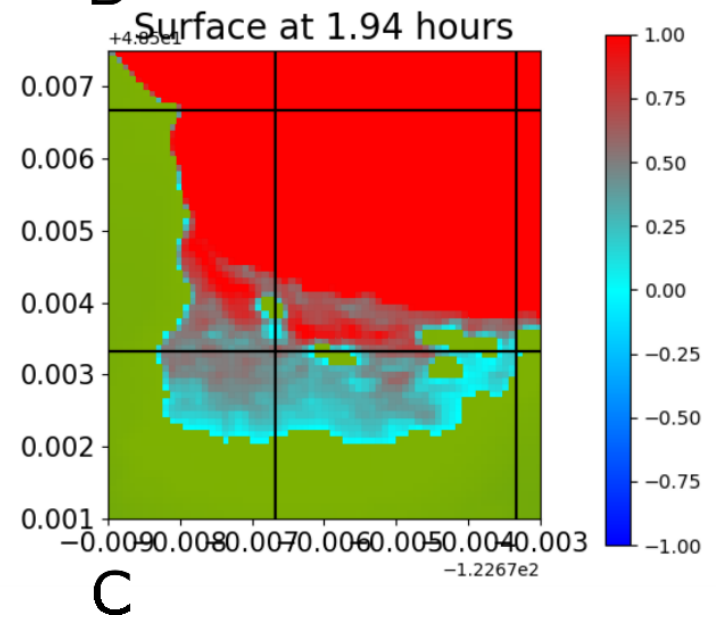

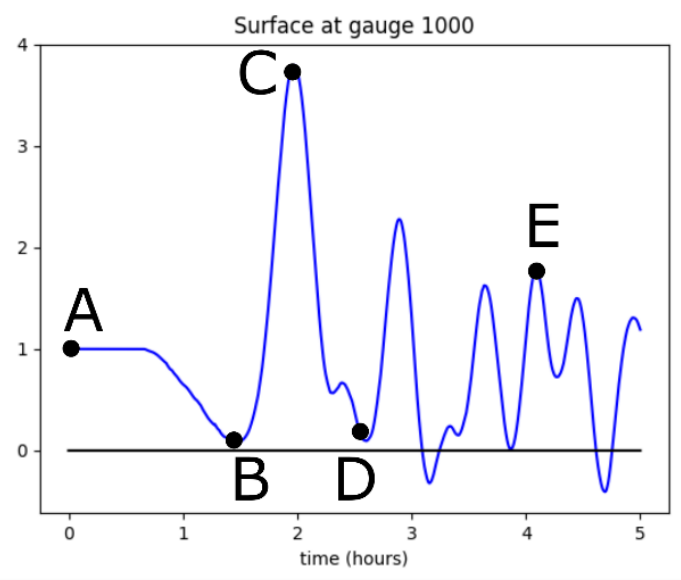
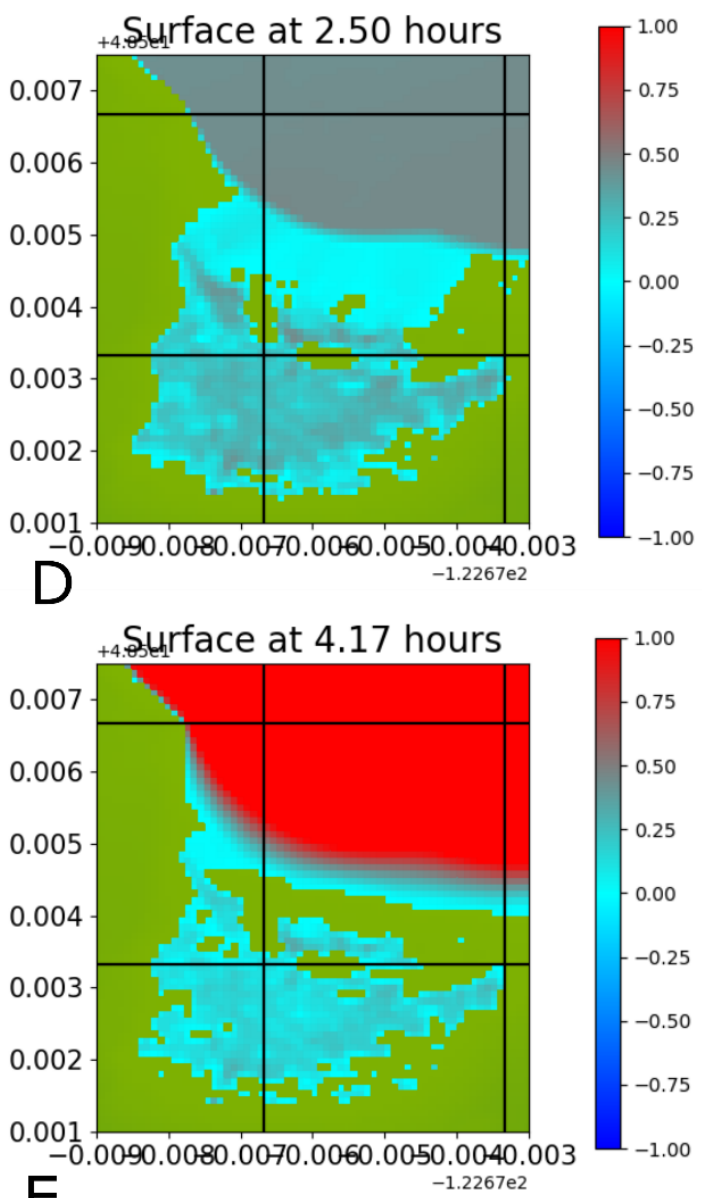
Figure 24. Continued from previous page

\section{Eliza Island, $\mathrm{M} 1,+1 \mathrm{~m}$ tide}
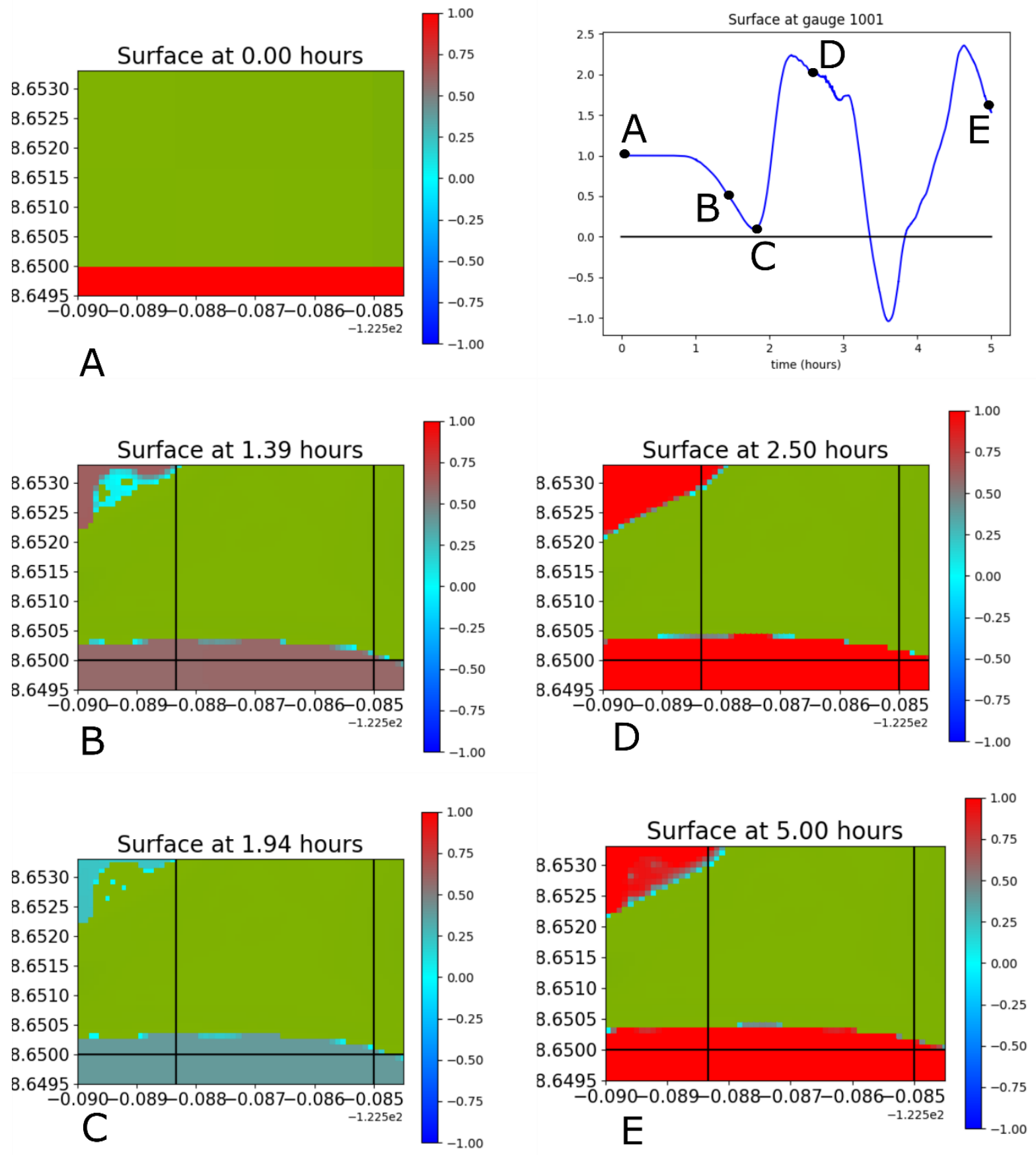
Figure 25a. Figure of simplified stratigraphic correlation for SHb1. Y-axis is depth below the surface in centimeters. X-axis based on latitude and longitudinal profile created in the field with a Trimble DGPS unit, y-axis is based on depth above sea level in meters. Left side of image is the landward (south-east) direction, right is seaward (northwest) direction.

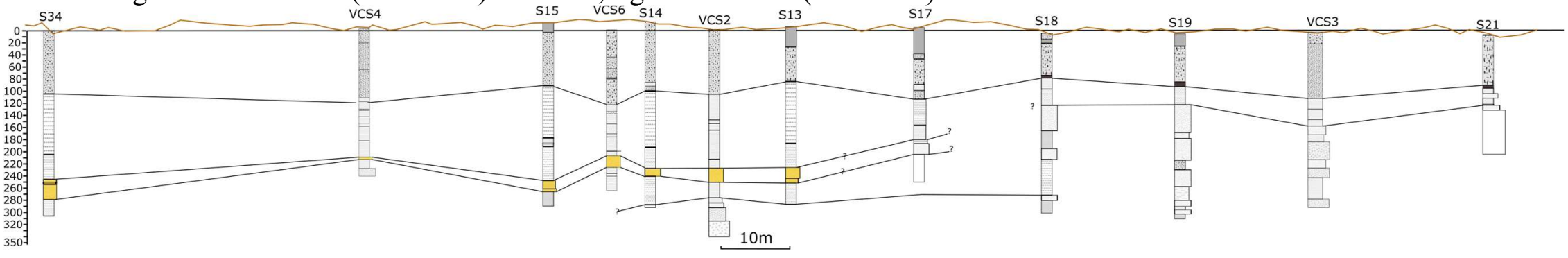

Figure 25b. Figure of alternate stratigraphic correlation for SHb1, extending north sand-sheet SHb1. Y-axis is depth below the surface in centimeters. X-axis based on latitude and longitudinal profile created in the field with a Trimble DGPS unit, y-axis is based on depth above sea level in meters. Left side of image is the landward (south-east) direction, right is seaward (northwest) direction.

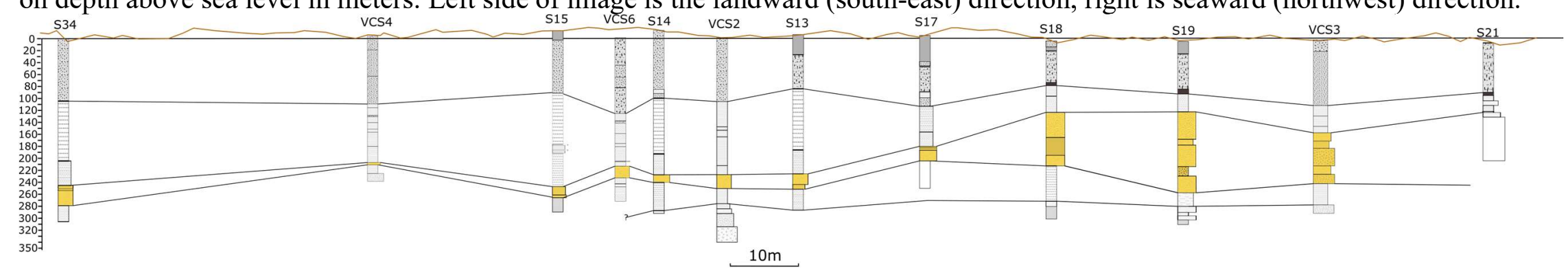


Figure 26a. Figure of Eliza Island Stratigraphic Correlation for EIb2, extending east-west along the southern extent of marsh West EI33
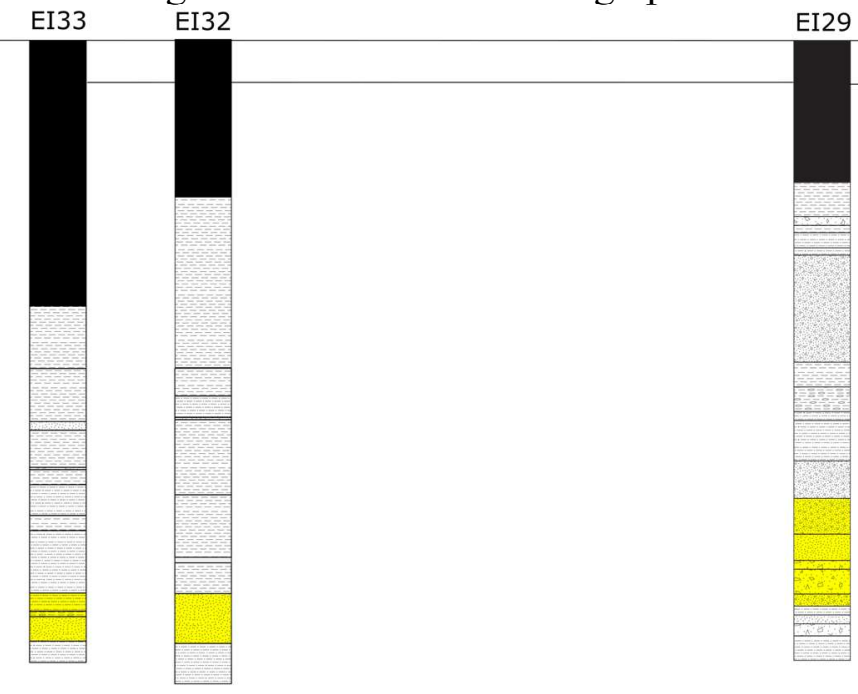

EI28
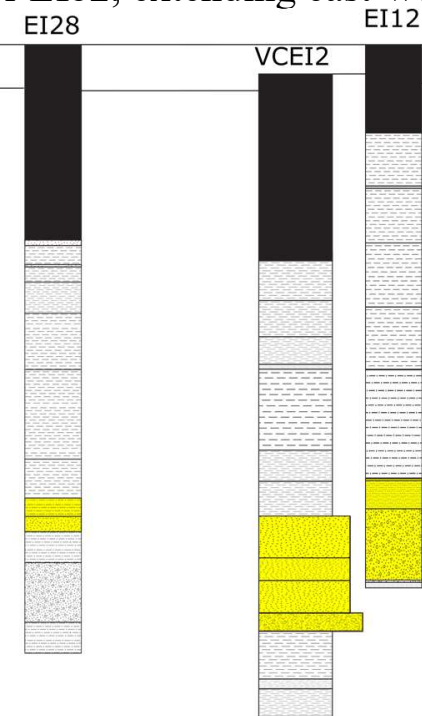

EI17 East

Figure 26b. Figure of Eliza Island Stratigraphic Correlation for EIb2 extending north to south across the central pond North EI22 Of Eliza EI1 $5 \mathrm{~mm}=1 \mathrm{~m}$
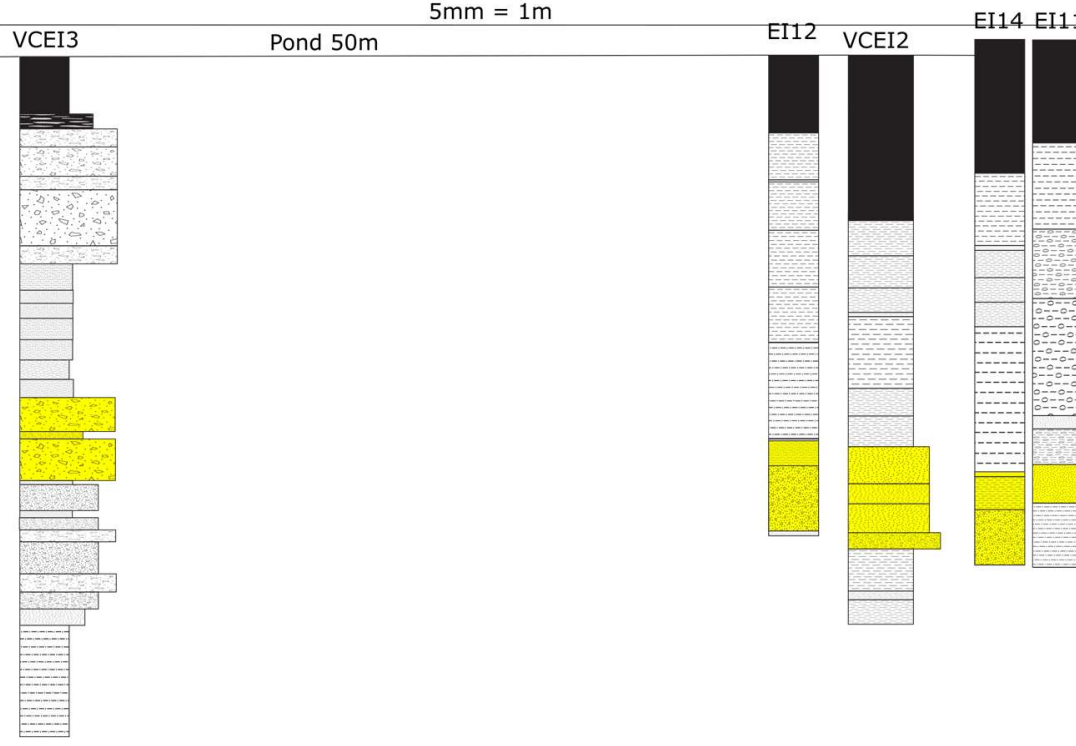
South

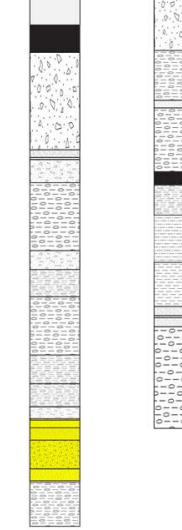
Pond 50m

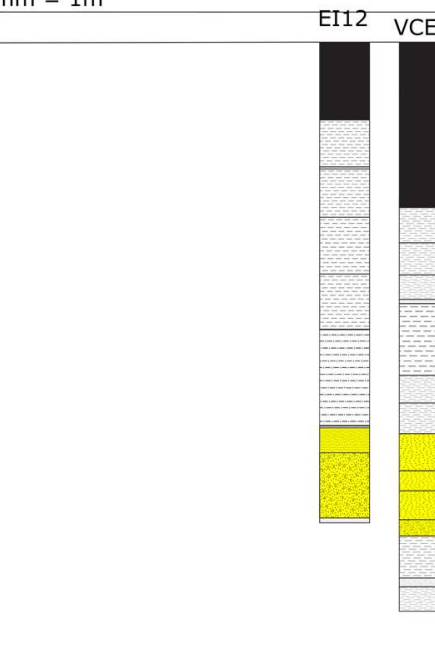


Table 1. Vibracore inner and outer measurements, taken in the field. Diagram to the right displays how compaction is calculated based on field measurements. Total outer field measurement is subtracted from the inner field measurement, producing a total amount of compaction. This is divided by the compacted core length to produce compaction per centimeter in the core. This factor is then used to calculate the total uncompacted length of the core.

\begin{tabular}{|l|l|l|l|l|l|l|l|}
\hline & $\begin{array}{l}\text { Inner Field } \\
\text { (IF) } \\
\text { Measurement } \\
(\mathrm{cm}) \text { (minus } \\
\text { material } \\
\text { removed if } \\
\text { done so) }\end{array}$ & $\begin{array}{l}\text { Total } \\
\text { Length } \\
\text { of pipe } \\
\text { (cm) }\end{array}$ & $\begin{array}{l}\text { Outer } \\
\text { Field } \\
\text { (OF) } \\
(\mathrm{cm})\end{array}$ & $\begin{array}{l}\text { Si: } \\
\text { IF-OF }= \\
(\mathrm{cm})\end{array}$ & $\begin{array}{l}\text { Penetration } \\
\text { depth (cm): } \\
\text { Total length }- \\
\text { OF }\end{array}$ & $\begin{array}{l}\text { Depth, } \\
\text { uncorrected } \\
\text { core (Du) } \\
(\mathrm{cm})\end{array}$ & $\begin{array}{l}\text { Compaction } \\
\text { Factor: (IF- } \\
\text { OF)/(Total } \\
\text { length-OF) }\end{array}$ \\
\hline VCS1 & 180.9 & 322 & 55.7 & 125.2 & 267.2 & 142 & 0.4686 \\
\hline VCS2 & 160.5 & 409.5 & 59.7 & 100.8 & 349.8 & 249 & 0.2882 \\
\hline VCS3 & 159.4 & 405.4 & 132.7 & 26.7 & 272.7 & 246 & 0.0978 \\
\hline VCS4 & 223.5 & 408.5 & 156.2 & 67.3 & 252.2 & 160.8 & 0.2668 \\
\hline VCS5 & 53.7 & 309.1 & 46.9 & 6.7 & 262.1 & 225 & 0.0254 \\
\hline VCS6 & 60.3 & 311.6 & 38.1 & 22.2 & 273.5 & 205.6 & 0.0812 \\
\hline VCEI1 & 78.9 & 315.6 & 38.4 & 40.5 & 277.1 & 210 & 0.1460 \\
\hline VCEI2 & 59.2 & 280.8 & 32.7 & 26.5 & 220.1 & 189 & 0.1414 \\
\hline VCEI3 & 91.8 & 312.2 & 60.6 & 31.1 & 251.5 & 220.4 & 0.1237 \\
\hline
\end{tabular}

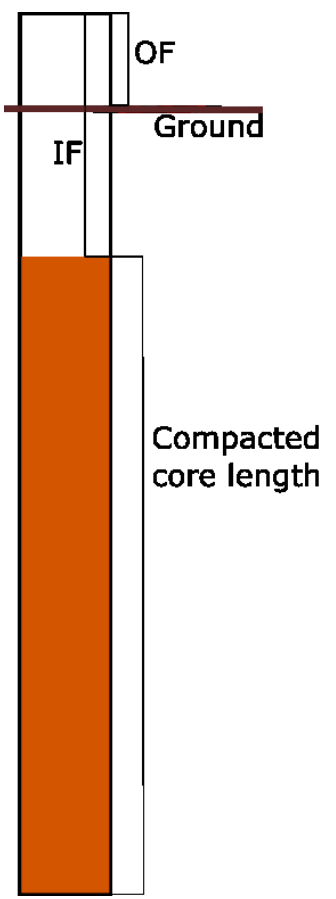


Table 2. Radiocarbon sample list sent to NOSAMS. Samples listed by site and stratigraphic depth.

\begin{tabular}{|c|c|c|c|c|c|c|}
\hline $\begin{array}{l}\text { Name and Site } \\
\text { Location }\end{array}$ & $\begin{array}{l}\text { Depth }(\mathrm{cm}) \\
\text { uncorrected } \\
\text { for } \\
\text { compaction }\end{array}$ & $\begin{array}{l}\text { Depth, } \\
\text { corrected } \\
\text { for } \\
\text { vibracore } \\
\text { compaction } \\
\text { (cm) }\end{array}$ & $\begin{array}{l}\text { Sample } \\
\text { type/ } \\
\text { Comments }\end{array}$ & $\begin{array}{l}\text { Weight } \\
\text { (mg) }\end{array}$ & $\begin{array}{l}\text { Note of likely } \\
\text { max/minimum }\end{array}$ & Type \\
\hline \multicolumn{7}{|l|}{ Ship Harbor } \\
\hline VCS2n_RC28 & 108 & 168.20 & Twig & 5.97 & Maximum & Plant/Wood \\
\hline VCS2n_RC6 & 146 & 217.15 & $\begin{array}{l}\text { Pinecone } \\
\text { needle or } \\
\text { very small } \\
\text { twig }\end{array}$ & 1.57 & Maximum age & Plant/Wood \\
\hline VCS2n_RC14 & 160.5 & 235.83 & Twig & 4.84 & Maximum age & Plant/Wood \\
\hline VCS2n_RC12 & 161 & 236.47 & Twig & 2.43 & Maximum age & Plant/Wood \\
\hline VCS2n_RC13 & 162.5 & 238.41 & $\begin{array}{l}\text { Wood } \\
\text { fragment }\end{array}$ & 29.22 & Maximum age & Plant/Wood \\
\hline VCS2n_RC17 & 170 & 248.07 & $\begin{array}{l}\text { Twig, in } \\
\text { tsunami } \\
\text { deposit }\end{array}$ & 3.55 & Maximum age & Plant/Wood \\
\hline VCS2n_RC23 & 207 & 295.73 & $\begin{array}{l}\text { Twig - } \\
\text { small }\end{array}$ & 3.63 & $\begin{array}{l}\text { Maximum below } \\
\text { age }\end{array}$ & Plant/Wood \\
\hline VCS2n_RC25 & 228 & 322.78 & $\begin{array}{l}\text { Potentially } \\
\text { bark }\end{array}$ & 4.05 & Oldest sample & Plant/Wood \\
\hline \multicolumn{7}{|l|}{ Eliza Island } \\
\hline VCEI2n_RC28 & 124.5 & 143.1 & Bark & 2.4 & Max age & Plant/Wood \\
\hline VCEI2n_RC19 & 135 & 154.9 & $\begin{array}{l}\text { Twig, } \\
\text { inside } \\
\text { normally } \\
\text { graded } \\
\text { sand } \\
\end{array}$ & 14 & $\begin{array}{l}\text { Max of sand } \\
\text { above }\end{array}$ & Plant/Wood \\
\hline VCEI2n_RC1 & 143.5 & 164.4 & $\begin{array}{l}\text { Twig trash } \\
\text { layer top }\end{array}$ & 68.98 & $\begin{array}{l}\text { Maximum age, } 7 \\
\text { growth rings } \\
\text { counted }\end{array}$ & Plant/Wood \\
\hline VCEI2n_RC8 & 154 & 176.2 & $\begin{array}{l}\text { Twig - } \\
\text { below } \\
\text { trash }\end{array}$ & 12.59 & $\begin{array}{l}\text { Max age, down } \\
\text { section from } \\
\text { "sand sheet } \\
\text { EIb2" }\end{array}$ & Plant/Wood \\
\hline
\end{tabular}


Table 3. Particle size analysis results for Ship Harbor. Grey indicates measurement was collected with a settling test, white samples were completed with the Melvern Mastersizer instrument. Texture is based on the USDA soil texture triangle. Percent organics is based on LOI data, and if taken between two measurements from LOI an average is taken from samples above and below.

\begin{tabular}{|c|c|c|c|c|c|c|c|c|c|c|c|}
\hline $\begin{array}{l}\text { Core name and } \\
\text { Uncorrected } \\
\text { Sampling depths } \\
(\mathrm{cm})\end{array}$ & $\begin{array}{l}\text { Top Depth } \\
(\mathrm{cm})\end{array}$ & $\begin{array}{l}\text { Bottom } \\
\text { depth }(\mathrm{cm})\end{array}$ & $\begin{array}{l}\text { Result \% } \\
\text { 0.01 } \mu \mathrm{m}- \\
3.90 \mu \mathrm{m} \\
\text { Clay }\end{array}$ & $\begin{array}{l}\text { Result \% } \\
3.91 \mu \mathrm{m}- \\
15.60 \mu \mathrm{m} \\
\text { Lower Silt } \\
\end{array}$ & $\begin{array}{l}\text { Result \% } \\
15.61 \mu \mathrm{m}- \\
62.50 \mu \mathrm{m} \\
\text { Silt }\end{array}$ & Silt \% & $\begin{array}{l}\text { Result \% } \\
62.51 \mu \mathrm{m}- \\
250.00 \mu \mathrm{m} \\
\text { (vfs to fs) }\end{array}$ & $\begin{array}{l}\text { Result \% } \\
250.01 \mu \mathrm{m}- \\
2500.00 \mu \mathrm{m}\end{array}$ & $\begin{array}{l}\text { Obscuration } \\
\%\end{array}$ & Texture & $\%$ Organics \\
\hline \multicolumn{12}{|l|}{ VCS2 } \\
\hline $70-80$ & 119.2 & 132.1 & 24.1 & 38.8 & 33.0 & 71.8 & 4.0 & 0.0 & 6.33 & Silty Clay Loam & 13.03 \\
\hline $80-90$ & 132.1 & 145.0 & 24.8 & 38.7 & 28.4 & 67.0 & 4.2 & 3.9 & 6.33 & Silty Clay Loam & 10.95 \\
\hline $90-95$ & 145.0 & 151.4 & 24.3 & 40.1 & 30.3 & 70.4 & 3.6 & 1.7 & 7.26 & Silt Loam & 11.50 \\
\hline $95-108$ & 151.4 & 168.2 & 7.0 & & & 51.2 & 41.9 & & & Silt Loam & 12.00 \\
\hline $108-118$ & 168.2 & 181.1 & 24.3 & 38.0 & 29.4 & 67.5 & 3.5 & 4.7 & 5.67 & Silt loam & 10.59 \\
\hline $118-124$ & 181.1 & 188.8 & 0.0 & 72.7 & & 72.7 & 27.3 & & & Silt Loam & 11.00 \\
\hline $124-134$ & 188.8 & 201.7 & 26.0 & 40.0 & 29.9 & 70.0 & 3.7 & 0.3 & 6.76 & Silt Loam & 11.67 \\
\hline $134-144$ & 201.7 & 214.6 & 24.2 & 38.3 & 30.9 & 69.2 & 3.3 & 3.2 & 7.23 & Silt Loam & 11.59 \\
\hline $144-146$ & 214.6 & 217.1 & 0.0 & & & 69.0 & 31.0 & & & Silt Loam & 11.00 \\
\hline 146-154 & 217.1 & 227.5 & 23.0 & 35.4 & 30.7 & 66.1 & 4.0 & 6.8 & 6.65 & Silt Loam & 10.99 \\
\hline $154-176$ & 227.5 & 255.8 & 5.0 & & & 55.0 & 40.0 & & & Silt Loam & $7-22$ \\
\hline 176-186 & 255.8 & 268.7 & 22.7 & 35.1 & 37.3 & 72.4 & 4.8 & 0.0 & 7.31 & Silt Loam & 10.20 \\
\hline 186-195 & 268.7 & 280.3 & 23.4 & 35.3 & 33.0 & 68.4 & 4.3 & 3.9 & 6.70 & Silt Loam & 10.10 \\
\hline $195-226$ & 280.3 & 320.2 & 7.1 & & & 40.5 & 52.4 & & & Silt Loam & $2-4$ \\
\hline $226-245$ & 320.2 & 344.7 & 20.7 & & & 6.9 & 72.4 & & & Sandy Clay Loam & 2.00 \\
\hline \multicolumn{12}{|l|}{ VCS6 } \\
\hline $85-92$ & 139.4 & 147.0 & 24.0 & 39.5 & 32.7 & 72.2 & 3.7 & 0.0 & & Silt Loam & 10.00 \\
\hline $92-100.6$ & 147.0 & 156.3 & 24.4 & 39.5 & 30.4 & 69.9 & 3.5 & 2.1 & & Silt Loam & 10.60 \\
\hline $100.6-110$ & 156.3 & 166.4 & 20.2 & 31.8 & 37.6 & 69.4 & 5.5 & 4.8 & & Silt Loam & 11.72 \\
\hline $110-116$ & 166.4 & 172.9 & 20.4 & 32.4 & 37.9 & 70.3 & 5.4 & 3.8 & & Silt Loam & 12.24 \\
\hline 116-121 & 172.9 & 178.3 & 21.9 & 35.3 & 37.8 & 73.1 & 4.9 & 0.0 & & Silt Loam & 13.74 \\
\hline $121-129$ & 178.3 & 187.0 & 7.0 & & & 55.8 & 37.2 & & & Silt Loam & 12.00 \\
\hline $129-135$ & 187.0 & 193.5 & 23.0 & 37.0 & 31.3 & 68.3 & 5.1 & 3.5 & & Silt Loam & 11.50 \\
\hline $135-160$ & 193.5 & 220.5 & 11.8 & & & 32.4 & 55.9 & & & Sandy Loam & 11.50 \\
\hline $160-170$ & 220.5 & 231.3 & 23.4 & 36.7 & 31.7 & 68.4 & 3.5 & 4.6 & & Silt Loam & 14.17 \\
\hline $170-178$ & 231.3 & 240.0 & 25.2 & 37.7 & 29.5 & 67.2 & 4.3 & 3.2 & & Silt Loam & 23.52 \\
\hline $178-185$ & 240.0 & 247.5 & 22.1 & 33.8 & 27.2 & 61.0 & 8.9 & 8.0 & & Silt Loam & 6.56 \\
\hline 190-205.6 & 252.9 & 269.8 & 25.1 & 38.6 & 28.9 & 67.4 & 4.0 & 3.4 & & Silt Loam & 10.95 \\
\hline
\end{tabular}


Table 4. Particle Size Analysis results for Eliza Island. Grey indicates measurement was collected with a settling test, white samples were completed with the Melvern Mastersizer instrument. Texture is based on the USDA soil texture triangle. Percent organics is based on LOI data, and if taken between two measurements from LOI an average is taken from samples above and below. Yellow indicates sample was lost during analysis. Bold are \% sand silt and clay used to determine texture.

\begin{tabular}{|c|c|c|c|c|c|c|c|c|c|c|c|}
\hline $\begin{array}{l}\text { Core name and } \\
\text { Uncorrected } \\
\text { Sampling depth } \\
\text { (cm) }\end{array}$ & $\begin{array}{l}\text { Corrected } \\
\text { Top Depth } \\
\text { (cm) }\end{array}$ & $\begin{array}{l}\text { Corrected } \\
\text { bottom } \\
\text { depth }(\mathrm{cm})\end{array}$ & $\begin{array}{l}\text { Result } \\
0.01 \mu \mathrm{m}- \\
3.90 \mu \mathrm{m} \\
\text { Clay }\end{array}$ & $\begin{array}{l}\text { Result } \\
3.91 \mu \mathrm{m}- \\
15.60 \mu \mathrm{m} \\
\text { Lower Silt }\end{array}$ & $\begin{array}{l}\text { Result } \\
15.61 \mu \mathrm{m}- \\
62.50 \mu \mathrm{m} \\
\text { Silt }\end{array}$ & $\begin{array}{l}\text { Silt } \\
\%\end{array}$ & $\begin{array}{l}\text { Result } \\
62.51 \mu \mathrm{m}- \\
250.00 \mu \mathrm{m} \\
\text { (vfs to fs) }\end{array}$ & $\begin{array}{l}\text { Result } \\
250.01 \mu \mathrm{m}- \\
2500.00 \mu \mathrm{m}\end{array}$ & $\begin{array}{l}\text { Obscuration } \\
\%\end{array}$ & Texture & $\%$ Organics \\
\hline \multicolumn{12}{|l|}{ VCEI2 } \\
\hline $49-57$ & 58.3 & 67.3 & 14.2 & 19.4 & 37.6 & $\mathbf{5 7 . 0}$ & 22.8 & 6.0 & 5.49 & Silt Loam & 6.71 \\
\hline $57-62$ & 67.3 & 72.9 & 10.0 & & & 65.0 & 25.0 & & & Silt Loam & 6.00 \\
\hline $62-72$ & 72.9 & 84.1 & 12.1 & 20.0 & 41.0 & 61.0 & 19.6 & 7.3 & 4.85 & Silt Loam & 7.16 \\
\hline $73-82$ & 85.2 & 95.3 & 17.8 & 25.5 & 41.6 & 67.2 & 13.0 & 2.0 & 8.00 & Silt Loam & 8.20 \\
\hline $82-92$ & 95.4 & 106.6 & 19.6 & 26.7 & 40.0 & 66.7 & 9.9 & 3.7 & 9.20 & Silt Loam & 6.36 \\
\hline $92-102$ & 106.6 & 117.8 & 16.5 & 22.9 & 38.7 & 61.6 & 13.6 & 8.3 & 7.57 & Silt Loam & 5.86 \\
\hline $102-112$ & 117.8 & 129.0 & & & & & & & & & 6.74 \\
\hline $124-136$ & 142.5 & 156.0 & 9.5 & & & 45.2 & 45.2 & & & Loam & $2-4$ \\
\hline $136-142.6$ & 155.9 & 163.4 & 2.4 & & & 42.9 & 54.8 & & & Sandy Loam & 3.80 \\
\hline $142.6-157.5$ & 163.4 & 180.1 & 6.7 & & & 66.7 & 26.7 & & & Silt Loam & $4-11$ \\
\hline $157.4-182$ & 180.0 & 207.6 & 2.6 & & & 71.1 & 26.3 & & & Silt Loam & $1.7-3.3$ \\
\hline \multicolumn{12}{|l|}{ VCEI3 } \\
\hline $15-26$ & 20.7 & 33.1 & $\mathbf{0 . 0}$ & & & 69.6 & 30.4 & & & Silt Loam & 2.40 \\
\hline $26-40$ & 33.1 & 48.8 & 20.0 & & & 34.3 & 45.7 & & & Loam & $1.6-2.4$ \\
\hline $40-58$ & 48.8 & 69.0 & 9.7 & & & 54.8 & 35.5 & & & Silt Loam & 1.60 \\
\hline $64-70$ & 75.8 & 82.5 & 11.8 & 17.0 & 31.2 & 48.2 & 27.0 & 13.0 & 4.70 & Loam & 4.12 \\
\hline $70-77$ & 82.5 & 90.4 & 13.0 & 22.3 & 38.3 & 60.6 & 12.8 & 13.5 & 3.47 & Silt Loam & 7.07 \\
\hline $77-82$ & 90.4 & 96.0 & 10.0 & 16.7 & 30.3 & 47.0 & 14.9 & 28.1 & 3.70 & Loam & 7.00 \\
\hline $82-89$ & 95.9 & 103.9 & 15.3 & 24.2 & 35.9 & 60.1 & 9.9 & 14.6 & 4.33 & Silt Loam & 8.33 \\
\hline $89-93$ & 103.9 & 108.4 & 12.3 & 22.6 & 45.0 & 67.6 & 11.9 & 8.2 & 4.33 & Silt Loam & 9.66 \\
\hline $98-101$ & 114.0 & 117.3 & 18.9 & 24.7 & 37.9 & 62.6 & 14.7 & 3.8 & 7.81 & Silt loam & 11.85 \\
\hline $103-107$ & 119.6 & 124.1 & 19.8 & 26.4 & 39.4 & 65.9 & 10.8 & 3.4 & 7.61 & Silt Loam & 7.67 \\
\hline $121.6-135$ & 140.5 & 155.6 & 4.5 & & & 63.6 & 31.8 & & & Silt Loam & $4.6-5.2$ \\
\hline $135-145$ & 155.6 & 166.8 & 7.1 & & & 52.4 & 40.5 & & & Silt Loam & 4.40 \\
\hline 154-166 & 176.9 & 190.4 & 5.9 & & & 35.3 & 58.8 & & & Sandy Loam & $2.1-3.7$ \\
\hline $166-173$ & 190.4 & 198.3 & 10.0 & & & 10.0 & 80.0 & & & Loamy Sand & $1-2$ \\
\hline $178-183$ & 203.9 & 209.5 & 9.1 & & & 12.1 & 78.8 & & & Loamy Sand & 1.00 \\
\hline $194-200$ & 217.7 & 228.6 & 30.6 & 31.2 & 23.4 & 54.6 & 9.7 & 5.1 & 9.77 & Silty Clay Loam & 1.88 \\
\hline $200-210$ & 224.3 & 239.8 & 37.4 & 35.5 & 20.4 & 55.9 & 3.5 & 3.1 & 8.20 & Silty Clay Loam & 2.37 \\
\hline $212-217$ & 237.61 & 247.7 & 27.1 & 27.6 & 24.3 & 51.9 & 12.6 & 8.3 & 9.85 & Silty Clay Loam & 2.42 \\
\hline
\end{tabular}


Table 5. Lateral extent of sand-sheet $\mathrm{SHb} 1$ from north (closest to beach) to south (landward) along transect $\mathrm{T} 1 \mathrm{a}$ and $\mathrm{T} 1 \mathrm{~b}$ (Figure 3b), gouge auger core name (Appendix 1) or vibracore name (Appendix 2) are listed in the far-right column, depths given are corrected for compaction as described in Figure 1. If sand sheet is not apparent, in "Sand-sheet name or comment of observation" column a comment of a potential correlating factor is made from field observations. Age here is based on the OxCal sequence model from ${ }^{14} \mathrm{C}$ dates (Table 10).

\begin{tabular}{|c|c|c|c|c|c|c|c|c|}
\hline N-S & \multicolumn{2}{|c|}{$\begin{array}{l}\text { Sand-sheet name or } \\
\text { comment of } \\
\text { observation }\end{array}$} & \multicolumn{2}{|c|}{$\begin{array}{l}\text { Depth (corrected) } \\
(\mathrm{cm})\end{array}$} & \multicolumn{2}{|l|}{ Thickness (cm) } & & \\
\hline S19 & \multicolumn{2}{|l|}{ SHb1 } & \multicolumn{2}{|c|}{$\begin{array}{l}124-134,186-245 \\
251+\end{array}$} & \multicolumn{2}{|l|}{$26+$} & & \\
\hline S17 & \multicolumn{2}{|l|}{$\mathrm{SHb} 1$} & \multicolumn{2}{|l|}{$187-212+$} & \multicolumn{2}{|l|}{$25+$} & & \\
\hline $\mathrm{S} 13$ & \multicolumn{2}{|l|}{ SHb1 } & \multicolumn{2}{|l|}{$233-259$} & \multicolumn{2}{|l|}{26} & & \\
\hline VCS2 & \multicolumn{2}{|l|}{ SHb1 } & \multicolumn{2}{|c|}{$230.7-254.7$} & \multicolumn{2}{|l|}{24} & & \\
\hline VCS6 & \multicolumn{2}{|l|}{ SHb1 } & \multicolumn{2}{|c|}{$214-234$} & \multicolumn{2}{|l|}{20} & & \\
\hline $\mathrm{S} 14$ & \multicolumn{2}{|l|}{$\mathrm{SHb} 1$} & \multicolumn{2}{|l|}{$240-253$} & \multicolumn{2}{|l|}{13} & & \\
\hline $\mathrm{S} 15$ & \multicolumn{2}{|l|}{ SHb1 } & \multicolumn{2}{|c|}{$190-205$} & \multicolumn{2}{|l|}{15} & & \\
\hline VCS4 & \multicolumn{2}{|l|}{$\mathrm{SHb} 1$} & \multicolumn{2}{|c|}{$213.1-217.2$} & \multicolumn{2}{|l|}{5} & & \\
\hline S34 & \multicolumn{2}{|l|}{$\mathrm{SHb} 1$} & \multicolumn{2}{|c|}{$246-253$} & \multicolumn{2}{|l|}{7} & & \\
\hline S33 & \multicolumn{2}{|c|}{$\begin{array}{l}\text { High Organics } \\
\text { Content }\end{array}$} & \multicolumn{2}{|l|}{220} & \multicolumn{2}{|l|}{$<1$} & & \\
\hline $\mathrm{S} 32$ & \multicolumn{2}{|c|}{\begin{tabular}{l|l} 
Shell fragments \\
\end{tabular}} & 221 & & $<1$ & & & \\
\hline $\begin{array}{l}\text { Sand- } \\
\text { sheet }\end{array}$ & $\begin{array}{l}\text { Distance } \\
\text { between } \\
\text { cores }\end{array}$ & $\begin{array}{l}\text { Age } \\
\text { (B.P.) }\end{array}$ & $\begin{array}{l}\text { Maximum } \\
\text { Thickness }\end{array}$ & $\begin{array}{l}\text { Minimur } \\
\text { Lateral } \\
\text { Extent }\end{array}$ & $\begin{array}{l}\text { Landward } \\
\text { Thinning }\end{array}$ & $\begin{array}{l}\text { Number } \\
\text { of } \\
\text { laminae }\end{array}$ & $\begin{array}{l}\text { Average } \\
\text { Grain } \\
\text { Size } \\
\end{array}$ & $\begin{array}{l}\text { Organic } \\
\text { Content } \\
\% \\
\end{array}$ \\
\hline SHb1 & $5-10 \mathrm{~m}$ & $\begin{array}{l}1802- \\
1730\end{array}$ & $26 \mathrm{~cm}$ & $50 \mathrm{~m}$ & yes & unclear & $\begin{array}{l}\text { Sandy } \\
\text { loam } \\
\text { (sand and } \\
\text { silt) }\end{array}$ & $\begin{array}{l}22.02 \% \\
\text { at top } \\
8.93 \% \text { at } \\
\text { bottom }\end{array}$ \\
\hline
\end{tabular}


Table 6. Table of lateral extent of sand and gravel sheets, Eliza Island. Gouge auger core name (Appendix 1) or vibracore name (Appendix 2) are listed in the far-right column, depths given are corrected for compaction as described in Figure 1. N-S indicates north to south transects, while $\mathrm{W}$-E indicates west to east facing transects. If sand sheet is not apparent in "Sand-sheet name or comment of observation" column, a comment of a potential correlating factor is made from field observations. Age here is based on the OxCal sequence model from ${ }^{14} \mathrm{C}$ dates (Table 10).

\begin{tabular}{|c|c|c|c|c|c|c|c|c|c|c|c|c|}
\hline \multicolumn{2}{|c|}{$\begin{array}{l}\mathrm{N}-\mathrm{S} \text {, to the } \\
\text { east of the } \\
\text { pond. } \\
\text { Name of } \\
\text { cores along } \\
\text { transect }\end{array}$} & Name & \multicolumn{2}{|c|}{$\begin{array}{l}\text { Depth below } \\
\text { surface }(\mathbf{c m})\end{array}$} & $\begin{array}{l}\text { Thickness } \\
\text { (cm) }\end{array}$ & \multicolumn{2}{|c|}{$\begin{array}{l}\text { W-E } \\
\text { South of } \\
\text { pond. } \\
\text { Name of } \\
\text { cores }\end{array}$} & \multicolumn{2}{|c|}{$\begin{array}{l}\text { Sand- } \\
\text { sheet } \\
\text { name }\end{array}$} & \multicolumn{2}{|c|}{$\begin{array}{l}\text { Depth } \\
\text { below } \\
\text { surface (cm) }\end{array}$} & $\begin{array}{l}\text { Thickness } \\
\text { (cm) }\end{array}$ \\
\hline \multicolumn{2}{|c|}{ EI7 } & EIb1 & \multicolumn{2}{|l|}{$53+?$} & - & \multicolumn{2}{|c|}{ EI17 } & \multicolumn{2}{|c|}{ EIb2 } & \multicolumn{2}{|c|}{$\begin{array}{l}\text { Refusal at } \\
175\end{array}$} & \\
\hline \multicolumn{2}{|l|}{ EI6 } & EIb1 & \multicolumn{2}{|l|}{$62-83$} & \multicolumn{2}{|l|}{21} & EI12 & \multicolumn{2}{|c|}{ EIb2 } & \multicolumn{2}{|c|}{$147.5-171$} & 23.5 \\
\hline \multicolumn{2}{|l|}{ EI8 } & EIb1 & \multicolumn{2}{|l|}{$63-73+?$} & $10+$ & & VCEI2 & \multicolumn{2}{|c|}{ EIb2 } & \multicolumn{2}{|c|}{$142.5-174$} & 32 \\
\hline \multicolumn{2}{|c|}{ EI24 * } & EIb1 & \multicolumn{2}{|l|}{$73-90$} & \multicolumn{2}{|l|}{17} & EI28 & \multicolumn{2}{|c|}{ EIb2 } & \multicolumn{2}{|c|}{$145-156$} & 11 \\
\hline \multicolumn{2}{|l|}{ EI25* } & EIb1 & $71-88$ & & 17 & EI2 & & $\mathrm{El}$ & & 133 & 180 & 47 \\
\hline EI19B & & EIb1 & $73-128$ & & 55 & $\mathrm{VC}$ & & $\mathrm{EI}$ & & 176 & $9-188.7$ & 12 \\
\hline EI26 & & EIb1 & $77-98+$ & & $21+$ & EI3 & & $\mathrm{EI}$ & & 176 & & $?$ \\
\hline VCEI & & EIb1 & $60-72$ & & 12 & $\mathrm{EI3}$ & & $\mathrm{EI}$ & & 185 & 193 & 8 \\
\hline $\begin{array}{l}\text { N-S, a } \\
\text { pond. } \\
\text { Name } \\
\text { cores } \\
\text { transe }\end{array}$ & $\begin{array}{l}\text { ross } \\
\text { fong } \\
\text { long }\end{array}$ & & & & & $\begin{array}{l}\text { W- } \\
\text { No } \\
\text { Sid } \\
\text { Por } \\
\text { Na } \\
\text { cor }\end{array}$ & $\begin{array}{l}\text { th } \\
\text { de of } \\
\text { th }\end{array}$ & & & & & \\
\hline EI22 & & EIb2 & $164-187$ & & 23 & $\mathrm{VC}$ & & El & & 140 & $5-166.8$ & 27 \\
\hline EI1 & & EIb2 & $\begin{array}{l}\text { Only reac } \\
163.5\end{array}$ & & & EI3 & & $\mathrm{EI}$ & & 139 & 157 & 18 \\
\hline VCEI & & EIb2 & $140.5-166$ & & 27 & EI4 & & $\mathrm{EI}$ & & 139 & 143 & 4 \\
\hline Pond & & & & & & & & & & & & \\
\hline EI12 & & EIb2 & $147.5-171$ & & 23.5 & & & & & & & \\
\hline VCEI2 & & EIb2 & $142.5-17$ & & 32 & & & & & & & \\
\hline EI13 & & EIb2 & 143-167 & & 24 & & & & & & & \\
\hline EI14 & & EIb2 & $156-174+$ & & $18+$ & & & & & & & \\
\hline EI15 & & EIb2 & Final dep & $140 \mathrm{~cm}$ & & & & & & & & \\
\hline EI11 & & EIb2 & 135-140, & $53-167$ & 32 & & & & & & & \\
\hline EI16 & & EIb2 & Final dep & $133 \mathrm{~cm}$ & & & & & & & & \\
\hline $\begin{array}{l}\text { Name } \\
\text { of } \\
\text { Bed }\end{array}$ & $\begin{array}{l}\text { Sand } \\
\text { Dept } \\
\text { surf: }\end{array}$ & $\begin{array}{l}\text { Bed } \\
\text { below } \\
\text { e (cm) }\end{array}$ & $\begin{array}{l}\text { Thickness } \\
\text { (cm) }\end{array}$ & $\begin{array}{l}\text { Distance } \\
\text { between } \\
\text { cores }\end{array}$ & $\begin{array}{l}\text { Lateral } \\
\text { Extent } \\
\text { (m) }\end{array}$ & $\begin{array}{l}\text { Landward } \\
\text { Thinning }\end{array}$ & $\begin{array}{l}\text { Num } \\
\text { of } \\
\text { lamir }\end{array}$ & & $\begin{array}{l}\text { Ave } \\
\text { Gra } \\
\text { Size }\end{array}$ & & $\begin{array}{l}\text { Organic } \\
\text { Content }\end{array}$ & \\
\hline EIb1 & $62-9$ & & $17-55 \mathrm{~cm}$ & $10 \mathrm{~m}$ & $94.4 \mathrm{~m}$ & None & None & & $\begin{array}{l}\text { Silt } \\
\text { Loa }\end{array}$ & & $3.5-5 \%$ & \\
\hline EIb2 & $140-$ & $8 \mathrm{~cm}$ & $4-47 \mathrm{~cm}$ & $10 \mathrm{~m}$ & $86.3 \mathrm{~m}$ & Unclear & $0-2$ & & $\begin{array}{l}\text { San } \\
\text { Loa }\end{array}$ & & $4-11 \%$ & \\
\hline
\end{tabular}


Table 7. Organic content calculated from loss of ignition for Ship Harbor cores VCS2 and VCS6. Samples collected at $10 \mathrm{~cm}$ intervals throughout cores, starting below top peat bed.

\begin{tabular}{|c|c|c|c|c|c|}
\hline $\begin{array}{l}\text { Sample name } \\
\text { and uncorrected } \\
\text { core depth }(\mathrm{cm})\end{array}$ & $\begin{array}{l}\text { Sample } \\
\text { Corrected } \\
\text { Depth }(\mathrm{cm})\end{array}$ & $\begin{array}{l}\text { Organic } \\
\text { Content \% }\end{array}$ & $\begin{array}{l}\text { Sample name and } \\
\text { uncorrected core } \\
\text { depth }(\mathrm{cm})\end{array}$ & $\begin{array}{l}\text { Sample Corrected } \\
\text { Depth }(\mathrm{cm})\end{array}$ & $\begin{array}{l}\text { Organic } \\
\text { Content \% }\end{array}$ \\
\hline VCS2_N & & & VCS6N & & \\
\hline 60 & 106.4 & 23.95 & 70 & 123.2 & 32.93 \\
\hline 70 & 119.2 & 15.65 & 80 & 134.0 & 12.28 \\
\hline 80 & 132.1 & 10.40 & 90 & 144.8 & 10.00 \\
\hline 90 & 145.0 & 11.50 & 100 & 155.7 & 11.20 \\
\hline 100 & 157.9 & 12.39 & 110 & 166.5 & 12.24 \\
\hline 110 & 170.8 & 10.59 & 120 & 177.3 & 13.74 \\
\hline 120 & 183.7 & 10.98 & 130 & 188.1 & 11.50 \\
\hline 130 & 196.5 & 11.67 & 140 & 198.9 & 11.49 \\
\hline 140 & 209.4 & 11.59 & 150 & 209.7 & 9.96 \\
\hline 150 & 222.3 & 10.99 & 160 & 220.5 & 4.83 \\
\hline 160 & 235.2 & 22.02 & 170 & 231.3 & 23.52 \\
\hline 170 & 248.1 & 7.67 & 180 & 242.2 & 6.56 \\
\hline 180 & 260.9 & 10.20 & 190 & 253.0 & 10.36 \\
\hline 190 & 273.8 & 10.10 & 200 & 263.8 & 10.95 \\
\hline 200 & 286.7 & 4.10 & & & \\
\hline 210 & 299.6 & 2.06 & & & \\
\hline 220 & 312.5 & 2.07 & & & \\
\hline 230 & 325.4 & 0.83 & & & \\
\hline 240 & 338.2 & 2.35 & & & \\
\hline
\end{tabular}


Table 8. Organic content calculated from LOI for Eliza Island cores VCEI2 and VCEI3. Samples collected at $10 \mathrm{~cm}$ intervals throughout cores, starting below top peat bed.

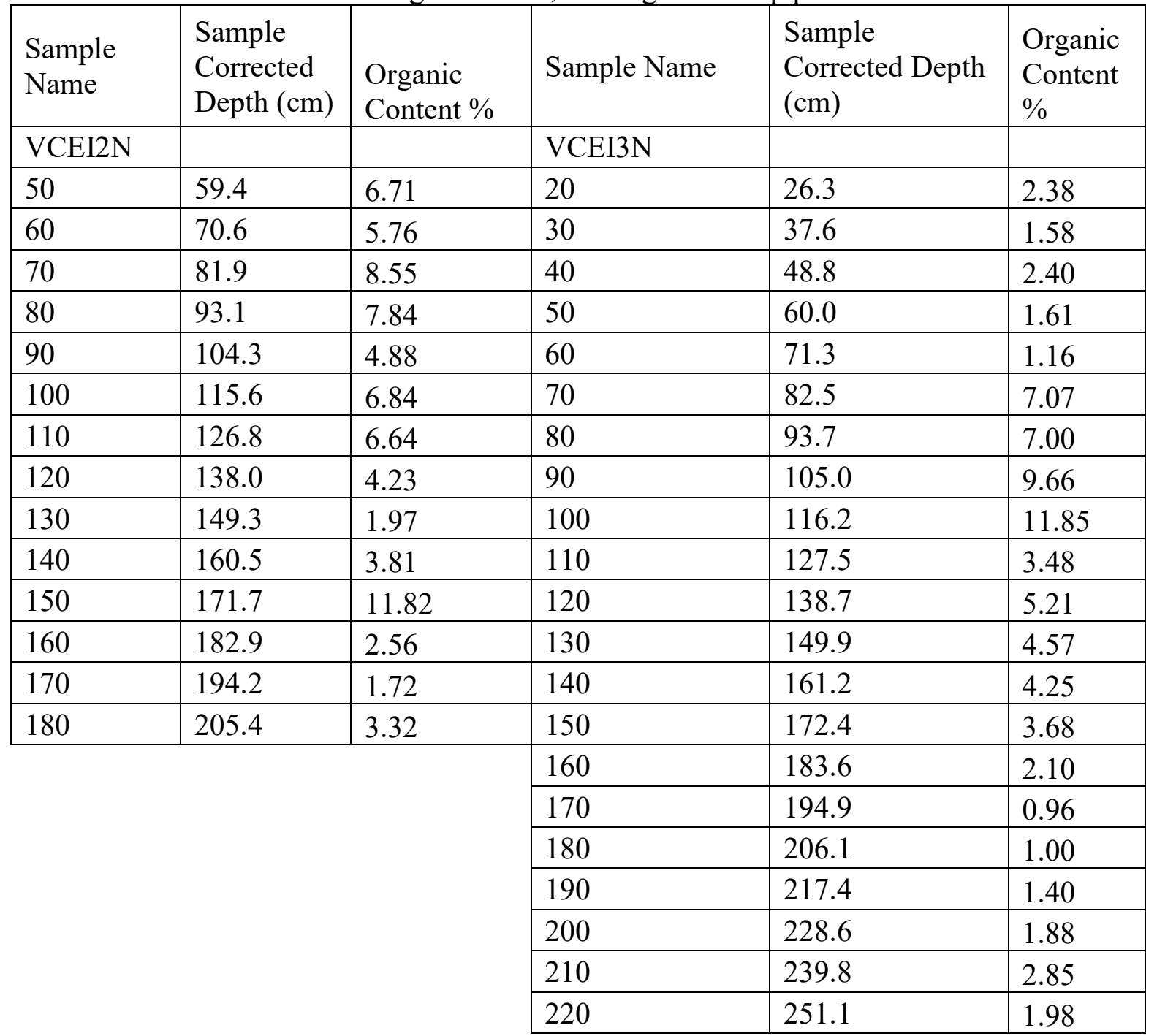


Table 9. Uncalibrated dates from NOSAMS ${ }^{14} \mathrm{C}$ dating analysis and $\mathrm{OxCal}$ calibrated dates using a simple OxCal C_Date calibration.

\begin{tabular}{|l|l|l|l|l|l|l|}
\hline Name & $\begin{array}{l}\text { Depth, } \\
\text { corrected } \\
\text { for } \\
\text { vibracore } \\
\text { compaction } \\
\text { (cm) }\end{array}$ & $\begin{array}{l}\text { Age, radiocarbon } \\
\text { years }\end{array}$ & $\begin{array}{l}\text { Age Error } \\
\text { (radio } \\
\text { carbon } \\
\text { years) }+ \text {-/ }\end{array}$ & $\begin{array}{l}\text { lalibrated } \\
\text { OxCal cal. years } \\
\text { BP }\end{array}$ & $\begin{array}{l}\text { \% } \\
\text { Confidence }\end{array}$ \\
\hline Ship Harbor & & & & from & to & \\
\hline VCS2n_RC28 & 168.20 & 1,600 & 25 & $\mathbf{1 5 4 6}$ & $\mathbf{1 4 1 4}$ & 95.4 \\
\hline VCS2n_RC6 & 217.15 & 1,860 & 15 & $\mathbf{1 8 6 4}$ & $\mathbf{1 7 3 0}$ & 95.4 \\
\hline VCS2n_RC14 & 235.83 & 1,820 & 15 & $\mathbf{1 8 1 5}$ & $\mathbf{1 7 1 4}$ & 95.4 \\
\hline VCS2n_RC12 & 236.47 & 1,840 & 15 & $\mathbf{1 8 2 1}$ & $\mathbf{1 7 2 2}$ & 95.4 \\
\hline VCS2n_RC13 & 238.41 & 2,610 & 15 & $\mathbf{2 7 5 9}$ & $\mathbf{2 7 3 9}$ & 95.4 \\
\hline VCS2n_RC17 & 248.07 & 2,470 & 15 & $\mathbf{2 7 0 5}$ & $\mathbf{2 4 6 4}$ & 95.4 \\
\hline VCS2n_RC23 & 295.73 & 3,290 & 20 & $\mathbf{3 5 6 7}$ & $\mathbf{3 4 6 2}$ & 95.4 \\
\hline VCS2n_RC25 & 322.78 & 3,920 & 20 & $\mathbf{4 4 2 4}$ & $\mathbf{4 2 9 1}$ & 95.4 \\
\hline Eliza Island & & & & & & \\
\hline VCEI2n_RC28 & 143.1 & 4,250 & 25 & $\mathbf{4 8 6 2}$ & $\mathbf{4 7 2 6}$ & 95.4 \\
\hline VCEI2n_RC19 & 154.9 & 4,420 & 20 & $\mathbf{5 2 1 3}$ & $\mathbf{4 8 7 8}$ & 95.3 \\
\hline VCEI2n_RC1 & 164.4 & 4,160 & 20 & $\mathbf{4 8 2 5}$ & $\mathbf{4 6 1 5}$ & 95.4 \\
\hline VCEI2n_RC8 & 176.2 & 4,480 & 20 & $\mathbf{5 2 8 7}$ & $\mathbf{5 0 3 9}$ & 95.4 \\
\hline
\end{tabular}


Table 10. OxCal sequence model results for Ship Harbor. Left if calibrated dates, right is sequence modeled age. Age of sand-sheet SHb1 is bold.

\begin{tabular}{|c|c|c|c|c|c|c|}
\hline \multirow[t]{2}{*}{ Name } & \multicolumn{2}{|c|}{$\begin{array}{l}\text { Calibrated } \\
\text { cal. years } \\
\text { B.P. }\end{array}$} & \multirow{2}{*}{$\begin{array}{l}\text { Confidence } \\
\% \\
\end{array}$} & \multicolumn{2}{|c|}{$\begin{array}{l}\text { OxCal Sequence } \\
\text { Modelled cal. } \\
\text { years BP }\end{array}$} & \multirow{2}{*}{$\begin{array}{l}\text { Confidence } \\
\% \\
\end{array}$} \\
\hline & from & to & & from & to & \\
\hline Boundary Top VCS2 & & & & 1122 & -713 & 95.4 \\
\hline C_Date Peat Bottom & 984 & 144 & 95.4 & 1134 & 265 & 95.4 \\
\hline R_Date VCS2n_RC28 & 1546 & 1414 & 95.4 & 1546 & 1414 & 95.4 \\
\hline R_Date VCS2n_RC6 & 1864 & 1730 & 95.4 & 1782 & 1717 & 95.4 \\
\hline Bed SHb1 & & & & 1802 & 1730 & 95.4 \\
\hline R_Date VCS2n_RC14 & 1815 & 1714 & 95.4 & 1820 & 1751 & 95.4 \\
\hline R_Date VCS2n_RC12 & 1821 & 1722 & 95.4 & 1825 & 1744 & 95.4 \\
\hline R_Date VCS2n_RC13 & 2759 & 2739 & 95.4 & 2759 & 2738 & 95.4 \\
\hline R_Date VCS2n_RC17 & 2705 & 2464 & 95.4 & 2705 & 2465 & 95.4 \\
\hline \multicolumn{7}{|l|}{ Phase Max Ages SHb1 } \\
\hline R_Date VCS2n_RC23 & 3567 & 3462 & 95.4 & 3568 & 3462 & 95.4 \\
\hline R_Date VCS2n_RC25 & 4424 & 4291 & 95.4 & 4424 & 4288 & 95.4 \\
\hline $\begin{array}{l}\text { Boundary Bottom } \\
\text { VCS2 }\end{array}$ & & & & 5623 & 4266 & 95.4 \\
\hline $\begin{array}{l}\text { Sequence Ship Harbor } \\
\text { B }\end{array}$ & & & & & & \\
\hline
\end{tabular}

Table 11. OxCal sequence model results for Eliza Island.

\begin{tabular}{|l|l|l|l|l|l|l|}
\hline & \multicolumn{2}{|l|}{$\begin{array}{l}\text { Calibrated cal. } \\
\text { Nears B.P. }\end{array}$} & $\begin{array}{l}\text { OxCal Sequence } \\
\text { Confidence }\end{array}$ & $\begin{array}{l}\text { Modelled cal. } \\
\text { years B.P. }\end{array}$ & $\begin{array}{l}\% \\
\text { Confidence }\end{array}$ \\
\hline & from & to & $\%$ & from & to & $\%$ \\
\hline Boundary Top & & & & 4756 & 4248 & 95.4 \\
\hline R_Date VCEI2n_RC28 & 4862 & 4726 & 95.4 & 4758 & 4652 & 95.4 \\
\hline Bed EIb2 & & & & $\mathbf{4 8 2 0}$ & $\mathbf{4 6 6 9}$ & $\mathbf{9 5 . 4}$ \\
\hline R_Date VCEI2n_RC19 & 5213 & 4878 & 95.3 & 5049 & 4880 & 95.4 \\
\hline R_Date VCEI2n_RC1 & 4825 & 4615 & 95.4 & 4830 & 4724 & 95.4 \\
\hline Phase Bed EIb2 Eliza & & & & & & \\
\hline R_Date VCEI2n_RC8 & 5287 & 5039 & 95.4 & 5274 & 4980 & 95.4 \\
\hline Boundary Base & & & & 5611 & 4985 & 95.4 \\
\hline Sequence Eliza Island & & & & & & \\
\hline
\end{tabular}


Table 12. Table of Error for Ship Harbor AMS results. AMS error is reported in \% error, calculated by the Kappabridge software during analysis. AMS error relates directly to the instruments ability to easily measure a susceptibility in one direction in the presence of the low field produced. A1, A2 and A3 all refer to axis positions used to do analysis with the KYL-3 Kappabridge for AMS analysis. Color indicates stratiraphic designation, with pink being peat, green being sand-poor silt-rich mud, and blue being sand-sheet beds sample from within the core. Sample name indicates which vibracore samples were collected in followed by T or B indicating top (T) or bottom (B) portion of core, and $\mathrm{N}$ or $\mathrm{S}$ indicating which half of the core was sampled, with $\mathrm{N}$ being for North out of the core barrel and $\mathrm{S}$ being for South out of the core barrel.

\begin{tabular}{|c|c|c|c|c|c|}
\hline Core Name & $\begin{array}{r}\text { Sampling } \\
\text { Depth Top } \\
(\mathrm{cm}), \\
\text { Corrected for } \\
\text { compaction }\end{array}$ & $\begin{array}{r}\text { Sampling depth } \\
\text { top, core reference } \\
\text { (uncorrected) }\end{array}$ & $\begin{array}{r}\text { AMS Error } \\
\text { A1 \% }\end{array}$ & $\begin{array}{r}\text { AMS } \\
\text { Error A2 } \\
\%\end{array}$ & AMS Error A3 \\
\hline VCS2_TN & 50.5 & 16.6 & 100 & 100 & 100 \\
\hline VCS2_TN & 60.2 & 24.2 & 100 & 100 & 100 \\
\hline VCS2_TN & 69.5 & 31.4 & 100 & 100 & 100 \\
\hline VCS2_TN & 88.1 & 45.8 & 100 & 100 & 100 \\
\hline VCS2_TN & 97.3 & 53 & 100 & 100 & 100 \\
\hline VCS2_TN & 114.3 & 66.2 & $5-11 \%$ & $5-11 \%$ & $5-11 \%$ \\
\hline VCS2_TN & 125.4 & 74.8 & 34.63 & 9.28 & 16.84 \\
\hline VCS2_TN & 134.4 & 81.8 & 62.31 & 12.32 & No Record \\
\hline VCS2_TN & 143.7 & 89 & 33.06 & 4.54 & No Record \\
\hline VCS2_TN & 151.7 & 95.2 & 7.02 & 3.74 & 5.27 \\
\hline VCS2_TN & 162.3 & 103.4 & 20.24 & 4.65 & 9.3 \\
\hline VCS2_TN & 171.5 & 110.6 & 19 & 8.62 & 7.79 \\
\hline VCS2_TN & 180.8 & 117.8 & No Record & $\begin{array}{l}\text { No } \\
\text { Record }\end{array}$ & No Record \\
\hline VCS2_BN & 190.1 & 125 & 116.96 & 10.8 & 5.93 \\
\hline VCS2_BN & 199.8 & 132.5 & 98.61 & 2.93 & 6.24 \\
\hline VCS2_BN & 209.4 & 140 & 45.87 & 5.27 & No Record \\
\hline VCS2_BN & 224.9 & 152 & 11.48 & 12.02 & 26.58 \\
\hline VCS2_BN & 236.0 & 160.6 & 7.68 & 6.76 & 7.63 \\
\hline VCS2_BN & 239.7 & 163.5 & 9.09 & 4.56 & $\sim 7$ \\
\hline VCS2_BN & 242.9 & 166 & 12.65 & 17.58 & 1.35 \\
\hline VCS2_BN & 246.1 & 168.5 & 3.24 & 3.24 & 28.84 \\
\hline VCS2_BN & 251.3 & 172.5 & 10.98 & 7.32 & No Record \\
\hline VCS2_BN & 253.2 & 174 & 10.1 & 2.74 & 1.59 \\
\hline VCS2_BN & 260.9 & 180 & 37.8 & 10.5 & 6.79 \\
\hline VCS2_BN & 270.6 & 187.5 & 9.61 & 10.01 & 29.02 \\
\hline VCS2_BN & 280.3 & 195 & 1.61 & 3.29 & 3.96 \\
\hline VCS2_BN & 309.3 & 217.5 & 1.24 & 6.6 & 0.75 \\
\hline
\end{tabular}




\begin{tabular}{|r|r|r|r|r|r|}
\hline VCS2_BN & 316.3 & 223 & 0.31 & 0.92 & 0.95 \\
\hline VCS2_BN & 334.4 & 237 & 0.54 & 2.93 & 1.25 \\
\hline
\end{tabular}

\begin{tabular}{|c|c|c|c|c|c|}
\hline Core Name & $\begin{array}{l}\text { Sampling Depth } \\
\text { Top, Corrected } \\
\text { for compaction }\end{array}$ & $\begin{array}{c}\text { Sampling } \\
\text { depth top, } \\
\text { core reference } \\
\text { (uncorrected) }\end{array}$ & AMS Error A1 & AMS Error A2 & $\begin{array}{c}\text { AMS Error } \\
\quad \text { A3 }\end{array}$ \\
\hline \multicolumn{6}{|l|}{ VCS6_TN } \\
\hline VCS6_TN & 58.3 & 10 & 48.6 & 30.5 & 113.68 \\
\hline VCS6_TN & 63.7 & 15 & 37.69 & 27.67 & 82.7 \\
\hline VCS6_TN & 71.5 & 22.2 & 36.29 & 48.86 & 108.97 \\
\hline VCS6_TN & 79.3 & 29.4 & 71.4 & 54.75 & 57.06 \\
\hline VCS6_TN & 87.1 & 36.6 & 43.41 & 56.38 & 100.11 \\
\hline VCS6_TN & 94.9 & 43.8 & 49.4 & 29.17 & 83.46 \\
\hline VCS6_TN & 102.7 & 51 & 70.75 & 31.49 & \\
\hline VCS6_TN & 110.5 & 58.2 & 74.63 & 55.38 & \\
\hline VCS6_TN & 118.2 & 65.4 & 65.62 & & \\
\hline VCS6_TN & 125.4 & 72 & 64.15 & & \\
\hline VCS6_TN & 131.6 & 77.8 & 122.54 & 52.34 & 53.99 \\
\hline VCS6_TN & 139.2 & 84.8 & 12.32 & 16.35 & 5.15 \\
\hline VCS6_TN & 147.0 & 92 & 41.24 & 34.57 & 7.59 \\
\hline VCS6_BN & 152.4 & 97 & 16.09 & 24.03 & \\
\hline VCS6_BN & 160.0 & 104 & 55.58 & 32.29 & 24.47 \\
\hline VCS6_BN & 167.8 & 111.2 & 49.29 & 11.66 & 21.92 \\
\hline VCS6_BN & 175.5 & 118.4 & 33.19 & 5.86 & 14.24 \\
\hline VCS6_BN & 183.3 & 125.6 & 20.57 & 10.23 & 4.81 \\
\hline VCS6_BN & 191.1 & 132.8 & 63.4 & 10.25 & 9.39 \\
\hline VCS6_BN & 198.9 & 140 & 147.5 & 9.43 & 9.36 \\
\hline VCS6_BN & 207.6 & 148 & 63.83 & 14.08 & 7.12 \\
\hline VCS6_BN & 214.5 & 154.4 & 2.9 & 3.74 & 2.23 \\
\hline VCS6_BN & 222.3 & 161.6 & 4.17 & 1.52 & 1.45 \\
\hline VCS6_BN & 220.5 & 160 & & & \\
\hline VCS6_BS & 217.3 & 157 & & & \\
\hline VCS6_BS & 221.6 & 161 & & & \\
\hline VCS6_BS & 224.3 & 163.5 & & & \\
\hline VCS6_BS & 228.1 & 167 & & & \\
\hline VCS6_BN & 230.0 & 168.8 & 67.56 & 5.64 & 6.15 \\
\hline VCS6_BN & 239.3 & 177.4 & 1.96 & 5.05 & 6.15 \\
\hline VCS6_BN & 245.6 & 183.2 & 25.06 & 17.17 & 25.31 \\
\hline VCS6_BN & 253.4 & 190.4 & 38.1 & 8.97 & 19.62 \\
\hline VCS6_BN & 262.7 & 199 & 56.05 & 62.95 & 34.7 \\
\hline
\end{tabular}


Table 13. Table of error for Eliza Island AMS results. AMS error is reported in \% error, calculated by the Kappabridge software during analysis. A1, A2 and A3 all refer to axis positions used to do analysis with the KYL-3 Kappabridge for AMS analysis. Color indicates stratiraphic designation, with pink being peat, green being sand-poor silt-rich mud, and blue being sand-sheet beds sample from within the core. Sample name indicates which vibracore samples were collected in followed by $\mathrm{T}$ or $\mathrm{B}$ indicating top (T) or bottom (B) portion of core, and $\mathrm{N}$ or $\mathrm{S}$ indicating which half of the core was sampled, with $\mathrm{N}$ being for North out of the core barrel and $\mathrm{S}$ being for South out of the core barrel.

\begin{tabular}{|c|c|c|c|c|c|}
\hline Core Name & $\begin{array}{l}\text { Sampling } \\
\text { Depth Top, } \\
\text { Corrected for } \\
\text { compaction } \\
\text { (cm) }\end{array}$ & $\begin{array}{l}\text { Sampling } \\
\text { depth top, core } \\
\text { reference } \\
\text { (uncorrected) } \\
\text { (cm) }\end{array}$ & $\begin{array}{l}\text { AMS } \\
\text { Error } \\
\text { Axis } 1 \%\end{array}$ & $\begin{array}{l}\text { AMS } \\
\text { Error } \\
\text { Axis } 2 \%\end{array}$ & $\begin{array}{l}\text { AMS Error } \\
\text { Axis } 3 \%\end{array}$ \\
\hline VCEI2_TN & 25.7 & 20 & 45.27 & 165.21 & 40.67 \\
\hline VCEI2_TN & 37.0 & 30 & 500.35 & 132.23 & 36 \\
\hline VCEI2_TN & 48.2 & 40 & 46.72 & 29.45 & 30.59 \\
\hline VCEI2_TN & 59.4 & 50 & 27.68 & 4.89 & 4.76 \\
\hline VCEI2_TN & 67.8 & 57.5 & 16.48 & 5.92 & 7.44 \\
\hline VCEI2_TN & 76.3 & 65 & 18.55 & 16.6 & No Record \\
\hline VCEI2_TN & 84.7 & 72.5 & 41.98 & 15 & 12.26 \\
\hline VCEI2_TN & 93.1 & 80 & 71.79 & 34.59 & 14.66 \\
\hline VCEI2_TN & 104.3 & 90 & 16.36 & 11.83 & 17.5 \\
\hline VCEI2_TN & 109.9 & 95 & 1.78 & 2.61 & 2.11 \\
\hline VCEI2_BN & 118.4 & 102.5 & 2.93 & 6.59 & 3.31 \\
\hline VCEI2_BN & 126.8 & 110 & 42.18 & 25.22 & 5.1 \\
\hline VCEI2_BN & 135.2 & 117.5 & 40.79 & 13.12 & 8.67 \\
\hline VCEI2_BN & 138.6 & 120.5 & 23.42 & 7.32 & 6.3 \\
\hline VCEI2_BN & 143.6 & 125 & 11.37 & 11.93 & 7.44 \\
\hline VCEI2_BN & 147.6 & 128.5 & 17.45 & 11.19 & 8.39 \\
\hline VCEI2_BN & 152.1 & 132.5 & 4.39 & 13.77 & 7.75 \\
\hline VCEI2_BN & 156.0 & 136 & 19.94 & 13.92 & 10.25 \\
\hline VCEI2_BN & 160.5 & 140 & 26.97 & 11.34 & 11.36 \\
\hline VCEI2_BN & 171.1 & 149.5 & 7.47 & 7.53 & 15.13 \\
\hline VCEI2_BN & 179.6 & 157 & 3.23 & 1.05 & 1.36 \\
\hline VCEI2_BN & 189.7 & 166 & 4.15 & 3.47 & 1.91 \\
\hline VCEI2_BN & 196.4 & 172 & 54 & 84.05 & 45.88 \\
\hline VCEI2_BN & 205.4 & 180 & 50.88 & 32.01 & 15.7 \\
\hline
\end{tabular}


Table 13. Continued from previous page

\begin{tabular}{|l|l|l|l|l|l|}
\hline Core Name & $\begin{array}{l}\text { Sampling } \\
\text { Depth Top, } \\
\text { Corrected for } \\
\text { compaction }\end{array}$ & $\begin{array}{l}\text { Sampling } \\
\text { depth top, core } \\
\text { reference } \\
\text { (uncorrected) }\end{array}$ & $\begin{array}{l}\text { AMS } \\
\text { Error A1 }\end{array}$ & $\begin{array}{l}\text { AMS } \\
\text { Error A2 }\end{array}$ & $\begin{array}{l}\text { AMS } \\
\text { Error A3 }\end{array}$ \\
\hline VCEI3_TN & 36.4 & 29 & 1.63 & 0.6 & low \\
\hline VCEI3_TN & 56.7 & 47 & 1.18 & 0.26 & 0.59 \\
\hline VCEI3_TN & 74.6 & 63 & 11.45 & 4.6 & 7.81 \\
\hline VCEI3_TN & 79.1 & 67 & 19.85 & 5.17 & 4.96 \\
\hline VCEI3_TN & 85.3 & 72.5 & 16.1 & 9.44 & 8.61 \\
\hline VCEI3_TN & 93.7 & 80 & 9.49 & 2.91 & 1.01 \\
\hline VCEI3_TN & 102.2 & 87.5 & 163.17 & 16.96 & 29.04 \\
\hline VCEI3_TN & 110.6 & 95 & 7.25 & 2.09 & 3.93 \\
\hline VCEI3_TN & 121.8 & 105 & 68.57 & 8.14 & 7.59 \\
\hline VCEI3_BN & 126.3 & 109 & 38.68 & 8.42 & 13.09 \\
\hline VCEI3_BN & 135.9 & 117.5 & 27.46 & 7.81 & 27.88 \\
\hline VCEI3_BN & 144.3 & 125 & 7.57 & 4.85 & 2.14 \\
\hline VCEI3_BN & 152.7 & 132.5 & 4.29 & 15.72 & 7 \\
\hline VCEI3_BN & 161.2 & 140 & 16.02 & 9.03 & 3.74 \\
\hline VCEI3_BN & 169.6 & 147.5 & 12.76 & 4.44 & 3.23 \\
\hline VCEI3_BN & 183.6 & 160 & 3.99 & 7.7 & 7.17 \\
\hline VCEI3_BN & 205.0 & 179 & 0.47 & 0.35 & 2.49 \\
\hline VCEI3_BN & 211.7 & 185 & 2.58 & 0.98 & 10.41 \\
\hline VCEI3_BN & 220.2 & 192.5 & 0.76 & 0.78 & 0.79 \\
\hline VCEI3_BN & 228.6 & 200 & 2.1 & 0.47 & 0.41 \\
\hline VCEI3_BN & 237.0 & 207.5 & 1.24 & 0.23 & 0.25 \\
\hline
\end{tabular}


Table 14. Table of AMS mean tensors for Ship Harbor. Declinations (Dec) and inclinations (Inc) are the mean grain orientations reported for each axis measured within the sample, corrected for geographic orientation in space. $\mathrm{K}_{\max }, \mathrm{K}_{\text {int }}$ and $\mathrm{K}_{\min }$ refer to the maximum, intermediate, and minimum susceptibility axes respectively. $\mathrm{N}$ is number of samples included in average.

\begin{tabular}{|c|c|c|c|c|c|c|c|c|c|}
\hline Core & Unit Type & $\mathrm{N}$ & $\begin{array}{l}\text { Mean } \\
K_{\max } \\
\text { Dec }\end{array}$ & $\begin{array}{l}\text { Mean } \\
\mathrm{K}_{\max } \\
\text { Inc }\end{array}$ & $\begin{array}{l}\text { Mean } \\
K_{\text {int }} \\
\text { Dec }\end{array}$ & $\begin{array}{l}\text { Mean } \\
K_{\text {int }} \\
\text { Inc }\end{array}$ & $\begin{array}{l}\text { Mean } \\
\mathrm{K}_{\text {min }} \\
\text { Dec }\end{array}$ & $\begin{array}{l}\text { Mean } \\
\mathrm{K}_{\min } \\
\text { Inc }\end{array}$ & Notes \\
\hline VCS2 & Peat & 5 & 333.3 & 52 & 170 & 36.7 & 74 & 8.3 & \\
\hline & Clay & 13 & 282.6 & 82 & 92.5 & 7.9 & 182.7 & 1.4 & \\
\hline & SHb1 & 6 & 34.5 & 33.8 & 275.2 & 36.1 & 153.4 & 35.8 & $\begin{array}{l}\text { Kmins appear } \\
\text { imbricated }\end{array}$ \\
\hline & Basal (bottom) & 3 & 89.2 & 41.2 & 289.3 & 47 & 188.2 & 10.2 & \\
\hline
\end{tabular}

\begin{tabular}{|c|c|c|c|c|c|c|c|c|c|}
\hline Core & Unit Type & $\mathrm{N}$ & $\begin{array}{l}\text { Mean } \\
\mathrm{K}_{\max } \text { Dec }\end{array}$ & $\begin{array}{l}\text { Mean } \\
\mathrm{K}_{\max } \text { Inc } \\
\end{array}$ & $\begin{array}{l}\text { Mean } \\
\mathrm{K}_{\text {int }} \text { Dec }\end{array}$ & $\begin{array}{l}\text { Mean } \\
\mathrm{K}_{\text {int }} \\
\text { Inc }\end{array}$ & $\begin{array}{l}\text { Mean } \\
\mathrm{K}_{\min } \\
\text { Dec }\end{array}$ & $\begin{array}{l}\text { Mean } \\
\mathrm{K}_{\min } \\
\text { Inc }\end{array}$ & Notes \\
\hline VCS6 & Peat & 8 & 3.1 & 19.5 & 226.2 & 64.2 & 99 & 16.3 & \\
\hline & Clay & 15 & 281.9 & 9.8 & 12.9 & 5.9 & 133.4 & 78.5 & \\
\hline & SHb1 & 3 & 108 & 11.2 & 200.1 & 10.6 & 332.4 & 74.5 & \\
\hline
\end{tabular}

Table 15. Table of AMS mean tensors for Eliza Island. Declinations (Dec) and inclinations (Inc) are the mean grain orientations reported for each axis measured within the sample, corrected for geographic orientation in space. Kmax, Kint and Kmin refer to the maximum, intermediate, and minimum susceptibility axes respectively.

\begin{tabular}{|c|c|c|c|c|c|c|c|c|c|}
\hline Core & Unit Type & $\mathrm{N}$ & $\begin{array}{l}\text { Mean } \\
\mathrm{K}_{\max } \text { Dec }\end{array}$ & $\begin{array}{l}\text { Mean } \\
\mathrm{K}_{\max } \text { Inc }\end{array}$ & $\begin{array}{l}\text { Mean } \\
\mathrm{K}_{\text {int }} \text { Dec }\end{array}$ & $\begin{array}{l}\text { Mean } \\
\mathrm{K}_{\text {int }} \\
\text { Inc }\end{array}$ & $\begin{array}{l}\text { Mean } \\
\mathrm{K}_{\min } \\
\text { Dec }\end{array}$ & $\begin{array}{l}\text { Mean } \\
\mathrm{K}_{\min } \\
\text { Inc }\end{array}$ & Notes \\
\hline VCEI2 & Soil & 3 & 2.8 & 19.2 & 93.7 & 2.7 & 191.5 & 70.6 & \\
\hline & Clay & 15 & 296.8 & 6.8 & 206.6 & 1.7 & 102.8 & 83 & $\begin{array}{l}\text { Kmax and Kint } \\
\text { distribution suggests } \\
\text { settling }\end{array}$ \\
\hline & EIb2 & 6 & 204.6 & 9.5 & 296.1 & 8.8 & 67.9 & 77 & $\begin{array}{l}\text { General grouping of } \\
\text { Kmax and Kints, } \\
\text { potential imbricaiton of } \\
\text { sands }\end{array}$ \\
\hline
\end{tabular}

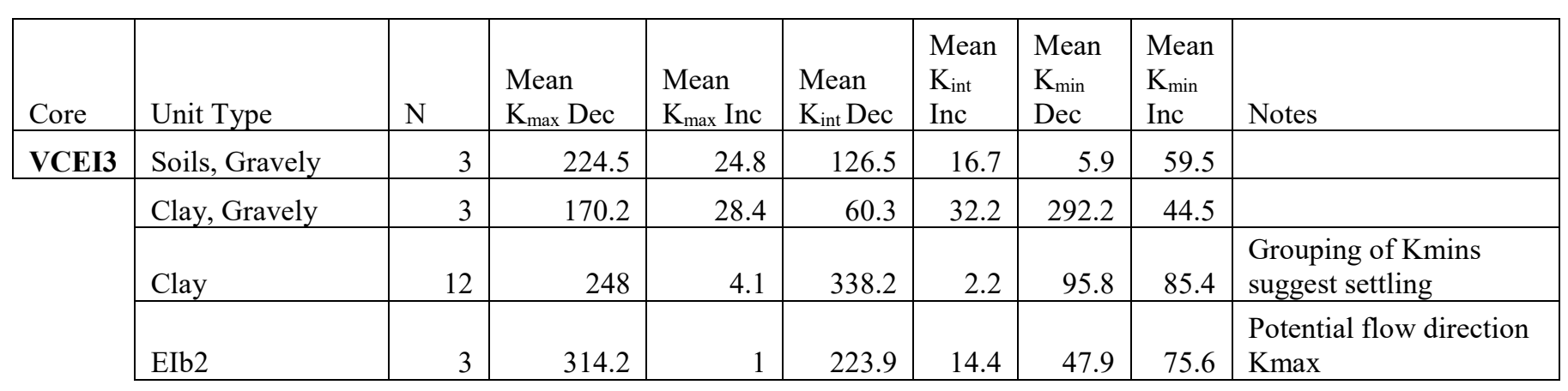


Table 16. AMS calculated parameters, with parameters described on pg. 41-42. Equations for parameter calculations are described in Appendix 4, page 3.

\begin{tabular}{|c|c|c|c|c|c|c|c|c|c|}
\hline $\begin{array}{l}\text { Sampling } \\
\text { Depth Top, } \\
\text { Corrected } \\
\text { for } \\
\text { compaction }\end{array}$ & $\begin{array}{l}\text { Sampling } \\
\text { depth top, } \\
\text { core } \\
\text { reference } \\
\text { (uncorrected) }\end{array}$ & $\mathbf{L}$ & $\mathbf{F}$ & $\mathbf{P}$ & $\mathbf{P j}$ & $\mathbf{T}$ & $\mathbf{U}$ & $\mathbf{Q}$ & $\mathbf{E}$ \\
\hline \multicolumn{10}{|l|}{ VCS2 } \\
\hline 50.5 & 16.6 & 1.02 & 1.00 & 1.02 & 1.02 & -0.76 & 0.76 & 0.13 & 0.99 \\
\hline 60.2 & 24.2 & 1.02 & 1.01 & 1.03 & 1.03 & -0.53 & 0.54 & 0.26 & 0.98 \\
\hline 69.5 & 31.4 & 1.01 & 1.03 & 1.04 & 1.04 & 0.69 & -0.68 & 1.45 & 1.02 \\
\hline 88.1 & 45.8 & 1.01 & 1.01 & 1.02 & 1.02 & -0.33 & 0.34 & 0.40 & 0.99 \\
\hline 97.3 & 53 & 1.01 & 1.00 & 1.02 & 1.02 & -0.45 & 0.45 & 0.32 & 0.99 \\
\hline 114.3 & 66.2 & 1.03 & 1.00 & 1.03 & 1.04 & -0.76 & -0.76 & 1.57 & 0.98 \\
\hline 125.4 & 74.8 & 1.01 & 1.02 & 1.03 & 1.03 & 0.30 & 0.29 & 0.43 & 1.01 \\
\hline 134.4 & 81.8 & 1.01 & 1.04 & 1.04 & 1.04 & 0.73 & 0.72 & 0.15 & 1.03 \\
\hline 143.7 & 89 & 1.01 & 1.03 & 1.04 & 1.04 & 0.41 & 0.41 & 0.35 & 1.01 \\
\hline 151.7 & 95.2 & 1.01 & 1.03 & 1.04 & 1.04 & 0.55 & 0.54 & 0.26 & 1.02 \\
\hline 162.3 & 103.4 & 1.01 & 1.03 & 1.04 & 1.05 & 0.51 & 0.51 & 0.28 & 1.02 \\
\hline 171.5 & 110.6 & 1.02 & 1.04 & 1.06 & 1.06 & 0.26 & 0.25 & 0.46 & 1.02 \\
\hline 180.8 & 117.8 & & & & & & & & \\
\hline 190.1 & 125 & 1.00 & 1.04 & 1.05 & 1.05 & 0.94 & 0.94 & 0.03 & 1.04 \\
\hline 199.8 & 132.5 & & & & & & & & \\
\hline 209.4 & 140 & 1.01 & 1.06 & 1.07 & 1.08 & 0.82 & 0.81 & 0.10 & 1.06 \\
\hline 224.9 & 152 & 1.01 & 1.01 & 1.02 & 1.02 & 0.19 & 0.18 & 0.51 & 1.00 \\
\hline 236.0 & 160.6 & 1.03 & 1.02 & 1.04 & 1.04 & -0.20 & -0.21 & 0.87 & 0.99 \\
\hline 239.7 & 163.5 & 1.01 & 1.02 & 1.03 & 1.03 & 0.17 & 0.16 & 0.53 & 1.01 \\
\hline 242.9 & 166 & 1.02 & 1.01 & 1.03 & 1.03 & -0.12 & -0.13 & 0.79 & 1.00 \\
\hline 246.1 & 168.5 & 1.01 & 1.04 & 1.05 & 1.05 & 0.76 & 0.76 & 0.13 & 1.04 \\
\hline 251.3 & 172.5 & 1.04 & 1.02 & 1.06 & 1.06 & -0.38 & -0.39 & 1.06 & 0.98 \\
\hline 253.2 & 174 & 1.01 & 1.00 & 1.01 & 1.01 & -0.17 & -0.17 & 0.83 & 1.00 \\
\hline 260.9 & 180 & 1.01 & 1.03 & 1.03 & 1.04 & 0.52 & 0.51 & 0.28 & 1.02 \\
\hline 270.6 & 187.5 & 1.02 & 1.01 & 1.03 & 1.03 & $\begin{array}{l}-0.19 \\
\end{array}$ & -0.20 & 0.86 & 1.00 \\
\hline 280.3 & 195 & 1.03 & 1.02 & 1.05 & 1.05 & -0.23 & -0.25 & 0.90 & 0.99 \\
\hline 309.3 & 217.5 & 1.02 & 1.02 & 1.04 & 1.04 & -0.14 & -0.15 & 0.81 & 0.99 \\
\hline 316.3 & 223 & 1.04 & 1.08 & 1.12 & 1.12 & 0.30 & 0.28 & 0.44 & 1.03 \\
\hline 334.4 & 237 & 1.01 & 1.02 & 1.03 & 1.03 & 0.59 & 0.59 & 0.23 & 1.02 \\
\hline \multicolumn{10}{|l|}{ VCS6 } \\
\hline 58.3 & 10 & & & & & & & & \\
\hline 63.7 & 15 & & & & & & & & \\
\hline 71.5 & 22.2 & & & & & & & & \\
\hline
\end{tabular}




\begin{tabular}{|c|c|c|c|c|c|c|c|c|c|}
\hline 79.3 & 29.4 & 1.03 & 1.01 & 1.04 & 1.04 & -0.36 & 0.37 & 0.37 & 0.99 \\
\hline 87.1 & 36.6 & 1.02 & 1.02 & 1.03 & 1.04 & 0.11 & -0.10 & 0.76 & 1.00 \\
\hline 94.9 & 43.8 & 1.03 & 1.05 & 1.08 & 1.08 & 0.25 & -0.24 & 0.89 & 1.02 \\
\hline 102.7 & 51 & 1.01 & 1.05 & 1.06 & 1.07 & 0.66 & -0.65 & 1.40 & 1.04 \\
\hline 110.5 & 58.2 & 1.03 & 1.02 & 1.06 & 1.06 & -0.16 & 0.18 & 0.52 & 0.99 \\
\hline 118.2 & 65.4 & 1.02 & 1.04 & 1.07 & 1.07 & 0.35 & -0.33 & 1.00 & 1.02 \\
\hline 125.4 & 72 & 1.01 & 1.01 & 1.03 & 1.03 & 0.00 & -0.01 & 0.67 & 1.00 \\
\hline 131.6 & 77.8 & 1.00 & 1.02 & 1.02 & 1.02 & 0.76 & 0.75 & 0.13 & 1.01 \\
\hline 139.2 & 84.8 & 1.02 & 1.03 & 1.05 & 1.05 & 0.19 & 0.17 & 0.52 & 1.01 \\
\hline 147.0 & 92 & 1.01 & 1.02 & 1.03 & 1.03 & 0.19 & 0.18 & 0.51 & 1.01 \\
\hline 152.4 & 97 & & & & & & & & \\
\hline 160.0 & 104 & 1.01 & 1.01 & 1.02 & 1.02 & 0.35 & 0.35 & 0.39 & 1.01 \\
\hline 167.8 & 111.2 & 1.01 & 1.01 & 1.01 & 1.01 & -0.07 & -0.08 & 0.74 & 1.00 \\
\hline 175.5 & 118.4 & 1.01 & 1.02 & 1.03 & 1.03 & 0.61 & 0.60 & 0.22 & 1.02 \\
\hline 183.3 & 125.6 & 1.02 & 1.06 & 1.09 & 1.09 & 0.44 & 0.42 & 0.34 & 1.04 \\
\hline 191.1 & 132.8 & 1.00 & 1.03 & 1.04 & 1.04 & 0.78 & 0.77 & 0.12 & 1.03 \\
\hline 198.9 & 140 & 1.00 & 1.03 & 1.04 & 1.04 & 0.81 & 0.80 & 0.10 & 1.03 \\
\hline 207.6 & 148 & 1.01 & 1.00 & 1.01 & 1.01 & -0.48 & -0.48 & 1.18 & 1.00 \\
\hline 214.5 & 154.4 & 1.02 & 1.00 & 1.02 & 1.02 & -0.59 & -0.60 & 1.33 & 0.99 \\
\hline 222.3 & 161.6 & 1.01 & 1.01 & 1.02 & 1.02 & 0.46 & 0.46 & 0.31 & 1.01 \\
\hline 220.5 & 160 & 1.01 & 1.09 & 1.09 & 1.11 & 0.83 & 0.83 & 0.09 & 1.08 \\
\hline 217.3 & 157 & 1.02 & 1.01 & 1.02 & 1.03 & -0.58 & -0.58 & 1.31 & 0.99 \\
\hline 221.6 & 161 & 1.02 & 1.01 & 1.02 & 1.02 & -0.49 & -0.49 & 1.19 & 0.99 \\
\hline 224.3 & 163.5 & 1.02 & 1.04 & 1.06 & 1.06 & 0.33 & 0.32 & 0.41 & 1.02 \\
\hline 228.1 & 167 & 1.01 & 1.01 & 1.02 & 1.02 & 0.01 & 0.01 & 0.66 & 1.00 \\
\hline 230.0 & 168.8 & 1.00 & 1.06 & 1.06 & 1.07 & 0.88 & 0.88 & 0.06 & 1.05 \\
\hline 239.3 & 177.4 & 1.02 & 1.02 & 1.04 & 1.04 & -0.06 & -0.07 & 0.73 & 1.00 \\
\hline 245.6 & 183.2 & 1.01 & 1.02 & 1.03 & 1.03 & 0.08 & 0.07 & 0.60 & 1.00 \\
\hline 253.4 & 190.4 & 1.01 & 1.02 & 1.04 & 1.04 & 0.34 & 0.33 & 0.40 & 1.01 \\
\hline 262.7 & 199 & 1.01 & 1.02 & 1.03 & 1.03 & 0.55 & 0.55 & 0.25 & 1.02 \\
\hline \multicolumn{10}{|l|}{ VCEI2 } \\
\hline 25.7 & 20 & 1.06 & 1.05 & 1.11 & 1.11 & -0.06 & 0.09 & 0.59 & 0.99 \\
\hline 37.0 & 30 & 1.02 & 1.02 & 1.05 & 1.05 & 0.02 & 0.00 & 0.67 & 1.00 \\
\hline 48.2 & 40 & 1.27 & 1.23 & 1.56 & 1.57 & -0.06 & 0.17 & 0.52 & 0.97 \\
\hline 59.4 & 50 & 1.01 & 1.05 & 1.06 & 1.06 & 0.53 & 0.52 & 0.27 & 1.03 \\
\hline 67.8 & 57.5 & 1.01 & 1.04 & 1.05 & 1.06 & 0.75 & 0.75 & 0.14 & 1.04 \\
\hline 76.3 & 65 & 1.03 & 1.02 & 1.05 & 1.05 & -0.13 & -0.14 & 0.79 & 0.99 \\
\hline 84.7 & 72.5 & 1.01 & 1.03 & 1.04 & 1.04 & 0.41 & 0.41 & 0.35 & 1.02 \\
\hline 93.1 & 80 & 1.01 & 1.02 & 1.03 & 1.03 & 0.39 & 0.38 & 0.37 & 1.01 \\
\hline
\end{tabular}




\begin{tabular}{|c|c|c|c|c|c|c|c|c|c|}
\hline 104.3 & 90 & 1.01 & 1.01 & 1.02 & 1.02 & -0.22 & -0.23 & 0.89 & 1.00 \\
\hline 109.9 & 95 & 1.01 & 1.05 & 1.06 & 1.06 & 0.59 & 0.58 & 0.24 & 1.04 \\
\hline 118.4 & 102.5 & 1.02 & 1.02 & 1.04 & 1.04 & -0.09 & -0.10 & 0.76 & 1.00 \\
\hline 126.8 & 110 & 1.01 & 1.02 & 1.03 & 1.03 & 0.24 & 0.23 & 0.48 & 1.01 \\
\hline 135.2 & 117.5 & 1.01 & 1.03 & 1.04 & 1.04 & 0.40 & 0.39 & 0.36 & 1.02 \\
\hline 138.6 & 120.5 & 1.01 & 1.01 & 1.03 & 1.03 & -0.01 & -0.01 & 0.68 & 1.00 \\
\hline 143.6 & 125 & 1.01 & 1.01 & 1.02 & 1.02 & 0.22 & 0.21 & 0.49 & 1.00 \\
\hline 147.6 & 128.5 & 1.01 & 1.00 & 1.01 & 1.02 & -0.65 & -0.65 & 1.41 & 0.99 \\
\hline 152.1 & 132.5 & 1.01 & 1.01 & 1.02 & 1.02 & 0.15 & 0.14 & 0.54 & 1.00 \\
\hline 156.0 & 136 & 1.00 & 1.02 & 1.02 & 1.02 & 0.63 & 0.62 & 0.21 & 1.01 \\
\hline 160.5 & 140 & 1.01 & 1.02 & 1.02 & 1.02 & 0.47 & 0.46 & 0.31 & 1.01 \\
\hline 171.1 & 149.5 & 1.01 & 1.01 & 1.02 & 1.02 & -0.20 & -0.21 & 0.87 & 1.00 \\
\hline 179.6 & 157 & 1.01 & 1.03 & 1.04 & 1.04 & 0.38 & 0.37 & 0.37 & 1.01 \\
\hline 189.7 & 166 & 1.01 & 1.01 & 1.02 & 1.02 & 0.17 & 0.17 & 0.53 & 1.00 \\
\hline 196.4 & 172 & 1.00 & 1.00 & 1.01 & 1.01 & 0.08 & 0.07 & 0.60 & 1.00 \\
\hline 205.4 & 180 & 1.01 & 1.00 & 1.01 & 1.02 & -0.60 & -0.60 & 1.34 & 0.99 \\
\hline \multicolumn{10}{|l|}{ VCEI3 } \\
\hline 36.4 & 29 & 1.05 & 1.02 & 1.07 & 1.07 & -0.39 & -0.41 & 1.08 & 0.97 \\
\hline 56.7 & 47 & 1.03 & 1.15 & 1.19 & 1.21 & 0.62 & 0.60 & 0.22 & 1.12 \\
\hline 74.6 & 63 & 1.01 & 1.02 & 1.03 & 1.03 & 0.44 & 0.43 & 0.33 & 1.01 \\
\hline 79.1 & 67 & 1.01 & 1.05 & 1.05 & 1.06 & 0.72 & 0.72 & 0.15 & 1.04 \\
\hline 85.3 & 72.5 & 1.01 & 1.01 & 1.03 & 1.03 & 0.01 & 0.01 & 0.66 & 1.00 \\
\hline 93.7 & 80 & 1.01 & 1.10 & 1.11 & 1.12 & 0.89 & 0.89 & 0.06 & 1.10 \\
\hline 102.2 & 87.5 & 1.01 & 1.01 & 1.02 & 1.02 & 0.35 & 0.34 & 0.39 & 1.01 \\
\hline 110.6 & 95 & 1.04 & 1.01 & 1.05 & 1.05 & -0.61 & -0.61 & 1.35 & 0.97 \\
\hline 121.8 & 105 & 1.00 & 1.03 & 1.03 & 1.04 & 0.87 & 0.87 & 0.07 & 1.03 \\
\hline 126.3 & 109 & 1.00 & 1.02 & 1.02 & 1.02 & 0.75 & 0.75 & 0.13 & 1.02 \\
\hline 135.9 & 117.5 & 1.02 & 1.01 & 1.03 & 1.03 & -0.07 & -0.08 & 0.74 & 1.00 \\
\hline 144.3 & 125 & 1.03 & 1.02 & 1.05 & 1.05 & -0.25 & -0.27 & 0.93 & 0.99 \\
\hline 152.7 & 132.5 & 1.02 & 1.01 & 1.03 & 1.03 & -0.14 & -0.14 & 0.80 & 1.00 \\
\hline 161.2 & 140 & 1.01 & 1.02 & 1.03 & 1.03 & 0.08 & 0.07 & 0.60 & 1.00 \\
\hline 169.6 & 147.5 & 1.03 & 1.01 & 1.04 & 1.04 & -0.66 & -0.67 & 1.43 & 0.97 \\
\hline 183.6 & 160 & 1.01 & 1.01 & 1.02 & 1.02 & -0.22 & -0.23 & 0.89 & 0.99 \\
\hline 205.0 & 179 & 1.02 & 1.00 & 1.02 & 1.02 & -0.86 & -0.86 & 1.74 & 0.98 \\
\hline 211.7 & 185 & 1.01 & 1.01 & 1.02 & 1.02 & 0.20 & 0.20 & 0.50 & 1.00 \\
\hline 220.2 & 192.5 & 1.01 & 1.01 & 1.02 & 1.02 & 0.05 & 0.04 & 0.63 & 1.00 \\
\hline 228.6 & 200 & 1.01 & 1.02 & 1.03 & 1.03 & 0.59 & 0.59 & 0.23 & 1.02 \\
\hline 237.0 & 207.5 & 1.02 & 1.07 & 1.08 & 1.09 & 0.62 & 0.61 & 0.22 & 1.05 \\
\hline
\end{tabular}


Table 17. Table of hysteresis and IRM data results for Ship Harbor

\begin{tabular}{|c|c|c|c|c|c|c|c|}
\hline Core Name & $\begin{array}{l}\text { Sampling } \\
\text { Depth Top, } \\
\text { Corrected } \\
\text { for } \\
\text { compaction }\end{array}$ & $\begin{array}{l}\text { Sampling } \\
\text { depth top } \\
\text { (cm), core } \\
\text { reference } \\
\text { uncorrected }\end{array}$ & $\begin{array}{l}\text { Bulk } \\
\text { Susceptibility }\end{array}$ & $\begin{array}{l}\text { Mass } \\
\text { normalized } \\
\text { magnetization } \\
\text { Ms }\end{array}$ & $\begin{array}{l}\text { Hysteresis } \\
\text { Saturation } \\
(\mathrm{Ms})(\mathrm{T})\end{array}$ & $\begin{array}{l}\text { Hysteresis } \\
\text { Remanence } \\
\text { (Mr) }\end{array}$ & $\begin{array}{l}\text { IRM } \\
\text { Coercivity } \\
\text { (mT) (Hcr) }\end{array}$ \\
\hline VCS6_TN & 58.3 & 10 & $-7.97 \mathrm{E}-06$ & & $-3.11 \mathrm{E}-07$ & $9.62 \mathrm{E}-09$ & 73.03 \\
\hline VCS6_TN & 63.7 & 15 & $-6.70 \mathrm{E}-06$ & & $5.85 \mathrm{E}-08$ & $2.17 \mathrm{E}-09$ & \\
\hline VCS6_TN & 71.5 & 22.2 & $-8.18 \mathrm{E}-06$ & $-1.79 \mathrm{E}-03$ & $-1.44 \mathrm{E}-07$ & $2.59 \mathrm{E}-09$ & \\
\hline VCS6_TN & 79.3 & 29.4 & $-6.38 \mathrm{E}-06$ & $9.49 \mathrm{E}-05$ & $7.67 \mathrm{E}-09$ & 5.04E-09 & \\
\hline VCS6_TN & 87.1 & 36.6 & $-9.62 \mathrm{E}-06$ & $-1.71 \mathrm{E}-03$ & $-1.41 \mathrm{E}-07$ & $3.43 \mathrm{E}-09$ & \\
\hline VCS6_TN & 94.9 & 43.8 & $-8.57 \mathrm{E}-06$ & $-3.49 \mathrm{E}-03$ & $-1.97 \mathrm{E}-07$ & $1.41 \mathrm{E}-09$ & 29.95 \\
\hline VCS6_TN & 102.7 & 51 & $-9.60 \mathrm{E}-06$ & $-3.07 \mathrm{E}-03$ & $-2.28 \mathrm{E}-07$ & $2.22 \mathrm{E}-09$ & \\
\hline VCS6_TN & 110.5 & 58.2 & $-8.85 \mathrm{E}-06$ & $-1.71 \mathrm{E}-03$ & $-1.06 \mathrm{E}-07$ & $-3.75 \mathrm{E}-10$ & \\
\hline VCS6_TN & 118.2 & 65.4 & $-8.58 \mathrm{E}-06$ & 5.32E-05 & $-1.37 \mathrm{E}-08$ & $-4.48 \mathrm{E}-09$ & \\
\hline VCS6_TN & 125.4 & 72 & $2.02 \mathrm{E}-05$ & $2.02 \mathrm{E}-03$ & $1.98 \mathrm{E}-06$ & $4.54 \mathrm{E}-08$ & 43.55 \\
\hline VCS6_TN & 131.6 & 77.8 & $3.29 \mathrm{E}-05$ & $9.81 \mathrm{E}-03$ & $3.51 \mathrm{E}-06$ & 4.44E-07 & 48.80 \\
\hline VCS6_TN & 139.2 & 84.8 & $8.86 \mathrm{E}-05$ & $3.00 \mathrm{E}-03$ & $1.90 \mathrm{E}-06$ & $3.36 \mathrm{E}-08$ & 44.61 \\
\hline VCS6_TN & 147.0 & 92 & $5.39 \mathrm{E}-05$ & $2.34 \mathrm{E}-03$ & $2.87 \mathrm{E}-06$ & $5.29 \mathrm{E}-08$ & 47.46 \\
\hline VCS6_BN & 152.4 & 97 & & $1.24 \mathrm{E}-02$ & $3.16 \mathrm{E}-06$ & 4.10E-07 & 44.42 \\
\hline VCS6_BN & 160.0 & 104 & $3.26 \mathrm{E}-05$ & $2.42 \mathrm{E}-03$ & $2.40 \mathrm{E}-06$ & 4.87E-08 & 43.32 \\
\hline VCS6_BN & 167.8 & 111.2 & $3.51 \mathrm{E}-05$ & $2.58 \mathrm{E}-03$ & $2.33 \mathrm{E}-06$ & $4.82 \mathrm{E}-08$ & \\
\hline VCS6_BN & 175.5 & 118.4 & $3.36 \mathrm{E}-05$ & $2.63 \mathrm{E}-03$ & 2.63E-06 & $6.84 \mathrm{E}-08$ & 46.08 \\
\hline VCS6_BN & 183.3 & 125.6 & $3.40 \mathrm{E}-05$ & $2.82 \mathrm{E}-03$ & $2.13 \mathrm{E}-06$ & $4.85 \mathrm{E}-08$ & 44.86 \\
\hline VCS6_BN & 191.1 & 132.8 & $3.02 \mathrm{E}-05$ & $2.21 \mathrm{E}-03$ & $2.52 \mathrm{E}-06$ & $5.48 \mathrm{E}-08$ & \\
\hline VCS6_BN & 198.9 & 140 & $2.54 \mathrm{E}-05$ & $2.01 \mathrm{E}-03$ & $2.06 \mathrm{E}-06$ & 4.47E-08 & \\
\hline VCS6_BN & 207.6 & 148 & $6.10 \mathrm{E}-05$ & $6.88 \mathrm{E}-03$ & $3.13 \mathrm{E}-06$ & 7.34E-08 & \\
\hline VCS6_BN & 214.5 & 154.4 & $1.44 \mathrm{E}-04$ & $1.46 \mathrm{E}-02$ & $5.44 \mathrm{E}-06$ & $1.40 \mathrm{E}-07$ & 37.72 \\
\hline VCS6_BN & 222.3 & 161.6 & $2.02 \mathrm{E}-04$ & $1.30 \mathrm{E}-02$ & $4.56 \mathrm{E}-06$ & $1.87 \mathrm{E}-07$ & 47.85 \\
\hline VCS6_BN & 230.0 & 168.8 & $2.84 \mathrm{E}-05$ & $1.86 \mathrm{E}-03$ & $2.12 \mathrm{E}-06$ & $3.65 \mathrm{E}-08$ & \\
\hline VCS6_BN & 239.3 & 177.4 & $5.55 \mathrm{E}-05$ & $1.29 \mathrm{E}-02$ & $3.57 \mathrm{E}-06$ & $1.81 \mathrm{E}-07$ & 42.93 \\
\hline VCS6_BN & 245.6 & 183.2 & $3.46 \mathrm{E}-05$ & $5.90 \mathrm{E}-03$ & $2.75 \mathrm{E}-06$ & $6.82 \mathrm{E}-08$ & \\
\hline VCS6_BN & 253.4 & 190.4 & $3.10 \mathrm{E}-05$ & $2.52 \mathrm{E}-03$ & $2.74 \mathrm{E}-06$ & $5.81 \mathrm{E}-08$ & 42.17 \\
\hline VCS6_BN & 262.7 & 199 & $1.44 \mathrm{E}-05$ & $1.01 \mathrm{E}-02$ & $2.77 \mathrm{E}-06$ & $5.34 \mathrm{E}-08$ & \\
\hline
\end{tabular}


Table 17. Continued from previous page

\begin{tabular}{|c|c|c|c|c|c|c|c|c|}
\hline $\begin{array}{l}\text { Core } \\
\text { Name }\end{array}$ & $\begin{array}{l}\text { Sampling } \\
\text { Depth } \\
\text { Top, } \\
\text { Corrected }\end{array}$ & $\begin{array}{l}\text { Sampling } \\
\text { depth } \\
\text { top, core } \\
\text { reference }\end{array}$ & $\begin{array}{l}\text { Bulk } \\
\text { Susceptibility }\end{array}$ & $\begin{array}{l}\text { NRM } \\
\text { Intensity }\end{array}$ & $\begin{array}{l}\text { Mass } \\
\text { normalized } \\
\text { Ms }\end{array}$ & $\begin{array}{l}\text { Hysteresis } \\
\text { Coercivity } \\
(\mathrm{mT}) \text { (Hc) }\end{array}$ & $\begin{array}{l}\text { Hysteresis } \\
\text { Remanence } \\
\text { (Mr) }\end{array}$ & $\begin{array}{l}\text { IRM } \\
\text { Coercivity } \\
\text { (mT) (Hcr) }\end{array}$ \\
\hline VCS2_TN & 50.5 & 16.6 & $-1.03 \mathrm{E}-05$ & & $-3.93 \mathrm{E}-03$ & 3.84 & $-5.72 \mathrm{E}-10$ & 51.90 \\
\hline VCS2_TN & 60.2 & 24.2 & $-9.82 \mathrm{E}-06$ & & & & & \\
\hline VCS2_TN & 69.5 & 31.4 & $-9.41 \mathrm{E}-06$ & & $-4.87 \mathrm{E}-03$ & -26.56 & $-1.59 \mathrm{E}-09$ & 52.35 \\
\hline VCS2_TN & 88.1 & 45.8 & $-9.82 \mathrm{E}-06$ & & & & & \\
\hline VCS2_TN & 97.3 & 53 & $-7.75 \mathrm{E}-06$ & $1.15 \mathrm{E}-03$ & $-1.18 \mathrm{E}-03$ & -37.06 & 8.04E-09 & 45.79 \\
\hline VCS2_TN & 114.3 & 66.2 & $3.70 \mathrm{E}-05$ & $9.51 \mathrm{E}-02$ & $2.32 \mathrm{E}-03$ & 20.66 & $8.42 \mathrm{E}-08$ & 45.69 \\
\hline VCS2_TN & 125.4 & 74.8 & $3.85 \mathrm{E}-05$ & $8.26 \mathrm{E}-02$ & $2.69 \mathrm{E}-03$ & 39.98 & $5.61 \mathrm{E}-08$ & 44.58 \\
\hline VCS2_TN & 134.4 & 81.8 & $3.12 \mathrm{E}-05$ & $1.25 \mathrm{E}-01$ & $3.08 \mathrm{E}-03$ & 14.19 & $2.22 \mathrm{E}-07$ & 44.79 \\
\hline VCS2_TN & 143.7 & 89 & $3.14 \mathrm{E}-05$ & 4.97E-02 & $1.95 \mathrm{E}-03$ & 7.06 & 2.99E-08 & 47.47 \\
\hline VCS2_TN & 151.7 & 95.2 & $3.60 \mathrm{E}-05$ & $3.94 \mathrm{E}-02$ & $2.62 \mathrm{E}-03$ & 11.81 & $5.82 \mathrm{E}-08$ & 46.28 \\
\hline VCS2_TN & 162.3 & 103.4 & $3.68 \mathrm{E}-05$ & $6.51 \mathrm{E}-02$ & $2.83 \mathrm{E}-03$ & 7.58 & $4.42 \mathrm{E}-08$ & 45.52 \\
\hline VCS2_TN & 171.5 & 110.6 & $3.29 \mathrm{E}-05$ & $8.66 \mathrm{E}-02$ & $2.45 \mathrm{E}-02$ & 13.63 & $1.58 \mathrm{E}-07$ & 45.24 \\
\hline VCS2_TN & 180.8 & 117.8 & & & $2.73 \mathrm{E}-03$ & 7.53 & $4.12 \mathrm{E}-08$ & 43.64 \\
\hline VCS2_BN & 190.1 & 125 & $2.64 \mathrm{E}-05$ & $7.95 \mathrm{E}-02$ & $2.43 \mathrm{E}-03$ & 9.84 & $3.36 \mathrm{E}-08$ & 0.00 \\
\hline VCS2_BN & 199.8 & 132.5 & $2.70 \mathrm{E}-05$ & $7.25 \mathrm{E}-02$ & $4.27 \mathrm{E}-03$ & 8.94 & $4.62 \mathrm{E}-08$ & 43.20 \\
\hline VCS2_BN & 209.4 & 140 & $2.65 \mathrm{E}-05$ & $8.02 \mathrm{E}-02$ & $2.48 \mathrm{E}-03$ & 10.30 & $3.81 \mathrm{E}-08$ & 45.08 \\
\hline VCS2_BN & 224.9 & 152 & $3.56 \mathrm{E}-05$ & 7.11E-02 & $3.01 \mathrm{E}-03$ & 10.00 & $3.19 \mathrm{E}-08$ & 46.62 \\
\hline VCS2_BN & 236.0 & 160.6 & $6.41 \mathrm{E}-05$ & $9.86 \mathrm{E}-02$ & $9.34 \mathrm{E}-03$ & 9.12 & 9.91E-08 & 40.50 \\
\hline VCS2_BN & 239.7 & 163.5 & $1.44 \mathrm{E}-04$ & $9.62 \mathrm{E}-02$ & $1.26 \mathrm{E}-02$ & 7.54 & $1.31 \mathrm{E}-07$ & 36.92 \\
\hline VCS2_BN & 242.9 & 166 & $1.14 \mathrm{E}-04$ & $1.65 \mathrm{E}-01$ & $1.28 \mathrm{E}-02$ & 6.37 & $7.88 \mathrm{E}-08$ & 37.86 \\
\hline VCS2_BN & 246.1 & 168.5 & $9.97 \mathrm{E}-05$ & $1.24 \mathrm{E}-01$ & $8.28 \mathrm{E}-03$ & 7.20 & $8.04 \mathrm{E}-08$ & 38.51 \\
\hline VCS2_BN & 251.3 & 172.5 & $1.06 \mathrm{E}-04$ & $6.69 \mathrm{E}-02$ & $4.97 \mathrm{E}-02$ & 3.38 & $1.11 \mathrm{E}-07$ & 35.88 \\
\hline VCS2_BN & 253.2 & 174 & $1.74 \mathrm{E}-04$ & $1.45 \mathrm{E}-01$ & $6.21 \mathrm{E}-03$ & 9.63 & $1.34 \mathrm{E}-07$ & 35.18 \\
\hline VCS2_BN & 260.9 & 180 & $3.47 \mathrm{E}-05$ & $1.12 \mathrm{E}-01$ & $2.95 \mathrm{E}-03$ & 10.62 & $4.40 \mathrm{E}-08$ & 48.46 \\
\hline VCS2_BN & 270.6 & 187.5 & $3.28 \mathrm{E}-05$ & $1.65 \mathrm{E}-01$ & $3.68 \mathrm{E}-03$ & 13.49 & $4.54 \mathrm{E}-08$ & 42.97 \\
\hline VCS2_BN & 280.3 & 195 & $1.67 \mathrm{E}-04$ & $1.26 \mathrm{E}-01$ & $2.14 \mathrm{E}-02$ & 6.56 & $1.52 \mathrm{E}-07$ & 32.06 \\
\hline VCS2_BN & 309.3 & 217.5 & 4.87E-04 & & $1.70 \mathrm{E}-01$ & 2.98 & 5.64E-07 & 18.19 \\
\hline VCS2_BN & 316.3 & 223 & $3.98 \mathrm{E}-04$ & $3.25 \mathrm{E}-01$ & $9.03 \mathrm{E}-03$ & 6.26 & $6.79 \mathrm{E}-08$ & 36.59 \\
\hline VCS2_BN & 334.4 & 237 & $7.05 \mathrm{E}-04$ & $\begin{array}{l}1.03 \mathrm{E}+0 \\
0\end{array}$ & $3.37 \mathrm{E}-03$ & 9.45 & $6.16 \mathrm{E}-07$ & 35.34 \\
\hline
\end{tabular}


Table 18. Table of hysteresis and IRM data results for Eliza Island

\begin{tabular}{|c|c|c|c|c|c|c|c|c|}
\hline Core Name & $\begin{array}{l}\text { Sampling } \\
\text { Depth Top, } \\
\text { Corrected } \\
\text { for } \\
\text { compaction }\end{array}$ & $\begin{array}{l}\text { Sampling } \\
\text { depth top, } \\
\text { core } \\
\text { reference } \\
\text { (uncorrected) }\end{array}$ & $\begin{array}{l}\text { Bulk } \\
\text { Susceptibility }\end{array}$ & $\begin{array}{l}\text { NRM } \\
\text { Intensity }\end{array}$ & $\begin{array}{l}\text { Hysteresis } \\
\text { Coercivity } \\
\text { (mT) }\end{array}$ & $\begin{array}{l}\text { Mass } \\
\text { normalized } \\
\text { Ms }\end{array}$ & $\begin{array}{l}\text { Hysteresis } \\
\text { Remanence } \\
\text { (Mr) }\end{array}$ & $\begin{array}{l}\text { IRM } \\
\text { Coercivity } \\
\text { (mT) (Her) }\end{array}$ \\
\hline VCEI2_TN & 25.7 & 20 & $-4.17 \mathrm{E}-06$ & & -0.02 & -0.002 & $-4.40 \mathrm{E}-10$ & \\
\hline VCEI2_TN & 37.0 & 30 & $-7.52 \mathrm{E}-06$ & & 56.18 & -0.002 & 7.98E-09 & 56.18 \\
\hline VCEI2_TN & 48.2 & 40 & $-1.15 \mathrm{E}-06$ & & 0.029 & 0.001 & 8.59E-09 & \\
\hline VCEI2_TN & 59.4 & 50 & $5.15 \mathrm{E}-05$ & & 48.39 & 0.003 & $1.07 \mathrm{E}-07$ & 48.39 \\
\hline VCEI2_TN & 67.8 & 57.5 & 7.07E-05 & & 15.70 & 0.004 & $1.01 \mathrm{E}-07$ & \\
\hline VCEI2_TN & 76.3 & 65 & $4.28 \mathrm{E}-05$ & & 52.13 & 0.003 & 7.03E-08 & 52.13 \\
\hline VCEI2_TN & 84.7 & 72.5 & $5.62 \mathrm{E}-05$ & & 16.55 & 0.003 & $1.04 \mathrm{E}-07$ & \\
\hline VCEI2_TN & 93.1 & 80 & $5.69 \mathrm{E}-05$ & & 81.99 & 0.004 & $1.30 \mathrm{E}-07$ & 81.99 \\
\hline VCEI2_TN & 104.3 & 90 & $7.86 \mathrm{E}-05$ & & 22.00 & 0.003 & $1.15 \mathrm{E}-07$ & \\
\hline VCEI2_TN & 109.9 & 95 & $1.83 \mathrm{E}-04$ & & 47.09 & 0.003 & $1.18 \mathrm{E}-07$ & 47.09 \\
\hline VCEI2_BN & 118.4 & 102.5 & $1.61 \mathrm{E}-04$ & & 23.38 & 0.025 & $1.27 \mathrm{E}-06$ & \\
\hline VCEI2_BN & 126.8 & 110 & $5.98 \mathrm{E}-05$ & & 47.57 & 0.004 & $5.26 \mathrm{E}-08$ & 47.57 \\
\hline VCEI2_BN & 135.2 & 117.5 & $8.25 \mathrm{E}-05$ & & 49.27 & 0.003 & $5.45 \mathrm{E}-08$ & 49.27 \\
\hline VCEI2_BN & 138.6 & 120.5 & $1.07 \mathrm{E}-04$ & & & & $\mathrm{n} / \mathrm{a}$ & \\
\hline VCEI2_BN & 143.6 & 125 & $1.14 \mathrm{E}-04$ & & 11.96 & 0.005 & $6.88 \mathrm{E}-08$ & 41.94 \\
\hline VCEI2_BN & 147.6 & 128.5 & $1.51 \mathrm{E}-04$ & & & & $\mathrm{n} / \mathrm{a}$ & \\
\hline VCEI2_BN & 152.1 & 132.5 & $2.08 \mathrm{E}-04$ & & 39.89 & 0.018 & $1.62 \mathrm{E}-07$ & 39.89 \\
\hline VCEI2_BN & 156.0 & 136 & $1.10 \mathrm{E}-04$ & & & & & \\
\hline VCEI2_BN & 160.5 & 140 & $8.20 \mathrm{E}-05$ & & 11.79 & 0.007 & $1.09 \mathrm{E}-07$ & \\
\hline VCEI2_BN & 171.1 & 149.5 & $7.82 \mathrm{E}-05$ & & 41.83 & 0.001 & $9.76 \mathrm{E}-08$ & 41.83 \\
\hline VCEI2_BN & 179.6 & 157 & $4.04 \mathrm{E}-04$ & & 23.20 & 0.005 & $2.15 \mathrm{E}-07$ & \\
\hline VCEI2_BN & 189.7 & 166 & 4.09E-04 & & 27.45 & 0.005 & $2.23 \mathrm{E}-07$ & 63.15 \\
\hline VCEI2_BN & 196.4 & 172 & $7.22 \mathrm{E}-05$ & & 9.08 & 0.012 & $1.56 \mathrm{E}-07$ & \\
\hline VCEI2_BN & 205.4 & 180 & $9.02 \mathrm{E}-05$ & & 22.36 & 0.004 & $1.31 \mathrm{E}-07$ & \\
\hline
\end{tabular}


Table 18. Continued Table of hysteresis and IRM data results for Eliza Island, continued from previous page.

\begin{tabular}{|c|c|c|c|c|c|c|c|}
\hline Core Name & $\begin{array}{l}\text { Sampling } \\
\text { Depth Top, } \\
\text { Corrected } \\
\text { for } \\
\text { compaction }\end{array}$ & $\begin{array}{l}\text { Sampling } \\
\text { depth top, } \\
\text { core } \\
\text { reference } \\
\text { (uncorrected) }\end{array}$ & $\begin{array}{l}\text { Bulk } \\
\text { Susceptibility }\end{array}$ & $\begin{array}{l}\text { Hysteresis } \\
\text { Coercivity } \\
\text { (T) }\end{array}$ & $\begin{array}{l}\text { Mass } \\
\text { normalized } \\
\text { (Ms) }\end{array}$ & $\begin{array}{l}\text { Hysteresis } \\
\text { Remanence } \\
\text { (Mr) }\end{array}$ & $\begin{array}{l}\text { IRM } \\
\text { Coercivity } \\
\text { (mT) } \\
\text { (Hcr) }\end{array}$ \\
\hline VCEI3_TN & 36.4 & 29 & $1.64 \mathrm{E}-03$ & $1.43 \mathrm{E}-02$ & 0.006 & $2.17 \mathrm{E}-07$ & 37.30 \\
\hline VCEI3_TN & 56.7 & 47 & 2.97E-04 & $6.60 \mathrm{E}-03$ & 0.003 & $6.16 \mathrm{E}-08$ & \\
\hline VCEI3_TN & 74.6 & 63 & $1.17 \mathrm{E}-04$ & $5.99 \mathrm{E}-03$ & 0.020 & $2.02 \mathrm{E}-07$ & \\
\hline VCEI3_TN & 79.1 & 67 & $8.27 \mathrm{E}-05$ & $8.67 \mathrm{E}-03$ & 0.007 & $1.14 \mathrm{E}-07$ & 44.86 \\
\hline VCEI3_TN & 85.3 & 72.5 & 7.19E-05 & $6.66 \mathrm{E}-03$ & 0.011 & $1.04 \mathrm{E}-07$ & \\
\hline VCEI3_TN & 93.7 & 80 & $1.30 \mathrm{E}-04$ & $1.11 \mathrm{E}-02$ & 0.008 & $1.29 \mathrm{E}-07$ & 45.23 \\
\hline VCEI3_TN & 102.2 & 87.5 & $6.41 \mathrm{E}-05$ & $7.84 \mathrm{E}-03$ & 0.006 & $6.59 \mathrm{E}-08$ & 48.86 \\
\hline VCEI3_TN & 110.6 & 95 & $2.32 \mathrm{E}-04$ & $1.01 \mathrm{E}-02$ & 0.004 & $8.55 \mathrm{E}-08$ & \\
\hline VCEI3_BN & 121.8 & 105 & $8.30 \mathrm{E}-05$ & $9.76 \mathrm{E}-03$ & 0.004 & $9.33 \mathrm{E}-08$ & \\
\hline VCEI3_BN & 126.3 & 109 & $7.80 \mathrm{E}-05$ & $8.55 \mathrm{E}-03$ & 0.003 & $1.04 \mathrm{E}-07$ & 45.93 \\
\hline VCEI3_BN & 135.9 & 117.5 & $7.51 \mathrm{E}-05$ & $1.16 \mathrm{E}-02$ & 0.003 & $1.08 \mathrm{E}-07$ & 11.15 \\
\hline VCEI3_BN & 144.3 & 125 & $1.06 \mathrm{E}-04$ & $1.24 \mathrm{E}-02$ & 0.006 & $1.96 \mathrm{E}-07$ & \\
\hline VCEI3_BN & 152.7 & 132.5 & $1.92 \mathrm{E}-04$ & $1.71 \mathrm{E}-03$ & 0.081 & $1.47 \mathrm{E}-07$ & 0.00 \\
\hline VCEI3_BN & 161.2 & 140 & $1.54 \mathrm{E}-04$ & $8.91 \mathrm{E}-03$ & 0.006 & $1.27 \mathrm{E}-07$ & \\
\hline VCEI3_BN & 169.6 & 147.5 & $1.13 \mathrm{E}-04$ & $1.09 \mathrm{E}-02$ & 0.006 & $1.43 \mathrm{E}-07$ & \\
\hline VCEI3_BN & 183.6 & 160 & $2.12 \mathrm{E}-04$ & $6.86 \mathrm{E}-03$ & 0.022 & $2.52 \mathrm{E}-07$ & 36.02 \\
\hline VCEI3_BN & 205.0 & 179 & $1.47 \mathrm{E}-03$ & $3.66 \mathrm{E}-03$ & 0.095 & $5.23 \mathrm{E}-07$ & \\
\hline VCEI3_BN & 211.7 & 185 & $1.13 \mathrm{E}-03$ & $6.96 \mathrm{E}-03$ & 0.130 & $1.42 \mathrm{E}-06$ & \\
\hline VCEI3_BN & 220.2 & 192.5 & $9.14 \mathrm{E}-04$ & $7.84 \mathrm{E}-03$ & 0.082 & $7.63 \mathrm{E}-07$ & 30.99 \\
\hline VCEI3_BN & 228.6 & 200 & $1.93 \mathrm{E}-03$ & $7.61 \mathrm{E}-03$ & 0.232 & $1.63 \mathrm{E}-06$ & \\
\hline VCEI3_BN & 237.0 & 207.5 & $9.14 \mathrm{E}-04$ & $1.12 \mathrm{E}-02$ & 0.089 & $1.15 \mathrm{E}-06$ & \\
\hline
\end{tabular}


Table 19. High temperature vs susceptibility for samples analyzed

\begin{tabular}{|l|l|l|l|l|}
\hline Core Name & $\begin{array}{l}\text { Sampling Depth } \\
\text { Top, Corrected } \\
\text { for compaction } \\
\text { (cm) }\end{array}$ & $\begin{array}{l}\text { Sampling } \\
\text { depth top, core } \\
\text { reference (cm) }\end{array}$ & $\begin{array}{l}\text { Temp vs } \\
\text { susceptibility } \\
\text { weight (g) }\end{array}$ & $\begin{array}{l}\text { Temperature Vs } \\
\text { Susceptibility Curie } \\
\text { Temperature }\end{array}$ \\
\hline VCS2n & 114.3 & 66.2 & 0.0905 & 575 \\
\hline VCS2n & 199.8 & 132.5 & 0.0815 & 575 \\
\hline VCS2n & 242.9 & 166.0 & 0.1642 & 575 \\
\hline VCS2n & 316.3 & 223.0 & 0.1084 & 575 \\
\hline VCS6n & 131.6 & 77.8 & - & - \\
\hline VCS6n & 222.3 & 161.6 & 0.2632 & 575 \\
\hline VCS6n & 253.4 & 190.4 & 0.0900 & $550-575$ \\
\hline VCEI2n & 93.1 & 80.0 & 0.1221 & unclear \\
\hline VCEI2n & 171.1 & 149.5 & 0.2189 & 575 \\
\hline VCEI2n & 196.4 & 172.0 & 0.2619 & 575 \\
\hline VCEI3n & 56.7 & 47.0 & 0.2345 & 575 \\
\hline VCEI3n & 102.2 & 87.5 & 0.0875 & 575 \\
\hline VCEI3n & 183.6 & 160.0 & 0.2549 & $550-575$ \\
\hline VCEI3n & 220.2 & 192.5 & 0.1775 & $575-600$ \\
\hline
\end{tabular}


Table 20. Table of PSV declinations and inclinations, other important data

\begin{tabular}{|c|c|c|c|c|c|c|c|c|c|c|c|c|}
\hline $\begin{array}{l}\text { Ship } \\
\text { Harbor }\end{array}$ & $\begin{array}{l}\text { OxCal } \\
\text { (years } \\
\text { before } \\
2000 \mathrm{CE} \text { ) }\end{array}$ & $\begin{array}{l}\text { Age } \\
\text { Error } \\
(+/-)\end{array}$ & MAD & Inclination & $\begin{array}{l}\text { Inclination } \\
\text { correction } \\
\text { degrees }\end{array}$ & Declination & $\begin{array}{l}\text { Core } \\
\text { Depth }\end{array}$ & $\begin{array}{l}\text { Age from } \\
\text { PSV } \\
\text { Inclination } \\
\text { before AD } \\
2000\end{array}$ & $\begin{array}{l}\text { Age from } \\
\text { PSV } \\
\text { Declination } \\
\text { before AD } \\
2000\end{array}$ & $\begin{array}{l}\text { Years } \\
\text { since } \\
2019\end{array}$ & Error & \\
\hline UC1 & 415.5 & 250 & 2.2 & 52.9 & 63.82 & 8.5 & 66.2 & & 440 & 1560 & 185 & UC1 \\
\hline $\mathrm{UC2}$ & 550 & 352 & 5.6 & 32.6 & 44.53 & 57 & 74.8 & & & & & $\mathrm{UC2}$ \\
\hline UC4 & 849.5 & 431 & 9.3 & 38.1 & 50.34 & 35.4 & 89 & & & & & UC4 \\
\hline UC5 & 1004.5 & 413 & 3.8 & 39.9 & 52.14 & 18 & 95.2 & & 1010 & 990 & 35 & UC5 \\
\hline UC6 & 1148 & 367 & 5.1 & 35.3 & 47.45 & 11.7 & 103.4 & & 1100 & 900 & 10 & UC6 \\
\hline UC7 & 1307 & 274 & 9.1 & 49.3 & 60.79 & 14.6 & 110.6 & & 1310 & 690 & 100 & UC7 \\
\hline UC8 & 1591 & 116 & 3.7 & 61.9 & 70.86 & 9.8 & 125 & 1580 & 1520 & 420 & 100 & UC8 \\
\hline UC9 & 1653 & 125 & 4.6 & 55 & 65.53 & 8.2 & 132.5 & & 1575 & 425 & 100 & UC9 \\
\hline UC10 & 1707.5 & 106 & 6.6 & 59.7 & 69.20 & 24.3 & 140 & 1720 & & 280 & 100 & $\mathrm{UC} 10$ \\
\hline $\mathrm{S} 2$ & 1824.5 & 34.5 & 17 & 50.6 & 61.90 & 54.4 & 152 & & & & & $\mathrm{~S} 2$ \\
\hline LC1 & 3101 & 256 & 3.6 & 53 & 63.90 & 37.7 & 180 & & & & & LC1 \\
\hline $\mathrm{LC} 2$ & 3275.5 & 273 & 6.6 & 52.6 & 63.57 & 41.8 & 187.5 & & & & & $\mathrm{LC} 2$ \\
\hline $\mathrm{S} 1$ & 1824.5 & 34.5 & 12.1 & 54.1 & 64.80 & 34.9 & 168.5 & & & & & $\mathrm{~S} 1$ \\
\hline \multicolumn{13}{|l|}{ Omitted } \\
\hline UC3 & 694.5 & 412 & & 40 & 52.24 & 90.9 & 81.8 & & & & & \\
\hline UC11 & 1811 & 34 & & 22.9 & 33.02 & 122.8 & 152 & & & & & \\
\hline $\mathrm{S} 1$ & 1824.5 & 34.5 & & 28 & 39.28 & 312.1 & 160.6 & & & & & \\
\hline $\mathrm{S} 1$ & 1824.5 & 34.5 & & 20.9 & 30.43 & 293.3 & 166 & & & & & \\
\hline $\mathrm{S} 3$ & 1824.5 & 34.5 & & 51.9 & 62.99 & 316.9 & 172.5 & & & & & \\
\hline BS1 & 4618 & 252 & & 46.6 & 58.42 & 288.1 & 237 & & & & & \\
\hline
\end{tabular}


Table 21. Table of Eliza Island declinations (Dec) and inclinations (Inc) measured

\begin{tabular}{|c|c|c|c|c|c|c|c|c|c|c|c|c|c|}
\hline Component & $\begin{array}{l}\text { Estimated } \\
\text { Age }\end{array}$ & Error & Dec & Inc & MAD & $\begin{array}{l}\text { Limit } \\
1\end{array}$ & $\begin{array}{l}\text { Limit } \\
2\end{array}$ & $\begin{array}{l}\text { Core } \\
\text { Depth }\end{array}$ & $\begin{array}{l}\text { Bulk } \\
\text { Susceptibility }\end{array}$ & $\begin{array}{l}\text { NRM } \\
\text { intensity }\end{array}$ & $\begin{array}{l}\text { PSV } \\
\text { Estimated } \\
\text { age, } \\
\text { inclination }\end{array}$ & $\begin{array}{l}\text { PSV } \\
\text { estimated } \\
\text { age, } \\
\text { Declination }\end{array}$ & $\begin{array}{l}\text { Years } \\
\text { before } \\
0 \mathrm{CE}\end{array}$ \\
\hline $\mathrm{C} 1$ & 1542 & 61 & 19.3 & 55.6 & 2.2 & 5 & 25 & 50 & $5.15 \mathrm{E}-05$ & $7.28 \mathrm{E}-02$ & & & \\
\hline $\mathrm{C} 2$ & 2221 & 165 & 142.3 & 65.7 & 8.5 & 2.5 & 20 & 57 & 7.07E-05 & $8.47 \mathrm{E}-02$ & 2200 & & -200 \\
\hline $\mathrm{C} 3$ & 2819 & 376 & 55.3 & 66.9 & 4 & 10 & 70 & 72.5 & $5.62 \mathrm{E}-05$ & $1.68 \mathrm{E}-01$ & 2575 & & -575 \\
\hline $\mathrm{C} 4$ & 3359 & 695 & 47.6 & 69.3 & 3.2 & 7.5 & 60 & 80 & $5.69 \mathrm{E}-05$ & $2.41 \mathrm{E}-01$ & & & \\
\hline $\mathrm{C} 5$ & 3810 & 1088 & 25.8 & 60.7 & 2.6 & 7.5 & 65 & 90 & $7.86 \mathrm{E}-05$ & $3.07 \mathrm{E}-01$ & & & \\
\hline C6 & 4218 & 1563 & 57 & 66.4 & 3 & 5 & 55 & 95 & $1.83 \mathrm{E}-04$ & $5.68 \mathrm{E}-01$ & & 4050 & -2050 \\
\hline C7 & 4526 & 2093 & 26.1 & 52.4 & 4.1 & 7.5 & 35 & 102.5 & $1.61 \mathrm{E}-04$ & $2.39 \mathrm{E}-01$ & & & \\
\hline $\mathrm{C} 8$ & & & 345.2 & 75.4 & 3.8 & 12.5 & 35 & 110 & $5.98 \mathrm{E}-05$ & $2.07 \mathrm{E}-01$ & & & \\
\hline C9 & 4731 & 2698 & 118.2 & 74.2 & 11.3 & 10 & 25 & 120.5 & $1.07 \mathrm{E}-04$ & $2.56 \mathrm{E}-01$ & & & \\
\hline S1 & 5291 & 4935 & 323.4 & 70.2 & 2.7 & 5 & 35 & 149.5 & 7.82E-05 & $2.65 \mathrm{E}-01$ & 5500 & & -3500 \\
\hline S2 & 6186 & 5051 & 49.1 & 72.9 & 4.4 & 10 & 60 & 166 & $4.09 \mathrm{E}-04$ & $2.32 \mathrm{E}+00$ & 6000 & & -4000 \\
\hline
\end{tabular}


Table 22. Table of GeoCLAW Modeling parameters, adapted from Witter et al. (2013)

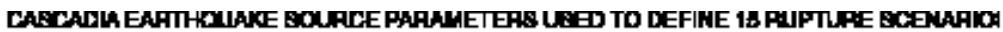

\begin{tabular}{|c|c|c|c|c|c|c|c|}
\hline \multirow[b]{2}{*}{ 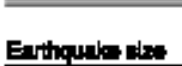 } & \multirow{2}{*}{ Interit } & \multirow[b]{2}{*}{ Fulk gomity } & \multicolumn{2}{|c|}{ 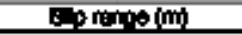 } & \multirow[b]{2}{*}{$\mathbf{M}$} & \multirow[b]{2}{*}{ Bownda neme } & \multirow[b]{2}{*}{ Tot min } \\
\hline & & & $h^{k} x$ & Ant & & & \\
\hline $\begin{array}{l}\text { Edra-adratiros } \\
\text { [0.020] }\end{array}$ & 1290 & 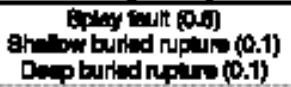 & $\begin{array}{l}5-44 \\
39-44 \\
30-44\end{array}$ & $\begin{array}{l}10-2 \\
10-00 \\
10-00\end{array}$ & $\begin{array}{l}\infty .1 \\
-0.1 \\
-8.1\end{array}$ & $\begin{array}{l}\mathbf{x 0 1 1} \\
\mathbf{x a 1} \\
\mathbf{x y 3}\end{array}$ & $\begin{array}{l}0.02 \\
0.0005 \\
0.0005\end{array}$ \\
\hline $\begin{array}{l}\text { Extratpo } \\
\text { ningen }\end{array}$ & $1000-1200$ & 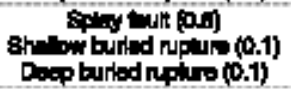 & $\begin{array}{l}5-44 \\
55-44 \\
35-44\end{array}$ & $\begin{array}{l}17-22 \\
17-02 \\
17-20\end{array}$ & $\begin{array}{l}-91 \\
-9.2 \\
-9.1\end{array}$ & $\begin{array}{l}x 11 \\
x 13\end{array}$ & $\begin{array}{l}\text { and } \\
\text { Bor.ts } \\
\text { ontes }\end{array}$ \\
\hline $\begin{array}{l}\text { Large } \\
(0.16)\end{array}$ & $650-800$ & $\begin{array}{l}\text { Splay fault }(0.8) \\
\text { Shallow buried rupture }(0.1) \\
\text { Deep buried rupture }(0.1)\end{array}$ & $\begin{array}{l}22-30 \\
22-30 \\
22-30 \\
\end{array}$ & $\begin{array}{l}11-15 \\
11-15 \\
11-15 \\
\end{array}$ & $\begin{array}{l}-9.0 \\
\sim 9.1 \\
\sim 9.0 \\
\end{array}$ & $\begin{array}{l}\mathrm{L} 1 \\
\mathrm{~L} 2 \\
\mathrm{~L} 3\end{array}$ & $\begin{array}{l}0.128 \\
0.016 \\
0.016 \\
\end{array}$ \\
\hline $\begin{array}{l}\text { Medium } \\
(0.53)\end{array}$ & $425-525$ & $\begin{array}{l}\text { Splay fault }(0.6) \\
\text { Shallow buried rupture }(0.2) \\
\text { Deep buried rupture }(0.2)\end{array}$ & $\begin{array}{l}14-19 \\
14-19 \\
14-19\end{array}$ & $\begin{array}{l}7-9 \\
7-9 \\
7-9\end{array}$ & $\begin{array}{r}-8.9 \\
\sim 9.0 \\
-8.9\end{array}$ & $\begin{array}{l}\text { M1 } \\
\text { M2 } \\
\text { M3 }\end{array}$ & $\begin{array}{l}0.318^{\circ} \\
0.106 \\
0.106\end{array}$ \\
\hline $\begin{array}{l}\text { Small } \\
(0.26)\end{array}$ & 300 & 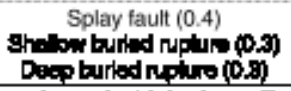 & $\begin{array}{l}9-11 \\
0-11 \\
g-11\end{array}$ & $\begin{array}{l}4-5 \\
4-6 \\
4-6\end{array}$ & $\begin{array}{l}-8.7 \\
\mathbf{- 8 . 8} \\
\mathbf{- 8 . 7} \\
\end{array}$ & $\begin{array}{l}\text { SM1 } \\
\text { Eut2 } \\
\text { Eit3 }\end{array}$ & $\begin{array}{l}0.104 \\
0.078 \\
\text { 0.078 }\end{array}$ \\
\hline
\end{tabular}

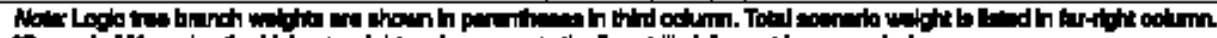

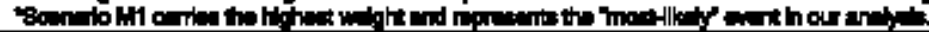

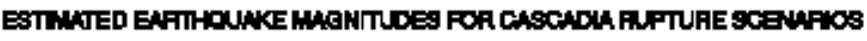

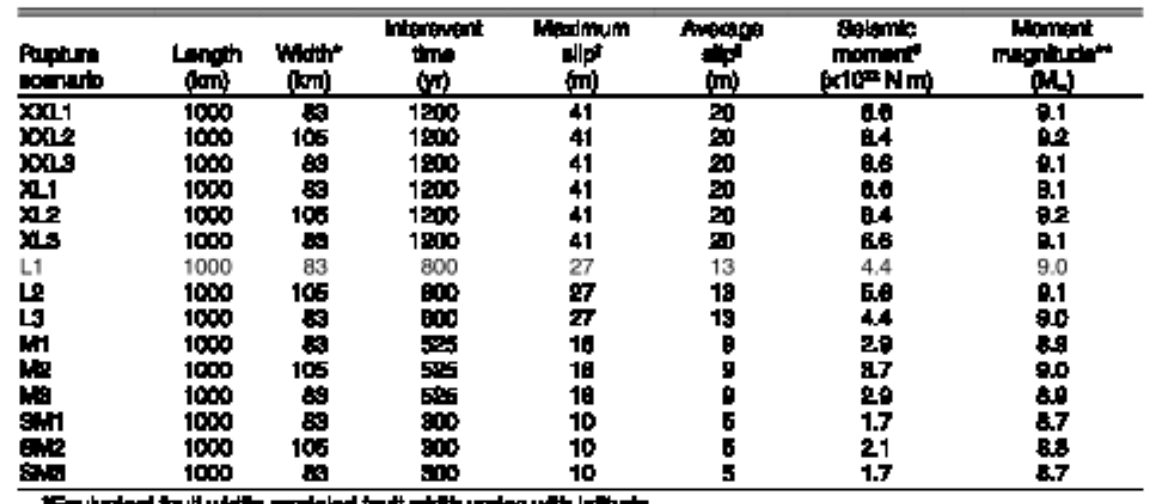

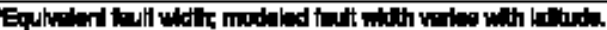

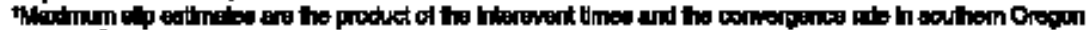

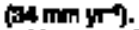

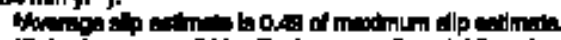

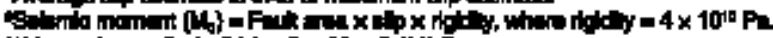

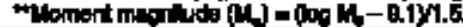


Table 23a. OxCal Sequence Model incorporating PSV dates and $\mathrm{C}^{14}$ dates to determine the age of SHb1. Estimated age for sand-sheet $\mathrm{SHb} 1$ is in bold.

\begin{tabular}{|c|c|c|c|c|c|c|}
\hline \multirow[b]{2}{*}{ Name } & \multicolumn{2}{|c|}{$\begin{array}{l}\text { Unmodelled cal. } \\
\text { years B.P. }\end{array}$} & \multirow{2}{*}{$\begin{array}{l}\text { Confidence } \\
\%\end{array}$} & \multicolumn{2}{|c|}{$\begin{array}{l}\text { Modelled cal. } \\
\text { years B.P. }\end{array}$} & \multirow{2}{*}{$\begin{array}{l}\text { Confidence } \\
\%\end{array}$} \\
\hline & from & to & & from & to & \\
\hline Boundary Top VCS2 & & & & 151 & -558 & 95.4 \\
\hline C_Date Western Settling & 151 & 111 & 95.4 & 152 & 111 & 95.4 \\
\hline C_Date UC1_66.2 & 761 & 21 & 95.4 & 718 & 133 & 95.4 \\
\hline C_Date UC5_89 & 1031 & 891 & 95.4 & 1030 & 892 & 95.4 \\
\hline C_Date UC6_95.2 & 1071 & 1031 & 95.4 & 1071 & 1031 & 95.4 \\
\hline C_Date UC7_103.4 & 1461 & 1061 & 95.4 & 1345 & 1064 & 95.4 \\
\hline C_Date UC8_110.5 & 1461 & 1061 & 95.4 & 1448 & 1165 & 95.4 \\
\hline R_Date VCS2n_RC28 & 1546 & 1414 & 95.4 & 1540 & 1412 & 95.4 \\
\hline C_Date UC9_125 & 1726 & 1326 & 95.4 & 1665 & 1439 & 95.4 \\
\hline C_Date UC10_132.5 & 1871 & 1471 & 95.4 & 1755 & 1543 & 95.4 \\
\hline R_Date VCS2n_RC6 & 1864 & 1730 & 95.4 & 1783 & 1718 & 95.4 \\
\hline Bed SHb1 & & & & 1804 & 1731 & 95.4 \\
\hline R_Date VCS2n_RC14 & 1815 & 1714 & 95.4 & 1820 & 1753 & 95.4 \\
\hline R_Date VCS2n_RC12 & 1821 & 1722 & 95.4 & 1825 & 1745 & 95.4 \\
\hline R_Date VCS2n_RC13 & 2759 & 2739 & 95.4 & 2759 & 2738 & 95.4 \\
\hline R_Date VCS2n_RC17 & 2705 & 2464 & 95.4 & 2705 & 2465 & 95.4 \\
\hline \multicolumn{7}{|l|}{ Phase Max Ages Bed A } \\
\hline R_Date VCS2n_RC23 & 3567 & 3462 & 95.4 & 3568 & 3462 & 95.4 \\
\hline R_Date VCS2n_RC25 & 4424 & 4291 & 95.4 & 4423 & 4259 & 95.4 \\
\hline Boundary Bottom VCS2 & & & & 5052 & 4265 & 95.3 \\
\hline Sequence Ship Harbor B & & & & & & \\
\hline
\end{tabular}


Table 23b. OxCal sequence model incorporating PSV dates from VCEI2 samples. The estimated age for sand-sheet EIb2 is in bold.

\begin{tabular}{|c|c|c|c|c|c|c|c|c|}
\hline \multirow{2}{*}{ Name } & \multicolumn{2}{|c|}{ Unmodelled (BP) } & \multirow[b]{2}{*}{$\%$} & \multicolumn{2}{|c|}{ Modelled (BP) } & \multirow[b]{2}{*}{$\%$} & \multirow[b]{2}{*}{$\mathrm{A}$} & \multirow[b]{2}{*}{$\mathrm{C}$} \\
\hline & from & to & & from & to & & & \\
\hline Boundary Top & & & & 2746 & 730 & 95.4 & & 96.2 \\
\hline C Date C2 57 & 2730 & 1530 & 95.4 & 2774 & 1724 & 95.4 & 101 & 99.7 \\
\hline C_Date C3_72.5 & 3105 & 1905 & 95.4 & 3157 & 2134 & 95.4 & 102 & 99.6 \\
\hline C_Date C6_95 & 4180 & 3780 & 95.4 & 4180 & 3780 & 95.4 & 99.9 & 99.8 \\
\hline $\begin{array}{l}\text { R_Date Min Age Bed } 2 \\
\text { Eliza VCEI2n_RC28 }\end{array}$ & 4862 & 4726 & 95.4 & 4755 & 4650 & 95.4 & 4.8 & 99.9 \\
\hline Bed 2 Eliza & & & & 4815 & 4667 & 95.4 & & 100 \\
\hline R_Date VCEI2n_RC19 & 5213 & 4878 & 95.3 & 5048 & 4879 & 95.4 & 100 & 100 \\
\hline R_Date VCEI2n_RC1 & 4825 & 4615 & 95.4 & 4830 & 4707 & 95.4 & 96.6 & 100 \\
\hline \multicolumn{9}{|l|}{ Phase A Bed EIb2 } \\
\hline C_Date S1_149.5 & 6030 & 4830 & 95.4 & 5261 & 4978 & 95.4 & 81.3 & 100 \\
\hline R_Date VCEI2n_RC8 & 5287 & 5039 & 95.4 & 5289 & 5050 & 95.4 & 107 & 100 \\
\hline C_Date S2_166 & 6330 & 5530 & 95.4 & 6219 & 5410 & 95.4 & 91.2 & 99.7 \\
\hline Boundary Base & & & & 7239 & 5428 & 95.4 & & 97.5 \\
\hline Sequence Eliza Island a & & & & & & & & \\
\hline
\end{tabular}


APPENDIX 1 GOUGE AUGER DESCRIPTIONS

S1

Depth

P1

0

63

66

77

\section{Description}

P1

Peats, possibly compacted due to pushing the auger in deeper than $1 \mathrm{~m}$

Muddy peat

$63-66 \mathrm{~cm}$ Sand with high organics content

$66-77 \mathrm{~cm}$ Mostly sand, with some mud content 
S2

Depth

P1

0

58.8

59

63

$76+$
Description

P1

Peat, possibly compacted $10-20 \mathrm{~cm}$

$58.8 \mathrm{~cm}$ Small layer, appears to contain some sand and consists of darker colored peat

$59-63 \mathrm{~cm}$ Peat

$63.5-76+$ Sand 
S3

Depth

P1

0

60

61

100

109

\section{Description}

P1

$0-60 \mathrm{~cm}$ Peat, alternating in colors

$60-61 \mathrm{~cm}$ Transition from peat to sand

$\sim 98$ is

another

peat

layer

$61-100 \mathrm{~cm}$ Sand, silty and grey/blue in color

$100-109 \mathrm{~cm}$ mud with some peat present 
S4

Depth

Description

P1

P1

0

130

132

160

$\mathrm{cm}$ Peat (was compacted into $60-130 \mathrm{~cm}$ )

$130-132 \mathrm{~cm}$ Muddy sand

132- $160 \mathrm{~cm}$ Sand 
S5

Depth

P1

0

100

140

\section{Description}

P1

Peat

Sand, contains various colored sand, sub angular to sub rounded clasts present at lower depths 
S6

Depth

P1

0

83

101

125

176

200

\author{
Description \\ P1 \\ $0-83 \mathrm{~cm}$ Peat \\ $83-101 \mathrm{~cm}$ Blue/grey mud \\ $101-125 \mathrm{~cm}$ Peat (possibly squished there? Might not be \\ natural) \\ $125-176 \mathrm{~cm}$ mud, similar to what is above \\ $176-200 \mathrm{~cm}$ Sand
}


S7

Depth

Description

P1

P1 
S8

Depth

Description

P1

P1

0

Lost return

50

Peat

60

Sand with angular clasts, unconsolidated

100 
S9

Depth

P1

0

30

67

133

173

190
Description

P1

Lost return

Peat - slightly muddy, produces turbulent water Grey mud, with $10 \%$ organics, roots etc blue/grey mud

Muddy sand, about 90\% sand, medium grained, some pockets of black and white, angular sand which contains $>50 \%$ quartz sand. Some small gravels present 
S10

Depth

P1

0

60

75

100

130

155

200
Description

P1

Peat

Peaty mud, mostly mud with $\sim 50 \%$ organics

Blue/grey mud

Mud w/several pinecones? And other organics, 10\% sandy mud, produces a 1 in ribbon (sandy loam?)

Lost end of the push, but residue in barrel suggests sand 
S11

Depth

P1

0

29

91

104

109

130

170

204

230

270
Description

P1

Lost return

Peat

Lost return

Peat

Mud, with $10 \%$ orgnaics, no gravels

Gritty mud, likely has some sand grains present

Sandy mud, with minor amounts of sand present

Muddy sand

Muddy sand with about 3-5 "pockets" of more pure sand, which are well sorted and contain black and white sands.

Some gravel clasts present, subangular to surrounded, and poorly sorted. 
$\mathrm{S} 12$

Depth

P1

0

84

87

104

183

185

220

238

240

284
Description

P1

Peat, when squeezed produces turbulent water

$84-87 \mathrm{~cm}$ Muddy, clayey peat, brown

$87-104 \mathrm{~cm}$ clayey mud, grey in color, contains about $10 \%$

organics

Silty clay mud, produces a 1.5 in ribbon, smells very

sulfurey, abundant organics $\sim 20 \%$

Peat (perhaps scraped from sides on way down?)

Mud - silty, grey and contains about $20 \%$ organics

Sand - poorly sorted, with some organics, white organic

"flakes" present, possibly some white small shell pieces??

Some bits of charcoal present as well. Roots exist in top 4-

$5 \mathrm{~cm}$. Some larger gravel clasts to $1 \mathrm{~cm}$ in size. Some larger

wood fragments to $1 \mathrm{~cm}$ in size.

Mud with some sand "pockets" present

Clay/Mud, blue/grey similar to above sand, gritty 
S13

Depth

P1

$34 \quad 0$

$57 \quad 34$

$102 \quad 91$

$40 \quad 193$

$5 \quad 233$

$13 \quad 238$

$8 \quad 251$

35

259
Description

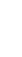

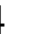

$91-193 \mathrm{~cm}$ grey mud with abundant organics, no gravels

$0-34 \mathrm{~cm}$ Lost return - maybe peat
$34-91 \mathrm{~cm}$ Peat - lighter in color down section

$$
233-238 \mathrm{~cm} \text { mixed sand and mud }
$$

$238-251$ mostly sand mixed with some mud, sub rounded, various colors

$251-259 \mathrm{~cm}$ Mud, mixed with some sand

$259-294 \mathrm{~cm}$ Mud, with some sand, poorly sorted, some

large clasts to $2 \mathrm{~cm}$ in size, subangular to sub rounded

294 
$\mathrm{S} 14$

Depth

P1

$97 \quad 0$

$7 \quad 97$

8

93

35

13

240

47

253

5
Description

$0-97 \mathrm{~cm}$ peat

$97-104 \mathrm{~cm}$ grey mud, slightly gritty

$104-112 \mathrm{~cm}$ Peat, possibly scraped from sides on way down

$112-205 \mathrm{~cm}$ Mud, organics 10\%

$205-240 \mathrm{~cm}$ Mud, no gravels, $5-10 \%$ organics

$240-251 \mathrm{~cm}$ Sand, one wood chunks present $2 \mathrm{~cm}$, clayey on top, grades to sand (normal grading), sand and some mud, sand appears subrounded, gravels at base of section $<1 \mathrm{~cm}$

$251-300 \mathrm{~cm}$ Pure mud, slightly grainy

$300-305 \mathrm{~cm}$ Gravely mud, gravels to $2 \mathrm{~cm}$ diameter 
S15

Depth

P1

$\begin{array}{ccc}16 & \text { P1 } & \text { Lost }- \text { potentially peat } \\ 88 & 0 & 16-104 \mathrm{~cm} \text { Peat } \\ 86 & 16 & 104-190 \mathrm{~cm} \mathrm{Clay/mud,} \mathrm{grey,} 10 \% \text { organics } \\ 2 & 104 & 190-192 \mathrm{~cm} \mathrm{Sand,} \mathrm{micas} \mathrm{present,} \mathrm{subangular,} \mathrm{poorly} \\ 7 & 190 & \text { sorted, }>50 \% \text { sand } \\ 2 & 192 & 192-199 \mathrm{~cm} \text { Sandy mud (mostly mud) } \\ 4 & 199 & 199-201 \mathrm{~cm} \mathrm{Sand,} \mathrm{poorly} \mathrm{sorted,}>50 \% \text { sand } \\ 56 & 201 & 201-205 \mathrm{~cm} \text { sandy mud, contains pebbles to } 7 \mathrm{~cm} \\ 14 & 205 & 205-261 \mathrm{~cm} \mathrm{Mud} \mathrm{with} \mathrm{one} \mathrm{gravel} 1 \mathrm{~cm} \text { in diameter } \\ 5 & 261 & 261-275 \mathrm{~cm} \text { Sandy mud, }>50 \% \text { mud } \\ 24 & 275 & 275-280 \mathrm{~cm} \mathrm{Muddy} \mathrm{sand,}>50 \% \text { sand, some gravels }<1 \mathrm{~cm} \\ & 280 & \text { and subangular } \\ & 304 & 280-304 \mathrm{~cm} \text { is muddy sand, bad return, soupy }\end{array}$


S16

Depth

P1

0

40

105

110

206

232

240

250

252

307

\section{Description}

P1

Lost - likely peat

$40-105 \mathrm{~cm}$ Peat

$105-110 \mathrm{~cm}$ Peat

$110-206 \mathrm{~cm}$ Grey mud, slightly gritty, some gravels $<.5 \mathrm{~cm} @ 165 \mathrm{~cm}, \sim 5 \%$ organics present $206-232 \mathrm{~cm}$ Sandy grey mud $232-240$ muddy sand, sand $>50 \%$, high quartz content, subangular to subrounded

$240-250 \mathrm{~cm}$ Sand, sand $>80 \%$, subangular to subrounded, high quartz content (lots of white sand present), abundant small gravels and several wood chips throughout. Gravels include larger quartz gravels

$250-252 \mathrm{~cm}$ muddy sand similar to $232-240 \mathrm{~cm}$ section

$252-307 \mathrm{~cm}$ Mud with some sand around 252 some gravels $0.4-1 \mathrm{~cm}$ diameter. 
S17

Depth

P1

$44 \quad 0$

$7 \quad 44$

$2 \quad 51$

$42 \quad 53$

5

95

5

15

43

120

24

163

0

4

95

00

105
Description

53
$20 \%$ organics $120-163 \mathrm{~cm} \mathrm{Mud,} \mathrm{gritty} \mathrm{(some} \mathrm{sand} \mathrm{content),} \mathrm{10-}$

Lost return

$51-53 \mathrm{~cm}$ Lost return

53 - 95 Peat

95 - 100 Trasition from peat to grey brown mud, very muddy peat $>50 \%$ organics

$100-105 \mathrm{~cm} \mathrm{Mud,} 20 \%$ organics, grey brown color

$105-120 \mathrm{~cm}$ Peat - may be artificial due to collection on way down hole

@ $176 \mathrm{~cm}$
large
gravel
clast $2 \mathrm{~cm}$
diameter

$163-180 \mathrm{~cm} \sim 10 \%$ sand in mud
$180-194 \mathrm{~cm}>50 \%$ sand in mud, $10 \%$ organics throughout
(a) $190-194 \mathrm{~cm}>80 \%$ sand
194 - 212cm similar to $190-194$

Sand, unconsolidated and soupie, poorly sorted, white and mixed colors, $>80 \%$ sand with gravels throughout

258

(a) $221 \mathrm{~cm}$ gravel $1.5 \mathrm{~cm}$

@ $227 \mathrm{~cm}$ large gravel clast 
S18

Depth

P1

$10 \quad 0$

$7 \quad 10$

$53 \quad 17$

$5 \quad 70$

$18.5 \quad 75$

27.5

42

30

18

193

121

163

93.5

$193-211 \mathrm{~cm}$ sand $>90 \%$, poorly sorted fine to coarse,
various colors ranging from black to white, mixed
with mud, brown/black, white large organic present

59

211

270

21
$193-211 \mathrm{~cm}$ sand $>90 \%$, poorly sorted fine to coarse,
various colors ranging from black to white, mixed
with mud, brown/black, white large organic present

$193-211 \mathrm{~cm}$ sand $>90 \%$, poorly sorted fine to coarse,
various colors ranging from black to white, mixed
with mud, brown/black, white large organic present

Sharp, distinct contact here

Description

$$
\begin{aligned}
& \text { Peat } \\
& 10-17 \mathrm{~cm} \text { Lost return } \\
& 17-70 \mathrm{~cm} \text { Peat }
\end{aligned}
$$

$70-75 \mathrm{~cm}$ transition, lighter brown peat

$70-93.5 \mathrm{~cm}$ mud, $20 \%$ organics, very smooth $<1 \%$

sand, brown grey color

$93.5-121 \mathrm{~cm} \mathrm{Mud,} \mathrm{brown} 30-40 \%$ organics, very soupie and unconsolidated

$121-163 \mathrm{~cm}$ Sand $>80 \%$ with some mud, gravels present starting at $150 \mathrm{~cm}$

$163-193 \mathrm{~cm}$ Lost return, unconsolidated and soupie sand

$211-270 \mathrm{~cm}$ Mud, smooth, slightly gritty, very well consolidated

@266

large

gravel

clast $1 \mathrm{~cm}$
$270-279 \mathrm{~cm}$ Soupy unconsolidated sand, poorly sorted up to $3 \mathrm{~mm},>80 \%$ sand

279

$279-300 \mathrm{~cm}$ soupie sand with $>50 \%$ organics 
S19

Depth

Description

P1

$22 \quad 0 \quad$ lost return

$59 \quad 22 \quad 22-81 \mathrm{~cm}$ peat

$1381 \quad 86-94 \mathrm{~cm}$ Muddy peat, $50 \%$ organics

$594 \quad 94-99 \mathrm{~cm}>50 \%$ organics

$2599 \quad 99-124 \mathrm{~cm} 20-30 \%$ organics

$10124 \quad 124-134 \mathrm{~cm}$ Muddy sand, $\sim 50 \%$ sand

$134-170 \mathrm{~cm}>80 \%$ sand, various colors black to white,

$36 \quad 134$

white quartz grains, poorly sorted fine to coarse

$16170 \quad 170-186 \mathrm{~cm}$ Peat

Sand, $>80 \%$, organics $10 \%$, mud present, sand poorly

$26 \quad 186 \quad$ sorted

23

212

$212-235 \mathrm{~cm} \mathrm{50/50 \%} \mathrm{sand} \mathrm{and} \mathrm{mud,} \mathrm{sand} \mathrm{similar} \mathrm{to} \mathrm{above}$

10

$235-245 \mathrm{~cm}$ Sand, poorly sorted $>80 \%$

Abrupt transition here

$6 \quad 245$

245 - 251 cm Mud, 5-10\% sand

$7 \quad 251$

$251-258 \mathrm{~cm}$ Sand, $>80 \%$ poorly sorted

$258-266 \mathrm{~cm}$ soupie unconsolidated mud with some sand

8

258

"pockets" concentrated within

266 
S20

Depth

P1

0

67

71

101

130

135

150

156

Description

P1

$0-67 \mathrm{~cm}$ Peat

$67-71 \mathrm{~cm}$ Gradual transition from peat to mud

$71-101 \mathrm{~cm}$ mud, $20 \%$ organics

$101-130 \mathrm{~cm}$ mud, grey brown, $20 \%$ organics

$130-135 \mathrm{~cm}$ sandy mud, appears well sorted with sand in "pockets" concentrated

$135-150 \mathrm{~cm}$ regular graded from mud at top to sand at bottom. Sand is poorly sorted and abundant

$150-156 \mathrm{~cm}$ sand, poorly sorted, contains pinecone parts or wood chips

$156-178 \mathrm{~cm}$ Sand, some organics, $>90 \%$ sand with some mud

$178-178-208 \mathrm{~cm}$ Sand, poorly sorted, contains gravles to $.7 \mathrm{~cm}$

$208-215 \mathrm{~cm}$ Gradual transition to mud $\sim 50 \%$ sand

215

$215-260 \mathrm{~cm}$ Mud with $10-30 \%$ sand, sand $\%$ increases down section, abundant gravels throughout $\sim 25 \%$ and up to $1.5 \mathrm{~cm}$ in size. Contains some spiral shell fragments

$176-208 \mathrm{~cm}$ contains many shell fragments

@200 small shell piece

@ 220 large shell piece 
S21

Depth

Description

P1

\begin{tabular}{|c|c|c|}
\hline 83 & 0 & $\begin{array}{c}0-83 \mathrm{~cm} \text { Peat, variable } \mathrm{n} \text { color, darker at top. Lighter in } \\
\text { middle, darkens again at bottom }\end{array}$ \\
\hline 5 & 83 & $83-88 \mathrm{~cm}$ transition from peat to mud \\
\hline 9 & 88 & $88-97 \mathrm{~cm}$ Mud wih $\sim 10 \%$ organics \\
\hline 8 & 97 & $\begin{array}{c}97-105 \mathrm{~cm} \text { Mud with sand, coarsens down section, } \sim 30- \\
50 \% \text { sand at bottom. Mud is grey brown }\end{array}$ \\
\hline 10 & 105 & $105-115 \mathrm{~cm}$ Mud \\
\hline 2 & 115 & $115-117 \mathrm{~cm}$ Peat \\
\hline 8 & 117 & $\begin{array}{l}117-125 \mathrm{~cm} \text { transition, coarsens down section to gravels } \\
<1 \mathrm{~cm}\end{array}$ \\
\hline 73 & 125 & $\begin{array}{l}125-198 \mathrm{~cm} \text { Sand, }>80 \%, 10-20 \% \text { organics with gravels } \\
\text { to } 1.8 \mathrm{~cm} \text {, sand poorly sorted, fine to coarse }\end{array}$ \\
\hline
\end{tabular}


S22

Depth

P1

$104 \quad 0$

4

97

29

3

3

7

3

9.5

19

265

20

104

108

205

234

237

240

247

250

255.5

284
Description

304

Lost return
$104-108 \mathrm{~cm}$ Peat

$108-205 \mathrm{~cm} \mathrm{Mud,}<5 \%$ sand, slightly gritty, Large organics grey brown color, Top half $\sim 10 \%$ organics, @138cm and $\sim 5 \%$ organics in bottom half

(a) $180 \mathrm{~cm}$

$$
205-234 \mathrm{~cm} \text { Mud with } \sim 5 \% \text { sand }
$$
$234-237 \mathrm{~cm}$ diagonal, small sand layer perhaps smeared due to core barrel sides?

$237-240 \mathrm{~cm}$ Mud with 50\% sand

$240-247 \mathrm{~cm}$ Sand, poorly sorted

$247-250 \mathrm{~cm}$ Mud with $~ 50 \%$ sand

$250-255.5 \mathrm{~cm}$ Peat with large gravels to $2 \mathrm{~m}$

$255.5-265 \mathrm{~cm}$ sand with gravels to $2 \mathrm{~cm}$, poorly sorted $>80 \%$ sand

$265-284 \mathrm{~cm}$ Soupie unconsolidated mud, smooth with $\sim 10 \%$ sand content 
S23

Depth

P1

0

19

85

97

104

122

129

205

222.5

231

244

257

305

Alternative:

134

214

223

232

\section{Description}

P1

$0-19 \mathrm{~cm}$ Lost return

$19-85 \mathrm{~cm}$ Peat

$85-97 \mathrm{~cm}$ Transition from peat to mud, $>50 \%$ organics

throughout but less towards bottom

$97-104 \mathrm{~cm}$ Mud, brown grey with $\sim 20-30 \%$ organics

$104-122 \mathrm{~cm}$ Peat

$122-129 \mathrm{~cm}$ Transition from peat to mud

$129-205 \mathrm{~cm} \mathrm{Mud,} \mathrm{grey/blue} \mathrm{in} \mathrm{top} 30 \mathrm{~cm}$, grey brown throughout, produces a 2 in ribbon

$205-222.5 \mathrm{~cm}$ Mud

Abrupt transition to Sand

$222.5-231 \mathrm{~cm}$ Sand with gravel $1 \mathrm{~cm}$ at bottom, grades normally, organics present throughout $231-244 \mathrm{~cm}$ Sandy clay with gravels to $.5 \mathrm{~cm}$

$257-305 \mathrm{~cm}$ lost return - soupy sand

$134-214 \mathrm{~cm} \mathrm{Mud}$

$214-223 \mathrm{~cm}$ Sand, poorly sorted, gravels throught to $1 \mathrm{~cm}$, organics present

$223-232 \mathrm{~cm}$ mud with $\sim 30 \%$ sand

$$
\begin{gathered}
\text { large } \\
\text { organic } \\
@ 156 \mathrm{~cm}, \\
\text { appears } \\
\text { to be a } \\
\text { pinecone } \\
\text { seed/part }
\end{gathered}
$$


S24

Depth

P1

0

79

94.5

193

127

134

209

223

229
Description

P1

$0-79 \mathrm{~cm}$ Peat

$79-94.5 \mathrm{~cm}$ Mud with 30-40\% organics

$94.5-193 \mathrm{~cm} \mathrm{Mud,} \mathrm{grey} \mathrm{brown,}<1 \%$ sand, large organic at $70-75 \mathrm{~cm}, 30 \%$ organics throughout

$127-134 \mathrm{~cm}$ Peat

$134-209 \mathrm{~cm}$ Mud, some sand towards the bottom, gravels to $.5 \mathrm{~cm}$

$209-223 \mathrm{~cm}$ Sand, poorly sorted $223-229 \mathrm{~cm} \mathrm{Mud,} \mathrm{with} \mathrm{sand} \mathrm{mixed}$ 
S25

Depth

P1

0

64

72.5

104

177

188

197

204

214

220

242

247.5

288

\section{Description}

P1

$0-64 \mathrm{~cm}$ Peat

$64-72.5 \mathrm{~cm}$ Transition to mud from peat

$72.5-104 \mathrm{~cm} \mathrm{Mud,} \mathrm{some} \mathrm{mica} \mathrm{flakes,} \sim 30 \%$ organics

$104-$

125 some

motteling

of clay

$177-198 \mathrm{~cm}$ Sand with some mud, large gravles to $1 \mathrm{~cm}$ at 178 and $185 \mathrm{~cm}$

$188-197 \mathrm{~cm}$ sand, poorly sorted, with gravels to $2 \mathrm{~cm}$

$197-204 \mathrm{~cm}$ no return

$204-214 \mathrm{~cm}$ mud and sand $50 / 50 \%$ only part of barrel is

full

$214-220 \mathrm{~cm}$ lost return

$220-242 \mathrm{~cm}$ poorly sorted sand, black to white, with gravels to $2 \mathrm{~cm}$ at base and throughout

$242-247.5$ Mud with some sand, bad return, soupey and unconsolidated, $\sim 10 \%$ organics

$247.5-288 \mathrm{~cm}$ soupey bad return, with large gravel $2.5 \mathrm{~cm}$ 
S26

Depth

P1

0

17

98

$$
\begin{gathered}
98-104.5 \mathrm{~cm} \text { Sand, } \sim 50 \% \text { sand with mud, abundant organics } \\
20 \%
\end{gathered}
$$

$$
\begin{gathered}
\text { Description } \\
\text { P1 } \\
0-17 \mathrm{~cm} \text { lost return } \\
17-98 \mathrm{~cm} \text { Peat }
\end{gathered}
$$

At base at $104.5 \mathrm{~cm}$ large organic, pinecone piece

\section{Abrupt transition to next unit}

$104.5 \quad 104.5-114 \mathrm{~cm} \mathrm{Mud,} \mathrm{smooth,} \mathrm{grey} \mathrm{brown,} \mathrm{large} \mathrm{organic,} \mathrm{gritty}$ $114-118 \mathrm{~cm} \mathrm{50/50 \%} \mathrm{mud} \mathrm{and} \mathrm{sand,} \mathrm{mottled} \mathrm{dark} \mathrm{and} \mathrm{light} \mathrm{in}$ color

$118 \quad 118-139.5 \mathrm{~cm}$ Sand $>70 \%$ with some mud, $\sim 20-30 \%$ organics

$139.5 \quad 139.5-167 \mathrm{~cm}$ Mud, gritty $<5 \%$ sand, $20 \%$ organics $167-176 \mathrm{~cm}$ sandy $>50 \%$, with large gravels to $1 \mathrm{~cm}$, matrix supported $167-198 \mathrm{~cm}$ Sandy mud, no good return, $\sim 40 \%$ organics, 30 - 
S27

Depth

P1

0

33

87

104

185

\section{Description}

P1

$0-33 \mathrm{~cm}$ lost return upon come up, some large organics left in barrel $33-87 \mathrm{~cm}$ Peat, block layer $4 \mathrm{~mm}$ thick at $70 \mathrm{~cm}$ and $78 \mathrm{~cm}$

$87-104 \mathrm{~cm}$ Sand, $\sim 40 \%$ organics, $>90 \%$ sand, large gravel at base, sand is poorly sorted, ranging from medium to coarse

$104-185 \mathrm{~cm}$ Sand $>90 \%$ with some mud, gravels throughout to $2.5 \mathrm{~cm}$, matrix supported, organics $\sim 20 \%$ throughout in small tufts

$185-204 \mathrm{~cm}$ lost return, appears as soupie unconsolidated sand and mud, sand is poorly sorted medium to coarse colors white to black 
S28

Depth

P1

0

23.5

98

105

114

116

118

119

160

197
Description

P1

$0-23.5 \mathrm{~cm}$ lost return

$23.5-98 \mathrm{~cm}$ Peat

$98-105 \mathrm{~cm}$ Peat

$105-114 \mathrm{~cm}$ Sand, poorly sorted, medium to coarse

$>90 \%$, contains small charcoals throughout, $10-20 \%$

organics

Distinct contact

$114-116 \mathrm{~cm} \mathrm{Mud,} 50 \%$ sand

Distinct contact

$116-118 \mathrm{~cm}$ sand $>80 \%$ in mud, poorly sorted medium to coarse, organics $5-10 \%$.

$118-119 \mathrm{~cm}$ mud $\sim 50 \%$ sand

$119-160 \mathrm{~cm}$ Sand, poorly sorted medium to coarse, $3 \mathrm{~mm}$

biggest, mixed quartz and other sand

$160-197 \mathrm{~cm}$ lost return 
Depth

P1

0

16

80

106

110

181

230
Description

\section{P1}

$0-16 \mathrm{~cm}$ lost return (peat?)

$16-80 \mathrm{~cm}$ Peat, lightens in color downsection

$80-106 \mathrm{~cm}$ Peat

$106-110 \mathrm{~cm}$ transition, appears "smeared" up and down section

$110-181 \mathrm{~cm} \mathrm{Mud,}<5 \%$ sand, $\sim 10 \%$ organics

$181-230 \mathrm{~cm} \mathrm{Mud,}<1 \%$ sand, grey brown, $\sim 5-10 \%$ organics, 2 in ribbon (mostly clay)

$230-241 \mathrm{~cm}$ Peat $>50 \%$ organics, mixed with mud with pinecone bits@ top of section

Abrupt transition

$241-262$ Sand $>90 \%$ organics $\sim 10 \%$ very solid top $10 \mathrm{~cm}$, unconsolidated/soupie below that

$262-270 \mathrm{~cm}$ Soupie, lost return, mostly sand in barrel

270 - $281 \mathrm{~cm}$ Clay at base of barrel, bad return 
S30

Depth

P1

Description

0

P1

$0-96 \mathrm{~cm}$ Peat

$9696-103 \mathrm{~cm}$ transition to mud from peat - gradual

$103103-106 \mathrm{~cm}$ peaty mud, $\sim 60 \%$ mud, $40 \%$ organics and $<1 \%$ sand

$106 \quad 106-111 \mathrm{~cm}$ Peat

$111-208 \mathrm{~cm}$ Mud, contains $<2 \%$ sand, slightly gritty, and typically $10-20 \%$ organics throughout

$208208-229.5 \mathrm{~cm} \mathrm{Mud,} \sim 10 \%$ organics, $<1 \%$ sand

229.5 $229.5-233 \mathrm{~cm}$ Sand, poorly sorted, $>70 \%$ sand, fine to coarse,

$\sim 10 \%$ organics throughout

$233 \quad 233-236 \mathrm{~cm}$ Mud and sand $50 / 50 \%$

$236236-238 \mathrm{~cm}$ Sand $>80 \%$, poorly sorted

$238238-249 \mathrm{~cm} \mathrm{Mud,}<5 \%$ sand, smooth to touch

Sharp, abrupt contact

\section{9}

$249-253 \mathrm{~cm}$ Sand $>90 \%$ poorly sorted fine to lower coarse, inset in some mud, some organics $\sim 10 \%$

253

$253-263 \mathrm{~cm}$ Mud with sand $\sim 30 \%$, poorly sorted and produces

1.5 in ribbon

$263263-309-$ lost return for most part, large organic at $288-290 \mathrm{~cm}$

309

$189189-223 \mathrm{~cm}$ Mud, normally graded and with sand at the bottom

Abrupt transition

223

$223-230 \mathrm{~cm}$ Sand in mud, sand poorly sorted, white to black, subrounded fine to coarse.

230

Abrupt transition

250

$230-250 \mathrm{~cm}$ Mud

$250-260 \mathrm{~cm}$ Sand concentrated into "pockets" within mud, sand

size is poorly sorted.

@ $159-163 \mathrm{~cm}$ large wood fragment organics make up most of barrel 
S31

Depth

P1

0

104

$\mathrm{P} 2$

104

127

205

P3

205

306

\section{Description}

P1

Peat, lighter downsection and more mud content

downsection

Peat, gradual transition below

Mud with $<5 \%$ sand, $\sim 20 \%$ organics. Sand increases at bottom. Lighter color at top, mottled color from 140-160, dark from 160 to bottom

Blue/grey mud, $\sim 5-10 \%$ organics throughout end push 3 
S32

Depth

P1

0

104

P2

104

P3

206

at 221

at 283

at 260

\section{Description}

P1

Lost most of push - top is $10 \mathrm{~cm}$ of peat with $20 \mathrm{~cm}$ of clay below that.

Tape lined up to top of push

Blue grey mud with $<5 \%$ sand, produces a 1 in ribbon Shell fragments with $60 \%$ organics Shell fragment

decomposed shell fragmetns, $\sim 10 \%$ shells 
S33

Depth

Description

P1

P1

0

Peat, soupey at top and base

104

P2

104

Grey green mud, $<5 \%$ sand, around $160-165 \mathrm{~cm}$ very

205

P3

205

at 220

280-282

soupey

306

Mud, organics content ranges from 5-60\%, mica sands can

be seen throughout but no grit inidcates very low sand

content

Organics are the most, at $60 \%$

shell fragments present 
S34

Thickness

104

102

5

Depth

P1

0

104

P2

104

206

P3

205

246

251

253

255

280

280

307
Description

Peat

end

Grey mud with $<5 \%$ sand, organics throughout, sand increasers to $5 \%$ at bottom of section end

$\sim 5 \%$ sand in mud, organics $\sim 20-30 \%$, gradual transition to layer below

Sand ,normally graded at tjop from fine sand and mud

Coarse sand $100 \%$, subangular

Muddier, with $\sim 60 \%$ sand

$90+\%$ sand in some mud, sand is fine to caorse, poorly sorted

Large organics and shell fragments

Mud, brown/grey, no sand $<5 \%$, organics $\sim 10 \%$ 
S35

Depth

P1

P2

104

176

at 194

276

\section{Description}

P1

Mud, gritty at bottomw ith few small gravels

Top $5 \mathrm{~cm} \sim 10 \%$ sand, rest below that is $<5 \%$ sand throughout, grey clay rich mud, well consolidated wth $\sim 20 \%$ organics

$\sim 5-10 \%$ sand 
El_1 Field Description

P1

\#VALUE! P1

Mud, wet, with some large gravels

18

3

Mud, grey and brown mixed, gravels throughout to $1.5 \mathrm{~cm}$ Large pocket of sand next to gravels, sand $>90 \%$ total Grey mud with gravels to $1.5 \mathrm{~cm}$, sand poor High organic content soil mixed with grey mud, small woodlooking fragments

Brown mud with no sand, some gravel clasts throughout

Grey mud, some grit $<5 \%$ coarse sand, few small gravels End Push

Push full but did not completely get auger in ground, matched tape to top of push on auger then recorded depth based on that. Perhaps did not get into hole straight for second push

Mud, matrix supported gravels within

Grey mud with occasional gravels

Brown organic rich mud

Grey mud

Two large gravels

Smooth, sand poor mud

Gravelly grey mud, some grit ( $\sim 5 \%$ sand), mud is compact at bottom

Concentration of gravels within section

End push 


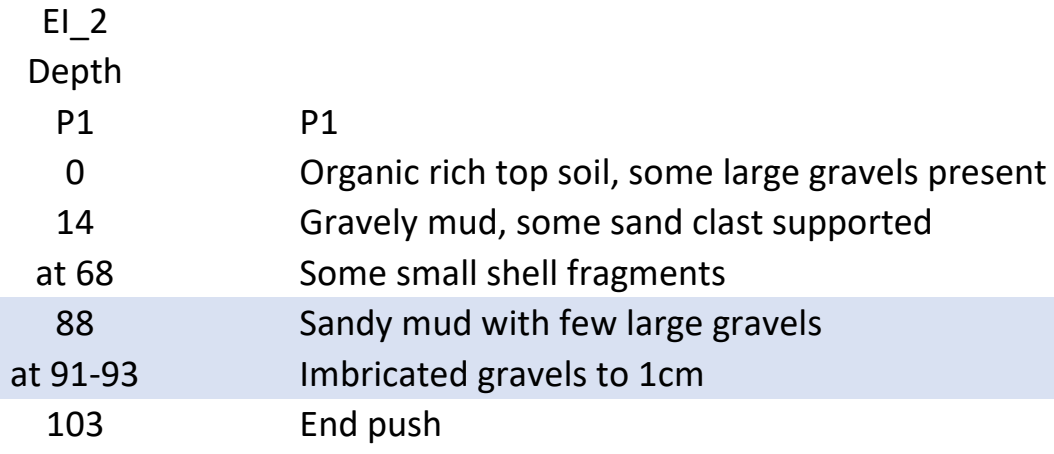


El_3

Depth

P1

P1

$0 \quad$ Coarse sand with gravels to $1.5 \mathrm{~cm}$

Clayey, silty sandy mud, fine to coarse sand, occasional gravel, most small to

$451 \mathrm{~cm}$, matrix supported. Soil ribbon is $1 \mathrm{in}$

$76 \quad$ End push 1

P2

76

Coarse sand and gravels, sand $>80 \%$ with some mud

Dark grey, mud with $\sim 50 \%$ sand, $>1$ in

83 ribbon

Mud with $<20 \%$ sand, some gravels

96 throughout to $1 \mathrm{~cm}$

Gravelly sandy mud, coarser sand $\sim 50 \%$

108 total

\begin{tabular}{|c|c|}
\hline at 128 & $2 \mathrm{~cm}$ thick pocket of sand, sand $>80 \%$ \\
\hline 139 & $\begin{array}{l}\text { Sand }>80 \% \text { with mud, whole shell at } \\
131 \mathrm{~cm}\end{array}$ \\
\hline 147 & Mud with $\sim 50 \%$ sand, some small gravels \\
\hline 152 & $\begin{array}{l}\text { Sand } \sim 80 \%, \text { grey color, mixed with mud, } \\
\text { large gravel at base } 1.5 \mathrm{~cm}\end{array}$ \\
\hline
\end{tabular}

157

Clay, grey, with fine sand $\sim 20 \%$

throughout, produces 3 in ribbon, more

174 sand at top and decreases downsection

End Push 2 
El_4

Depth

P1

0

55

102

105

P2

75

90

97

103

125

132-133

135

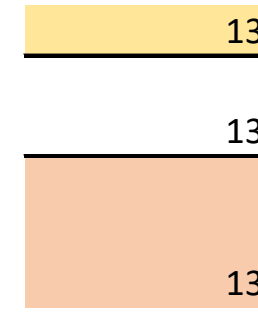

139

Compact, hard clay, occasional gravel to $.5 \mathrm{~cm}$. @64cm some more sand, clay has areas of grey and brown, sand content increases at bottom, produces a 5 in ribbon, charcole can be seen

143 throughout

167
Coarse, gravelly sand

Mud with $\sim 50 \%$ sand, gravels to $1 \mathrm{~cm}$

Grey mud, clay rich, produces 2 in ribbon, some coarse sands but no large gravels End push
Coarse sand mixed with gravles, $<30 \%$ sand in grey mud $\sim 50 \%$ sand in mud Organic rich, brown mud with some organics present Large gravel fills core barrel Brown mud with clay and Sand $95 \%$, including quartz sand, subrounded, white and black

End P2 


\begin{tabular}{|c|c|}
\hline \multicolumn{2}{|l|}{ El_5 } \\
\hline \\
\hline P1 & P1 \\
\hline 0 & Top soil \\
\hline & Brown sand $>80 \%$ sand, occasional \\
\hline 15 & gravels to $.75 \mathrm{~cm}$ \\
\hline 24.5 & $\begin{array}{c}\text { Mottled sand, grey mostly with } \\
\text { some light brown color motteled } \\
\text { throughout }\end{array}$ \\
\hline & $\begin{array}{l}\text { Blue grey mud, some light brown } \\
\text { organics, but mostly mud, basically } \\
\text { no sand, occaional small wood } \\
\text { fragments. Dark streaks throughout }\end{array}$ \\
\hline 78 & perhaps charcol \\
\hline 105 & End push \\
\hline
\end{tabular}

Unable to collect P2 
EI_6

Depth

P1

P1

0 Top soil, modern roots

16 Transition, gradual to sand

Sand $>90 \%$, grey, varies from

23 fine to coarsee

Coarser sand $>90 \%$, grey with

52 small gravels to $.5 \mathrm{~cm}$

Brown/red mud, grainey with a

$58 \quad$ little sand $\sim 5 \%$

Sand, coarse, slanted due to

barrel? $>90 \%$ sand, coarse, small

62

gravels

Mud - clay rich, grey blue, few

coarse sands, produces 4 in

63

ribbon

Sandy clay, grey with $\sim 40-50 \%$

79

sand

Mud, $<40 \%$ sand, less sand

83 further down section

$87 \quad$ End push

Refusal 
El_7

Depth

P1

0

30

50

53

62
P1

Top soil

Brown sandy soil with some light brown motteling in color

Clayey, light tan

Coarse sand in mud, sand $>50 \%$

End push 
El8

Depth

P1

P1

0 Top soil

Sandy soil, large gravel at $33 \mathrm{~cm} 2.5 \mathrm{~cm}$

13 large

Mottled grey with light brown sandy

42 soil

Mud/clay rich, grey blue with some

brown organics and mottled area,

varies in color from grey blue to

brown, last $5 \mathrm{~cm}$ are crumbly, dry and

54 hard

50\% sand above $100 \%$ mud, some

63 gravels to $1 \mathrm{~cm}$

73 End push 


\begin{tabular}{|c|c|}
\hline \multicolumn{2}{|c|}{$\begin{array}{c}\text { El_9 } \\
\text { Depth }\end{array}$} \\
\hline P1 & P1 \\
\hline 0 & Lost \\
\hline 17 & Top soil \\
\hline & Grey sand with organics and ocassional gravels to \\
\hline 25 & $1.5 \mathrm{~cm}$ \\
\hline & Dark $~ 50 \%$ sand mostly clay $/$ mud, at $80 \mathrm{~cm}$ there \\
\hline 14 & $\begin{array}{l}\text { are many roots around gravel clasts } \\
\text { sand }\end{array}$ \\
\hline $\begin{array}{l}83 \\
89\end{array}$ & Dark brown, same as above \\
\hline 91 & Grey sand similar to $83-89$ \\
\hline & Crumbly blue clay, super compact, block ytexture, \\
\hline 95 & no sand, no gravels \\
\hline 104 & End push \\
\hline
\end{tabular}


El_10

Depth

P1

P1

0 Top soil

37

Large gravel $2 \mathrm{~cm}$

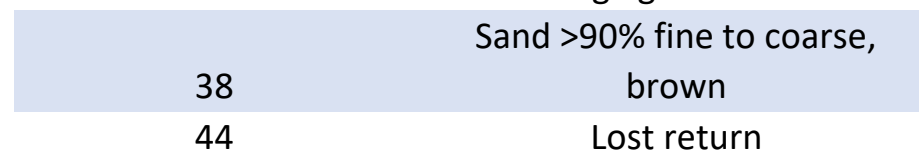

Clay mud with coarse sand, some gravels to $1 \mathrm{~cm}$, organic

63

rich

74.5 lost return, some roots present

105

Refusal 
EI_11

Depth

P1

37

31

0

37

25

68

93

P2

42

93

5

135

13

14

23

140

Mud, grey/brown with some ravels to $.5 \mathrm{~cm}<1 \%$ sand, no grit

Sand, quartz sand white and black, medium to coarse grained, some organics present throughout

Dark brown clay mud, very little sand, large gravel @150 to $1 \mathrm{~cm}$

Sand $>80 \%$ mixed with some mud

Mud, with $<10 \%$ sand, dark brown,

organics and wood chips present

end push - bottom lost, sounded like

190

gravel/sand at the bottom 
EI_12

Depth

P1

28

0

17

1

28

45

Top soil, O horizon,

Organic rich brown soil with

high clay content

small pocket of sand

Grey blue clay, no grit, nos and, exept sand conentrated

into pockets at $47 \mathrm{~cm}$ and 60 -

$61 \mathrm{~cm}$. Sand is coarse and

17.5

46

have some gravels $0.5 \mathrm{~cm}$

47

Small pocket of sand

at $60-61$

Pocket of sand

Organic rich clay, some areas

of concentrated organics with

roots present, some mica

sands seen throughout,

20.5

63.5

basically no grit/sand

84

End push, lost bottom

P2

went to $1.5 \mathrm{~m}$ depth

20

84

Clay, grey with areas of brown concentarted organics

Grey clay, $<5 \%$ sand, some

grit from coarse sand, sub-

34.5

104

angular

Small sand layer, sand is subangular to subrounded,

at 138.5 Coarse, and contains quartz

at 143

Same as 138.5

Mud, grey/brown, with some

9

138.5

mica sands, $<5 \%$

Silty sand, sand starts around

$5 \%$ and increases

23.5

147.5

downsection to $>50 \%$

Abrupt transition

2

Mud, brown, with $5 \%$ sand

173

End push 
El_13

Depth cm

P1

P1

Top soil, organic rich, brown, abudnant roots, gradual transition to

0

clay

27.5

Grey clay, organics throughout

Small line/pocket of sand and gravel
At 56 to $1.5 \mathrm{~cm}$

Grey and brown mud, sand $<5 \%$, 57 some grit, some organics thorughout 66.5 Sand pocket

Brown silty clay, breaks aparts into

68 blocky chunks

69

Grey and brown mud with $<5 \%$ sand

$\begin{array}{cc}73 & \begin{array}{c}\text { Sand, poorly sorted, fine to lower } \\ \text { coarse }\end{array} \\ 74 & \begin{array}{c}\text { Brown grey mud with }<5 \% \text { sand } \\ \text { at } 80\end{array} \\ & \begin{array}{c}\text { Large gravel } 2 \mathrm{~cm} \\ 82\end{array} \\ 86 & \text { throughout, charcole present } \\ \text { end push }\end{array}$

Lost end of push

P2

Mud $<5 \%$, some grit, mostly unconsolidated, organics presnt

86 throughout, gradual lower transition

Silty brown mud with $10 \%$ sand, micas and quartz grains, subangular

109 to subrounded

Brown mud wtih sand increasing downsection, sand is white and black,

121 quartz and micas large wood fragment

Soubey sand-rich brown mud, $50 \%$ sand, organics $\sim 40 \%$ total Mud, clay rich, grey with sand and some organics throughout, sand is gerally coarse 
P3

188

193

lost top

Grey brown clay

$\begin{array}{cc} & \text { Blue grey mud with } \sim 50 \% \text { gravel and } \\ 198 & \text { sand } \\ 218.5 & \text { Grey blue clay } \\ & \text { Pocket of coarse sand and gravels } \\ \text { From 221-224 } & \sim 50 \%+ \\ 244 & \text { End push 3 }\end{array}$


EI_14

Depth

P1

40

0

40

8

26

48

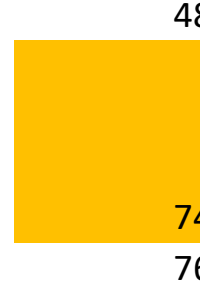

86

95

104

P2

52

$104 \quad \begin{array}{r}\text { less consolidated from } 141-144 \\ \sim 50 \% \text { coarse sand in some grey clay- } \\ \text { rich mud }\end{array}$
Brown mud/clay with $<5 \%$ sand,

12

158

20

170

190 which appear as micas, very smooth, produces 1.5 in ribbion, silty and

Top soil, o horizon, brown

Transition from soil to clay, graudal and light brown

Clay rich mud, mottled in color, light brown and grey $<5 \%$ sand, roots and wood throughout, gravel to $1.3 \mathrm{~cm}$ at $68 \mathrm{~cm}$

Large pocket of coarse sand, white and quartz rich, within similar clay as Same as above 48-74

Dark brown organic rich clay, $>50 \%$ organics, some sand $<5 \%$ Mottled grey and brown colored mud with $<5 \%$ sand End push

Mud, clay rich, with $\sim 20 \%$ organics, mottled colors of grey and light brown, mostly well compacted, but crumbly

Sand $>50 \%$, content increases downsecection, sand is poorly sorted fine to $L c 0,>90 \%$ at bottom, wth a few gravels throughout to $.5 \mathrm{~cm}$ End push 2 above, gravels to $.3 \mathrm{~cm}$ 
EI_15

Depth

0

34

45

56

At 81

85

P2

Grey mud/clay, well consolidated, some sand at $90 \mathrm{~cm}$ some large

85 organic fragments hroughout

Transition to clay/mud, light brown

Grey and brown clay with gravels to $.9 \mathrm{~cm}, \sim 5 \%$ sand, with coarse sand seen throughout

Similar to above with $50 \%$ sand, sorted into "pockets" but alos throughout in matrix, sand is coarse and has abudant quartz. Organics throughout and gravels to $1.3 \mathrm{~cm}$ throughout, making up $10 \%$ of composition Pocket of sand End push 1

85

$$
\text { End push } 1
$$

\begin{tabular}{|c|c|}
\hline 85 & $\begin{array}{c}\text { Grey mud/clay, well consolidated, } \\
\text { some sand at } 90 \mathrm{~cm} \text { some large } \\
\text { organic fragments hroughout }\end{array}$ \\
\hline at 90 within section & Sand \\
\hline 101 & $\begin{array}{l}\text { Mud in } 1 / 2 \text { of barrel, rest is same as } \\
\text { above with alrge pocket to sand } \\
\sim 80 \% \text { in mud, sand is poorly sorted, } \\
\text { medium to coarse and has some } \\
\text { small gravels }\end{array}$ \\
\hline 105 & $\begin{array}{c}\text { Same as } 85-100 \text { section } \\
\text { Abrupt transtion }\end{array}$ \\
\hline 108 & $\begin{array}{c}\text { Brown, organic rich material, with } \\
\text { sand concentrated at } 112 \mathrm{~cm} \text {, sand is } \\
\text { medium to coarse, gra vels to } .8 \mathrm{~cm} \\
\text { throughout }\end{array}$ \\
\hline at 112 & Sand within section \\
\hline 124.5 & $\begin{array}{l}\text { Soupey brown mud with gravels to } \\
\qquad 1.1 \mathrm{~cm} \\
\text { Brown silty soil, compact, crumbly, } \\
\text { some organics, produces a } 1 \text { in } \\
\text { ribbon }\end{array}$ \\
\hline $128-129$ & $\begin{array}{l}\text { Half of barrel is fine sand in the same } \\
\text { material as above } \\
\text { Fine sand well sorted into brown } \\
\text { silty soil }\end{array}$ \\
\hline
\end{tabular}

Brown, organic rich material, with sand concentrated at $112 \mathrm{~cm}$, sand is medium to coarse, gra vels to $.8 \mathrm{~cm}$ Sand within section 
EI_16

Depth

P1

0

20

20

30

36

41

63

P2

63

67

79

82

at 113

at 120

127

133
P1

Top soil, dark brown, from $15-20$ is a lighter brown color and gradual transition Large gravel $2 \mathrm{~cm}$

$>50 \%$ sand and gravesl in grey/brown mud, abundant organics

$\sim 30-40 \%$

Grey mud with $\sim 30 \%$ sand and

gravels

$>50 \%$ sand and gravels in grey mud

Grey brown mud with gravels

throughout to $1.4 \mathrm{~cm}$ abundant

organics (10-20\%) and coarse sand

(10-20\%)

End Push 1

Unconsolidated mud and organics

Soupey mud, $\sim 30 \%$ organics

lost return

Grey mud, clay rich, with $20-30 \%$

coarse sand and gravels $\sim 10 \%$ and to

$1.6 \mathrm{~cm}$, sand contains quartz and micas, some roots concentration of sand concentration of sand

Mud with $80 \%$ sand, sand is poorly sorted, fine to lower coarse, roots and organics present

End $p 2$ 
EI_17

Depth

P1

31

5

14

1

4

2

50

51

55

57

63

65

79

80

84

99

P2

8

99

107

137
Top soil, dark brown to black

Transition from to clay

grey clay rich mud with $\sim 5 \%$ sand, gritty with gravel to $.5 \mathrm{~cm}$

Pocke of sand in grey mud, sand is coarse, $100 \%$ sand, mixed

composition with quartz and sand

Gritty mud similar to $36-50$

sand and gravels to $.5 \mathrm{~cm}$

Grey /brown mud, clay rich with

sand concentrated into areas listed below. Whole section is generally $\sim 30 \%$ sand, with small gravels present throughout, mostly grey mud. coarse sand $>50 \%$

Sandy mud (similar to above) $>50 \%$ sand

Large gravel

large gravel

End of section and push

Dark grey mudw ith 30\% sand, large

$2.2 \mathrm{~cm}$ gravel at $105 \mathrm{~cm}$

Grey and brown mud with $20-30 \%$

sand, organics $\sim 10-20 \%$, and

occasional gravels $5-10 \%$ to $1 \mathrm{~cm}$. Lost end of push

Hard at end, hitting refusal about

$1.75 \mathrm{~m}$ depth, possibly super hard clay? 


$\begin{array}{cc}\text { El_18 } \\ \text { Depth } \\ \text { P1 } \\ 0 \\ 26 & \text { 14cm at top of barrel empty } \\ & \text { Top soil - dark brown } \\ 30 & \text { Transition to clay, light brown } \\ & \text { Brown/greyh mud, sand }>50 \%, \\ & \text { gravels throughout to } 1.2 \mathrm{~cm} \\ 43 & \text { Mud, grey brown, with } ~ 30-40 \% \\ 53 & \text { sand, poorly soted coarse, with fine } \\ 90 & \text {.5cm or less gravels } \\ & \text { Lost end of push } \\ \end{array}$


El_19b
Depth

0

26

31

38

52

63

67

73

104

P2

73

128

157.5
P1

Transition to clay - light brown

Sand $>50 \%$, gravels throughout to

$2 \mathrm{~cm}$, some organics present

lost return

Same as 31-38

Mud, $<50 \%$ sand, sand is coarse

Same as $52-63 \mathrm{~cm}$, sand is coarse

$>50 \%$ (>80\%), gravels abundant to

$.5 \mathrm{~cm}$

Lost end of push, sounded like sand/gravels at bottom of push End of barrel

Mud, soupey, with $>80 \%$ sand, mostly coarse and sub-angular, some gravels to $1.6 \mathrm{~cm}$

Light blue/grey clay, super compact, $<5 \%$ asnd contains some organics, crumbly, can see glimer of mica sands present throughout End Push 2 
EI_20

Depth

0

P1

28 Clay, grey, with $\sim 5 \%$ sand, compact

Sand rich $>90 \%$, poorly sorted, fine

32

to coarse, subrounded to rounded

44

Mud, grey with 30\% sand

Sand $>90 \%$, fine to coarse,

47

subangular, in mud

50

same as 44-47

Sand $>80 \%$, some areas are light

brown in color, rest is grey, sand

53 contains quartz

sand $\sim 60-80 \%$, brown mud, organics

60 throughout

Light blue/grey mud, very compact,

67

some charcol

Mush, unconsolidated, blacka dn

84

light brown mud, contains organics

87

Blue/grey mud

at 89

Large $2 \mathrm{~cm}$ gravel

94

End push 
EI_21

Depth

0

P1

Mud, compact, grey with fine micas

27 seen throughout $>80 \%$ sand, coarse, organics present

31 $\sim 10 \%$ in grey mud

39 Mud with $\sim 40-50 \%$ sand

$\begin{array}{cc}42 & \begin{array}{c}\text { Coarse sand }>80 \% \text { like } 31-39 \text { with } \\ \text { ravels to } 1 \mathrm{~cm}, \text { angular to subangular } \\ 46.5\end{array} \\ 49 & \begin{array}{c}\text { Mud with } \sim 40-50 \% \text { sand } \\ \text { Sand }>80 \%\end{array} \\ 51.5 & \text { Sand } \sim 50 \% \text { in grey mud, with } \\ 58 & \text { organics (roots) } \\ \text { Sand }>50 \%, \text { coarse }\end{array}$

Light blue/grey clay, color is mottled with light brown, some dark soupier mud at 83-85, some small gravels at

63

top

From 83-85

89.5

Soupier/unconcsolidated

End push 


\begin{tabular}{|c|c|c|}
\hline & EI_22 & \\
\hline & Depth & \\
\hline & P1 & \\
\hline 20 & 0 & no return \\
\hline 10 & 20 & top soil \\
\hline & & Soupey gravelly mud, contains rock \\
\hline 35 & 30 & $3 \mathrm{~cm}$ \\
\hline & & abrupt transition \\
\hline & & Grey mud with gravels and $\sim 5 \%$ sand \\
\hline & 65 & including mica sand \\
\hline 1 & 68 & Sand rich black layer, sand is coarse \\
\hline & & Soupey gravelly sabnd, with alrge \\
\hline & & gravels to $2.5 \mathrm{~cm}$ at base, gravels at \\
\hline 8.5 & 69 & $\begin{array}{l}\text { base are Imbricated } \\
\text { Mud, grey with gravels throughout }\end{array}$ \\
\hline 24.5 & 77.5 & to $.5 \mathrm{~cm}$ \\
\hline \#VALUE! & at 90 & Large shell fragment \\
\hline \#VALUE! & at 93 & Large shell fragment \\
\hline 0 & 102 & End P1 \\
\hline & $\mathrm{P} 2$ & \\
\hline 7 & 102 & Gra vely soupey - artifical? \\
\hline & & Mud, grey with gravels, matrix \\
\hline 10 & 109 & supported \\
\hline & & $\begin{array}{l}\text { Mud, well consolidated, grey/brown, } \\
\text { gravels throughout to } 1.1 \mathrm{~cm}, \sim 5-10 \%\end{array}$ \\
\hline 21 & 119 & sand \\
\hline & & $\begin{array}{l}\text { Dark brown mud with }<5 \% \text { sand, } \\
\text { gravels throughout concentrated }\end{array}$ \\
\hline 10.5 & 140 & @144 \\
\hline & & Grey mud, some gravels to $.5 \mathrm{~cm}$, \\
\hline 8.5 & 150.5 & $<5 \%$ sand \\
\hline & & Soupey mud with clast supporeted \\
\hline 5 & 159 & gravels \\
\hline 3 & 164 & Sand $>80 \%$, small gravels $<.5 \mathrm{~cm}$ \\
\hline 4.5 & 167 & $\begin{array}{l}\text { Mud, grey with } \sim 30 \% \text { sand } \\
\text { Mud with gravesl } \sim 40 \% \text {, and } \sim 30 \%\end{array}$ \\
\hline 10.5 & 171.5 & sand \\
\hline 5 & 182 & $\begin{array}{c}>80 \% \text { sand, coarse, poorly sorted in } \\
\text { mud, subangular }\end{array}$ \\
\hline 16 & 187 & Brown grey mud, some gravels \\
\hline & at 194 & Sand $>50 \%$ \\
\hline & at 197 & Small shell fragment \\
\hline & 203 & end of push 2 \\
\hline
\end{tabular}


EI_23

Depth

0

36

46

67

96
P1

Top soil

Mixed dandy soil + top soil

Sandy organic rich soil, produces

$<1$ in ribbon, some clay content, abundant organics. Clay content increases to $100 \%$ clay grey/green at bottom, last $2-3 \mathrm{~cm}$. Some micas can be seen within

End push 
EI_24

Depth

0

P1

14

Top soil

Sand $>90 \%$ in clay, sand is fine to coarse, occasional small gravels.

From 43-57 there is a mottled section, light brown and grey

22 Clay rich section $\sim 1 \mathrm{~cm}$ thick

at 64 Clay rich, sand $\sim 30-40 \%$

68

Large light brown sand pocket

70

Brown mud, with $\sim 30 \%$ coarse sand

$73 \quad \begin{gathered}\text { Light grey/blue mud with } 80 \% \text { coarse } \\ \text { sand }\end{gathered}$
light grey mud with less sand, sand
concentrated into pockets
Sand $>80 \%$ fine to coarse in light
grey mud, roots and organics
present. Unconsolidated and very
gravelly at base

Mud with $<30 \%$ coarse sand. Some

90

gravels to $.5 \mathrm{~cm}$

Sooth mud, grey with larege sand

pocket running vertically throught

93

middle

98.5

sand layer, $>80 \%$ sand

99

Same as 93-98

Sumer compact light blue mud, contains charcol, crumbly, no sand,

101.5 mottled in color, light brown and

105 light blue/bre.

End push

Refusal beyond this point. 
EI_25

Depth

0

P1

10

top soil

37

at 40

Grey brown clay with 20\% sand

40

Large gravels and roots

\begin{tabular}{|c|c|}
\hline 40 & sandy clay, sand $>80 \%$, poorly sorted \\
\hline 48.5 & clay rich, sand $\sim 50 \%$ \\
\hline 50 & sand $\sim 90 \%$ \\
\hline 54 & $\begin{array}{c}\text { Sand } ~ 80 \% \text { in grey clay with areas of } \\
\text { light brown mottled color }\end{array}$ \\
\hline 62 & $\begin{array}{l}\text { Sand }>90 \% \text {, same mottled color, } \\
\text { more clay and gravel to } 1 \mathrm{~cm} \text { at base }\end{array}$ \\
\hline 66 & Grey clay with $20-30 \%$ sand \\
\hline 71 & $\begin{array}{c}\text { Sand }>80 \% \text { in grey mud with mottled } \\
\text { light brown throughout }\end{array}$ \\
\hline 76 & $\begin{array}{l}\sim 50 \% \text { sand in mud/clay, grey with } \\
\text { mottled color of light brown }\end{array}$ \\
\hline $\begin{array}{l}88 \\
94\end{array}$ & $\begin{array}{l}\text { Grey green mud with some } \\
\text { concentrated sand @90 and @93, } \\
\text { otherwise ery little sand, some } \\
\text { gravels to .5cm } \\
\text { Mud, light grey and green, super } \\
\text { compact, no sand }\end{array}$ \\
\hline 98 & $\begin{array}{l}\text { Light grey sand with mud, sand } \\
>80 \% \text {, fien to coarse grained }\end{array}$ \\
\hline
\end{tabular}

101

Mottled light grey/blue and green,

super compact mud, no sand end push 
EI_26

Depth

0

34

53

77

98
P1

Top soil

Dark b rown clay rich with $~ 30-40 \%$

coarse sand throughout, some large

gravels within, large gravel @66cm,

@70cm,@72cm

Gravelly sand $>80 \%$ in grey mud.

Sand is subangular and coarse,

gravels throughout to $1 \mathrm{~cm}$.

End push

Lost P2 
EI_27

Was not able to collect or penetrate below $10 \mathrm{~cm}$ with auger. Sounds like gravel 
EI_28

Depth

P1

62

64

6

1

5

10

18

28.5

6

5

10

156

19

166

at 169

at 175

185

195

P2 151
Sand $>80 \%$, concentrated in grey mud, sand is subangular to rounded, fine to coarse, gravel at base to $1 \mathrm{~cm}$ Grey mud, 10\% sand Pocket/line of sand $>50 \%$, fine to coarse Sooth grey mud

Organic rich dark brown mud with $<5 \%$ sand

Grey mud, $<1 \%$ sand, basically no grit at all

Grey mud with $<5 \%$ sand, some micas can be seen throughout, produces a 2 in ribbon

Concentration of medium to coarse sand

Organic rich grey and light brown

$132.5 \quad$ mud $<5 \%$ sand abrupt transition

Grey mud with $~ 50 \%$ sand, grades into layer below Sand $>90 \%$, fine to lower coarse, mixed with grey mud, gravel at botom to $1 \mathrm{~cm}$ abrupt transition

Mud, dark grey, with $10-20 \%$ sand Mud with at least $50 \%$ sand, produces a .5in ribbon. Organics

throughout including wood fragments, some gravels to $1.2 \mathrm{~cm}$, sand is fine to caorse $>90 \%$ sand $>90 \%$ sand

$\sim 50 \%$ sand in brown mud, abundant organics 


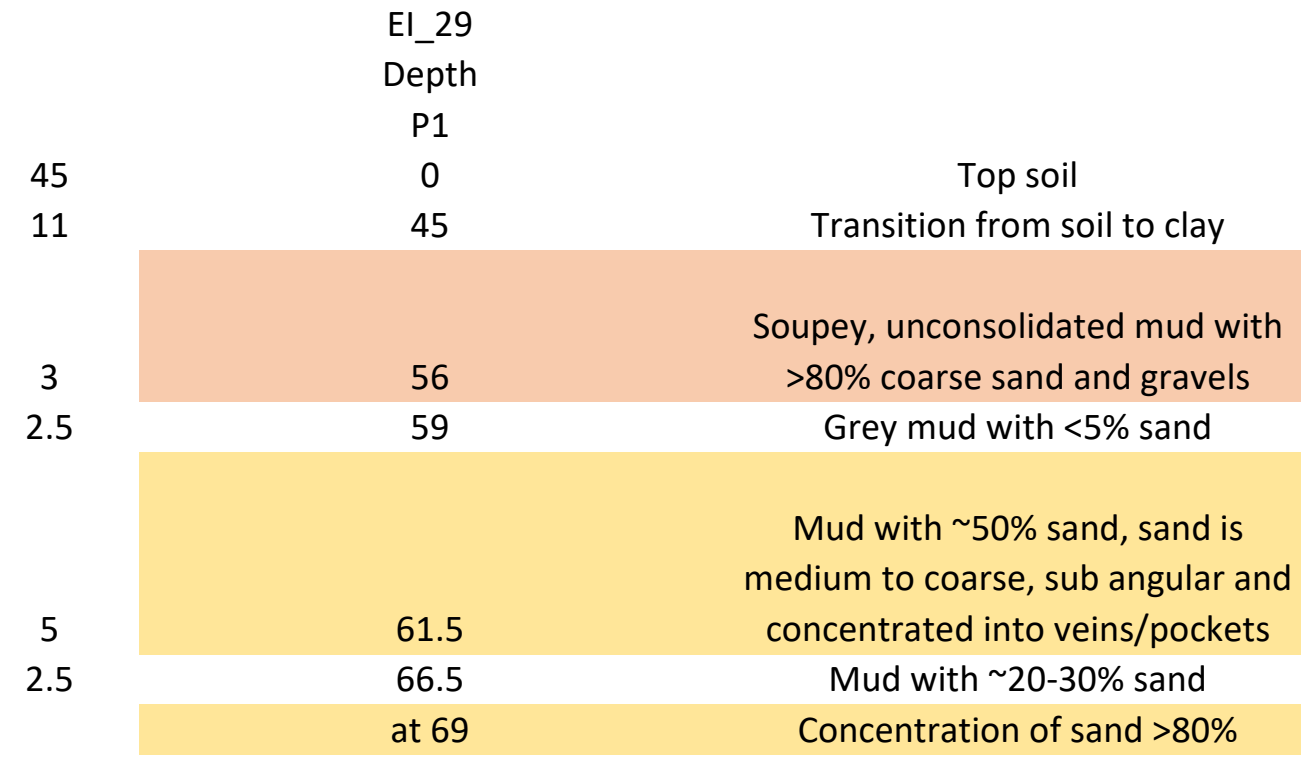

Grey mud with $\sim 50 \%$ sand, some gravels throughout to $1 \mathrm{~cm}$, sand

34 69 contains quartz and is fine to coarse at 74 Concentration of sand $>80 \%$ at 90 Concentration of sand $>80 \%$ 103 End push 1

P2 103

Smooth brownmud $<5 \%$ sand, large 8 111 gravel $2 \mathrm{~cm}$

Smooth mud with no sand, large

8

3

119 gravels

Sand $>50 \%$ in grey mud, large gravel 11 122 at base

\begin{tabular}{|c|c|c|}
\hline 11 & 122 & Grey mud with 30\% sand \\
\hline \multirow[t]{2}{*}{12} & 133 & $\begin{array}{l}>50 \% \text { sand in mud, sand is fine to } \\
\text { coarse, poorly sorted gravels } \\
\text { throughout (about } 15-20 \% \text { total } \\
\text { comp) to } 1 \mathrm{~cm}\end{array}$ \\
\hline & at 140 & $\begin{array}{c}\text { Concentration of of fine sand and } \\
\text { organics seen throughout }\end{array}$ \\
\hline 11.5 & 145 & $\begin{array}{c}\text { Mud with } \sim 50 \% \text { sand, large gravels } \\
\text { to } 2.5 \mathrm{~cm} \text { with } \sim 80 \% \text { sand around } \\
\text { gravels }\end{array}$ \\
\hline 8.5 & 156.5 & $\begin{array}{l}\sim 80 \% \text { sand in mud, sand is fine to } \\
\text { coarse, sub rounded }\end{array}$ \\
\hline 3 & 165 & $\begin{array}{c}\text { Soupey mud with } \sim 80 \% \text { coarse sand } \\
\text { and gravels }\end{array}$ \\
\hline 8 & 168 & $\begin{array}{l}\text { Soupey mud with large gravels and } \\
\text { sand }>60 \%\end{array}$ \\
\hline
\end{tabular}




\begin{tabular}{|c|c|c|}
\hline 4 & 176 & $\begin{array}{l}90 \% \text { sand and gravels in mud, poorly } \\
\text { sorted gravels to } .5 \mathrm{~cm}\end{array}$ \\
\hline 3 & 180 & Smooth brown mud, $<20 \%$ sand \\
\hline 3 & 183 & $\begin{array}{l}\text { Soupey, unconsolidated with } \sim 80 \% \\
\text { sand }\end{array}$ \\
\hline 4 & 186 & $\begin{array}{l}\text { Unconsolidated soupey return, } \\
\text { brown mud with some coarse sand } \\
\text { and small gravels }\end{array}$ \\
\hline & & $\begin{array}{c}\text { Mud with } \sim 30-50 \% \text { sand and gravels, } \\
\text { grey brown color, gravels are }\end{array}$ \\
\hline 8 & 190 & subrounded \\
\hline & 198 & End Push 2 \\
\hline
\end{tabular}


EI_30

Depth

0

P1

Grey mud with $\sim 30 \%$ coarse sand,
mottled colors of brown and grey

$>80 \%$ sand in mud, fine to coarse, one large gravel $2.6 \mathrm{~cm}$ in size

$53 \quad$ Grey mud with $<30 \%$ sand $90 \%$ sand, coarse, in mud, grav el at

56.5 base $1 \mathrm{~cm}$

Mud, grey with $40-50 \%$ sand and gravels to $1 \mathrm{~cm}$, sand is medium

$58 \quad$ coarse and subrounded

$77 \quad 50-70 \%$ sand in mud

Soupey mud with $\sim 20 \%$ sand,

$84 \quad$ contains gravels

\begin{tabular}{|c|c|}
\hline 89 & $\begin{array}{c}\sim 50 \% \text { mud and } \sim 50 \% \text { sand, with } \\
\text { coarse gravels to } 1 \mathrm{~cm}\end{array}$ \\
\hline at 97 & Sand is concentrated here \\
\hline
\end{tabular}

$103 \quad$ End push 1

P2

103

Sandy brown mud, sand $\sim 50-70 \%$

117

Soupey mud, with $\sim 50 \%$ sand,

133

gravels to $.5 \mathrm{~cm}$

End Push 2

Refusal 
EI_31

Depth

P1

0

55

at 80

at 89

104

P2

\begin{tabular}{|c|c|}
\multicolumn{1}{c}{} & $\begin{array}{c}\text { whole push: Mud, dark grey with } \\
\text { ares of concentrated sand and } \\
\text { occasional gravels, mud contains } \\
<10 \% \text { sand }\end{array}$ \\
\hline 104 & Sand $>80 \%$ \\
\hline 111 & Sand $>80 \%$ \\
\hline 117 & Sand $>80 \%$ \\
\hline $133-127$ & Sand $>80 \%$ \\
\hline 149 & $\begin{array}{c}\text { Organic rich section - brown } \\
\text { Below 150, }<5 \% \text { sand and produces a } \\
1.5 \mathrm{~cm} \text { ribbon }\end{array}$ \\
\hline 150 & Sand $>80 \%$ \\
\hline 195 & $\begin{array}{c}\text { Soupey return at bottom - } \\
\text { unconsolidated mud } \\
\text { End push } 2\end{array}$ \\
\hline 197 &
\end{tabular}

P1

Top soil

Grey mud with $<10 \%$ ( 5\%) sand, some mica sands seen throughout sand in small layer

small amount of sand and gravels present in concentration

End push 1 
EI_32

Depth

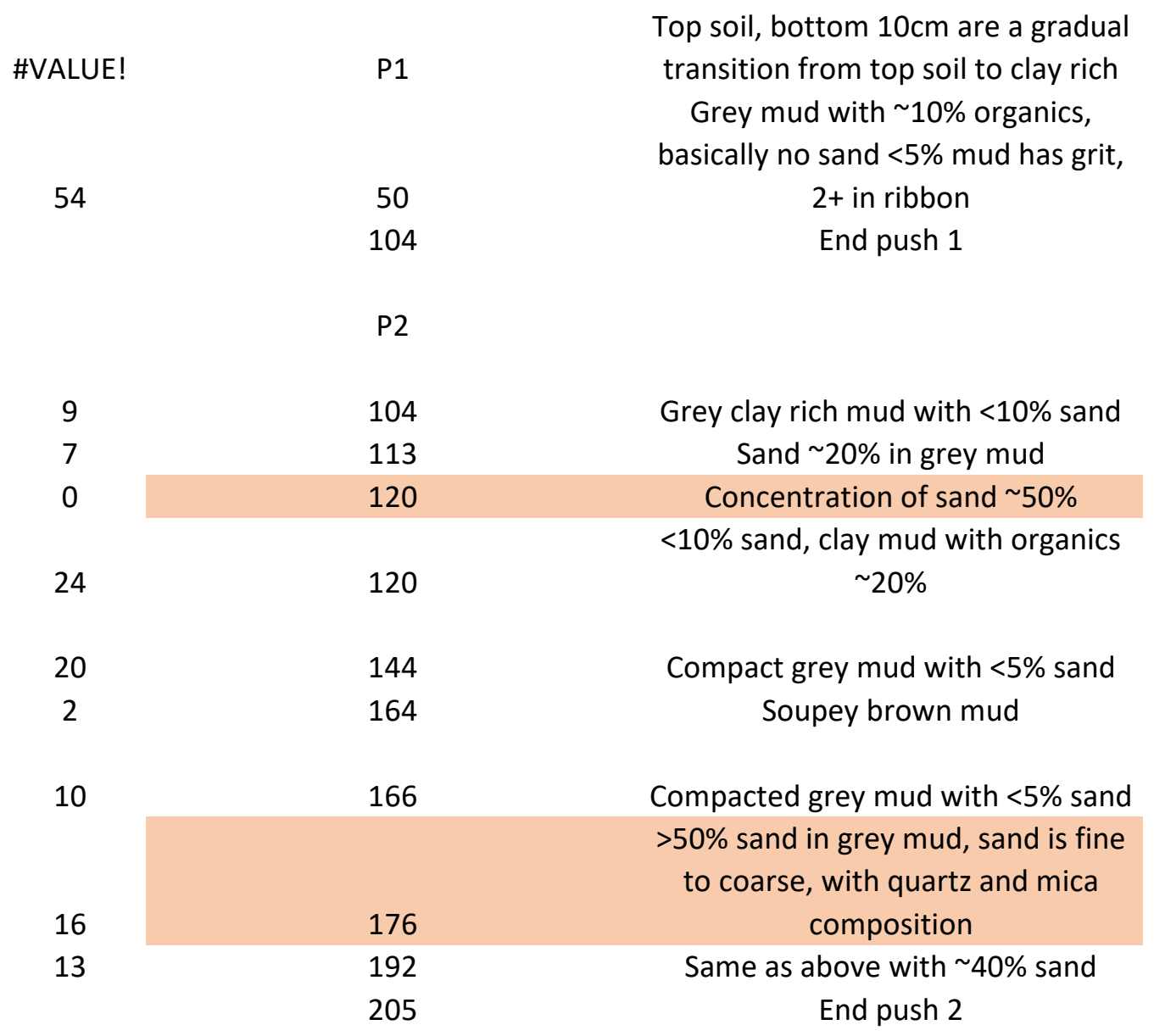




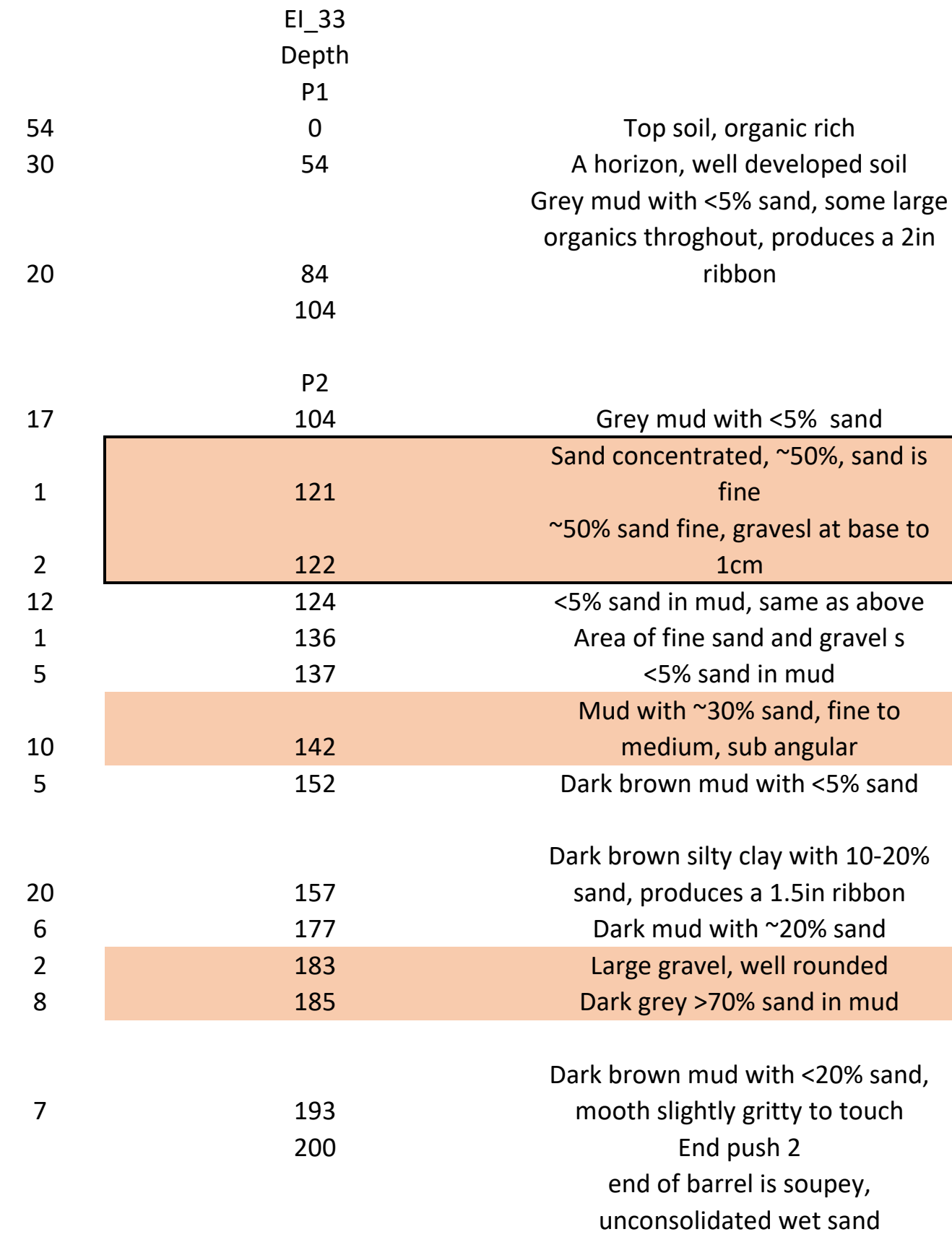


Appendix 2: Vibracore Descriptions 


\begin{tabular}{|c|c|c|c|c|c|c|c|c|}
\hline & VCS1_N & $\begin{array}{l}\text { Location: Ship } \\
\text { Harbor, } \\
\text { Anacortes }\end{array}$ & Date core collected: & Compacton: & $\begin{array}{l}\text { Date core } \\
\text { analyzed: }\end{array}$ & $\begin{array}{l}\text { Starting } \\
\text { length: } 10 \mathrm{ft}\end{array}$ & 322.975 & \\
\hline & & & & & 9/9/2018 & IF: & 180.975 & \\
\hline & & & Compaction factor: & 0.468606627 & & $\mathrm{Si}$ & 125.222 & \\
\hline & & & & & & $\mathrm{Pi}$ & 267.222 & \\
\hline & & & & & & $\begin{array}{l}\text { Du } \\
\text { (excpected) }\end{array}$ & 123.825 & \\
\hline $\begin{array}{l}\text { Thickness } \\
(\mathrm{cm})\end{array}$ & $\begin{array}{l}\text { Corrected } \\
\text { depth for } \\
\text { compaction } \\
\text { (cm) }\end{array}$ & Depth $(\mathrm{cm})$ & Color & $\begin{array}{l}\text { Texture, grain } \\
\text { sizes, \% present, } \\
\text { other important } \\
\text { features }\end{array}$ & Shape/Rounding & Gradeing & $\begin{array}{l}\text { Boundary to } \\
\text { lower } \\
\text { horizon }\end{array}$ & Notes \\
\hline 105.7 & 0.0 & 0.0 & Brown & Peat & \begin{tabular}{|l} 
Coarse, plant \\
structures not \\
identified
\end{tabular} & & gradual & $\begin{array}{l}100 \% \text { peat, produces } \\
\text { turbulent water when } \\
\text { squeezed }\end{array}$ \\
\hline 27.2 & 187.9 & 88.0 & black, white, grey & Clay & Fine, smooth & & wavy & $\begin{array}{l}\text { Clay mud with abudnant } \\
\text { organics }\end{array}$ \\
\hline 2.2 & 215.1 & 106.5 & Black, white, grey & Sandy clay & & $\begin{array}{l}\text { sand is well } \\
\text { sorted }\end{array}$ & unclear & Band of sand, mostly sand \\
\hline 11.7 & 217.3 & 108.0 & Grey, black & $\begin{array}{l}\text { Sand pockets } \\
\text { within mud }\end{array}$ & & well sorted & & $\begin{array}{l}\text { pockets of sand contained in } \\
\text { mud }\end{array}$ \\
\hline 27.9 & 229.0 & 116.0 & grey brown & Clay & & well sorted & diagonal & Clay mud, no sand \\
\hline 10.3 & 256.9 & 135.0 & Brown grey & Clay, organics & & & & $\begin{array}{l}\text { Partially clay tapering off, } \\
\text { organic at base of core, large } \\
\text { organic at base = appears to } \\
\text { be a cattail reed root. }\end{array}$ \\
\hline
\end{tabular}




\begin{tabular}{|c|c|c|c|c|c|c|c|c|}
\hline VCS2_N & & & \begin{tabular}{|l} 
Location: Ship \\
Harbor, \\
Anacortes
\end{tabular} & Date core collected: & Compacton: & $\begin{array}{l}\text { Date core } \\
\text { analyzed: }\end{array}$ & Starting length: $13 \mathrm{ft}$ & 409.5 \\
\hline & & & At S12 & & & $9 / 17 / 2018$ & IF: & 160.528 \\
\hline & & & & & & & OF: & 59.69 \\
\hline & & & & Compaction factor: & 0.288241986 & & $\mathrm{Si}$ & 100.838 \\
\hline & & & & & & & $\mathrm{Pi}$ & 349.838 \\
\hline & & & & & & & Du (actual) & 249 \\
\hline & & & & & & & Du (expected) & 235.712 \\
\hline & & & & & & & Difference: & 13.288 \\
\hline $\begin{array}{l}\text { Section } \\
\text { Thickness } \\
(\mathrm{cm}) \\
\end{array}$ & $\begin{array}{l}\text { Corrected depth } \\
\text { for compaction } \\
(\mathrm{cm})\end{array}$ & $\begin{array}{l}\text { Depth } \\
(\mathrm{cm})\end{array}$ & Color & $\begin{array}{l}\text { Texture, grain sizes, } \\
\% \text { present, other } \\
\text { important features }\end{array}$ & Shape/Rounding & Gradeing & $\begin{array}{l}\text { Boundary to lower } \\
\text { horizon }\end{array}$ & Notes \\
\hline 106.4 & 0.0 & 0.0 & $\begin{array}{l}5 Y R \text { 2.5/1, 10YR } \\
2 / 2 \\
\end{array}$ & Organic - peat & & & gradual, over $8 \mathrm{~cm}$ & Peat with $100 \%$ organics \\
\hline 42.5 & 106.4 & 60.0 & $\begin{array}{l}\text { 4/10Y with } \\
\text { lighter color } \\
\text { mottled } \\
\text { throughout, } \\
\text { with motteling } \\
\text { decreasing } \\
\text { dowsection } \\
\end{array}$ & $\begin{array}{l}\text { Clay, organics } \\
\text { present throughout }\end{array}$ & & & $\begin{array}{l}\text { Gradual end of } \\
\text { mottled coloring }\end{array}$ & $\begin{array}{l}\text { Large organic from 69- } \\
71 \mathrm{~cm}\end{array}$ \\
\hline 6.4 & 148.9 & 93.0 & $4 / 10 Y$ & $\begin{array}{l}\text { Clay, organics } \\
\text { present throughout, } \\
<5 \% \text { sand }\end{array}$ & & & gradual & \\
\hline 11.6 & 155.3 & 98.0 & $4 / 10 Y$ & $\begin{array}{l}\text { Clay with }<5 \% \text { sand, } \\
\sim 30 \% \text { organics } \\
\text { throughout }\end{array}$ & & & gradual & Large organics present \\
\hline 48.3 & 166.9 & 107.0 & $4 / 10 Y$ & Clay with $<5 \%$ sand & & & Gradual & \\
\hline 15.5 & 215.2 & 144.5 & $4 / 10 Y$ & $\begin{array}{l}\text { Clay with } 10-20 \% \\
\text { organics }\end{array}$ & & & Gradual & $\begin{array}{l}\text { at } 144.5 \mathrm{~cm} \text {, large organic } \\
\text { fragment }\end{array}$ \\
\hline
\end{tabular}




\begin{tabular}{|c|c|c|c|c|c|c|c|c|}
\hline 23.8 & 230.7 & 156.5 & $4 / 10 \mathrm{Y}, 2.5 / \mathrm{N}$ & $\begin{array}{l}\text { Clay, sand, } \\
\text { organics, clay } \\
\text { coatings on shells, } \\
\text { large shell } \\
\text { fragments } \\
\text { throughout, sand is } \\
\text { sorted well into its } \\
\text { own areas with } \\
\text { shells } \\
\end{array}$ & & Well sorted & $\begin{array}{l}\text { gradual, with pockets } \\
\text { of sand extending } \\
\text { downwards and into } \\
\text { lower section }\end{array}$ & $\begin{array}{l}\text { South marked section of } \\
\text { core contains a half a } \\
\text { muscel shell, herbaceous } \\
\text { organics from } 167-171 \mathrm{~cm}\end{array}$ \\
\hline 25.8 & 254.5 & 175.0 & $4 / 10 Y$ & $\begin{array}{l}\text { Clay, clear organic } \\
\text { at } 183 \mathrm{~cm}\end{array}$ & & & Gradual & No sand \\
\hline 9.0 & 280.3 & 195.0 & $3 / 10 Y$ & $\begin{array}{l}\text { Clay with } 20-30 \% \\
\text { sand, large gravel } \\
\text { between 198- } \\
201 \mathrm{~cm} . \\
\end{array}$ & & & $\begin{array}{l}\text { Gradual, cut off by } \\
\text { large wood }\end{array}$ & \\
\hline 8.4 & 289.3 & 202.0 & $3 / \mathrm{N}$ & $\begin{array}{l}\text { Sand, fine to lower } \\
\text { coarse }\end{array}$ & $\begin{array}{l}\text { Sub angular to } \\
\text { subrounded }\end{array}$ & & Gradual & \begin{tabular}{|l|} 
Shell fragments \\
throughout, shells appear \\
stratified
\end{tabular} \\
\hline 22.5 & 297.7 & 208.5 & $4 / 10 Y$ & $\begin{array}{l}\text { Sandy mud and } \\
\text { gravels }\end{array}$ & Subrounded & Sorted & $\begin{array}{l}\text { abrupt change in } \\
\text { gravel content }\end{array}$ & $\begin{array}{l}\text { Gravels present are } \\
\text { concentrated between } \\
112-116, \text { sand and mud } \\
\text { are well sorted in areas }\end{array}$ \\
\hline 29.6 & 320.2 & 226.0 & $2.5 / \mathrm{N}$ & $\begin{array}{l}\text { Coarse gravesl and } \\
\text { shelss mised with } \\
\text { sand and mud, } \\
\text { Large gravel at base } \\
\text { is } 4 \mathrm{~cm} \text { in diameter }\end{array}$ & Subrounded & $\begin{array}{l}\text { Normally } \\
\text { graded }\end{array}$ & & $\begin{array}{l}\text { 235-238 More mud, 235- } \\
237 \text { Shell debris present }\end{array}$ \\
\hline 349.8 & 349.8 & 249.0 & & & & & & \\
\hline
\end{tabular}




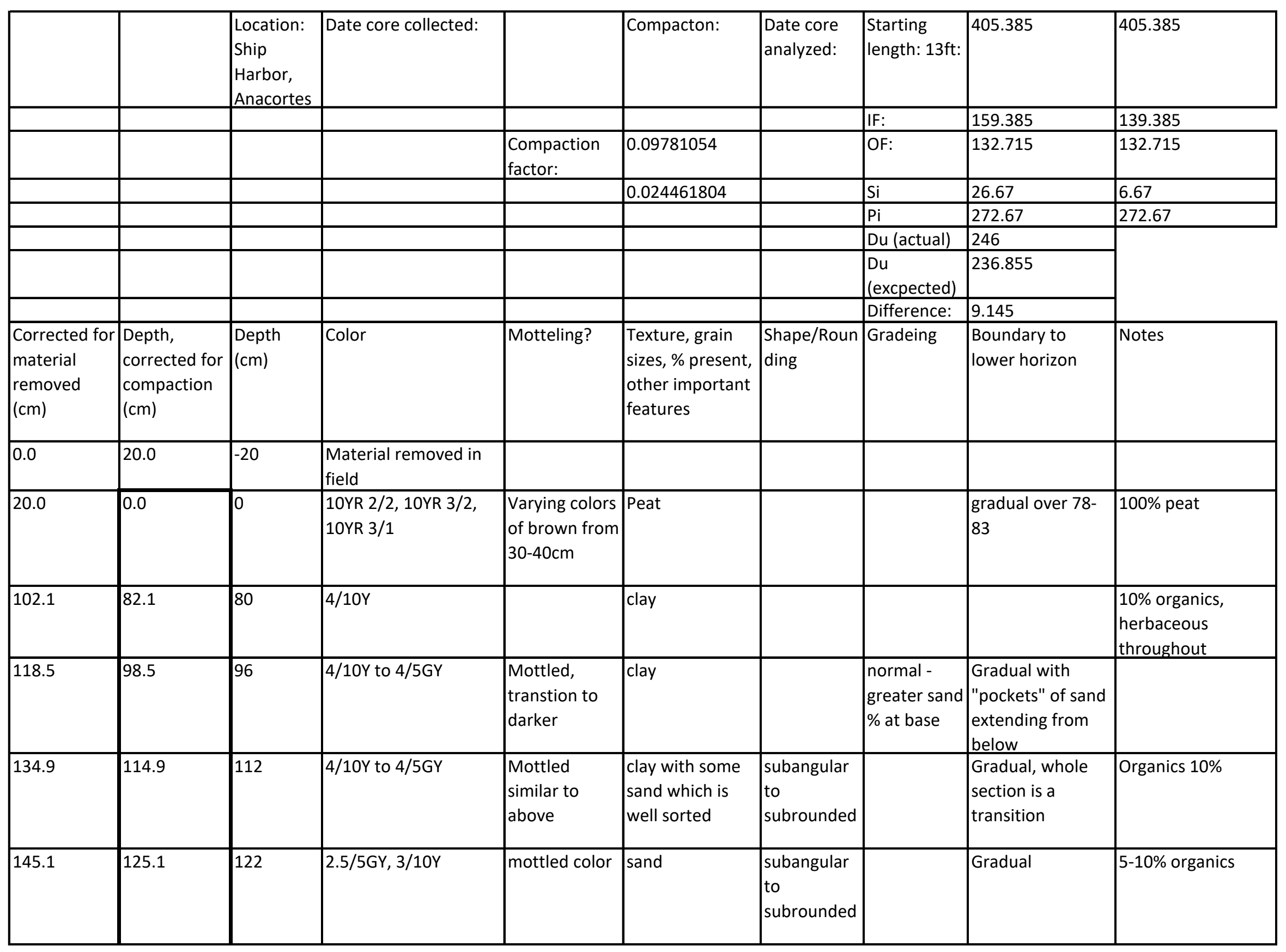




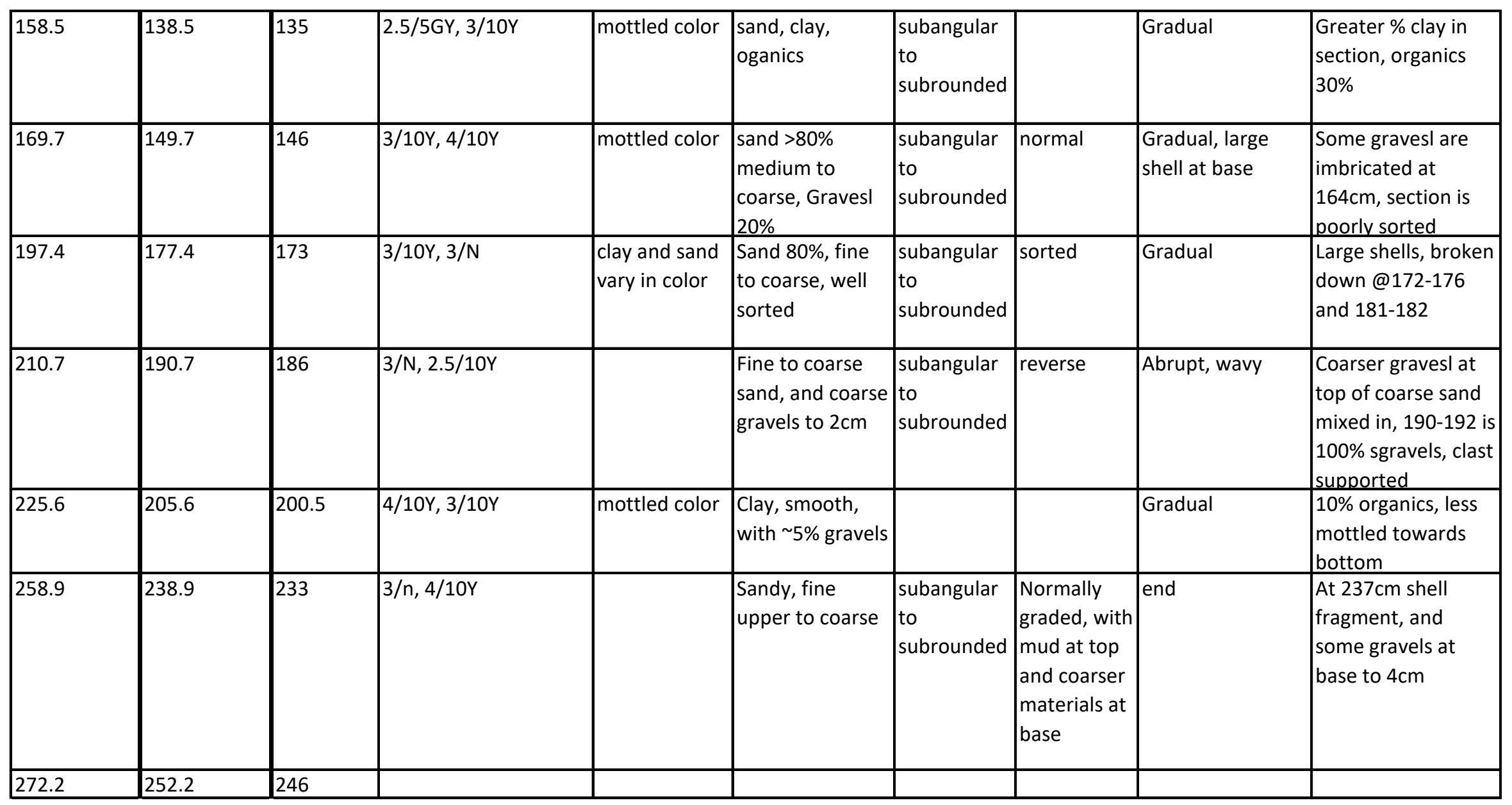




\begin{tabular}{|c|c|c|c|c|c|c|c|c|c|}
\hline & & PM18_VCS4 & $\begin{array}{l}\text { Compac } \\
\text { tion: }\end{array}$ & $\begin{array}{l}\text { Date core } \\
\text { collected: }\end{array}$ & Compacton: & $\begin{array}{l}\text { Date core } \\
\text { analyzed: }\end{array}$ & & $\begin{array}{l}\text { Root } \\
\text { subtract }\end{array}$ & \\
\hline & & & & & & $\begin{array}{l}\text { Starting length: } \\
13 \mathrm{ft}\end{array}$ & 408.45 & 408.45 & \\
\hline & & & & & & IF: & 247.65 & 223.52 & \\
\hline & & & $\begin{array}{l}\text { Compac } \\
\text { tion } \\
\text { factor: }\end{array}$ & 0.266849 & & OF: & 156.21 & 156.21 & \\
\hline & & & & & & $\mathrm{Si}$ & 91.44 & 67.31 & \\
\hline & & & & & & $\mathrm{Pi}$ & 252.24 & 252.24 & \\
\hline & & & & & & Du (calculated) & 148.59 & & \\
\hline & & & & & & Du (actual) & 160.8 & & \\
\hline & & & & & & Difference: & 12.21 & & \\
\hline Thickness (cm) & $\begin{array}{l}\text { Corrected Top } \\
\text { Depth for } \\
\text { removal of } \\
\text { roots and } \\
\text { compaction } \\
(\mathrm{cm})\end{array}$ & $\begin{array}{l}\text { Corrected } \\
\text { depth for } \\
\text { compaction } \\
(\mathrm{cm})\end{array}$ & $\begin{array}{l}\text { Depth } \\
(\mathrm{cm})\end{array}$ & Color & \begin{tabular}{|l|} 
Texture, grain sizes, \\
$\%$ present, other \\
important features
\end{tabular} & Shape/Rounding & $\begin{array}{l}\text { Gradein } \\
\mathrm{g}\end{array}$ & \begin{tabular}{|l} 
Boundary to \\
lower \\
horizon
\end{tabular} & Notes \\
\hline 24.1 & 0.0 & 24.1 & -24.1 & & $\begin{array}{l}\text { Modern root } \\
\text { structures, } \\
\text { removed prior to } \\
\text { coring }\end{array}$ & & & graudal & $\begin{array}{l}\text { clear root structures } \\
\text { still present, partial } \\
\text { catail root at } 37 \mathrm{~cm} \\
\text { depth }\end{array}$ \\
\hline 39.2 & 24.1 & 0.0 & 0.0 & 10YR 2/2 & $\begin{array}{l}\text { H4-H5 humification } \\
\text { peat }\end{array}$ & & & graudal & $\begin{array}{l}\text { From 33-43 slightly } \\
\text { darker brown color }\end{array}$ \\
\hline 47.9 & 63.4 & 39.2 & 16.8 & 10YR 3/1 & H5-H6 peat & & & graudal & $\begin{array}{l}\text { Transition zone from } \\
\text { peat to clay }\end{array}$ \\
\hline 6.6 & 111.3 & 87.1 & 54.6 & $\begin{array}{l}10 Y R 3 / 2 \\
\text { and } 2.5 Y \\
3 / 2\end{array}$ & $\begin{array}{l}\text { Clay rich mud with } \\
50 \% \text { organics }\end{array}$ & & & graudal & $\begin{array}{l}\text { With above layer } \\
\text { together form a } \\
\text { transition zone from } \\
\text { peat to mud/clay }\end{array}$ \\
\hline 13.2 & 117.8 & 93.7 & 59.8 & $2.5 Y 4 / 2$ & $\begin{array}{l}\text { similar to above } \\
\text { but decreasing } \\
\text { organic \% } \\
\text { downsection, mud } \\
\text { is very smooth }\end{array}$ & & & $\begin{array}{l}\text { abrupt, but } \\
\text { same } \\
\text { material } \\
\text { extends } \\
\text { upwards } \\
\text { along edge }\end{array}$ & $\begin{array}{l}\text { Ranges from black } \\
\text { to dark brown, vey } \\
\text { distinct avrupt }\end{array}$ \\
\hline
\end{tabular}




\begin{tabular}{|c|c|c|c|c|c|c|c|c|c|}
\hline 2.3 & 131.0 & 106.9 & 70.2 & 7.5YR $2.5 / 3$ & $\begin{array}{l}100 \% \text { organics, } \\
\text { wood fragments, } \\
\text { H4 peat? }\end{array}$ & & & abrupt & $\begin{array}{l}\text { Minor organics } \\
\text { throughout } 5-10 \%\end{array}$ \\
\hline 10.6 & 133.3 & 109.2 & 72.0 & $4 / 10 Y$ & $\begin{array}{l}\text { clay rich mud, }<2 \% \\
\text { sand, minor grit to } \\
\text { touch of mud, few } \\
\text { rounded micas } \\
\text { visible }\end{array}$ & rounded & & $x$ & $\begin{array}{l}\text { Few organics } \\
\text { throughout }\end{array}$ \\
\hline 11.4 & 143.9 & 119.8 & 80.4 & $\begin{array}{l}/ 10 \mathrm{Y} \text { and } \\
3 / 10 \mathrm{Y}, \\
\text { mottled } \\
\end{array}$ & $\begin{array}{l}\text { Clay rich mud, no } \\
\text { sand except visual } \\
\text { mica grains }\end{array}$ & & & gradual & Occasional \\
\hline 5.3 & 155.3 & 131.2 & 89.4 & \begin{tabular}{|l|}
$4 / 10 Y$ and \\
$3 / 10 Y$
\end{tabular} & $\begin{array}{l}\text { mud, clay rich with } \\
40 \% \text { organics } \\
\end{array}$ & & & $\begin{array}{l}\text { graudal but } \\
\text { clear }\end{array}$ & mottling dissappears \\
\hline 24.6 & 160.7 & 136.5 & 93.6 & $\begin{array}{l}4 / 10 \mathrm{Y} \text { and } \\
3 / 10 \mathrm{Y}\end{array}$ & $\begin{array}{l}\text { Clay rich mud few } \\
\text { micas seen }\end{array}$ & rounded & $\begin{array}{l}\text { poorly } \\
\text { sorted }\end{array}$ & gradual & $\begin{array}{l}\text { Mor mica grains } \\
\text { seen at bottom of } \\
\text { section }\end{array}$ \\
\hline 27.9 & 185.2 & 161.1 & 113.0 & $3 / 10 Y$ & \begin{tabular}{|l|} 
Clay rich mud, \\
ocassional mica, $5-$ \\
$10 \%$ organics \\
throughout \\
\end{tabular} & & & gradual & gradual \\
\hline 4.1 & 213.1 & 189.0 & 135.0 & $3 / 10 Y$ & $\begin{array}{l}50 \% \text { organics, more } \\
\text { sand (unclear \%, } \\
\text { perhaps } 30-40 \%, \\
\text { some clay rich mud } \\
\text { fine to coarse }\end{array}$ & & & gradual & subrounded \\
\hline 15.2 & 217.2 & 193.0 & 138.2 & $3 / 10 Y$ & \begin{tabular}{|l|} 
clay rich mud, $10-$ \\
$20 \%$ gravels \\
throughout, $10-20 \%$ \\
sand, well sorted \\
into "pockets"
\end{tabular} & & & abrupt & $\begin{array}{l}\text { some organics at } \\
\text { bottom along edges } \\
\text { of core barrel }\end{array}$ \\
\hline 13.4 & 232.4 & 208.2 & 150.2 & $3 / N$ & \begin{tabular}{|l|} 
Large gravels $50-$ \\
$60 \%, 40 \%$ sand, \\
coarse, sand \\
contains quartz and \\
micas
\end{tabular} & $\begin{array}{l}\text { subangular to } \\
\text { subrounded }\end{array}$ & & end & \\
\hline 245.8 & 245.8 & 221.7 & 160.8 & & & & & & \\
\hline
\end{tabular}




\begin{tabular}{|c|c|c|c|c|c|c|c|c|c|}
\hline & & VCS5_N & \begin{tabular}{|l|} 
Location: Ship \\
Harbor, \\
Anacortes
\end{tabular} & $\begin{array}{l}\text { Date core } \\
\text { collected: }\end{array}$ & Compacton: & $\begin{array}{l}\text { Date core } \\
\text { analyzed: }\end{array}$ & Total length: $10 \mathrm{ft}$ & 309.1375 & 309.1375 \\
\hline & & & & & & & IF: & 84.1375 & 53.6575 \\
\hline & & & & $\begin{array}{l}\text { Compaction } \\
\text { factor: }\end{array}$ & 0.141704575 & & OF: & 46.99 & 46.99 \\
\hline & & & & & 0.025434154 & & $\mathrm{Si}$ & 37.1475 & 6.6675 \\
\hline & & & & & & & $\mathrm{Pi}$ & 262.1475 & 262.1475 \\
\hline & & & & & & & Du (expected) & 220.6625 & \\
\hline & & & & & & & Du (actual) & 225 & \\
\hline & & & & & & & Difference: & 4.3375 & \\
\hline $\begin{array}{l}\text { Thickness } \\
(\mathrm{cm})\end{array}$ & $\begin{array}{l}\text { Corrected top } \\
\text { depth for roots } \\
\text { removed and } \\
\text { compaction }(\mathrm{cm})\end{array}$ & $\begin{array}{l}\text { Corrected } \\
\text { depth for } \\
\text { compaction } \\
(\mathrm{cm})\end{array}$ & Depth $(\mathrm{cm})$ & Color & $\begin{array}{l}\text { Texture, grain } \\
\text { sizes, \% present, } \\
\text { other important } \\
\text { features }\end{array}$ & $\begin{array}{l}\text { Shape } \\
\text { Rounding }\end{array}$ & Gradeing & $\begin{array}{l}\text { Boundary to } \\
\text { lower horizon }\end{array}$ & Notes \\
\hline 30.5 & 0.0 & 30.5 & -30.5 & & & & & & \\
\hline 26.6 & 30.5 & 0.0 & 0.0 & $\begin{array}{l}10 Y R 2 / 1 \\
\text { (bottom), } \\
10 Y R 2 / 2 \\
\text { (top) } \\
\end{array}$ & Peat - H4 hum & & & $\begin{array}{l}\text { color and roots } \\
\text { change }\end{array}$ & $\begin{array}{l}\text { more identifiable } \\
\text { plan materials }\end{array}$ \\
\hline 16.2 & 57.1 & 26.6 & 25.8 & $\begin{array}{l}5 Y R \text { 2.5/1, } \\
\text { 5YR 2.5/2 }\end{array}$ & Peat H5 hum & & & $\begin{array}{l}\text { change in visible } \\
\text { roots }\end{array}$ & few roots present \\
\hline 31.6 & 73.3 & 42.8 & 41.6 & \begin{tabular}{|l|} 
10YR $2 / 2$, \\
10YR $2 / 1$ \\
\end{tabular} & Peat H5 hum & & & gradual & Peat \\
\hline 3.9 & 104.9 & 74.4 & 72.4 & 10YR 3/2 & $\begin{array}{l}\% \text { fine sand in } \\
\text { clay with organics } \\
50+\%\end{array}$ & & & gradual & $\begin{array}{l}\text { Gradual } \\
\text { transition from } \\
\text { peat to clay-rich } \\
\text { mud }\end{array}$ \\
\hline 2.3 & 108.8 & 78.3 & 76.2 & $5 Y 4 / 2$ & $\begin{array}{l}50 \% \text { fine sand in } \\
\text { clay rich mud }\end{array}$ & subrounded & & abrupt & \\
\hline 2.7 & 111.0 & 80.6 & 78.4 & $5 Y 4 / 2$ & $\begin{array}{l}<5 \% \text { fine sand in } \\
\text { clay rich mud }\end{array}$ & & & seperated & \\
\hline 1.0 & 113.7 & 83.2 & 81.0 & $5 Y 4 / 2$ & $\begin{array}{l}50 \% \text { fine sand in } \\
\mathrm{mud} / \text { clay }\end{array}$ & & & $\begin{array}{l}\text { seperated by } \\
\text { charcoal }\end{array}$ & \\
\hline
\end{tabular}




\begin{tabular}{|c|c|c|c|c|c|c|c|c|}
\hline 7.2 & 114.7 & 84.3 & 82.0 & $4 / 10 Y$ & $\begin{array}{l}\text { Sand }>80 \% \text {, fine to } \\
\text { medium, contains } \\
\text { quartz and micas, } \\
\text { some mud } 15-20 \%\end{array}$ & $\begin{array}{l}\text { subrounded to } \\
\text { rounded }\end{array}$ & clear bur wavy & $\begin{array}{l}\text { Top is } \\
\text { horizontally } \\
\text { oriented, charcol } \\
\text { is close to } 30 \% \\
\text { organics }\end{array}$ \\
\hline 8.2 & 121.9 & 91.4 & 89.0 & $\begin{array}{l}\text { Clay: } 4 / 10 Y, \\
\text { upper } 3 / N\end{array}$ & $\begin{array}{l}25 \% \text { sand with } \\
25 \% \text { clay mixed } \\
\text { with } 50 \% \text { organics, } \\
\text { which are } \\
\text { brown/dark } \\
\text { brown }\end{array}$ & & clear and abrupt & $\begin{array}{l}\text { micas seen } \\
\text { throughout, } \\
\text { organics are } \\
\text { fiberous and } \\
\text { appear as wood } \\
\text { and pinecones }\end{array}$ \\
\hline 2.5 & 130.1 & 99.6 & 97.0 & $3 / 10 Y$ & $\begin{array}{l}\text { good emount of } \\
\text { visible mica sands, } \\
\text { with } 50 \% \text { sand in } \\
\text { mud, } 40-50 \% \\
\text { organics }\end{array}$ & & gradual & \begin{tabular}{|l} 
lots of organics, \\
very small $40-$ \\
$50 \%$
\end{tabular} \\
\hline 3.5 & 132.6 & 102.1 & 99.4 & $3 / 10 Y$ & $\begin{array}{l}\text { Some mottled } \\
\text { color, Mostly clay } \\
\text { rich mud with } 5 \% \\
\text { gritty fine sand } \\
\text { when rubbed } \\
\text { between fingers }\end{array}$ & & clear & $\begin{array}{l}\text { Some visible mica } \\
\text { grains }\end{array}$ \\
\hline 2.8 & 136.1 & 105.6 & 102.8 & $3 / 10 Y$ & \begin{tabular}{|l} 
Large sand section \\
- smaller along \\
edges, $50 \%$ sand \\
contains micas \\
and quarts with \\
$50 \%$ mud
\end{tabular} & & & $\begin{array}{l}\text { amorphous } \\
\text { organics present } \\
\text { throughout }\end{array}$ \\
\hline 5.2 & 138.8 & 108.4 & 105.5 & $3 / 10 Y$ & $\begin{array}{l}\text { Similar to } 99.4- \\
102.8, \text { few mica } \\
\text { sand grains } \\
\text { throughout, } \\
\text { mostly mud which } \\
\text { is clay rich with } \\
\text { some sand, } \\
\text { organics } 20 \% \text { and } \\
\text { fiherews }\end{array}$ & & abrupt- curved & $\begin{array}{l}\text { Pocke of sand } \\
\text { from 109-109.6 }\end{array}$ \\
\hline
\end{tabular}




\begin{tabular}{|c|c|c|c|c|c|c|c|c|c|}
\hline 7.0 & 144.1 & 113.6 & 110.6 & $3 / 10 Y$ & $\begin{array}{l}\text { Clay-rich mud with } \\
\text { fine sand } 5-10 \%\end{array}$ & & & abrupt & $\begin{array}{l}20 \% \text { organics } \\
\text { visible, fiberous } \\
\text { and running up } \\
\text { and down core }\end{array}$ \\
\hline 4.7 & 151.0 & 120.6 & 117.4 & $4 / 10 Y$ & $\begin{array}{l}50 \% \text { sand, clay } \\
\text { and mud } 20 \% \text {, } \\
30 \% \text { organics }\end{array}$ & & & abrupt & $\begin{array}{l}\text { very large branch } \\
\text { within section, } \\
\text { appears to be } \\
\text { oriented vertical } \\
\text { towards the east }\end{array}$ \\
\hline 8.8 & 155.8 & 125.3 & 122.0 & $\begin{array}{l}\text { 3/10Y, dark } \\
\text { brown }\end{array}$ & $\begin{array}{l}\text { clay-rich mud } \\
60 \% \text {, visible sand } \\
10 \% \text {, organics } 30 \%\end{array}$ & subrounded & & clear and abrupt & \\
\hline 0.4 & 164.6 & 134.1 & 130.6 & $2.5 / 5 \mathrm{GY}$ & $\begin{array}{l}\text { Sand up tot } 20 \% \text {, } \\
\text { thin sline of } \\
\text { organics, dark } \\
\text { brown and make } \\
\text { up } 2 / 3 \text { of barrel }\end{array}$ & & & abrupt, curved & $\begin{array}{l}\text { orgnaics appear } \\
\text { fiverous }\end{array}$ \\
\hline 5.1 & 165.0 & 134.5 & 131.0 & $3 / 10 Y$ & $\begin{array}{l}\text { Mud similar to } \\
122-130.6, \text { some } \\
\text { sand }\end{array}$ & & normal & $\begin{array}{l}\text { becomes 100\% } \\
\text { sand }\end{array}$ & $\begin{array}{l}\text { Sand \% } \\
\text { increasess } \\
\text { downsection, } \\
\text { organics } 30 \% \\
\text { throughout } \\
\end{array}$ \\
\hline 7.8 & 170.1 & 139.6 & 136.0 & $2.5 / 5 \mathrm{GY}$ & $\begin{array}{l}\text { Mix of sand, } 70 \% \text {, } \\
\text { and gravels } 10- \\
20 \% . \text { Mud } 10 \% . \\
\text { Larger gravels } \\
\text { from } 137-141\end{array}$ & $\begin{array}{l}\text { subroudned to } \\
\text { rounded }\end{array}$ & & gradual & $\begin{array}{l}\text { some organics } \\
\text { seen througout, } \\
\text { especially around } \\
\text { gravels }\end{array}$ \\
\hline 3.5 & 177.9 & 147.4 & 143.6 & $4 / 10 Y$ & $\begin{array}{l}\text { lower \% sand, } \\
60 \% \text {, but similar to } \\
\text { above and below, } \\
\text { higher clay rich } \\
\text { mud } 20 \% \text {, with } \\
\text { some gravels }\end{array}$ & subrounded & & gradual & $\begin{array}{l}\text { organics are } \\
\text { small and } \\
\text { fiberous }\end{array}$ \\
\hline
\end{tabular}




\begin{tabular}{|c|c|c|c|c|c|c|c|c|c|}
\hline 9.2 & 181.4 & 150.9 & 147.0 & $3 / N$ & $\begin{array}{l}\text { Sand } 60 \% \text {, mud } \\
10 \% \text {, and gravels } \\
30 \%\end{array}$ & $\begin{array}{l}\text { subangular to } \\
\text { subrounded }\end{array}$ & $\begin{array}{l}\text { sort of normal } \\
\text { with larger } \\
\text { gravels at base }\end{array}$ & $\begin{array}{l}\text { slanted but } \\
\text { abrupt and } \\
\text { curved }\end{array}$ & $\begin{array}{l}\text { Bottom section is } \\
\text { slanted in barrel, } \\
\text { sand contains } \\
\text { quartz, micas, } \\
\text { fiberous, light } \\
\text { brown organics }\end{array}$ \\
\hline 6.8 & 190.6 & 160.1 & 156.0 & $4 / 10 Y$ & $\begin{array}{l}\text { Clay-rich mud 60- } \\
70 \% \text {, sand } 20 \% \\
\text { and organics } 10- \\
20 \%\end{array}$ & rounded & & $\begin{array}{l}\text { abrupt, wavy, } \\
\text { change in grain } \\
\text { size, some } \\
\text { intermixing with } \\
\text { lower level } \\
\end{array}$ & $\begin{array}{l}\text { Whole section } \\
\text { slanted in barrel } \\
\text { to east. }\end{array}$ \\
\hline 43.5 & 197.4 & 166.9 & 162.6 & $3 / N$ & $\begin{array}{l}\text { Gravels and } \\
\text { coarse sand } 90 \% \text {, } \\
\text { mud } 10 \%\end{array}$ & $\begin{array}{l}\text { subangular to } \\
\text { rounded }\end{array}$ & poorly sorted & end & $\begin{array}{l}\text { Mixed sand and } \\
\text { gravels, clast } \\
\text { supported, large } \\
\text { gravel } 3.5 \mathrm{~cm} \text { in } \\
\text { size at base } \\
\end{array}$ \\
\hline 20.5 & 240.9 & 210.4 & 205.0 & $\begin{array}{l}\text { Last section } \\
\text { was lost } \\
\text { during core } \\
\text { recovery - } \\
\text { assumed to } \\
\text { be similar to } \\
\text { above, } \\
\text { gravelly }\end{array}$ & & & & & \\
\hline 261.4 & 261.4 & 230.9 & 225.0 & & & & & & \\
\hline
\end{tabular}




\begin{tabular}{|c|c|c|c|c|c|c|c|c|c|}
\hline ves6tN & & & & \begin{tabular}{|l|} 
Date core \\
collected:
\end{tabular} & Compacton: & \begin{tabular}{|l} 
Date core \\
analyzed:
\end{tabular} & $\begin{array}{l}\text { Total length: } \\
\text { 1oft }\end{array}$ & 311.645 & 311.645 \\
\hline $\begin{array}{l}\text { North marked } \\
\text { half }\end{array}$ & & & & & & & IF: & 106.045 & 60.325 \\
\hline & & $\begin{array}{l}\text { Compaction } \\
\text { factor: }\end{array}$ & 0.24838692 & & & & OF: & 38.1 & 38.1 \\
\hline & & & 0.081248058 & & & & $\mathrm{Si}$ & 67.945 & 22.225 \\
\hline & & & & & & & $\mathrm{Pi}$ & 273.545 & 273.545 \\
\hline & & & & & & & $\begin{array}{l}\text { Du } \\
\text { (excpected) }\end{array}$ & 198.755 & \\
\hline & & & & & & & Du (actual) & 205.6 & 205.6 \\
\hline & & & & & & & Difference: & 6.845 & \\
\hline Thickness $(\mathrm{cm})$ & \begin{tabular}{|l} 
lorrected depth \\
for compaction \\
and root removal \\
$(\mathrm{cm})$
\end{tabular} & $\begin{array}{l}\text { Corrected depth } \\
\text { for compaction } \\
\text { (cm) }\end{array}$ & $\begin{array}{l}\text { Core referenced } \\
\text { depth }(\mathrm{cm})\end{array}$ & Color & $\begin{array}{l}\text { Texture, grain } \\
\text { sizes, \% present, } \\
\text { other important } \\
\text { features }\end{array}$ & $\begin{array}{l}\text { Shape/Rou } \\
\text { nding }\end{array}$ & Gradeing & \begin{tabular}{|} 
Boundary \\
to lower \\
horizon
\end{tabular} & Notes \\
\hline 45.7 & 0.0 & 45.7 & \begin{tabular}{|l|}
-45.7 \\
\end{tabular} & & & & & & \\
\hline 19.6 & 45.7 & 0.0 & 0.0 & $\begin{array}{l}\text { 5YR 2.5/1, } \\
\text { black }\end{array}$ & $\begin{array}{l}\text { Peat, } \mathrm{H} 4 \\
\text { humification, } \\
\text { releases very } \\
\text { muddy water, } \\
\text { past like residue }\end{array}$ & & & abrupt & $\begin{array}{l}\text { Roots and } \\
\text { other features } \\
\text { identifiable }\end{array}$ \\
\hline 17.5 & 65.3 & 19.6 & 13.0 & $\begin{array}{l}\text { 10YR } 3 / 1 \text {, Very } \\
\text { dark grey }\end{array}$ & $\begin{array}{l}\text { Peat, H5-H6 } \\
\text { humification, } \\
\text { little muddy } \\
\text { water, mostly } \\
\text { amorphous peat } \\
\text { between fingers, } \\
\text { past-like }\end{array}$ & & & abrupt & \\
\hline 0.6 & 82.8 & 37.1 & 29.2 & $2.5 Y 2.5 / 1$ & Thin dark line & & & abrupt & $\begin{array}{l}\text { potentially a } \\
\text { fire? Very dark, } \\
\text { slanted in core } \\
\text { barrel }\end{array}$ \\
\hline 0.6 & 83.5 & 37.7 & 29.8 & $\begin{array}{l}\text { Same as 13- } \\
29.2\end{array}$ & & & & abrupt & \\
\hline
\end{tabular}




\begin{tabular}{|c|c|c|c|c|c|c|c|c|}
\hline 42.8 & 84.1 & 38.4 & 30.4 & $\begin{array}{l}10 Y R \quad 2 / 2 \text {, very } \\
\text { dark brown }\end{array}$ & $\begin{array}{l}\text { Peat, } \mathrm{H6} \\
\text { humifictaion, } \\
\text { closer to H7 at } \\
\text { base }\end{array}$ & & gradual & \begin{tabular}{|l|} 
amorphous \\
plant material, \\
well composed, \\
stringy roots \\
visible \\
\end{tabular} \\
\hline 11.9 & 126.9 & 81.2 & 70.0 & $\begin{array}{l}4 / 10 Y, 10 Y R \\
4 / 1 \text { at top } \\
\end{array}$ & $\begin{array}{l}\text { Transition from } \\
\text { peat to mud }\end{array}$ & 54.71 & abrupt & $\begin{array}{l}\text { organic content } \\
\text { decreasess } \\
\text { from }>80 \% \text { to } \\
\sim 20 \% \text { at } \\
\text { bottom }\end{array}$ \\
\hline 4.3 & 138.8 & 93.1 & 81.0 & $4 / 10 \mathrm{Y}$ & $\begin{array}{l}\sim 90 \% \text { organics, } \\
\text { appears to be a } \\
\text { cattail root }\end{array}$ & & & $\begin{array}{l}\text { Huge root, root } \\
\text { came out with } \\
\text { S. half, cut to } \\
\text { place back }\end{array}$ \\
\hline 16.9 & 143.1 & 97.4 & 85.0 & $\begin{array}{l} \\
4 / 10 Y \text { (spots), } \\
\text { 4/10GY, } \\
\text { mottled color }\end{array}$ & $\begin{array}{l}\text { clay rich mud, } \\
<5 \% \text { fine sand, } \\
\text { few micas seen } \\
\text { throghout, } 20 \% \\
\text { organics } \\
\text { throughout } \\
\end{array}$ & & & $\begin{array}{l}\text { mottled color } \\
\text { throuhgout }\end{array}$ \\
\hline 16.7 & 160.0 & 114.3 & 100.6 & $\begin{array}{l}4 / 10 \mathrm{Y} \text { (spots), } \\
4 / 10 \mathrm{GY}\end{array}$ & $\begin{array}{l}\text { Clay with }<5 \% \\
\text { fine sand, } \sim 20 \% \\
\text { organics } \\
\text { throughout } \\
\end{array}$ & & clear & $\begin{array}{l}\text { motteling } \\
\text { decreases } \\
\text { downsection }\end{array}$ \\
\hline 5.4 & 176.7 & 130.9 & 116.0 & $4 / 10 \mathrm{GY}$ & $\begin{array}{l}\text { Clay with 50\% } \\
\text { organic } \\
\text { fragments }\end{array}$ & & gradual & $\begin{array}{l}\text { appear } \\
\text { fiberous and } \\
\text { concentrated } \\
\text { into area, } \\
\text { decreasing } \\
\text { organics } \\
\text { towards } \\
\text { bottom to } \\
40 \% \\
4\end{array}$ \\
\hline
\end{tabular}




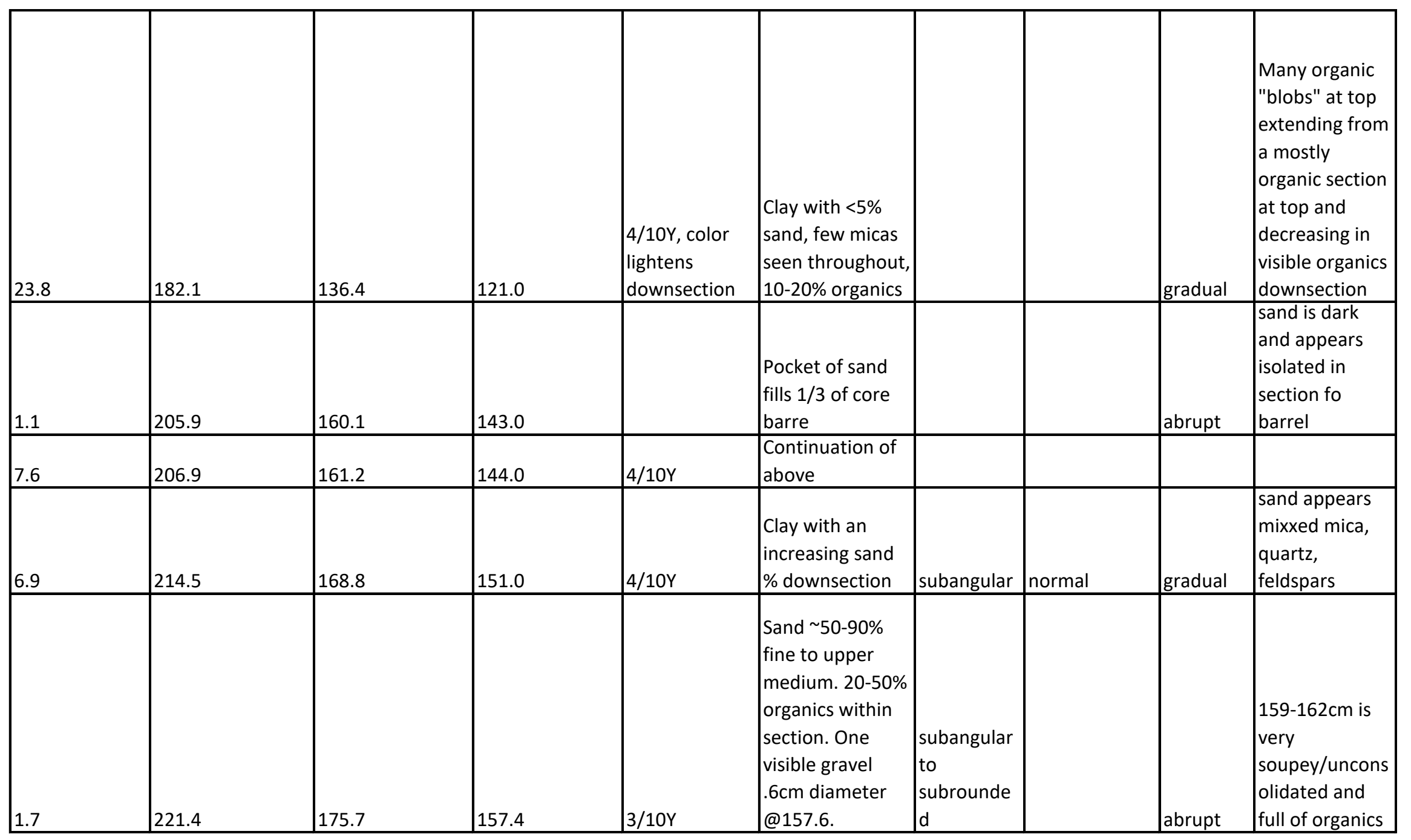




\begin{tabular}{|c|c|c|c|c|c|c|c|}
\hline 10.8 & 223.2 & 177.4 & 159.0 & & $\begin{array}{l}\text { filled with clay } \\
\text { lob, appears to } \\
\text { come up from } \\
\text { below in barrel, } \\
\text { or sand is } \\
\text { squished } \\
\text { dowards - very } \\
\text { wavy contact. } \\
\text { Sand appears } \\
\text { lobed at base } \\
\text { along contact } \\
\end{array}$ & $\begin{array}{l}\text { Contact is } \\
\text { abrupt } \\
\text { but not } \\
\text { horizontal } \\
\text { ly well } \\
\text { defined/is } \\
\text { olated, } \\
\text { and is } \\
\text { very wavy }\end{array}$ & \\
\hline 9.9 & 234.0 & 188.3 & 169.0 & $4 / 10 Y$ & $\begin{array}{l}\text { Clay-rich mud } \\
\text { with }<2 \% \text { sand - } \\
\text { some grit to } \\
\text { touch }\end{array}$ & abrupt & $\begin{array}{l}\text { few organics } \\
\text { throughout, } \\
\text { warped } \\
\text { towards core } \\
\text { barrel edges }\end{array}$ \\
\hline 5.0 & 244.6 & 198.8 & 178.8 & $4 / 10 Y$ & $\begin{array}{l}\text { Section of mud, } \\
\text { similar to above } \\
\text { with "pockets" of } \\
\text { sand }\end{array}$ & gradual & \\
\hline 24.0 & 249.5 & 203.8 & 183.4 & $4 / 10 Y$ & $\begin{array}{l}\text { Clay with very } \\
\text { little sand, very } \\
\text { little grit to } \\
\text { touch, } 10 \% \\
\text { organics which } \\
\text { are fiberous }\end{array}$ & end & $\begin{array}{l}\text { Clay is very } \\
\text { smooth and } \\
\text { dryes light } \\
\text { grey, large } \\
\text { lack/dark } \\
\text { brown organic } \\
\text { at } 200.4 \mathrm{~cm}\end{array}$ \\
\hline
\end{tabular}




\begin{tabular}{|c|c|c|c|c|c|c|c|c|}
\hline VCEI1 & & \begin{tabular}{|l|} 
Location: \\
Eliza \\
Island \\
\end{tabular} & $\begin{array}{l}\text { Date core } \\
\text { collected: }\end{array}$ & Compacton: & $\begin{array}{l}\text { Date core } \\
\text { analyzed: }\end{array}$ & Orig Length: $10 \mathrm{ft}$ & 315.56 & \\
\hline & & & & & & IF: & 78.89 & \\
\hline & & & & & & OF: & 38.42 & \\
\hline & & & & & & $\mathrm{Si}$ & 40.47 & \\
\hline & & & $\begin{array}{l}\text { Compaction } \\
\text { factor: }\end{array}$ & 0.146027279 & & $\mathrm{Pi}$ & 277.14 & \\
\hline & & & & & & Du (excpected) & 225.91 & \\
\hline & & & & & & Du (actual) & 236.67 & \\
\hline & & & & & & Difference: & 10.76 & \\
\hline & & & & & & & & \\
\hline $\begin{array}{l}\text { Thickness } \\
(\mathrm{cm})\end{array}$ & $\begin{array}{l}\text { Corrected } \\
\text { depth for } \\
\text { compaction } \\
(\mathrm{cm})\end{array}$ & $\begin{array}{l}\text { Depth } \\
(\mathrm{cm})\end{array}$ & Color & $\begin{array}{l}\text { Texture, grain sizes, } \% \\
\text { present, other important } \\
\text { features }\end{array}$ & $\begin{array}{l}\text { Shape/Roun } \\
\text { ding }\end{array}$ & Gradeing & $\begin{array}{l}\text { Boundary to } \\
\text { lower horizon }\end{array}$ & Notes \\
\hline 25.4 & 0.0 & 0 & $\begin{array}{l}\text { 10YR } 2 / 2, \\
\text { very dark } \\
\text { brown }\end{array}$ & Peat, $\mathrm{H} 3-\mathrm{H} 4$ hummification & & & clear, wavy & $\begin{array}{l}\text { lear roots, easily identifiable, } \\
\text { releases muddy water when } \\
\text { squeezed, some roots are } \\
\text { thick to } .5 \mathrm{~cm} \text { diameter }\end{array}$ \\
\hline 8.0 & 25.4 & 17 & 10YR $2 / 2$ & $\begin{array}{l}\text { Peat, H5 hum, more broken } \\
\text { down }\end{array}$ & & & \begin{tabular}{|l} 
Unclear, \\
graudal
\end{tabular} & \begin{tabular}{|l|} 
Fiberous peat with few \\
identifiable roots
\end{tabular} \\
\hline 32.8 & 33.4 & 24 & $\begin{array}{l}\text { 10YR } 2 / 2 \\
1 \text { OYR } 2 / 1\end{array}$ & H6-H7 hummification & & & $\begin{array}{l}\text { Clear, wavy, } \\
\text { clear color and } \\
\text { texture change }\end{array}$ & $\begin{array}{l}\text { Few identifiable roots, half of } \\
\text { beap escapes between } \\
\text { fingers when squeezed }\end{array}$ \\
\hline 6.2 & 66.2 & 52.6 & 10YR 3/1 & $\begin{array}{l}\text { Peat, H9 hummification, past } \\
\text { produced with } 1 \text { identifiable } \\
\text { root }\end{array}$ & & & Abrupt, wavy & \\
\hline 17.2 & 72.4 & 58 & $\begin{array}{l}/ 10 Y \text { - base, } \\
4 / 10 Y- \\
\text { mottling spots }\end{array}$ & $\begin{array}{l}\text { Clay } 80 \% \text {, sand } 5 \% \text {, some grit } \\
\text { to touch, fiberous organics } \\
15 \%\end{array}$ & Rounded & & Mottling ends & $\begin{array}{l}\text { Some gravels throughout } \\
\text { section @67cm, } \\
\text { concentration of motteling in } \\
\text { color decreases downsection }\end{array}$ \\
\hline 11.5 & 89.6 & 73 & $3 / 10 Y$ & $\begin{array}{l}\text { Clay } 60 \% \text {, sand } 20 \% \text { fine to } \\
\text { medium size, micas seen } \\
\text { visually, organics } 20 \% \text {, } \\
\text { occasional gravels }\end{array}$ & Rounded & Normally graded & $\begin{array}{l}\text { Color and } \\
\text { texture clearly } \\
\text { change }\end{array}$ & Gravels at base of secion \\
\hline
\end{tabular}




\begin{tabular}{|c|c|c|c|c|c|c|c|c|}
\hline 7.8 & 101.0 & 83 & $4 / 10 Y$ & $\begin{array}{l}\text { decreas in sand to } 5-10 \% \text {, } \\
\text { increase of clay to } 80 \% \text {, } \\
\text { organics } 10+\%\end{array}$ & & & $\begin{array}{l}\text { Clear texture } \\
\text { change }\end{array}$ & $\begin{array}{l}\text { No gravels seen on surface, } \\
\text { organics concentrated at } \\
\text { base }\end{array}$ \\
\hline 16.3 & 108.8 & 89.8 & $3 / 10 Y$ & $\begin{array}{l}\text { lay } 75 \% \text {, sand } 15 \% \text { and fine, } \\
\text { organics } 10 \%\end{array}$ & & $\begin{array}{l}\text { Well sorted, sand } \\
\text { concentrateinto } \\
\text { pockets }\end{array}$ & clear, curved & $\begin{array}{l}\text { Few small .4cm gravels - } \\
\text { quartz sand concentrated } \\
\text { from } 90-93, \text { appears } \\
\text { dispursed in pockets } \\
\end{array}$ \\
\hline 4.6 & 125.1 & 104 & $\begin{array}{l}\text { 10YR } 3 / 1, \\
\text { color extends } \\
\text { down to form } \\
\text { mottled color. } \\
\text { Mottling } \\
\text { decreases } \\
\text { downsection } \\
\text { below }\end{array}$ & $\begin{array}{l}\text { Sand }<5 \% \text {, fine in organic rich } \\
\text { mud, which is pasty. Sand is } \\
\text { not visible }\end{array}$ & & $\begin{array}{l}\text { Normal, less sand } \\
\text { downsection }\end{array}$ & gradual & $\begin{array}{l}\text { Appears very smooth, very } \\
\text { littl grit to }\end{array}$ \\
\hline 12.6 & 129.7 & 108 & $3 / N$ & $\begin{array}{l}\text { Organic rich mud, with }<2 \% \\
\text { fine sand }\end{array}$ & & & end top & $\begin{array}{l}\text { Large organic, looks like a } \\
\text { well-preserved stick or root, } \\
\text { organics present, small, } \\
\text { throughout section }\end{array}$ \\
\hline 34.6 & 142.3 & 119 & $3 / N$ & $\begin{array}{l}\text { Clay and silt rich mud, with } \\
<2 \% \text { sand, with occasional } \\
\text { coarse sand seen }\end{array}$ & & & $\begin{array}{l}\text { abrupt, gravel } \\
\text { along contact }\end{array}$ & $\begin{array}{l}\text { Samll oranics throughout } \\
<.4 \mathrm{~cm}\end{array}$ \\
\hline 11.8 & 176.9 & 149.2 & $2.5 Y 2.5 / 1$ & $\begin{array}{l}\text { Mud } 40 \% \text {, sand } 60 \% \text {, medium } \\
\text { to coarse, organics } 10 \%\end{array}$ & $\begin{array}{l}\text { Subrounded } \\
\text { to rounded }\end{array}$ & & $\begin{array}{l}\text { gradual but } \\
\text { clear, } \\
\text { decreases in } \\
\text { sand amount } \\
\text { downsection }\end{array}$ & $\begin{array}{l}\text { Sticky, sand appears white to } \\
\text { black, gravels throughout to } \\
1 \mathrm{~cm}\end{array}$ \\
\hline 17.8 & 188.7 & 159.5 & $3 / N$ & $\begin{array}{l}\text { Coarse sand } 30 \% \text {, mud } 60 \% \text {, } \\
\text { gravels } 5-10 \% \text {, organics } 5 \%\end{array}$ & Subrounded & $\begin{array}{l}\text { Sand is concentrated } \\
\text { more in one section }\end{array}$ & \begin{tabular}{|l|} 
gradual increas \\
in sand \% \\
downsection
\end{tabular} & Gravels throughout to $1 \mathrm{~cm}$ \\
\hline 14.9 & 206.5 & 175 & $4 / N$ & $\begin{array}{l}\text { Sand } 80 \%, \text { fine to coarse, } \\
\text { gravels } 10 \% \text {, organics } 10 \%\end{array}$ & $\begin{array}{l}\text { Subangular } \\
\text { to } \\
\text { subrounded }\end{array}$ & Normal & $\begin{array}{l}\text { Unclear if } \\
\text { boundary, } \\
\text { grain size } \\
\text { abruptly } \\
\text { changes }\end{array}$ & Sand contains quartz \\
\hline
\end{tabular}




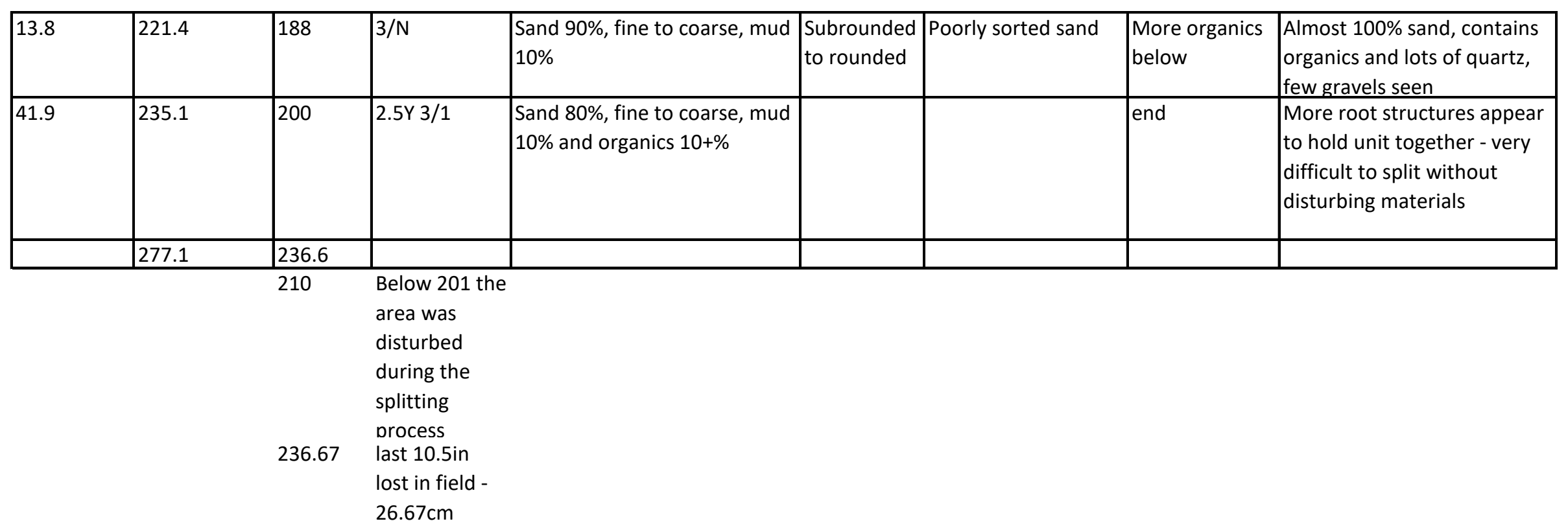




\begin{tabular}{|c|c|c|c|c|c|c|c|c|}
\hline & VCEI2_N & $\begin{array}{l}\text { Location } \\
\text { : Eliza } \\
\text { Island }\end{array}$ & $\begin{array}{l}\text { Date core } \\
\text { collected: }\end{array}$ & Compacton $(\mathrm{cm})$ : & $\begin{array}{l}\text { Date core } \\
\text { analyzed: }\end{array}$ & & Orig length: $8 \mathrm{ft}$ & 248.21 \\
\hline & & & & & & & IF: & 59.21 \\
\hline & & & $\begin{array}{l}\text { Compaction } \\
\text { factor: }\end{array}$ & 0.122998325 & & & OF: & 32.703 \\
\hline & & & & & & & $\mathrm{Si}$ & 26.507 \\
\hline & & & & & & & $\mathrm{Pi}$ & 215.507 \\
\hline & & & & & & & Du (expected) & 184.63 \\
\hline & & & & & & & Du (actual) & 189 \\
\hline & & & & & & & Difference: & 4.37 \\
\hline Thickness (cm) & $\begin{array}{l}\text { Corrected } \\
\text { depth for } \\
\text { compaction } \\
(\mathrm{cm})\end{array}$ & $\begin{array}{l}\text { Depth } \\
(\mathrm{cm})\end{array}$ & Color & $\begin{array}{l}\text { Texture, grain } \\
\text { sizes, \% present, } \\
\text { other important } \\
\text { features }\end{array}$ & Shape/Rounding & Gradeing & $\begin{array}{l}\text { Boundary to lower } \\
\text { horizon }\end{array}$ & Notes \\
\hline 17.86 & 0.00 & 0 & $\begin{array}{l}\text { 7.5YR 3/1, 7.5YR } \\
2.5 / 1 \\
\end{array}$ & Peat & & & Gradual & $>95 \%$ organic top soil \\
\hline 38.86 & 17.86 & 13 & $\begin{array}{l}\text { 10YR 2.5/1, 10YR } \\
2 / 2\end{array}$ & $\begin{array}{l}\text { Peat, visible roots } \\
\text { in tact }\end{array}$ & & & gradual & from 37-49 darker color \\
\hline 2.25 & 56.72 & 47.6 & 10YR 2.5/1 & Peat & & & $\begin{array}{l}\text { Abrupt, roots } \\
\text { extend downwards }\end{array}$ & Dark top soil - O horizon \\
\hline 1.12 & 58.96 & 49.6 & $4 / 5 G Y$ & Clay & & & Gradual & $\begin{array}{l}\text { No motteling in color - flat } \\
\text { color }\end{array}$ \\
\hline 12.80 & 60.08 & 50.6 & $3 / 10 Y, 5 Y 3 / 1$ & $\begin{array}{l}\text { Clay, occasional } \\
\text { gravel/coarse } \\
\text { sand to } .3 \mathrm{~cm}\end{array}$ & & & Gradual & $\begin{array}{l}\text { Large orgnaic in South } \\
\text { core from } 50-55 \mathrm{~cm} \text {, small } \\
\text { gravel @60.8cm }\end{array}$ \\
\hline 11.68 & 72.89 & 62 & $\begin{array}{l}2.5 / 10 Y \text { (dark } \\
\text { areas between .6- } \\
1.4 \mathrm{~cm} \text { in } \\
\text { diameter), } 2.5 / \mathrm{N} \text { - } \\
\text { motteling in color }\end{array}$ & Clay & & & Abrupt & $\begin{array}{l}\text { Scattered organics } \\
\text { throughout }\end{array}$ \\
\hline 8.98 & 84.57 & 72.4 & $2.5 Y 3 / 1$ & Clay & & & abrupt, clear & $\begin{array}{l}\text { Scattered dark organics } \\
\text { (small) throughout }\end{array}$ \\
\hline 1.80 & 93.55 & 80.4 & $2.5 Y 3 / 2$ & $\begin{array}{l}\text { Clay, }<5 \% \text { sand } \\
\text { containing micas } \\
\text { (visually) }\end{array}$ & & & abrupt, clear & $\begin{array}{l}\text { Fine mica sands, lighter } \\
\text { color to clay than above } \\
\text { and below }\end{array}$ \\
\hline
\end{tabular}




\begin{tabular}{|c|c|c|c|c|c|c|c|c|}
\hline 25.83 & 95.35 & 82 & $2.5 Y 3 / 1$ & $\begin{array}{l}\text { clay-rich mud, } \\
\text { with small \% sand } \\
\text { micas visually } \\
\text { seen }\end{array}$ & & & Gradual & $\begin{array}{l}\text { Large dark are from } 82- \\
86.5, \text { dark organics seen } \\
\text { throughout }\end{array}$ \\
\hline 10.11 & 121.18 & 105 & $\begin{array}{l}2.5 Y 3 / 1,2.5 Y \\
2.5 / 1, \text { mottled } \\
\text { color starts lighter } \\
\text { and gradual at top, } \\
\text { and increases in } \\
\text { motteling down } \\
\text { section to create a } \\
\text { solid color of lower } \\
\text { section }\end{array}$ & $\begin{array}{l}\text { Clay rich mud, } \\
\text { with sand }<5 \% \\
\text { increasing } \\
\text { downsection }\end{array}$ & & $\begin{array}{l}\text { Normal } \\
\text { graded }\end{array}$ & Gradual & $\begin{array}{l}\text { Sand }<5 \% \text {, organics seen } \\
\text { throughout }\end{array}$ \\
\hline 11.23 & 131.28 & 114 & $2.5 / 10 Y$ & $\begin{array}{l}\text { Clay rich mud, } \\
\text { with } 5-10 \% \text { sand - } \\
\text { micas }\end{array}$ & & & Clear but gradual & \\
\hline 13.48 & 142.51 & 124 & $3 / \mathrm{N}$ & $\begin{array}{l}\text { Sand }>80 \% \text {, with } \\
\text { some clay rich } \\
\text { mud }\end{array}$ & Subrounded & $\begin{array}{l}\text { normally } \\
\text { graded, } \\
\text { with sand } \\
\text { coarsening } \\
\text { at bottom } \\
\end{array}$ & Gradual & \\
\hline 7.41 & 155.99 & 136 & $3 / \mathrm{N}$ & $\begin{array}{l}\text { Sand decreases in } \\
\%, \text { with clay and } \\
\text { mud \% increasing } \\
(20 \% ?)\end{array}$ & Subrounded & & $\begin{array}{l}\text { abrupt but some } \\
\text { mixing }\end{array}$ & \\
\hline 10.56 & 163.40 & 142.6 & $3 / \mathrm{N}, 2.5 \mathrm{Y} 3 / 2$ & $\begin{array}{l}\text { Coarse sand and } \\
\text { some organics, } \\
\text { sand to } .3 \mathrm{~cm}\end{array}$ & $\begin{array}{l}\text { Subrounded and } \\
\text { subangular }\end{array}$ & & Gradual & $\begin{array}{l}>90 \% \text { organic fragments, } \\
\text { mixed with coarse sand } \\
\text { and fine gravels, trash } \\
\text { layer }\end{array}$ \\
\hline 6.06 & 173.96 & 152 & $2.5 Y 2.5 / 1,2.5 / \mathrm{N}$ & $\begin{array}{l}\text { Clay with } 10 \% \\
\text { coarse sand and } \\
\text { gravels to } 1.5 \mathrm{~cm}, \\
\text { gravels at base } \\
\end{array}$ & & Normal & Clear but gradual & $\begin{array}{l}\text { Abundant small organics } \\
\text { throughout }\end{array}$ \\
\hline 15.27 & 180.02 & 157.4 & $3 / 10 Y$ & $\begin{array}{l}\text { Clay with gravels } \\
\text { to } .8 \mathrm{~cm}\end{array}$ & $\begin{array}{l}\text { Angular to } \\
\text { subangular }\end{array}$ & & Clear and abrupt & $\begin{array}{l}\text { Some very large clasts } \\
\text { burried - unsure how large }\end{array}$ \\
\hline
\end{tabular}




\begin{tabular}{|c|c|c|c|c|c|c|}
\hline 3.37 & 195.29 & 171 & $2.5 / 10 Y$ & $\begin{array}{l}\text { Mud, clay rich, } \\
\text { with <5\% sand } \\
\text { and gravels, fine } \\
\text { sand felt to touch } \\
\text { but not visually } \\
\text { seen }\end{array}$ & clear & \\
\hline 8.98 & 198.66 & 174 & $5 / 10 G Y$ & $\begin{array}{l}\text { Mud with gravels, } \\
1.5 \mathrm{~cm} \text { at least for } \\
\text { largest gravel } \\
\text { present }\end{array}$ & clear & Very large gravels @181 \\
\hline
\end{tabular}




\begin{tabular}{|c|c|c|c|c|c|c|c|c|}
\hline VCEI3_N & & $\begin{array}{l}\text { Location: Eliza } \\
\text { Island }\end{array}$ & $\begin{array}{l}\text { Date core } \\
\text { collected: }\end{array}$ & Compacton: & $\begin{array}{l}\text { Date core } \\
\text { analyzed: }\end{array}$ & Orig Length: $10 \mathrm{ft}$ & 312.156 & \\
\hline & & & & & $9 / 30 / 2018$ & IF: & 91.756 & \\
\hline & & & $\begin{array}{l}\text { Compaction } \\
\text { factor: }\end{array}$ & 0.1237138 & & OF: & 60.64 & \\
\hline & & & & & & $\mathrm{Si}$ & 31.116 & \\
\hline & & & & & & $\mathrm{Pi}$ & 251.516 & \\
\hline & & & & & & Du (excpected) & 213.044 & \\
\hline & & & & & & Du (actual) & 220.4 & \\
\hline & & & & & & Difference: & 7.356 & \\
\hline Thickness (cm) & $\begin{array}{l}\text { Corrected depth } \\
\text { for compaction } \\
(\mathrm{cm})\end{array}$ & Depth (cm) & Color & \begin{tabular}{|l|} 
Texture, grain sizes, \% \\
present, other \\
important features
\end{tabular} & $\begin{array}{l}\text { Shape/Roundin } \\
\mathrm{g}\end{array}$ & Gradeing & $\begin{array}{l}\text { Boundary to } \\
\text { lower horizon }\end{array}$ & Notes \\
\hline 20.71 & 0.00 & 0 & $\begin{array}{l}7.5 Y R \text { 2.5/2, } \\
7.5 Y R 3 / 3 \\
\end{array}$ & Organic, O horizon & & & Gradual & $\begin{array}{l}\text { Abundant roots, } \\
\text { organics }\end{array}$ \\
\hline 5.62 & 20.71 & 15 & 10YR 3/2 & Gravles to $1.5 \mathrm{~cm}$ & Rounded & Normal & $\begin{array}{l}\text { Gradual but } \\
\text { clear }\end{array}$ & $\begin{array}{l}\text { Gravels are } \\
\text { normally graded } \\
\text { with }>50 \% \text { organics }\end{array}$ \\
\hline 6.74 & 26.32 & 20 & 3/10B (Grey 2) & $\begin{array}{l}40 \% \text { organics, with } \\
\text { mud and coarse sand } \\
\text { and gravels to } 1 \mathrm{~cm}\end{array}$ & subrounded & & $\begin{array}{l}\text { Clear color } \\
\text { change }\end{array}$ & $\begin{array}{l}\text { Appears to be } \\
\text { smaller gravels }\end{array}$ \\
\hline 10.68 & 33.07 & 26 & $4 / N$ & $\begin{array}{l}20 \% \text { organics and } \\
\text { gravels, gravels to } \\
2 \mathrm{~cm}\end{array}$ & & & & $\begin{array}{l}\text { Larger clasts than } \\
\text { above and below }\end{array}$ \\
\hline 5.06 & 43.74 & 35.5 & $4 / 10 Y$ & \begin{tabular}{|l|} 
Gravels, generally \\
small, but large gravel \\
in southern half
\end{tabular} & & & & \\
\hline 20.23 & 48.80 & 40 & $3 / 10 Y$ & $\begin{array}{l}\text { Abundant gravels } \\
>80 \%\end{array}$ & subrounded & & & $\begin{array}{l}49 \mathrm{~cm} \text { gravels are } \\
\text { imbricated, gravels } \\
\text { appear white }\end{array}$ \\
\hline 6.74 & 69.02 & 58 & $3 / N$ & $\begin{array}{l}\text { Gravels and sand, } \\
\text { sand is coarse }\end{array}$ & $\begin{array}{l}\text { Subrouded to } \\
\text { rounded }\end{array}$ & & Abrupt & $\begin{array}{l}\text { Coarse sand and } \\
\text { gravels, biggest } \\
\text { gravels at base }\end{array}$ \\
\hline
\end{tabular}




\begin{tabular}{|c|c|c|c|c|c|c|}
\hline 9.66 & 75.77 & 64 & $3 / 10 Y$ & $\begin{array}{l}\text { Mud } 90 \% \text {, sand }<10 \% \text {, } \\
\text { few gravels }<1 \mathrm{~cm}\end{array}$ & rounded & $\begin{array}{l}\text { Gravels appear } \\
\text { around edges, } \\
\text { shell fragments } \\
\text { seen @65 and } \\
@ 69 \mathrm{~cm}\end{array}$ \\
\hline 4.94 & 85.43 & 72.6 & $3 / N$ & Mud with some sand & & $\begin{array}{l}\text { Same as above, } \\
\text { except color }\end{array}$ \\
\hline 5.62 & 90.38 & 77 & $2.5 / 10 Y$ & $\begin{array}{l}\text { Mud }>80 \% \text { with } \\
\text { coarse sand } \\
\text { throughout }<10 \% \text {, } \\
10 \% \text { organics }\end{array}$ & & $\begin{array}{l}\text { Organics speard } \\
\text { throughout - black } \\
\text { and brown, about } \\
10 \%\end{array}$ \\
\hline 7.87 & 95.99 & 82 & $2.5 / 10 Y$ & $\begin{array}{l}\text { Same as above with } \\
\text { more sand along } \\
\text { edges and more } \\
\text { organics }\end{array}$ & & \\
\hline 2.47 & 103.86 & 89 & $3 / 10 Y$ & $\begin{array}{l}\text { Mud with some } \\
\text { gravels to } 1 \mathrm{~cm} \text {, large } \\
\text { pocket of sand makes } \\
\text { up } 1 / 3 \text { of core barrel }\end{array}$ & & $\begin{array}{l}\text { Large organic } \\
\text { "blob" next to } \\
\text { sand pocket }\end{array}$ \\
\hline 2.92 & 106.33 & 91.2 & $2.5 / 10 Y$ & $\begin{array}{l}\text { Same as } 89-91 \mathrm{~cm} \text {, but } \\
\text { different color }\end{array}$ & & \\
\hline 2.02 & 109.25 & 93.8 & $\begin{array}{l}\text { Mottled color, } \\
2.5 / \mathrm{N} \text { and } \\
3 / 10 \mathrm{Y}\end{array}$ & $\begin{array}{l}\text { Large sand pocket in } \\
\text { middle of core } 2 \mathrm{~cm} \\
\text { vertical in barrel, } \\
\text { within clay-rich mud }\end{array}$ & & \\
\hline 7.19 & 111.28 & 95.6 & $\begin{array}{l}\text { Mottled color, } \\
2.5 / \mathrm{N} \text { and } \\
3 / 10 \mathrm{Y}\end{array}$ & $\begin{array}{l}\text { Clay-rich mud, with } \\
\text { sand at } 67.4 \mathrm{~cm}\end{array}$ & & Mud \\
\hline 2.25 & 118.47 & 102 & $\begin{array}{l}3 / 10 Y \text { and } 10 Y R \\
2 / 1\end{array}$ & $\begin{array}{l}\text { Large cobble } 2 \mathrm{~cm} \text { by } \\
3 \mathrm{~cm} \text {. Some other } \\
\text { small gravels seen too }\end{array}$ & & \\
\hline 4.49 & 120.72 & 104 & $3 / 10 Y$ & $\begin{array}{l}\text { Clay-rich mud, with } \\
10 \% \text { coarse sand }\end{array}$ & subrounded & $\begin{array}{l}\text { Some organics } \\
\text { present at bottom }\end{array}$ \\
\hline
\end{tabular}




\begin{tabular}{|c|c|c|c|c|c|c|c|c|}
\hline 12.36 & 125.21 & 108 & $3 / 10 Y$ & $\begin{array}{l}\text { Clay-rich mud } 80 \%, \\
\text { gravel to } 1 \mathrm{~cm}, 10 \% \\
\text { and coarse sand } 10 \%\end{array}$ & $\begin{array}{l}\text { Subrounded to } \\
\text { rounded }\end{array}$ & $\begin{array}{l}\text { well sorted, sand } \\
\text { and gravels are } \\
\text { concentrated into } \\
\text { areas }\end{array}$ & $\begin{array}{l}\text { Graudal but } \\
\text { clear }\end{array}$ & $\begin{array}{l}\text { Some organics } \\
\text { throughout, sand } \\
\text { concentrated } \\
\text { between 115- } \\
118.5\end{array}$ \\
\hline 2.92 & 137.57 & 119 & $2.5 / 10 \mathrm{Y}$ & $\begin{array}{l}\text { Mud, very smooth } \\
>90 \%\end{array}$ & & & abrupt & $\begin{array}{l}\text { Black organics } \\
\text { seen throughout }\end{array}$ \\
\hline 15.06 & 140.49 & 121.6 & $3 / 10 \mathrm{Y}, 2.5 / 10 \mathrm{Y}$ & $\begin{array}{l}\text { Mud matrix } 50 \% \text {, } \\
\text { gravels to } 2 \mathrm{~cm} \text { at top } \\
\text { and base } 30 \% \text {, coarse } \\
\text { sand } 20-30 \%\end{array}$ & & poorly sorted & clear, wavy & $\begin{array}{l}\text { Organics } \\
\text { throughout, large } \\
@ 128.6-130.6, \\
\text { sand in large } \\
\text { pocket at top }\end{array}$ \\
\hline 1.69 & 155.55 & 135 & $2.5 / 10 \mathrm{Y}$ & $\begin{array}{l}\text { Less consolidated } \\
\text { mud with } 50 \% \text { sand }\end{array}$ & & & & $\begin{array}{l}\text { Appears } \\
\text { "smushed" } \\
\text { between upper } \\
\text { and lower sections }\end{array}$ \\
\hline 9.55 & 157.24 & 136.5 & $3 / N$ & $\begin{array}{l}\text { Sand } 70 \%, \text { mud } 30 \% \\
\text { and minor gravels }\end{array}$ & $\begin{array}{l}\text { Subangular to } \\
\text { subrounded }\end{array}$ & \begin{tabular}{|l|} 
well sorted, sand \\
and gravels are \\
concentrated into \\
areas
\end{tabular} & $\begin{array}{l}\text { clear but } \\
\text { slanted and } \\
\text { wavy }\end{array}$ & $\begin{array}{l}142-143.5 \text { large } \\
\text { pocket of white } \\
\text { coarse sand, roots } \\
\text { and organics } \\
\text { present }\end{array}$ \\
\hline 2.81 & 166.79 & 145 & $5 Y 2.5 / 1$ & $\begin{array}{l}\text { Mud }>80 \% \text {, sand } 20 \% \\
\text { in matrix }\end{array}$ & Subroudned & \begin{tabular}{|l|}
$\begin{array}{l}\text { poorly sorted (well } \\
\text { mixed) }\end{array}$ \\
\end{tabular} & abrupt & $\begin{array}{l}\text { less consolidated } \\
\text { "Mud" } \\
\end{array}$ \\
\hline 4.61 & 169.60 & 147.5 & $5 Y 2.5 / 1$ & \begin{tabular}{|l|} 
Sand $50 \%+$ in mud, \\
some small gravels 5- \\
$10 \%$
\end{tabular} & Subrounded & homogeneous & $\begin{array}{l}\text { Graudal but } \\
\text { clear }\end{array}$ & $\begin{array}{l}\text { Similar to } 136.5- \\
145 \text { section }\end{array}$ \\
\hline 4.49 & 174.20 & 151.6 & $2.5 / \mathrm{N}$ & $\begin{array}{l}\text { Clast supported }>80 \% \\
\text { gravles, with some } \\
\text { mud and coarse } \\
\text { sands. Gravels range } \\
\text { in size up to } 2 \mathrm{~cm}\end{array}$ & $\begin{array}{l}\text { Subrounded to } \\
\text { rounded }\end{array}$ & & clear and abrupt & \\
\hline
\end{tabular}




\begin{tabular}{|c|c|c|c|c|c|c|c|c|}
\hline 11.69 & 178.70 & 155.6 & $2.5 / \mathrm{N}, 2.5 / 10 \mathrm{Y}$ & $\begin{array}{l}\text { Mixed gravels and } \\
\text { sand } 70 \% \text { with mud } \\
30 \% . \text { Gravels to } 2 \mathrm{~cm} \\
\text { in size. }\end{array}$ & $\begin{array}{l}\text { Subangular to } \\
\text { subrounded }\end{array}$ & Normally graded & $\begin{array}{l}\text { clear change in } \\
\text { sand size makes } \\
\text { the boundary } \\
\text { clear }\end{array}$ & $\begin{array}{l}\text { Large gravels } \\
\text { throughout, but } \\
\text { sand is graded, } \\
\text { gravels are matrix } \\
\text { supported } \\
\end{array}$ \\
\hline 6.74 & 190.39 & 166 & $3 / N$ & $\begin{array}{l}\text { Coarse sand and fine } \\
\text { gravels are } 90 \% \text { of } \\
\text { matrix, with } 10 \% \text { mud } \\
\text { mixed in }\end{array}$ & $\begin{array}{l}\text { Subangular to } \\
\text { subrounded }\end{array}$ & poorly sorted & abrupt & $\begin{array}{l}\text { Mostly coarse } \\
\text { sand. Disturbed } \\
\text { section when } \\
\text { splitting core, most } \\
\text { came out in the } \\
\text { southern half } \\
\text { when solit }\end{array}$ \\
\hline 6.29 & 197.13 & 172 & $3 / N, 3 / 10 Y$ & $\begin{array}{l}\text { Large rock fragments, } \\
\text { bladed, appear to be } \\
\text { serpentinite } 50 \% \text {, fine } \\
\text { to medium sand } 25 \% \text {, } \\
\text { mud } 25 \%\end{array}$ & $\begin{array}{l}\text { Subangular to } \\
\text { rounded }\end{array}$ & $\begin{array}{l}\text { clast supported in } \\
\text { sections }\end{array}$ & $\begin{array}{l}\text { abrupt and } \\
\text { slanted }\end{array}$ & $\begin{array}{l}\text { Mica sands seen, } \\
\text { rock fragments } \\
\text { appear imbricated }\end{array}$ \\
\hline 6.07 & 203.42 & 177.6 & $4 / \mathrm{N}$ & $\begin{array}{l}\text { Coasre sand, medium } \\
\text { to coarse } 95 \% \text {, some } \\
\text { minor clay/mud }\end{array}$ & subrounded & homogenous & $\begin{array}{l}\text { abrupt, wavy, } \\
\text { slanted }\end{array}$ & $\begin{array}{l}\text { Minor amount of } \\
\text { organics seen }\end{array}$ \\
\hline 42.03 & 209.49 & 183 & $\begin{array}{l}5 / 5 G \text { and } \\
5 / 10 G Y\end{array}$ & $\begin{array}{l}\text { Clay }>90 \% \text { with } 10 \% \\
\text { fine grained sand }\end{array}$ & subrounded & well sorted & end & $\begin{array}{l}\text { Some organics } \\
\text { throughout, Sand } \\
\text { in "pockets" or } \\
\text { lines throughout. } \\
\text { Large sand pocket } \\
\text { present. Sands are } \\
\text { white with micas } \\
\text { seen }\end{array}$ \\
\hline & 251.52 & 220.4 & & & & & & \\
\hline
\end{tabular}


Appendix 3 Smear Slide Images

VCS2, reference depths: $80-90 \mathrm{~cm}$

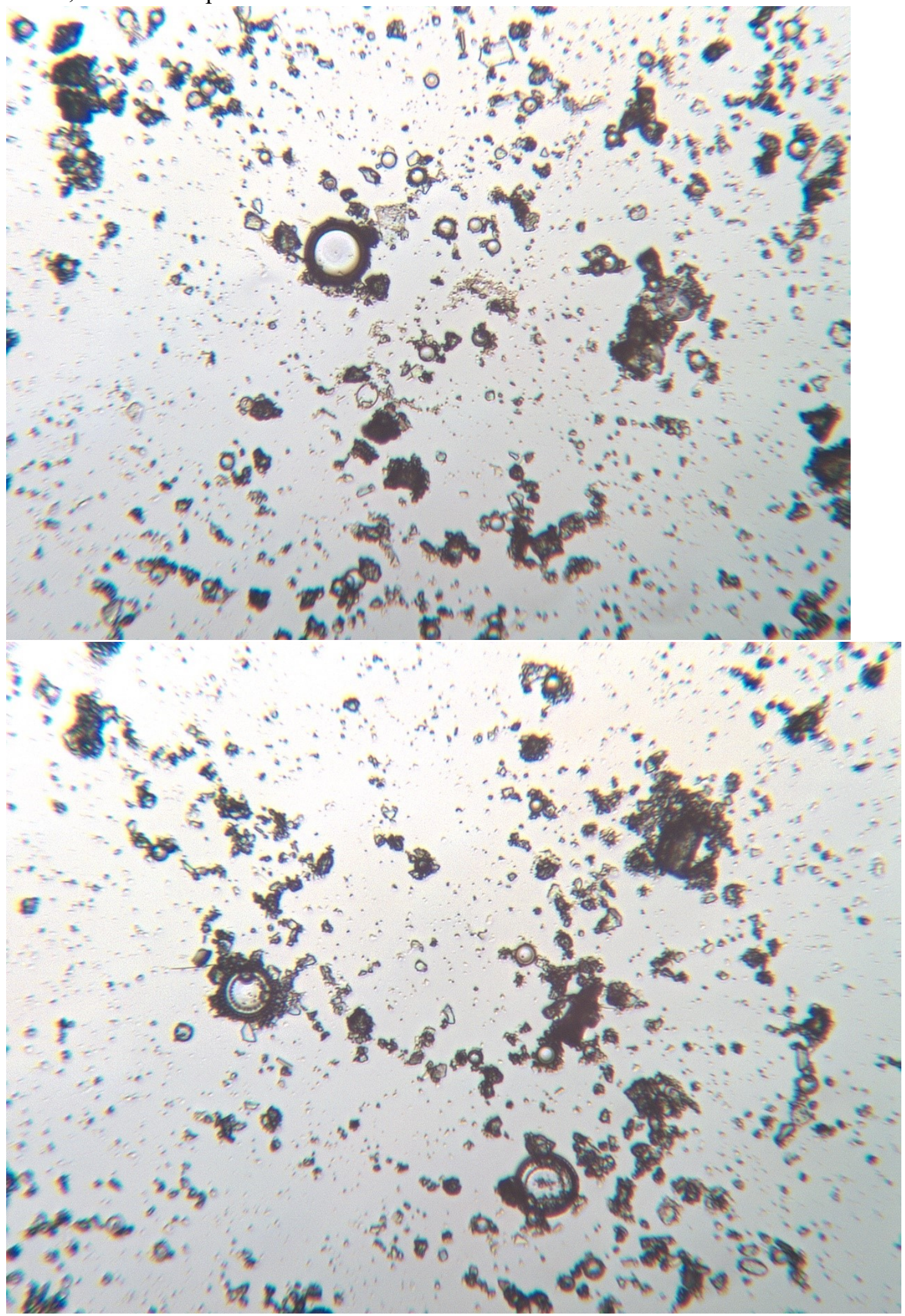


VCS6, reference depths: $178-185 \mathrm{~cm}$

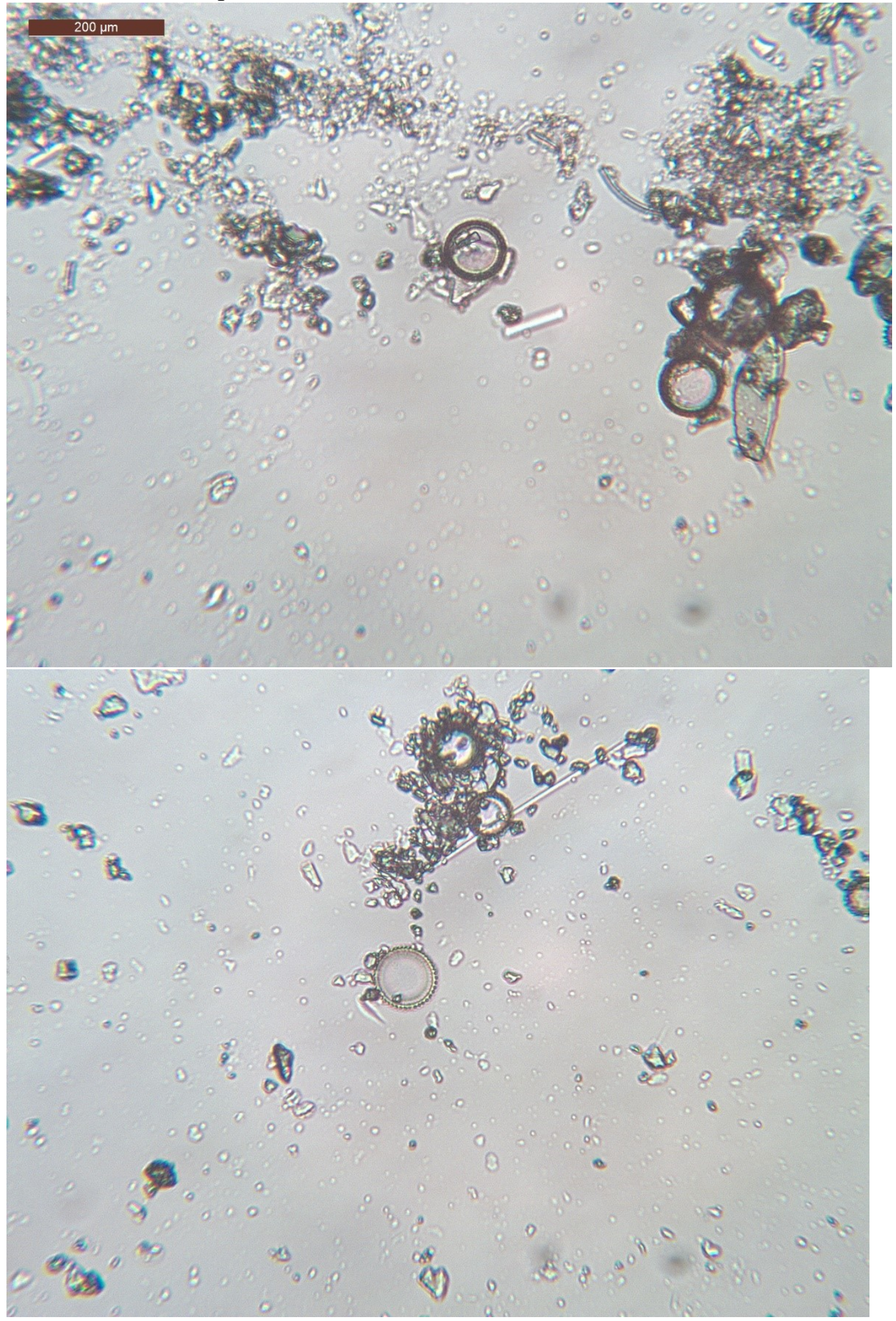


VCEI2, reference depths: $82-92 \mathrm{~cm}$

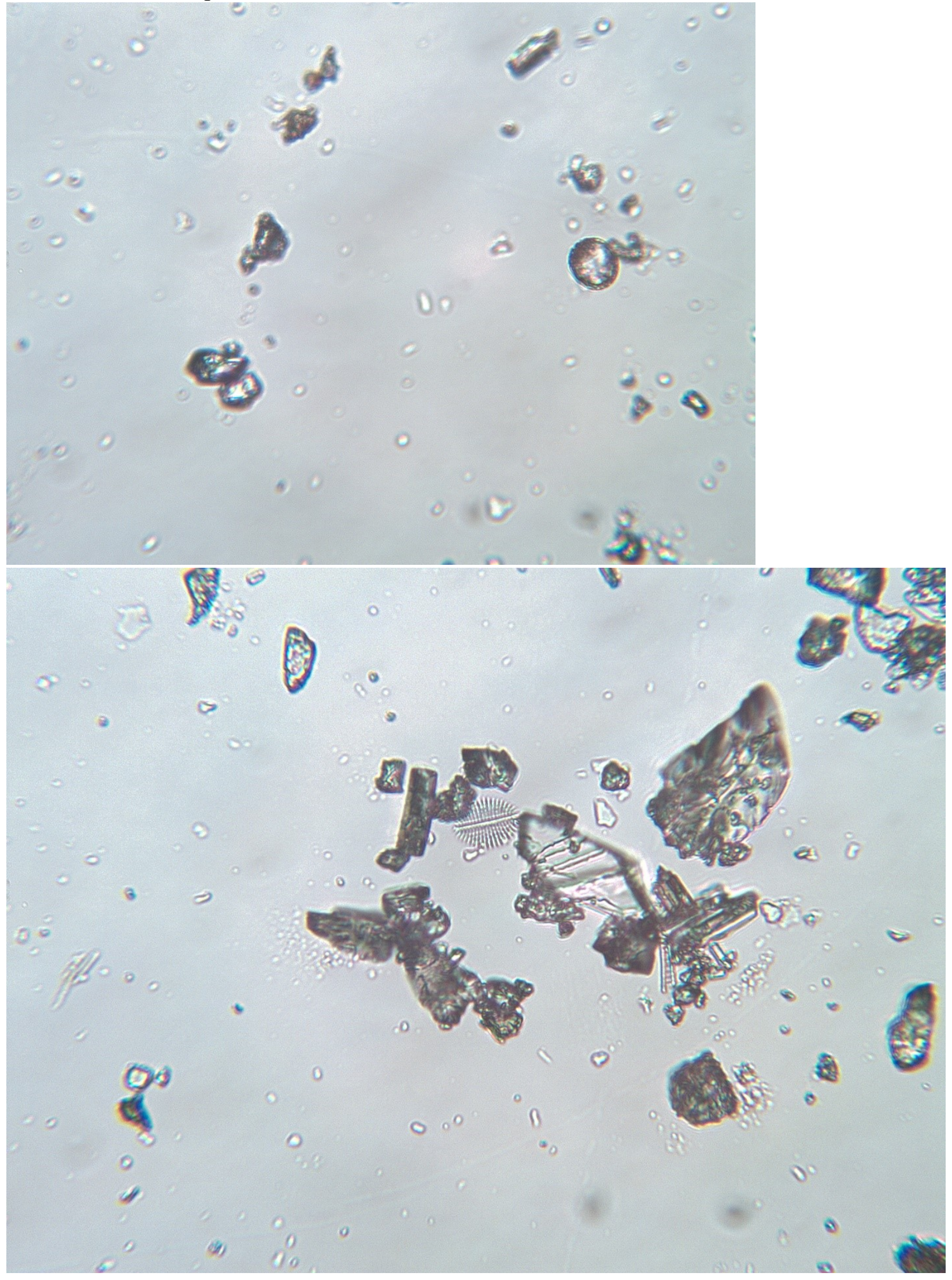


VCEI3, reference depths: $80-90 \mathrm{~cm}$

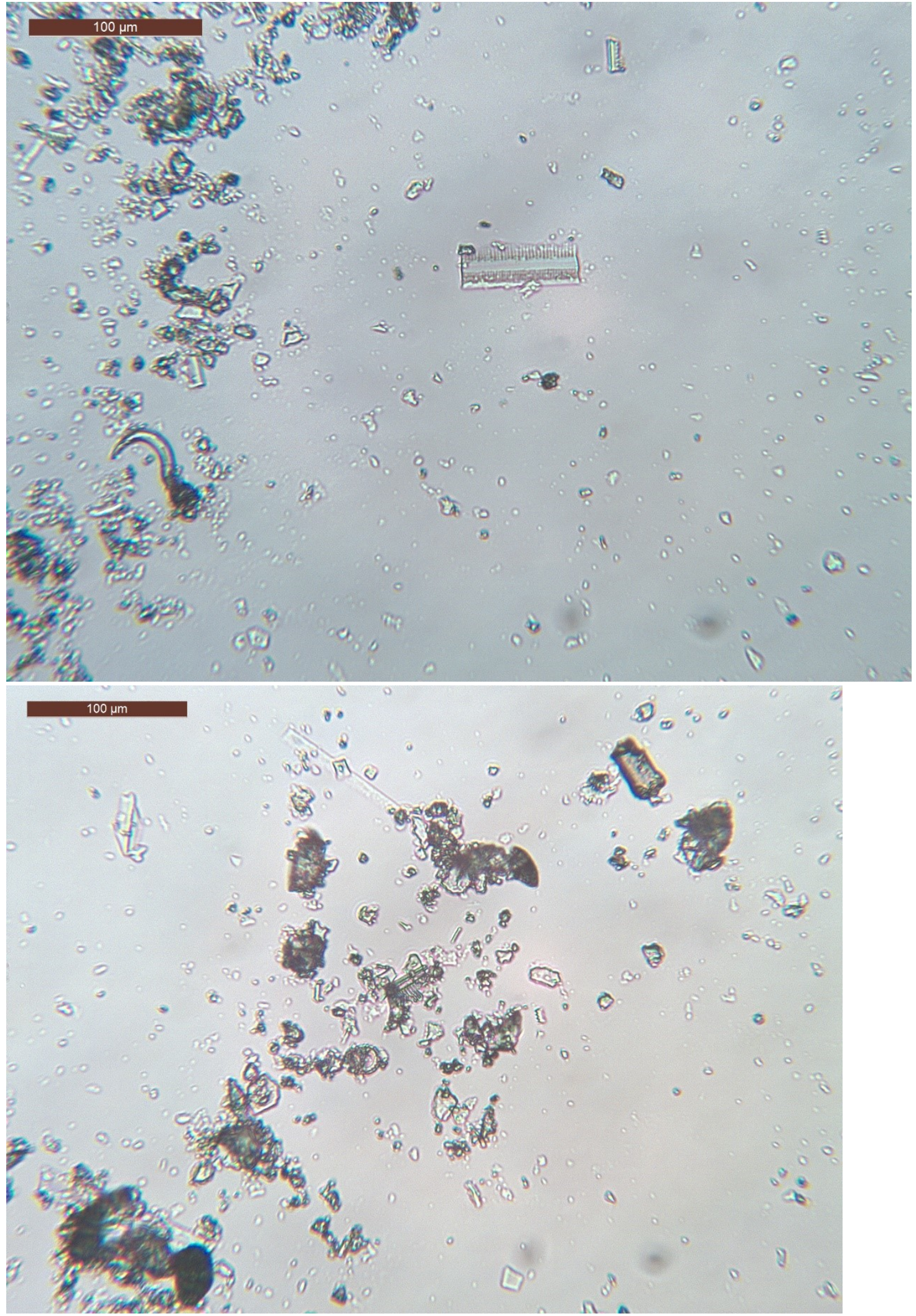




\section{Equations used to calculate PSV curves adapted from Butler (1992)}

\section{EXPECTED MAGNETIC FIELD DIRECTION}

The problem here is to derive expressions that allow determination of the magnetic field direction expected at an observing site $\left(\lambda_{s}, \phi_{s}\right)$ due to a geocentric dipole with pole position $\left(\lambda_{p}, \phi_{p}\right)$. We also derive expressions for the confidence limits on the expected direction that result from circular confidence limits (usually $A_{95}$ ) on the pole. The geometry of the problem is illustrated in Figure A.5.

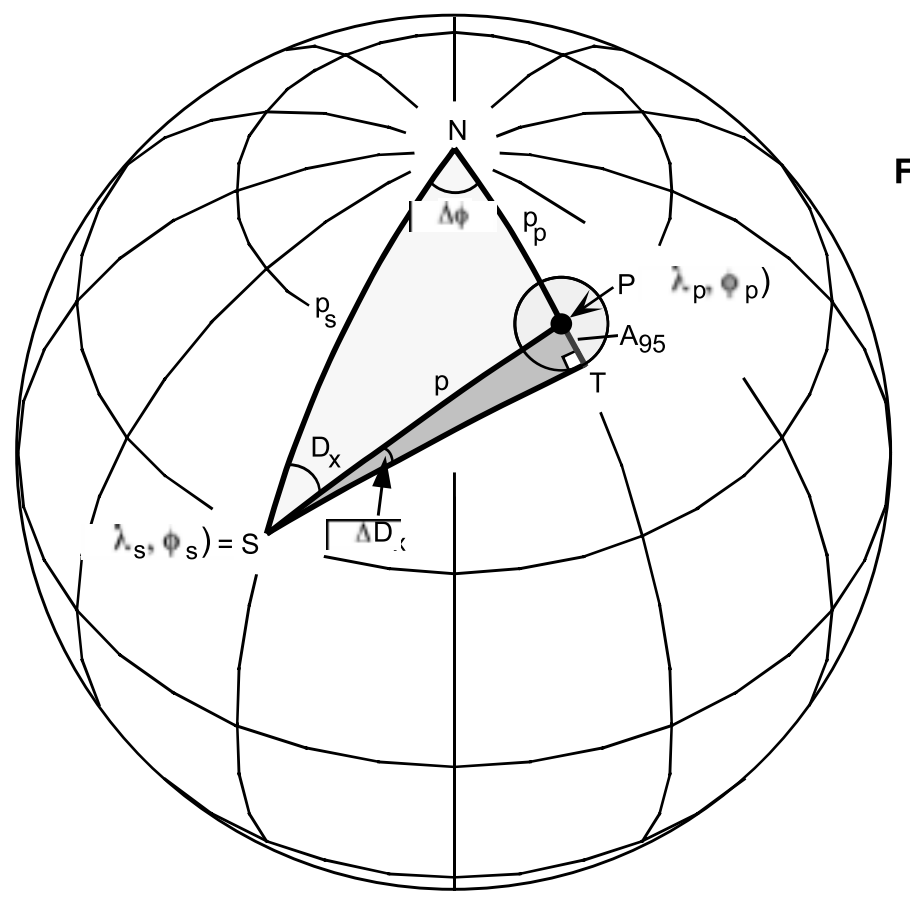

Figure A.5 Geometry used to determine the expected magnetic field direction from a magnetic pole. The magnetic pole is at $P\left(\lambda_{p}, \phi_{p}\right)$ with circular confidence limit $A_{95}$; the site location is at $S\left(\lambda_{s}, \phi_{s}\right) ; N$ is the geographic north pole; $p$ is the magnetic colatitude of the site; $p_{s}$ is the geographic colatitude of the site; $p_{p}$ is the geographic colatitude of the magnetic pole; $\Delta \phi$ is the longitudinal difference between the magnetic pole and the site; $D_{X}$ is the expected magnetic field declination at the site with confidence limit $=\Delta D_{X}$.

A spherical triangle $S P N$ is constructed with $N$ at the geographic pole, $P$ at the magnetic pole $\left(\lambda_{p}, \phi_{p}\right)$, and $S$ at the site $\left(\lambda_{s}, \phi_{s}\right)$. Having gone through a similar problem before, we realize that the declination of the expected magnetic field direction, $D_{x}$, at site $\left(\lambda_{s}, \phi_{s}\right)$ is the angle at apex $S$.

The first step in the derivation is to determine the angular distance, $p$, from $\left(\lambda_{p}, \phi_{p}\right)$ to $\left(\lambda_{s}, \phi_{s}\right)$. Apply the law of sines to triangle $S P N$ in Figure A.5 to get

$$
\cos p=\cos p_{p} \cos p_{s}+\sin p_{p} \sin p_{s} \cos \Delta \phi
$$

Now substitute

$$
p_{p}=\frac{p}{2}-\lambda_{p}, \quad p_{s}=\frac{\pi}{2}-\lambda_{s}, \text { and } \Delta \phi=\phi_{p}-\phi_{s}
$$

into Equation (A.53) and use

$$
\cos \left(\frac{\pi}{2}-\lambda_{p}\right)=\sin \lambda_{p} \text { and } \sin \left(\frac{\pi}{2}-\lambda_{p}\right)=\cos \lambda_{p}
$$


to find

$$
\cos p=\sin \lambda_{p} \sin \lambda_{s}+\cos \lambda_{p} \cos \lambda_{s} \cos \left(\phi_{p}-\phi_{s}\right)
$$

from which you can determine $p$.

The expected inclination, $I_{x}$, can be determined from $p$ by using the dipole equation (Equation (A.10)):

$$
I_{x}=\tan ^{-1}(2 \cot p)
$$

The confidence limit on $I_{x}$ is defined as $\Delta I_{x}$ and can be determined from the equation that we derived to get $d p$ from $\Delta l\left(=\alpha_{95}\right.$ in Equation (A.52)) and substituting $A_{95}$ for $d p$ :

$$
A_{95}=2 \Delta I_{x}\left(\frac{1}{1+3 \cos ^{2} I_{x}}\right)
$$

which rearranges to give

$$
\Delta I_{x}=\frac{A_{95}}{2}\left(1+3 \cos ^{2} I_{x}\right)=A_{95}\left(\frac{2}{1+3 \cos ^{2} p}\right)
$$

To determine the expected declination, $D_{x}$, we can use Equation (A.28) derived above:

$$
\sin \lambda_{p}=\sin \lambda_{s} \cos p+\cos \lambda_{s} \sin p \cos D
$$

and rearrange to solve for $D_{X}$ :

$$
\cos D_{x}=\frac{\sin \lambda_{p}-\sin \lambda_{s} \cos p}{\cos \lambda_{s} \sin p}
$$

from which $D_{X}$ can be determined.

The confidence limit on $D_{x}$ is $\Delta D_{x}$, which can be derived by applying the Law of Sines to the spherical triangle STP (Figure A.5):

$$
\frac{\sin A_{95}}{\sin \Delta D_{x}}=\frac{\sin p}{\sin T}
$$

Now note that $T=\pi / 2$ (thus $\sin T=1$ ) and rearrange to give

$$
\Delta D_{x}=\sin ^{-1}\left(\frac{\sin A_{95}}{\sin p}\right)
$$

If you actually go through some calculations of $\Delta I_{x}$ and $\Delta D_{x}$, you will find that these confidence limits change with $I_{x}$ (and $p$ ) in a systematic fashion. For small $p$ (steep inclination), $\Delta D_{x}>\Delta I_{x} ; \Delta I_{x} \approx \Delta D_{x}$ at about $p=60^{\circ}\left(I_{x} \approx 50^{\circ}\right)$; for $60^{\circ}<p \leq 90^{\circ}\left(I_{x}<50^{\circ}\right), \Delta I_{x}>\Delta D_{x}$.

This determination of the confidence limits $\Delta I_{x}$ and $\Delta D_{x}$ produces a confidence oval (not circle) about $I_{x}, D_{x} . \Delta I_{x}$ is the semi-axis of the confidence oval in the vertical plane through $I_{x}, D_{x}$. But the other semi-axis of the confidence oval is not $\Delta D_{x}$. Remember that $\Delta D_{x}$ is the projection of the direction space confidence limit onto the periphery of the equal-area projection (Figure A.4a). The required dimension of the confidence limit about $I_{x}, D_{x}$ can be determined from Equation (A.44) by substituting the desired angular distance $c$ (Figure A.4a) for $\alpha_{95}$. This leads to

$$
c=\sin ^{-1}\left(\cos I_{x} \sin \Delta D_{x}\right)
$$




\section{Equations for AMS parameter calculations:}

$n 1$ relates to $K_{\max }$, $n 2$ relates to $K_{\text {int }}$ and $n 3$ relates to $K_{\text {min }}$

$\mathrm{L}=\mathrm{K}_{\max } / \mathrm{K}_{\text {int }}$

$\mathrm{F}=\mathrm{K}_{\text {int }} / \mathrm{K}_{\min }$

$\mathrm{P}=\mathrm{K}_{\max } / \mathrm{K}_{\min }$

$\operatorname{Pj}=\exp \left\{\operatorname{sqr}\left[2\left((n 1-n)^{\wedge} 2+\left(n 2-n 0^{\wedge} 2+(n 3-n)^{\wedge} 2\right)\right]\right\}\right.$

$\mathrm{T}=(2 \mathrm{n} 2-\mathrm{n} 1-\mathrm{n} 3) /(\mathrm{n} 1-\mathrm{n} 3)$

$\mathrm{U}=\left(2 \mathrm{~K}_{\mathrm{int}}-\mathrm{K}_{\max }-\mathrm{K}_{\min }\right) /\left(\mathrm{K}_{\max }-\mathrm{K}_{\min }\right)$

$\left.\mathrm{Q}=\left(\mathrm{K}_{\max }-\mathrm{K}_{\text {int }}\right) /\left(\mathrm{K}_{\max }+\mathrm{K}_{\text {int }}\right) / 2-\mathrm{K}_{\min }\right)$

$\mathrm{E}=\left(\mathrm{K}_{\mathrm{int}}\right)^{2} /\left(\mathrm{K}_{\max } * \mathrm{~K}_{\min }\right)$ 